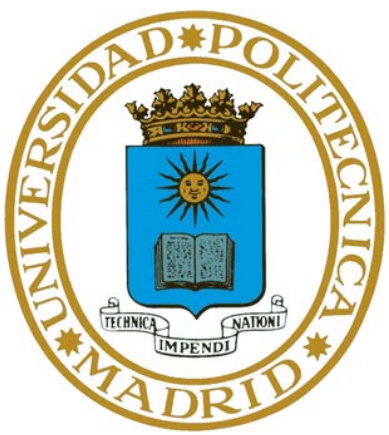

Universidad Politécnica DE MAdRID

TESIS DOCTORAL

\title{
Valoración de sistemas de seguimiento de la mirada con usuarios con discapacidades neuromotoras graves
}

\author{
Autor: \\ Alejandro Clemotte Miret \\ Directores: \\ Rafael Raya López \\ Ricardo de Córdoba Herralde
}


Universidad Politécnica de Madrid

Consejo Superior de Investigaciones Científicas

2017

\section{Tesis doctoral}

Valoración de sistemas de seguimiento de la mirada con usuarios con discapacidades neuromotoras graves

\section{Autor}

Alejandro Clemotte Miret

\section{Directores}

Rafael Raya López y Ricardo de Córdoba Herralde 


\title{
TESIS DOCTORAL
}

\section{VALORACIÓN DE SISTEMAS DE SEGUIMIENTO DE LA MIRADA CON USUARIOS CON DISCAPACIDADES NEUROMOTORAS GRAVES}

\author{
Autor: \\ Alejandro Clemotte Miret \\ Directores: \\ Rafael Raya López \\ Ricardo de Córdoba Herralde
}

Firma del Tribunal Calificador:

Presidente:

Secretario:

Vocal 1:

Vocal 2:

Vocal 3:

Calificación: 

A mis padres y a mi esposa 



\section{Agradecimientos}

Quiero dedicar las primeras palabras de esta tesis a dar gracias. Un grupo extenso de personas ha aportado a la construcción de esta tesis durante todo este tiempo. Las contribuciones han tenido muchas formas, tanto consejos profesionales como personales.

Primero que todo quiero agradecer a mis directores Rafael y a Ricardo, por haberme acompañado durante estos años en el desarrollo de este trabajo. Han sido fundamentales para que este trabajo esté culminado con gran calidad y rigurosidad.

También quiero agradecer al grupo de grandes colegas con los que trabajé durante este tiempo, a mucha gente que hoy ya no está trabajando conmigo pero que han aportado de una $\mathrm{u}$ otra manera $\mathrm{y}$ en una $\mathrm{u}$ otra medida.

Sin la buena predisposición de responsables de los centros colaboradores, de los terapeutas y de los usuarios todo este trabajo no hubiese sido posible. Muchas gracias a Aspace-Cantabria, Ademgi-Gipuzkoa, Atenpace-Madrid, San Rafael-Madrid.

Parte del trabajo presentado en esta tesis ha sido realizado en el contexto de proyectos de colaboración, a través de los cuales he podido compartir experiencia profesional. Por nombrar algunos de los más resaltantes agradezco a: Interplay, Interaac, Ivanpace, ABC.

Itaipu Binacional merece una mención especial, ya que gracias a ellos toda esta historia del doctorado ha pasado de ser un sueño, al final del curso de maestría, a convertirse en una realidad.

A nivel personal debo y tengo que agradecer a mis padres Juan y Myriam, quienes me han apoyado y acompañado durante todo el inicio y desarrollo de mi carrera profesional. Ellos han confiado siempre en mí, lo cual ha sido fundamental para mi desarrollo profesional y personal.

Otra persona que merece un agradecimiento especial es mi esposa Alma, quien me ha acompañado durante todo el doctorado, apoyándome y dejándome saber siempre que el camino que estaba haciendo era - y sigue siendo - el camino para el que había nacido.

A todas estas personas e instituciones, muchas gracias. 



\section{Resumen}

La parálisis cerebral (PC) es una condición permanente que causa severas alteraciones motoras y trastornos de comunicación e interacción, que limitan la actividad física y social severamente. Últimamente, la prevalencia de la PC ha aumentado debido al incremento de la tasa de supervivencia de los niños prematuros. Las personas con PC en general poseen una capacidad cognitiva normal, pero debido al trastorno que padecen, tienen dificultades neuromotoras que limitan considerablemente su capacidad de expresión y de interacción con otras personas y con el entorno, lo que les provoca normalmente retraso en el desarrollo cognitivo. Esta discrepancia entre el potencial de estas personas y su capacidad real se debe principalmente a su deteriorada habilidad de comunicación e interacción, lo que dificulta sus procesos de aprendizaje. Este problema no sólo afecta al desarrollo cognitivo, sino también a otros procesos claves como la salud, el ocio, las relaciones sociales, el control del entorno, la formación académica y profesional etc. Todos estos factores, combinados con la falta de movilidad, conducen a aumentar la soledad, la exclusión social, lo que deriva en la reducción de la calidad de vida.

Los sistemas de comunicación e interacción aumentativos y alternativos (AAC) suelen ser una opción para esta población afectada. Uno de estos sistemas AAC son los seguidores de la mirada, que permiten controlar al ordenador mediante uno de los pocos gestos residuales de las personas con trastornos motores: el movimiento de los ojos. Sin embargo, las personas con PC severamente afectadas en su capacidad de control motor y postura no suelen utilizar estas ayudas o si lo hacen, presentan muchas dificultades. Entre los múltiples motivos de este problema se encuentra la falta de sistemas de evaluación formales de la interacción con el ordenador. Existen pocos estudios, rigurosos y sistemáticos, sobre la naturaleza precisa de la evaluación de los dispositivos AAC, por lo tanto, suele ser difícil determinar la adecuación de los AAC existentes de manera objetiva. En este sentido, el trabajo realizado a intentado responder a la pregunta: ¿cómo valorar la interacción entre una persona con discapacidad motora y el ordenador, cuando éste se controla mediante un sistema AAC?

La principal contribución original de esta tesis fue el diseño de una metodología de evaluación, categorización y clasificación de la interacción entre una persona con trastornos neuromotores y un ordenador, cuando el control del cursor se realiza a través de los movimientos oculares. El método se vale única y exclusivamente de patrones de la trayectoria del cursor, identificados mediante métricas especiales y técnicas de aprendizaje automático. Los tipos de interacción observados son susceptibles de detección automática. El procedimiento ha sido valorado para la comparación de tres seguidores de la mirada y dos técnicas de clic. Todos los estudios han sido realizados con personas con y sin discapacidad, en colaboración activa con múltiples centros especializados en parálisis cerebral y síndromes afines.

Nuestro trabajo proporciona un paso adelante en el desarrollo de procedimientos para la 
evaluación y caracterización objetiva de la interacción entre usuarios con trastornos motores y el ordenador a través un sistema de seguimiento de la mirada. Además, nuestros resultados aportan medidas objetivas sobre cómo se comportan los usuarios con discapacidad cuando interactúan con el ordenador a través de un sistema de seguimiento de la mirada.

Palabras clave: Parálisis cerebral, Interacción Hombre-Computador, Interfaz de Acceso al Ordenador, Seguimiento de la mirada, Métricas, AAC, 


\section{Índice general}

$\begin{array}{ll}\text { Nomenclaturas } & \text { XxV }\end{array}$

I Introducción 1

II Marco Conceptual $\quad 13$

1 La parálisis cerebral $\quad 15$

1.1 La parálisis cerebral . . . . . . . . . . . . . . . . . 15

1.2 Factores clínicos de valoración y clasificación de la PC . . . . . . . . 16

1.3 Perfil de usuario objetivo . . . . . . . . . . . . . . . . 19

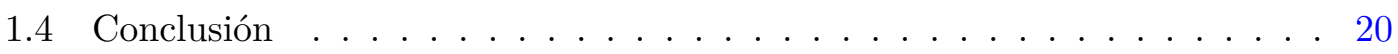

2 La interacción hombre computador $\quad 21$

2.1 Elementos de la interacción hombre computador . . . . . . . . . . . 22

2.2 Interfaz de acceso: del gesto al comando básico . . . . . . . . . . . . 23

2.3 Las interfaces de acceso alternativas y el HID . . . . . . . . . . . . . 24

2.4 Usabilidad . . . . . . . . . . . . . . . . . . . 25

2.5 Tarea de apuntamiento: alcance y selección . . . . . . . . . . . 26

2.6 Conclusión . . . . . . . . . . . . . . . . . . . . . . . . . 27

$\begin{array}{lll}3 & \text { Los sistemas de seguimiento de la mirada } & 29\end{array}$

3.1 El ojo humano y sus movimientos . . . . . . . . . . . . . . . . 30

3.2 Los eye-trackers . . . . . . . . . . . . . . . . . . . . . . . . 34

3.3 Los eye-trackers como interfaz de acceso . . . . . . . . . . . . . . 38

3.4 Interacción Hombre con PC Computador, mediante eye-tracking . . . . . 39

3.5 Conclusión . . . . . . . . . . . . . . . . . . . . 40

4 Valoración de la interacción hombre computador 43

4.1 Métricas de valoración de la interacción . . . . . . . . . . . . . . . 43 
4.2 Clasificación de usuarios según la valoración de la interacción . . . . . . 52

4.3 Conclusión . . . . . . . . . . . . . . . . . . . . . 52

III Aportaciones

5 Metodología de evaluación de la interacción $\quad 57$

5.1 Evaluación I: Precisión y veracidad sin restricciones cervicales . . . . . . . 58

5.2 Evaluación II: Ley de Fitts _ . . . . . . . . . . . . . . . . . 67

5.3 Evaluación III: Tasa de error y tiempo de clic con dos técnicas de clic . . 80

5.4 Evaluación IV: Fallos en la calibración de tres eye-trackers . . . . . . . . . 88

5.5 Conclusión . . . . . . . . . . . . . . . . . . . . . . . . 97

6 Metodología de caracterización de la interacción 101

6.1 Caracterización de usuarios según su interacción con el ordenador . . . . . 102

6.2 Evaluación de la clasificación de tareas de alcance y de las métricas . . . . 117

6.3 Conclusión . . . . . . . . . . . . . . . . . . . . . . 130

IV Conclusiones y difusión de los resultados 133

7 Conclusiones 135

7.1 Principales aportaciones . . . . . . . . . . . . . . . . . 137

7.2 Líneas futuras . . . . . . . . . . . . . . . . . . . . . . . . . 141

7.3 Limitaciones del estudio . . . . . . . . . . . . . . . . . . . . . . . 142

8 Difusión científica de los resultados $\quad 143$

8.1 Principales publicaciones científicas . . . . . . . . . . . . . . . . . . . 143

8.2 Otras publicaciones . . . . . . . . . . . . . . . . . . . . . . 144

8.3 Distinciones . . . . . . . . . . . . . . . . . . . . . . . 146

8.4 Proyectos de colaboración . . . . . . . . . . . . . . . . . . . . 147

$\begin{array}{llr}\text { V Apéndices } & 149\end{array}$

A Tecnologías de asistencia en la comunicación e interacción $\quad 151$

A.1 Tecnologías alternativas para el apuntamiento basadas en visión . . . . . . 151

A.2 Ayudas al alcance . . . . . . . . . . . . . . . . . . . . . . . . . 155

A.3 Ayudas a la selección . . . . . . . . . . . . . . . . . . . . . . 156

A.4 Sistemas de estimulación visual y evaluación del apuntamiento . . . . . . 157

A.5 Tecnologías no basadas en visión . . . . . . . . . . . . . . . . 159 
$\begin{array}{ll}\text { B Procesamiento de los datos del eyetracker } & 163\end{array}$

B.1 Algoritmos para la identificación de fijaciones . . . . . . . . . . . 163

B.2 Algoritmos de filtrado . . . . . . . . . . . . . . . . . . 165

Bibliografía 



\section{Índice de figuras}

1 Esquema de los elementos que interactúan durante el contacto hombre computador. En la Parte II presentaremos los conceptos claves de cada uno de estos elementos. Todas las aportaciones, presentadas en la Parte III, se obtendrán a partir de la información de la posición del cursor. 12

2.1 Esquema de los elementos que entran en juego durante la interacción hombre computador: Hombre $(\mathrm{H})$, Computador (C) y Contexto y Uso (U). Este esquema está basado en uno de $[1] \ldots \ldots$. . . . . . . . . . . 23

2.2 El modelo de Meyer [2] estable que el sistema motor inicia con un movimiento inicial rápido que cubre una distancia larga (a, b, c) y uno o varios movimientos de corrección en la región cercana al objetivo (d, e). F es el centro del objetivo y $\mathrm{W}$ el ancho de este. . . . . . . . . . . . . . 26

3.1 (a) Anatomía del ojo humano. Basado en [3]. (b) Distribución de los dos tipos de células nerviosas (conos y bastones) con respecto a la fóvea. La zona ciega no la percibimos naturalmente, aunque existen experimentos para verlo. . . . . . . . . . . . . . . . 30

3.2 Izquierda: Patrón para demostrar los movimientos durante la fijación. Mantenga la mirada durante aproximadamente 1 minuto sobre el punto negro central. Después mire el punto blanco. Verá las líneas blancas (de la fijación anterior) en constante movimiento. Derecha: Dos de los movimientos que ocurren durante una fijación: a) las derivas y b) las micro sacadas. Los círculos representan a los fotorreceptores de la retina. . . . . 33

3.3 Ejemplo de la imagen que captura la cámara IR. En el caso a) el sistema es del tipo portátil, y en el caso b) del tipo remoto. En el caso a) las fuentes de luz se colocaron lejos del eje óptico de la cámara, por lo que se produce el efecto de pupila oscura (dark pupil). En esta subfigura se ve además los reflejos de las dos fuentes de luz infrarroja sobre el ojo, como dos puntos blancos bajo la pupila. . . . . . . . . . . . 36

3.4 Esta imagen presenta un solo reflejo corneal. Para mejorar las prestaciones se puede usar dos puntos de reflejo corneal, como la Figura 3.3a. Basado en $[4] \ldots \ldots \ldots \ldots \ldots$

3.5 Efecto "toque de Midas": cuando el ojo es utilizado como gesto de control y como sentido para la percepción de lo que está ocurriendo se produce una ambigüedad en el lazo de control (lazo gris): ¿los ojos están apuntando o simplemente están realizando una inspección? 
4.1 a) Número de cruces del eje de la tarea NAC igual a 1. b) Cambios de dirección de movimiento CPM igual a 3. c) Cambios de dirección ortogonal COM igual a 2 . Basado en $[5] \ldots \ldots \ldots$. . . . . . . . . . 46

4.2 a) Número de entradas al objetivo CEO es igual a 2. b) Distancia del clic al objetivo DCO igual a la dimensión del vector X, sin normalizar con el radio del objetivo. c) Error de ángulo de movimiento EANG. . . . . . . . 4

4.3 Representación gráfica de los parámetros amplitud de movimiento (A) y tamaño del objeto en pantalla (W) de una tarea de alcance a un objetivo, los cuales definen el índice de dificultad según la Ley de Fitts. Además, se representa el eje de la tarea como la línea que une los puntos S y C. . . 48

4.4 Valores que puede tomar DES. En el caso de la izquierda, el valor de DES normalizado será menor que 1 , en el caso de la derecha por el contrario será mayor a $1 . \ldots \ldots \ldots \ldots \ldots$

5.1 (a) Los fabricante miden a sus dispositivos en condiciones especiales, restringiendo los movimientos de la cabeza mediante un posa barbilla o posa mentón. Luego, los usuarios con trastornos motores graves no saben si el ET se ve afectado por los movimientos de la cabeza (b) El objeto estímulo consistió en dos círculos concéntricos, uno negro interno y otro rojo externo. El objeto estímulo apareció en una de 4 filas y 4 columnas. En la figura se muestran las 16 posiciones posibles del estímulo, sin embargo, solo se mostraba un objeto a la vez. El origen de coordenadas está en la parte superior izquierda. . . . . . . . . . . . . . .

5.2 (a) Esta figura representa la mirada de cada ojo proyectada sobre la pantalla como una línea roja y azul. También se representan los puntos de intersección entre la mirada y la pantalla como los círculos rojo y azul. El origen de coordenadas 3D es la esquina superior izquierda de la pantalla. (b) Los datos posteriores a la simplificación son la posición del ojo medio (Eye), de la mirada media (Gaze) y del objeto estímulo (Target) . . . . .

5.3 Distancia entre el centro del círculo estímulo (línea de puntos) y la mirada (líneas de colores), como función del tiempo. El rectángulo gris encierra los primeros 0,75 segundos no analizados en el procesamiento de datos, considerado el tiempo necesario para fijar el ojo en el círculo. Existen cuatro líneas de colores, porque la mirada de cada ojo tiene dos coordenadas, $\mathrm{x}$ e y. Entonces, las líneas rojas y la azul son la mirada x e y del ojo izquierdo, y las líneas verde y amarillo son la mirada x e y del ojo derecho. 63

5.4 (a) Histograma de los ángulos $\angle A B$. El pico se produjo a los 1,15 grados. Se ha hecho una representación del estímulo visual, suponiendo que el usuario se encuentra a $60 \mathrm{~cm}$ de la pantalla. La función para calcular el ángulo de los círculos es $\alpha(x)=t g^{-1}(x / 60)$, donde $x$ son los radios 0,5 y 1,75 y $\alpha$ el ángulo resultante. Con esta suposición, el pico se encuentra en el área de círculo mayor, de color rojo. (b) Histograma en 2D de los datos de la mirada $(G a z e)$, en píxeles . . . . . . . . . . . .

5.5 Cada cruz roja representa la posición media de la mirada (Gaze), por cada uno de los 16 círculos estímulo, por cada uno de los 10 participantes, por cada una de las 2 sesiones, en total 320 cruces. Además, la cruz azul representa la posición media por cada círculo. El eje está en píxeles . . . . 66 
5.6 Representación de los tiempos T0, T1 y T2. En azul el valor Error, en rojo el valor DeltaError, en verde el valor de TH. . . . . . . . . . . 70

5.7 Índice de dificultad ( $I D$, en bits) vs. TO (en segundos), de los participantes con PC (arriba) y sin PC (abajo). . . . . . . . . . . . . . . . 74

5.8 Índice de dificultad ( $I D$, en bits) vs. $T 1$ (en segundos), de los participantes con PC (arriba) y sin PC (abajo). . . . . . . . . . . . . . 75

5.9 Índice de dificultad (ID, en bits) vs. T2 (en segundos), de los participantes con PC (arriba) y sin PC (abajo). . . . . . . . . . . . . . 76

5.10 Gráfico típico de puntos TM en función de ID. (a) Representación de 40 puntos con su recta de regresión lineal en rojo. (b) Representación de 5 puntos con su recta de regresión lineal, en azul. . . . . . . . . . . . 77

5.11 Configuración mecánica de los experimentos de Fitts, con rayas metálicas de tamaños discretos. . . . . . . . . . . . . . . . . . . . . 78

5.12 Propiedades dinámicas de un movimiento sacádico. Velocidad pico (izquierda) y duración (derecha) de movimientos sacádicos en función de la amplitud del movimiento, $[6]$. . . . . . . . . . . . . . . . . . 79

5.13 Representación gráfica de los parámetros amplitud de movimiento (A) y tamaño del objeto en pantalla (W) de una tarea de alcance a un objetivo, los cuales definen el índice de dificultad según la Ley de Fitts. Además, se representa el eje de la tarea como la línea que une los puntos S y C, y el ángulo de aparición del objetivo con respecto a la horizontal $a$, establecido aleatoriamente en tiempo de ejecución. . . . . . . . . . . . . . . . 81

5.14 Captura de un momento de una sesión. El participante con PC está frente a la pantalla de la computadora y el ET (debajo de la pantalla). . . . . . 83

5.15 Histograma de los tiempos de clic de los usuarios sin PC (a) y con PC (b) luego de haber extraído los outliers. . . . . . . . . . . . . . . . 84

5.16 Tasas de error de los usuarios, con ambos tipos de clic. Los usuarios han sido agrupados según tengan mejor resultado con uno u otro tipo de clic.

5.17 Flujo del procesamiento global de los datos. Las cajas en el recuadro gris de la izquierda señalan los cálculos con los datos de las personas sin PC y las que se encuentran en el recuadro de la derecha los cálculos con los datos de las personas con PC. Los cuadros con una papelera al lado implican tareas descartadas. Los cuadros celestes implican el cálculo de

5.18 a) Gráfico de cajas del error de calibración de los participantes sin y b) con PC, por cada ET utilizado. En el gráfico de cajas de los participantes con PC (a) el umbral U1 se representa como una línea de trazos (100

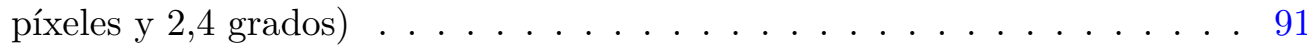

5.19 Distancia entre el cursor y el centro del objetivo en pantalla en función del tiempo, para distancias tareas realizadas por un mismo participante con PC. 
6.1 (a) Esquema de la tarea de apuntamiento (PT) y sus principales parámetros: amplitud de movimiento $(A)$ y diámetro del objetivo $(W)$. (b) Un momento de la prueba. Todos los participantes se localizaron en la distancia óptima al eye-tracker, a la altura del centro de la pantalla, lo que garantiza las mejores mediciones. . . . . . . . . . . . . . . . 103

6.2 Esquema del método propuesto. Los cuadrados de colores representan instancias de PT y cada color representa un usuario diferente. El PTsDB es la base de datos de PTs. ML es la técnica de agrupamiento que separó los $\mathrm{PT}$ en tres grupos $(\mathrm{C} 0, \mathrm{C} 1$ y $\mathrm{C} 2)$. T0, T1 y T2 representan la tendencia de cada usuario y las características de cada grupo. . . . . . . . 106

6.3 (a) K-means asigna a cada instancia una distancia al centroide del cluster correspondiente. En el diagrama de cajas vemos las distancias de cada instancia al centroide de su clúster correspondiente. (b) El algoritmo EM asigna a cada instancia una probabilidad de pertenecer a cada cluster, llamada loglikelihood. Además, este algoritmo puede decidir el número de clusters a generar por validación cruzada de forma recursiva. Para ello calcula la probabilidad loglikelihood promedio de todas las instancias con un número diferente de clusters, de forma incremental. Cuando el incremento es menor a un umbral, el algoritmo se detiene. En nuestro caso, el algoritmo se detuvo en 3 clusters. En la figura vemos el valor loglikelihood por cada número de clusters y la variación del valor loglikelihood. . . . . 107

6.4 Trayectorias superpuestas y rotadas, asociadas a cada uno de los tres clústeres (la primera columna para $C_{2}$, la segunda para $C_{0}$, y la última para $C_{1}$ ), para cada uno de los cuatro tamaños de objetivo (la primera fila para un tamaño de objetivo 50 , la siguiente 100 , la tercera 200 , y la última para 300). . . . . . . . . . . . . . . . . . . . . 114

6.5 Velocidades superpuestas de las trayectorias asociadas a cada uno de los tres clústeres (columnas), para cada uno de los cuatro tamaños de objetivo (filas). . . . . . . . . . . . . . . . . . . . 115

6.6 A: Tasa de error (\%) de todos los clasificadores seleccionados (línea azul) junto con sus bandas de significancia al $95 \%$ (línea gris), configurados con los mejores parámetros, previamente a la selección de atributos, Tabla 6.7. Además, los recuadros B, C, y D son detalles de la figura A, donde se pueden apreciar los solapes de las bandas de significancia, excepto en B entre AdaBoostM1 y SMO. Los asteriscos $(*)$ indican una diferencia significativa. . . . . . . . . . . . . . . . . . . . 121

6.7 A: Tasa de error (\%) del clasificador AdaBoostM1 junto con SMO (línea azul) junto con sus bandas de significancia al $95 \%$ (línea gris), configurado con sus mejores parámetros, en función creciente de la tasa de error de los evaluadores, Tabla 6.13. Además, los recuadros B, y C son detalles de la figura A, donde se pueden apreciar los solapes de las bandas de significancia. Los asteriscos $(*)$ indican una diferencia significativa. . . . . 128 
6.8 A: Tasa de error (\%) del clasificador AdaBoostM1 junto con SMO (línea azul) junto con sus bandas de significancia al $95 \%$ (línea gris), configurado con sus mejores parámetros, en función decreciente del número de métricas seleccionadas por los evaluadores, Tabla 6.14. Además, el recuadro B es un detalle de la figura $\mathrm{A}$, donde se pueden apreciar los solapes de las bandas de significancia. Los asteriscos $(*)$ indican una diferencia significativa. . . 129

7.1 Flujo del procesamiento global de los datos. Las cajas agrupadas en el recuadro gris de la izquierda señalan los cálculos que se realizan con los datos de las personas sin PC y las que se encuentran en el recuadro de la derecha los cálculos con los datos de las personas con PC. Los cuadros con una papelera al lado implican datos descartadas. Los cuadros celestes implican el cálculo de una métrica. . . . . . . . . . . . . . . . . . . . 139

7.2 Valoración visual de las trayectorias del cursor de las tareas de alcance de cada uno de los tres grupos $C_{2}, C_{0}$, y $C_{1}$. La agrupación fue realizada a partir de las métricas, mediante la técnica de aprendizaje automático no supervisado $k$-means.

8.1 La propuesta de proyecto InteraPCion dio principal énfasis a la comunicación entre usuarios con PC (y no comunicación de usuarios con $\mathrm{PC}$ ), de múltiples maneras con múltiples canales en múltiples contextos. En la figura se ve un esquema de la propuesta. . . . . . . . . . . . . . . . . . 146

A.1 El sistema seguidor de cabeza SmartNav (izquierda). La cámara sigue al punto reflectante de luz infrarroja puesto en la frente del usuario (derecha).152

A.2 Módulo de inicialización: a) detección automática de rostro. b) Selección de las mejores características usando restricciones de simetría. c) La media de todas las funciones: punta de la nariz. . . . . . . . . . . . . . . . . 154

A.3 The EyeTribe presume de ser el eye-tracker comercial más barato del mundo, con un coste de lanzamiento de $99 \$$ y una API en tres lenguajes para el desarrollo de aplicaciones. . . . . . . . . . . . . . . . . . . 154

A.4 Navallas propone realizar el clic mediante activaciones musculares solo cuando se produce una fijación de la mirada en un punto (Caso C, en el recuadro verde). . . . . . . . . . . . . . . . . . 157

A.5 Uno de los dos esquemas de estimulación visual que permite FittsStudy: círculos concéntricos. Se puede ajustar tanto la separación entre los círculos como el tamaño de los mismos. . . . . . . . . . . . . . . . . . 158

A.6 Una PDA Palm con una plantilla de EdgeWrite sobre el área de entrada de texto . . . . . . . . . . . . . . . . . . . . . . . . . . . . . .

A.7 Los ensayos con la interfaz inercial (izquierda). La interfaz inercial (derecha). La comunicación entre la interfaz y el ordenador puede ser USB o Bluetooth. . . . . . . . . . . . . . . . . . . . . . 161

B.1 Los datos que proveen los ETs, antes de utilizarlos, deben ser pre-procesados. Etapas de procesamiento de la información de los datos del eye-tracker. . 163 



\section{Índice de tablas}

1.1 Clasificación de la PC según formas clínicas, con las características de los 4 niveles y la parte del cerebro afectada. . . . . . . . . . . . 17

1.2 Clasificación de las personas con PC según la zona del cuerpo afectada. 17

1.3 Clasificación de la PC según el grado de dependencia. . . . . . . . . . . 17

1.4 Sistema de clasificación de las personas con PC según su capacidad de movilizarse GMFCS. . . . . . . . . . . . . . . . . . . . . 18

1.5 Clasificación de las personas con PC según las habilidades manuales MACS. 18

1.6 Clasificación de la PC según la emisión del habla, establecido por el sistema Viking Speeach Scale [7]. . . . . . . . . . . . . . . . . . . 19

1.7 Niveles de interés de esta tesis, según los sistemas de clasificación de la PC descritos. . . . . . . . . . . . . . . . . . . 19

3.1 Taxonomía de los eye-trackers, según distintas características. . . . . . . . 35

3.2 Los sistemas de eye-tracker basados en visión pueden ser categorizados en dos tipos: remotos o portátiles. . . . . . . . . . . . . . 35

4.1 Throughput de distintos dispositivos. Ninguno de estos dispositivos ha sido validado con personas con algún tipo de discapacidad . . . . . . . . . 49

4.2 Lista de métricas que se propone calcular para cada tarea de apuntamiento. 53

5.1 Participantes con su edad, sexo, color de ojos, ojo dominante y corrector de vista. Los participantes $\mathrm{Ux}^{*}$ han tenido contacto con un ET anterior-

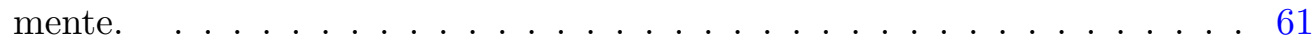

5.2 Precisión y veracidad de los datos proporcionados por la prueba y por la hoja de datos (Tobii X2-30 Eye Tracker Manual del usuario, Apéndice A: Especificaciones del Tobii X2-30 Eye Tracker, 2013), en grados. . . . . . . 63

5.3 Perfil de los nueve participantes con $\mathrm{PC}$ reclutados para las pruebas, con sus niveles MACS (M), GMFCS (G), sexo (S), edad (E) y experiencia en el uso de ETs y los siete participantes del grupo de control. . . . . . . . . 69

5.4 Información acerca del número y tasa de outliers identificados en cada tipo de TM y cada grupo de usuarios. . . . . . . . . . . . . . . . 71 
5.5 Correlación de Pearson ( $\rho$ ), significancia de los datos (Sig.), coeficiente de determinación $\left(R^{2}\right)$ y el número de muestras $(\mathrm{N})$ por cada grupo de usuarios y cada tiempo de movimiento. . . . . . . . . . . . 72

5.6 Correlación de Pearson $(\rho)$, significancia de los datos (Sig.) y coeficiente de determinación $\left(R^{2}\right)$ por cada grupo de participantes y la amplitud de movimiento $(\mathrm{A})$ y el tamaño del objeto $(\mathrm{W}) . \ldots \ldots \ldots$. . . . . . 72

5.7 Secuencia de los índices de dificultad $I D$, distribuidos al azar, con las amplitudes de movimiento $A$ (en cm y píxeles) y tamaños de las figuras en pantalla $W$ (en cm y píxeles) necesarios para generar el $I D$ correspondiente. 81

5.8 Perfil de los seis participantes con PC reclutados para las pruebas y los cuatro participantes del grupo de control. . . . . . . . . . . . . . . 83

5.9 Número de tareas por cada usuario sin PC y con PC, según el tipo de clic. 85

5.10 Tiempo de clic medio y desviación estándar por cada usuario sin PC y con PC, según el tipo de clic. . . . . . . . . . . . . . . . 86

5.11 Tasa de error de los usuarios sin PC y con PC, según el tipo de clic. . . . 86

5.12 Tasa de fallo de calibración por participante y por ET, para el grupo con PC. Las celdas con (-) indican que las calibraciones no se han realizado. Los datos de los participantes con $\left(^{*}\right)$ no se utilizaron en el resto del análisis. Los valores $(\psi)$ se calcularon con las medidas de cada ET y los $(\tau)$ con todas las medidas. . . . . . . . . . . . . .

5.13 Número de tareas de alcance por participante y por ET de ambos grupos de participantes. Las celdas con (-) corresponden con tareas no realizadas. Las celdas con * corresponden con tareas con una tasa de fallos en la calibración del $100 \%$, por lo que no se han analizado estos datos. Los valores $(\psi)$ se calcularon con las medidas de cada ET y los $(\tau)$ con las medidas de cada usuario. . . . . . . . . . . . . . . . .

5.14 Tasa de error del clic (\%) por participantes y por ET de ambos grupos de participantes. Las celdas con (-) corresponden a tareas no realizadas. Las celdas con ${ }^{*}$ corresponden con tareas con una tasa de fallos en la calibración del $100 \%$, por lo que no se han analizado estos datos. Los valores $(\psi)$ fueron calculados con las medidas de cada ET y los $(\tau)$ con todas las medidas del grupo. . . . . . . . . . . . . . . 93

5.15 Tiempo de clic por participante por ET expresado en segundos. Este tiempo incluye el tiempo de permanencia y el margen entre clics consecutivos. Las celdas con (-) corresponden a tareas no realizadas. Las celdas con * corresponden con tareas con una tasa de fallos en la calibración del 100\%, por lo que no se han analizado estos datos. Los valores $(\psi)$ se calcularon con las medidas de cada ET y los $(\tau)$ con todas las medidas del grupo. . . 94

5.16 Análisis comparativo entre usuarios sin y con PC de las medias y desviaciones estándar de las métricas presentadas en las dos últimas evaluacio-

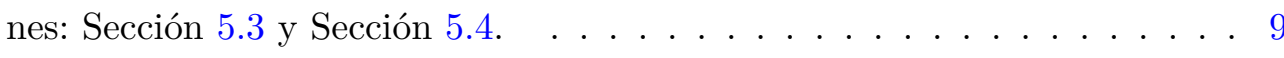

5.17 Distintas evaluaciones presentadas, con las interrogantes de partida, las conclusiones y los aspectos claves del estudio. . . . . . . . . . . . . 98

5.18 Distintas evaluaciones presentadas, con las interrogantes de partida, las conclusiones y los aspectos claves del estudio. . . . . . . . . . . . 
6.1 Participantes con su perfil clínico (P), sexo, edad y experiencia en el uso de eye-trackers $($ Exp. ET) . . . . . . . . . . . . . . . . . 105

6.2 Resultados del análisis cuantitativo de los centroides de cada clúster. $\mathrm{N}=$ normalizada, $\mathrm{S}=$ sobre muestreada. $C_{0}(\mathrm{n}=206), C_{1}(\mathrm{n}=237), C_{2}(\mathrm{n}=279) 109$

6.3 El radio máximo, mínimo y mediano de cada clúster. . . . . . . . . . . . . 110

6.4 Distribución (\%) de las trayectorias de los participantes entre los clústeres. La trayectoria preferida se define como el grupo con el número máximo de instancias. . . . . . . . . . . . . . . . . . . . 110

6.5 Resultados del análisis cualitativo de los centroides de los clústeres. $\mathrm{N}=$ normalizado, $\mathrm{S}=$ sobre muestreada . . . . . . . . . . . . . 112

6.6 Las tareas de alcance han sido etiquetadas según a que clase pertenecen:

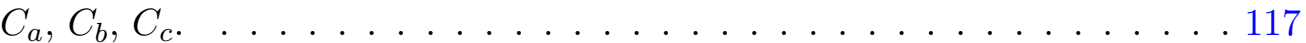

6.7 Tasa de error de los distintos clasificadores, previamente a la selección de atributos, ordenados de manera ascendente, junto con sus bandas de significancia al $95 \%$ y los parámetros con los que se obtienen los mejores resultados. . . . . . . . . . . . . . . . . . . . . . . 122

6.8 Matriz de confusión del clasificador AdaBoostM1 junto con $S M O$, con todas las métricas. . . . . . . . . . . . . . . . . . . . 123

6.9 Selección de métricas por subconjuntos. Atributos seleccionados por el evaluador de grupo de atributos Cfs-Subset y Wrapper-Subset. Los atributos repetidos con ambos evaluadores se encuentran en la misma fila. Además, se señala el Ranking de los atributos según la Tabla 6.11. . . . . 124

6.10 Transformada de componentes principales (PCA) del conjunto de métricas: varianza de cada eje componente y varianza acumulada. 21 componentes explican más del $95 \%$ de la varianza total, 15 el $88 \%$ y 6 el $67 \%$.

6.11 Evaluación de métricas individualmente. Ranking de métricas según su figura de mérito y ranking promedio. No se han incluido en la tabla todas las métricas que han quedado por encima del ranking 34. Las métricas señaladas con $(\dagger)$ han sido seleccionadas por el evaluador Cfs-Subset y las señaladas con $(\star)$ por Wrapper-Subset, Tabla 6.9 . . . . . . . . . . . . 125

6.12 Matriz de confusión del clasificador AdaBoostM1 junto con SMO, con los 15 atributos seleccionados por Wrapper-Subset $(15$ m.). . . . . . . . . . 126

6.13 Tasa de error del clasificador AdaBoostM1 con las distintas métricas seleccionadas por los evaluadores, ordenados de manera descendente con respecto a la tasa de error, donde $m$. indica métricas. . . . . . . . . . . 127

6.14 Tasa de error del clasificador AdaBoostM1 con las distintas métricas seleccionadas por los evaluadores, ordenados de manera descendente con respecto al número de métricas, donde $m$. indica métricas. . . . . . . . . 127

A.1 Distintas tecnologías revisadas con sus características respectivas según diferentes aspectos. WebC: Webcam . . . . . . . . . . . . . . 155 



\title{
Nomenclaturas
}

\author{
AAC Augmentative and Alternative Communication, Comunicación aumentativa y al- \\ ternativa \\ EOG Electro oculografía \\ ET Eye-tracker, Seguidor de la mirada \\ GUI Graphical user interface, Interfaz gráfica de usuario \\ HCI Human-Computer Interaction, Interacción hombre computador \\ HID Human Interface Device, Dispositivo de interfaz humana \\ IA Interfaz de acceso \\ IR Infrared light, Luz infrarroja \\ LOS Line of sight, Linea de visión \\ ML Machine learning, Aprendizaje automático \\ ND Neuromuscular Disorders, Trastornos neuromusculares \\ P\&V Precisión y veracidad \\ PC Parálisis cerebral \\ POG Point of regard, Punto de la mirada \\ PT Pointing task, Tarea de apuntamiento y selección \\ SCI Spinal Cord Injury, Lesión de la medula espinal \\ VOG Video oculografía
}





\section{Parte I}

\section{Introducción}





\section{Motivación}

Para un desarrollo integral, las personas con discapacidades neuromotoras deben desarrollar su capacidad de comunicación e interacción. Estas capacidades se deben potenciar ya sea a través del lenguaje oral o a través de los sistemas de comunicación aumentativos alternativos [8]. Sin embargo, cuando existe una limitación motora grave en una persona, muchos de estos sistemas no pueden utilizarse por diversos motivos. Por ejemplo, existe una población significativa que no puede acceder al ordenador a través de los canales comúnmente utilizados (el teclado o el ratón), o incluso a través de canales adaptados [9]. Es decir, una de las causas que impiden el acceso a estas herramientas tecnológicas es el canal de interacción con el dispositivo.

Entre la población afectada por esta circunstancia se encuentran las personas que padecen de parálisis cerebral (PC). La PC puede ser definida, según la Confederación Española de Federaciones y Asociaciones de Atención a las personas con Parálisis cerebral y Afines - ASPACE ${ }^{1}$, como un "trastorno global de la persona consistente en un desorden permanente y no inmutable del tono muscular, la postura y el movimiento, debido a una lesión no progresiva en el cerebro antes de que su desarrollo y crecimiento sean completos" [10]. La PC es la causa más frecuente de discapacidad motora en la edad pediátrica [11].

A la hora de desarrollar canales de interacción alternativos de comunicación se buscan gestos residuales en las personas afectadas que permitan una interacción entre el hombre y el dispositivo electrónico. Para este proyecto, el gesto que se decidió utilizar para realizar la comunicación fue la mirada, por ser uno de los más naturales y residuales en los estadios más graves de la discapacidad. Los seguidores de mirada son dispositivos capaces de estimar la posición de la mirada sobre la pantalla de un ordenador. Con esta información se puede controlar un dispositivo electrónico [12]. Existen varias técnicas para identificar el punto de mirada. Las menos invasivas son las basadas en cámaras y entre estas se destacan las basados en luz infrarroja, por su precisión y robustez. Estos dispositivos cuentan con una fuente de luz infrarroja, con una cámara infrarroja y algoritmos de procesamiento de imágenes. La luz infrarroja se proyecta sobre el rostro del usuario y la cámara captura las imágenes. Estas imágenes son procesadas por algoritmos especializados, que estiman la ubicación de la mirada [4].

Existen muchas plataformas electrónicas que pueden ser controladas mediante un seguidor de la mirada: teléfonos móviles, tablets, etc. Sin embargo, la plataforma electrónica más accesible es el ordenador, por cuestiones de tamaño de la pantalla y porque permite la ejecución de infinidad de aplicaciones accesibles. Por este motivo se decidió que el dispositivo electrónico al que acceder sea el conjunto ordenador-pantalla.

Nos encontramos con distintas cuestiones cuando personas con trastornos motores gra-

\footnotetext{
${ }^{1}$ http://www.aspace.org/
} 
ves utilizan este tipo de control del ordenador. Las personas con PC suelen padecer problemas neuromotores (reflejados en un bajo control postural y en movimientos involuntarios), intelectuales (que repercute en la atención y en la capacidad de realizar tareas complejas), visuales (temblor en los ojos, nistagmo, estrabismo, ojo vago) y auditivos.

Además, existen cuestiones técnicas, como la calibración de los seguidores de la mirada. Este proceso muchas veces resulta complejo y aburrido para estos usuarios, lo que repercute finalmente en la baja precisión y en la mala experiencia de los usuarios.

Existe también un problema metodológico, relacionado con los protocolos de medida y las métricas de comparación, que impide una valoración repetible y comparable y que además permita identificar evoluciones de los usuarios o mejoras en la interacción. Finalmente, es importante mencionar que los fabricantes de estos dispositivos no consideran a esta población cuando diseñan sus herramientas, debido a que el nicho de mercado de estos dispositivos suele ser otro. Los estudios de experiencia de usuario no suelen incluir a personas con limitaciones motoras en la validación de sus sistemas.

Todas estas cuestiones repercuten en la interacción con el ordenador y en la experiencia que tiene el usuario. Este amplio grupo de limitaciones de las tecnologías actuales, las limitaciones de los usuarios con PC y la casi nula metodología para la evaluación de la interacción, constituyen un tema interesante de abordar. Para afrontar todos estos desafíos, el principal motor que nos ha movido fue: mejorar el acceso al ordenador de las personas con severos trastornos motores cuando éste se realiza a través de los sistemas de seguimiento de la mirada. 


\section{Objetivos del proyecto}

El objetivo principal de este proyecto fue desarrollar métodos de evaluación y caracterización de la interacción entre personas con discapacidades neuromotoras graves y el ordenador, cuando el control se realiza mediante un sistema de seguimiento de la mirada. La información a partir de la cual se valoró la interacción fue la posición del cursor. Los usuarios objetivo fueron personas que se encuentran en los estadios más graves de la discapacidad motora, en particular la personas con parálisis cerebral o síndromes afines. Estos estadios suelen estar caracterizados por la incapacidad de manipular las interfaces comúnmente utilizadas: el ratón y el teclado. Este nivel de discapacidad suele corresponderse con el nivel IV y V de la MACS [13] o GMFCS [14, 15]. Este dispositivo será valorado en el contexto de su utilización con ordenadores.

Para conseguir este objetivo se plantearon dos subobjetivos:

Objetivo 1 Identificación, desarrollo y evaluación de un protocolo de valoración basado en métricas funcionales, para cuantificar la calidad de la interacción entre usuarios con trastornos motores graves y el ordenador, cuando el ordenador se controla a través de la mirada.

- Hitos

- Valorar los métodos estándar.

- Si no son válidos, proponer y validar una metodología

- Requisitos

- Funcional: valorar la realización de la tarea de A\&S

- Integral: con todos los elementos de la interacción H-C

Objetivo 2 Categorización de la interacción de usuarios con discapacidad neuromotora en grupos, cuando interactúan con el ordenador mediante un seguidor de la mirada, mediante técnicas de aprendizaje automático y métricas especialmente definidas que parametrizan las tareas de alcance y selección. Con los grupos de interacción identificados, valorar la capacidad de clasificar a usuarios según estos tipos de interacción.

- Hitos

- Identificación de tipos de tarea de A\&S

- Clasificación según los tipos identificados

- Selección de métricas más relevantes

- Requisitos

- Automática: sin intervención del usuario/terapeuta

- Escalable: ampliable a un mayor volumen de datos 



\section{Hipótesis de trabajo}

El trabajo partió de varias hipótesis, las cuales presentaremos a continuación agrupadas según distintas categorías. Las primeras son relativas a los usuarios objetivo de esta tesis, las siguientes a la interacción entre el usuario y el ordenador, luego las relativas a la tecnología y finalmente las que guardan relación con la valoración de la interacción. Estas categorías serán los pilares sobre los que se construirán las aportaciones de este proyecto.

\section{Relativas a los usuarios}

Hipótesis 1 El perfil de los usuarios con parálisis cerebral es muy heterogéneo, existe mucha diversidad en las características motrices, cognitivas, visuales, etc.

Hipótesis 2 Los perfiles más severos no pueden acceder a un ordenador, por problemas asociados al control motor y a la postura que les impiden manipular las interfaces estándar (ratón o teclado).

Hipótesis 3 Los perfiles más severos tampoco pueden usar la voz como gesto de control.

Hipótesis 4 Entre los usuarios más afectados, existen usuarios con capacidad intelectual/visual que son potenciales usuarios de tecnologías de comunicación alternativas.

Hipótesis 5 La mirada es el gesto residual controlado más ampliamente encontrado en los casos más severos de la discapacidad (GMFCS MACS IV y V).

Hipótesis 6 No solo los usuarios con PC se podrán beneficiar con los resultados de este trabajo, sino también aquellos que padecen de trastornos similares o incluso menos afectados, como la esclerosis lateral amiotrófica o la lesión medular.

\section{Relativas a la interacción hombre-computador}

Hipótesis $7 \mathrm{El}$ ordenador es la plataforma electrónica más accesible respecto a otros dispositivos como los teléfonos móviles o tablets por el tamaño de la pantalla y la posibilidad de ejecutar muchas más aplicaciones.

Hipótesis 8 Los elementos y los factores que forman parte de la interacción hombre computador presentan una casuística muy amplia. 
Hipótesis 9 Esta interacción está siendo estudiada por investigadores de todo el mundo, pero centrándose en personas sin ningún tipo de discapacidad. Si nos apartamos de este patrón de diseño, centrándonos en usuarios con discapacidades motoras, muchas de las suposiciones sobre las capacidades de los usuarios dejan de cumplirse.

Hipótesis 10 Existe una relación de compromiso entre la personalización de un sistema de comunicación alternativo y la estandarización

Hipótesis 11 Las tareas en las interfaces gráficas son básicamente dos: alcance y selección.

\section{Relativas a la tecnología de seguimiento de la mirada}

Hipótesis $12 \mathrm{El}$ gesto de la mirada permite controlar un ordenador e interactuar con el entorno.

Hipótesis 13 Los sistemas de seguimiento de la mirada no pueden ser utilizados por todos los usuarios con parálisis cerebral. Sin embargo, existen casos que pueden beneficiarse de estos dispositivos.

Hipótesis $14 \mathrm{El}$ calibrado de los sistemas apuntadores es un proceso complejo para personas con parálisis cerebral y trastornos motores.

Hipótesis 15 No es necesario un sistema de seguimiento de la mirada muy preciso debido a que las tareas a realizar con un ordenador no son complejas y a que las capacidades de las personas con parálisis cerebral no son muy altas.

Hipótesis 16 Hoy en día los seguidores de la mirada son sistemas accesibles, en términos económicos.

Hipótesis 17 Los seguidores de la mirada basados en luz infrarroja son mejores a los basados en luz visible por su mayor inmunidad a condiciones especiales de luz.

Hipótesis 18 Los sistemas de seguimiento de la mirada remotos son sistemas con una invasividad nula, lo que los hace altamente usables.

\section{Relativas a la valoración de la interacción}

Hipótesis 19 Es posible cuantificar la calidad de la interacción y conocer las características de los usuarios con trastorno mediante un análisis de la trayectoria del cursor.

Hipótesis 20 Existen métricas o parámetros que permitirán cuantificar la interacción de una persona, tanto con trastornos como sin ninguna patología.

Hipótesis 21 Existe una falta de metodología y de métricas respecto a la valoración de la interacción de personas con discapacidades neuromotoras, que permite identificar claramente como es - en términos cuantitativos- el control del ordenador. 
Hipótesis 22 No todos los usuarios con discapacidades motoras - incluso los que tienen una misma discapacidad-, tienen la misma estrategia para controlar un ordenador, por lo que cada grupo de usuarios se beneficiará de manera diferente de los nuevos desarrollos

Hipótesis 23 El perfil patológico de una persona no define de forma exclusiva el tipo o clase de interacción con el ordenador

Hipótesis 24 La alta complejidad del procesamiento de datos para evaluar la interacción exige utilizar técnicas de minería de datos para aliviar la carga de exploración, interpretación y evaluación de la información. 



\section{Metodología de trabajo y organización del documento}

Se ha utilizado el método "diseño centrado en el usuario", partiendo de las necesidades concretas de éste. Esta forma de trabajo maximiza la satisfacción y experiencia de uso posible con el mínimo esfuerzo por parte del usuario. Para ello, realizamos el trabajo en iteraciones que incluían validaciones con usuarios reales, lo que permitió enriquecer cada objetivo a medida que el proyecto avanzó en sus distintas etapas. De esta manera evitamos realizar un trabajo para personas con discapacidad sin contar con las mismas, como por ejemplo [16] o [17] o [18].

Este documento se ha organizado en Partes, las cuales agrupan Capítulos por temas, los cuales serán detallados a continuación.

\section{Parte II}

En la Parte II presentaremos los conceptos claves del trabajo e incluye cuatro capítulos. Por el carácter multidisciplinario del trabajo, en el Capítulo 1 se documentó todo lo relativo a la discapacidad, con especial énfasis en la parálisis cerebral - usuario en la Figura 1-. Se buscó describir el perfil del usuario con parálisis cerebral objetivo según los criterios clínicos que se utilizan y comprender las múltiples dimensiones que pueden verse afectadas por esta patología.

En el Capítulo 2 se presentará terminología referida a los elementos que interactúan en la interacción hombre-computador - flechas celestes de fondo en la Figura 1-. Se verán los factores que intervienen en la interacción y que riesgos conlleva desarrollar interfaces alternativas. En el Apéndice A de este capítulo se presentarán las tecnologías de asistencia que actualmente estén documentadas en la literatura científica, especialmente las de los últimos años y que estén orientadas a la asistencia del alcance y selección de objetivos en pantalla, para usuarios con trastornos motores. En particular, fueron de prioridad aquellas que tuvieron como objetivo personas severamente afectadas.

En el Capítulo 3, junto con el Apéndice B, está documentado todo lo relativo a la anatomía del ojo y su comportamiento dinámico y los dispositivos de seguimiento de la mirada, la clasificación, las tecnologías, los algoritmos, los tipos, etc. — gesto de control y canal de acceso en la Figura 1-.

Finalmente, en el Capítulo 4 se documentó la recopilación de métricas para la cuantificación de la interacción entre el ordenador y el usuario - tarea en la Figura 1-. Se prefirieron métricas cuantificables, que permitan dar una medida objetiva y repetible de la tarea y el usuario. Además, se presentará una revisión de técnicas inteligentes de 


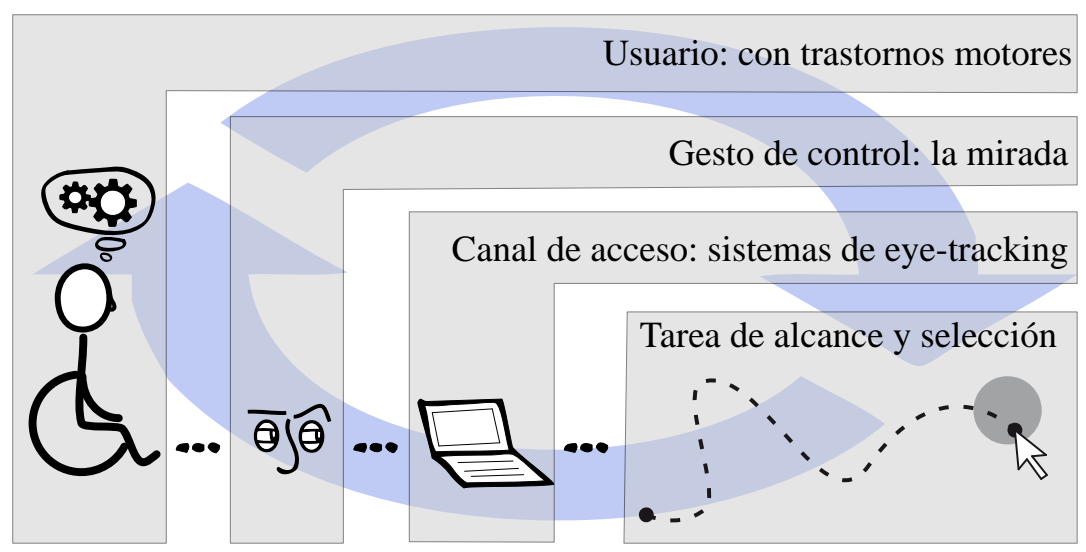

Figura 1: Esquema de los elementos que interactúan durante el contacto hombre computador. En la Parte II presentaremos los conceptos claves de cada uno de estos elementos. Todas las aportaciones, presentadas en la Parte III, se obtendrán a partir de la información de la posición del cursor.

procesamientos de estas métricas.

\section{Parte III}

En la Parte III, se documentará lo relacionado con las aportaciones realizadas, tanto teóricas como prácticas. En el Capítulo 5 se documentó la valoración y desarrollo de metodologías de evaluación de la interacción entre personas con parálisis cerebral y el ordenador, a través de sistemas de seguimiento de la mirada. Estudiamos la precisión y la veracidad de las medidas de un seguidor de la mirada además de una de las definiciones más importantes de la interacción hombre computador, la Ley de Fitts. Tras descartar estas tres métricas, presentamos una metodología basada en tres métricas y su evaluación, mientras usuarios con PC utilizan el ordenador. Ambos capítulos cumplen con el Objetivo 1.

En el Capítulo 6 se presentará una metodología de agrupación de usuarios según sus semejanzas en la interacción con el ordenador, y se evaluará la tasa de error de distintos clasificadores según estas agrupaciones, con diferentes subconjuntos de métricas seleccionadas por técnicas especiales. Este último capítulo logra la consecución del Objetivo 2. Todos los capítulos presentarán los resultados evaluados con datos de personas con trastornos neuromotores.

\section{Parte IV}

En la última parte, la IV, se presentarán las conclusiones, las líneas futuras de trabajo y las principales publicaciones y difusiones en distintos medios.

El trabajo se ha realizado en el marco de los proyectos INTERPLAY, INTERAAC, Ivanpace, $\mathrm{ABC}$. En todo el transcurso de esta tesis se ha trabajado con un equipo de profesionales multidisciplinar, desde el estudio de las necesidades de los usuarios hasta la construcción y validación de los modelos desarrollados. 
Parte II

Marco Conceptual 



\section{Capítulo 1}

\section{La parálisis cerebral}

Según estudios del Instituto Nacional de Estadística de España (INE) hay 3,85 millones de personas que afirman tener discapacidad o limitación (8,5\% de la población) [19]. Más de $65 \%$ de personas con discapacidad reciben algún tipo de ayuda técnica, personal o ambas [19] y más del $60 \%$ de ellas afirman que las ayudas recibidas cubren sus necesidades. Sin embargo, hay un $40 \%$ que no cree en los beneficios de las ayudas. Esta percepción subjetiva es fundamental para que cualquier tipo de ayuda sea útil. Entre esta población de personas se encuentran las personas con PC.

En este capítulo nos interesó documentar la definición y las características clínicas que presentan las personas con PC, según distintos sistemas de valoración y clasificación. El objetivo fue responder a la pregunta de: ¿qué es la PC? —Sección 1.1—, ¿cómo son las personas con PC?, ¿qué criterios se utilizan para evaluarlas? — Sección 1.2-. Además, con estos mecanismos de evaluación acotamos la población objetivo de este estudio - Sección 1.3-.

\subsection{La parálisis cerebral}

La definición más extendida de la PC la define como: "Un trastorno persistente, pero no invariable, de la postura y el movimiento, debido a una disfunción del encéfalo antes de que su crecimiento y desarrollo se completen" [10,20]. Se suele decir que la PC es un término paraguas por agrupar una serie de desórdenes [9, 21, 22]. Es posible que debido a esto que existan otras definiciones de la PC. La parálisis cerebral (PC) es la causa más frecuente de discapacidad motora en la edad pediátrica [23].

En primer lugar, es importante recalcar que los trastornos de la $\mathrm{PC}$ son debidos a una lesión cerebral (encéfalo) que interfiere en el desarrollo normal del niño. Se produce en el primer año de vida, o incluso en el período de gestación, y puede ocurrir hasta los cinco años. Se distingue por el daño dominante de las funciones motrices, el cual afecta al tono, a la postura y al movimiento. Por último, hay un concepto generalizado de que la lesión no es evolutiva pero sus consecuencias pueden variar en el niño [24].

En España se ha prestado escasa atención a la epidemiología de la PC. Según la Encuesta sobre Discapacidades, Deficiencias y Estado de Salud, en 1999 se estimaban en casi sesenta mil las personas mayores de 6 años que en España sufrían PC [25], pero aún se desconoce cuál es la frecuencia real de la PC en España. En el año 2003, el grupo SCPE 
(Surveillance of Cerebral Palsy in Europe ${ }^{1}$ ) contactó con el Hospital 12 de Octubre de Madrid ${ }^{2}$ y desde entonces este centro español forma parte del proyecto europeo y, aplicando su metodología, está recogiendo casos nacidos desde 1991, con el objetivo de tener un escrutinio claro de la prevalencia de la PC [11].

El grupo especializado SCPE ha desarrollado una serie de documentos con el fin de estandarizar la definición y clasificación de la PC (para poder realizar comparaciones entre los distintos centros); desarrollar una base de datos centralizada de niños con PC para monitorizar las tasas de prevalencia y proporcionar información para la planificación de servicios; crear un marco de investigación coordinada en el campo de la PC [23]. Sin embargo, pocos centros se han unido a esta iniciativa (actualmente solo 1 en toda España).

La PC afecta de diferentes formas y en distinta medida a las personas que la padecen. Por ejemplo, puede manifestar: problemas de movilidad, problemas de comunicación, dolor, problemas para comer y beber, control de la saliva, discapacidad intelectual, dificultades de aprendizaje, discapacidad auditiva, discapacidad visual, desequilibrios en el comportamiento y emocionales, epilepsia, problemas de sueño, anomalías de la columna vertebral y de cadera, control de la vejiga y el intestino [26, 27, 28].

Actualmente no se conoce una cura para la PC. Sin embargo, existen una serie de mecanismos que pueden reducir la posibilidad de que una persona sufra de PC: enfriamiento del bebe recién nacido que ha sufrido de una falta de oxígeno al nacer [29] , administración de esteroides prenatales [30] o de sulfato de magnesio [31] a la mujer embarazada con riesgo de tener un parto prematuro.

Novak [28] ofrece una serie de posibles intervenciones en diferentes ámbitos de una persona que tiene PC. Por ejemplo, en lo que se refiere a dificultades en el movimiento, problemas relacionados con los músculos, huesos y articulaciones, en la comunicación, en las discapacidades intelectuales, en las dificultades para el aprendizaje y las epilepsias.

Raya [32] inició una línea de trabajo que ofrecía nuevas estrategias para la interacción (comunicación) y la movilidad de niños con parálisis cerebral, según un modelo convergente. Esta tesis parte de este trabajo y continua sobre esta línea de investigación.

En algunas personas, la PC apenas es apreciable y otras pueden estar muy afectadas. Además, no hay dos personas afectadas de la misma manera [24] (Hipótesis 1). A continuación, se presentará las clasificaciones que existen actualmente de las personas que sufren de PC, que se encuentran documentadas en la literatura científica. Finalmente se identificará al tipo de usuario que es de interés en esta tesis doctoral, mediante estos sistemas de clasificación presentados.

\subsection{Factores clínicos de valoración y clasificación de la PC}

Los criterios más generales de clasificación se centran en las formas clínicas [24], los cuales discriminan $3+1$ formas: espásticos, discinéticos, atáxico y mixtos (combinación de alguna de las anteriores). Todas estas formas están resumidas en la Tabla 1.1, con sus características y la zona afectada del cerebro. Este sistema de clasificación es la utilizada por el grupo SCPE [23], tiene 4 niveles (3+1), aunque lo común es encontrar a usuarios con todas estas características, llamados usuarios mixtos (Hipótesis 1).

\footnotetext{
${ }^{1}$ www.scpenetwork.eu/

${ }^{2}$ www.madrid.org/hospital12octubre/
} 


\begin{tabular}{ll}
\hline $\begin{array}{l}\text { Formas } \\
\text { clínicas }\end{array}$ & Características \\
\hline Espástico & $\begin{array}{l}\text { Tipo de PC más habitual. Los músculos se sienten rígidos y apretados. Pre- } \\
\text { sentan daño en la corteza motora }\end{array}$ \\
Discinético & $\begin{array}{l}\text { Caracterizado por movimientos involuntarios (falta de control). Presentan } \\
\text { daños en los ganglios basales. }\end{array}$ \\
Atáxico & $\begin{array}{l}\text { Se caracteriza por movimientos temblorosos, falta de equilibrio y sentido de } \\
\text { ubicación espacial. Presentan daño en el cerebelo }\end{array}$ \\
Mixto & $\begin{array}{l}\text { Presentan una combinación de algunos de los tipos anteriores, debido a una } \\
\text { lesión en distintas zonas del cerebro. }\end{array}$
\end{tabular}

Tabla 1.1: Clasificación de la PC según formas clínicas, con las características de los 4 niveles y la parte del cerebro afectada.

\begin{tabular}{ll}
\hline $\begin{array}{l}\text { Zona } \\
\text { afectada }\end{array}$ & Descripción \\
\hline Cuadriplejia & $\begin{array}{l}\text { Ambos brazos y piernas están afectados. Los músculos del tronco, la cara y } \\
\text { la boca a menudo también se ven afectados }\end{array}$ \\
Diplejia & $\begin{array}{l}\text { Ambas piernas están afectadas. Los brazos pueden estar afectados en menor } \\
\text { medida }\end{array}$ \\
Hemiplejia & Uno de los lados del cuerpo (un brazo y una pierna) se encuentra afectada \\
\hline
\end{tabular}

Tabla 1.2: Clasificación de las personas con PC según la zona del cuerpo afectada.

De acuerdo a la zona del cuerpo afectada, una persona con PC puede ser clasificada como: cuadripléjica (ambos brazos y piernas están afectados), dipléjica (ambas piernas están afectadas) o hemipléjica (uno de los lados del cuerpo se encuentra afectada) [26]. Para detalles ver Tabla 1.2.

Otra clasificación, según el grado de dependencia, puede leerse en la Tabla 1.3. Esta clasificación hace énfasis en nivel de asistencia que necesita la persona para realizar actividades de la vida diaria.

Por otro lado, la clasificación GMFCS (Gross Motor Function Classification System) [14] hace énfasis en la capacidad de movilidad de la persona. Sin embargo, está restringida a usuarios menores de 18 años. Tiene 5 niveles y ha sido desarrollada en Canadá por

\begin{tabular}{ll}
\hline $\begin{array}{l}\text { Grado de } \\
\text { dependencia }\end{array}$ & Características \\
\hline Grave & $\begin{array}{l}\text { Carece de autonomía para la realización de todas o casi todas las actividades } \\
\text { de la vida diaria (vestirse, comer, asearse), por lo que precisa de la ayuda } \\
\text { de otra persona para poder vivir. Necesitará una silla de ruedas o un equipo } \\
\text { especial } \\
\text { Nocesita apoyo de una tercera persona para determinadas actividades y/o } \\
\text { ayudas técnicas u ortopédicas como un bastón } \\
\text { Eeve }\end{array} \quad \begin{array}{l}\text { Es totalmente independiente, aunque con limitaciones cuando realiza ciertas } \\
\text { actividades }\end{array}$ \\
\hline
\end{tabular}

Tabla 1.3: Clasificación de la PC según el grado de dependencia. 


\begin{tabular}{|c|c|}
\hline Nivel & Características \\
\hline I & $\begin{array}{l}\text { Los niños realizan las habilidades motoras gruesas, tales como correr y saltar, } \\
\text { pero la velocidad, el equilibrio y la coordinación son limitados }\end{array}$ \\
\hline II & $\begin{array}{l}\text { Los niños sólo tienen una capacidad mínima para llevar a cabo las habilidades } \\
\text { motoras gruesas, tales como correr y saltar }\end{array}$ \\
\hline III & $\begin{array}{l}\text { Los niños caminan usando un dispositivo de movilidad de mano en la mayoría } \\
\text { de los entornos de interior }\end{array}$ \\
\hline IV & $\begin{array}{l}\text { Los niños utilizan métodos de movilidad que requieren asistencia física o } \\
\text { electromecánica en la mayoría de los escenarios }\end{array}$ \\
\hline V & $\begin{array}{l}\text { Los niños son transportados en una silla de ruedas manual en todos los en- } \\
\text { tornos. Los niños están limitados en su capacidad para mantener la cabeza } \\
\text { erguida y la postura del tronco }\end{array}$ \\
\hline
\end{tabular}

Tabla 1.4: Sistema de clasificación de las personas con PC según su capacidad de movilizarse GMFCS.

\begin{tabular}{ll}
\hline $\begin{array}{l}\text { Habilidades } \\
\text { manuales }\end{array}$ & Característica \\
\hline I & Maneja objetos fácilmente y con éxito \\
II & Maneja la mayoría de los objetos, con menos calidad y/o velocidad \\
III & $\begin{array}{l}\text { Maneja objetos con dificultad; necesita ayuda para preparar y/o modificar } \\
\text { las actividades }\end{array}$ \\
IV & $\begin{array}{l}\text { Maneja una selección limitada de objetos fáciles en situaciones adaptadas } \\
\text { Vo maneja objetos y tiene capacidad muy limitada para realizar acciones } \\
\text { incluso simples }\end{array}$ \\
\hline
\end{tabular}

Tabla 1.5: Clasificación de las personas con PC según las habilidades manuales MACS.

CanChild ${ }^{3}$. Los distintos niveles con los criterios pueden verse en la Tabla 1.4.

La clasificación MACS (Manual Ability Classification System) [13], hace énfasis en la valoración de las funciones de la mano y del brazo, ofreciendo 5 niveles, como se puede ver en la Tabla 1.5. Esta clasificación nace a raíz de que 2 de cada 3 personas con PC tienen alguna dificultad en el movimiento de los brazos. Este sistema también está restringido a usuarios menores de 18 años.

Para valorar la comunicación, en particular la emisión del habla, existen muchos sistemas de clasificación [20]. En este estudio de Virella concluyen que el sistema Viking Speech Scale [7] es el más difícil de usar por los padres y los profesionales. La escala Viking del habla se ha desarrollado para utilizarse en niños a partir de 4 años. La escala tiene 4 niveles.

Además, para valorar a los usuarios con PC es importante cuantificar su grado de discapacidad intelectual (coeficiente intelectual), su agudeza visual y auditiva [20].

\footnotetext{
${ }^{3}$ https://www.canchild.ca
} 


\begin{tabular}{ll}
\hline $\begin{array}{l}\text { Emisión } \\
\text { del habla }\end{array}$ & Características \\
\hline I & $\begin{array}{l}\text { El habla no se ve afectada por un trastorno motor } \\
\text { II }\end{array}$ \\
El habla es imprecisa, pero suele ser comprensible por parte de personas \\
III & $\begin{array}{l}\text { Extrañas habla no es clara y habitualmente no es entendida por personas no fami- } \\
\text { liarizadas fuera de contexto } \\
\text { IV }\end{array}$ \\
\hline
\end{tabular}

Tabla 1.6: Clasificación de la PC según la emisión del habla, establecido por el sistema Viking Speeach Scale [7].

\begin{tabular}{ll}
\hline Sistema de clasificación & Nivel de interés \\
\hline Forma clínica & Independiente \\
Zona del cuerpo afectada & Cuadriplejia \\
Grado de dependencia & Grave \\
GMFCS & Niveles IV o V \\
MACS & Niveles IV o V \\
Comunicación & Niveles III o IV \\
Cognición & Capaz de seguir instrucciones básicas \\
Visión & Capaz de identificar objetos en la \\
& pantalla de un ordenador \\
Audición & Capaz de seguir instrucciones básicas \\
\hline
\end{tabular}

Tabla 1.7: Niveles de interés de esta tesis, según los sistemas de clasificación de la PC descritos.

\subsection{Perfil de usuario objetivo}

Existen muchos más sistemas de clasificación de la PC, cada uno haciendo énfasis en ciertos factores: parte del cuerpo afectado, grado de dependencia, capacidad de movilidad, de comunicación, de manipulación, cognitiva, visual o auditiva. Sin embargo, los presentados cubren toda la gama de trastornos posibles de las personas con PC.

Como se ha visto, la PC es un trastorno muy amplio y heterogéneo. Esta tesis se enfocará en un grupo de estos, en particular, aquellos usuarios con una capacidad visual, auditiva y cognitiva mínima que permita seguir las instrucciones de las pruebas y ver los objetos que aparecen en pantalla - Hipótesis 4 - . De la misma forma, esta tesis estará dirigida a usuarios con el grado de dependencia grave, normalmente asociados con el grado GMFCS IV o V, nivel MACS IV o V, los cuales son usuarios que no pueden controlar el ordenador mediante el teclado o el ratón con las manos - Hipótesis 2-. Este grupo de usuarios generalmente presenta un nivel de habla relacionado con el nivel III o IV.

Si bien este proyecto está orientado a personas con PC, existen otras personas con perfiles patológicos similares al acotado, que también se podrán beneficiar con los resultados de este trabajo, como por ejemplo la esclerosis lateral amiotrófica o la lesión medular Hipótesis 6-. 


\subsection{Conclusión}

En este capítulo se describió a la PC, el cual es un trastorno físico motor persistente, pero no invariable de la postura y el movimiento. El origen de la disfunción es el cerebro inmaduro del niño. El cerebro al crecer se desarrolla, y esta evolución es el motivo de la variabilidad en el tiempo de los síntomas de la PC.

Los posibles déficits asociados a la $\mathrm{PC}$ son de múltiple naturaleza y grado. A raíz de esto, existen muchos sistemas de clasificación para valorar a este trastorno, según distintas dimensiones, por ejemplo: la forma clínica, la parte del cuerpo afectada, el grado de dependencia, la capacidad de movilidad autónoma, las habilidades manuales o las capacidades del habla.

Se han utilizado estos sistemas de clasificación para acotar la población de interés de esta tesis, ya que la $\mathrm{PC}$ es un trastorno muy amplio y heterogéneo. El perfil objetivo agrupó a los casos más severos, que no pueden acceder a un ordenador mediante las interfaces estándar (ratón o teclado), por problemas asociados al control motor y a la postura - Hipótesis 2-, que tampoco tiene capacidad del habla - Hipótesis 3-, pero que sí son capaces de seguir instrucciones básicas y de identificar objetos en la pantalla de un ordenador - Hipótesis 4.

Este proyecto está dirigido a personas con PC. No obstante, existen otras personas con perfiles patológicos similares a la PC, que también se podrán beneficiar con los resultados de este trabajo, como por ejemplo la esclerosis lateral amiotrófica o la lesión medular - Hipótesis 6-.

Además de la notable heterogeneidad de la PC - Hipótesis 1-, es interesante notar la subjetividad de los sistemas de clasificación, que permiten un grado de dependencia alto con respecto al sujeto que lo practica. Otra cuestión que también llama la atención es que, si bien la tecnología parece ser una herramienta de asistencia útil para algunos casos, no existen sistemas de valoración de la interacción con el ordenador que permitan valorar el acceso mediante distintos dispositivos o bajo distintas condiciones o incluso valorara evolución - Hipótesis 21-.

Nuestros aportes irán orientados en esta dirección, intentando dar un paso adelante en la definición de metodologías y métricas de valoración de la interacción con el ordenador. 


\section{Capítulo 2}

\section{La interacción hombre computador}

El uso de las tecnologías como medio para mantener, mejorar o incrementar las capacidades funcionales de los individuos es una práctica común en el ámbito de la intervención con personas con discapacidad [33]. La clasificación elaborada por el estudio de la Unión Europea HEART [34], identifica cuatro áreas de influencia de la tecnología: comunicación, movilidad, manipulación y orientación. En el área de la comunicación se encuentran las tecnologías de comunicación aumentativa alternativa, las cuales hoy día forman parte de la vida cotidiana de muchas personas.

Cuando una persona y un dispositivo tecnológico, como por ejemplo un computador, entran en contacto existen una serie de elementos y factores que interactúan. La disciplina "Interacción hombre computador" o "Human-Computer Interaction" (HCI) ${ }^{1}$ estudia todos estos elementos y la interacción entre ellos. Mediante los fundamentos de esta disciplina, veremos cuáles de estos elementos requieren de adaptaciones especiales cuando la interacción se realiza con una persona con trastornos motores.

Dentro de la HCI, la usabilidad es un término ubicuo, tanto que muchas veces es empleado sin definirlo. Sin embargo, debido a los últimos y rápidos desarrollos tecnológicos, existen múltiples definiciones de usabilidad. Hertzum et al. delinean seis imágenes de este término, aclarando el aporte de cada una de las vistas parciales [35]. De modo general, aclaran que usabilidad no es utilidad. Cuando se habla de usabilidad, la utilidad no se discute. Más bien, el foco está sobre la facilidad de utilización o de uso.

A continuación, en la Sección 2.1 se presentarán los factores en juego en la interacción hombre-computador, comentando de forma particular las interfaces de acceso en la Sección 2.2 y discutiéndolas con respecto al HID (Human Interface Devices, una especificación del protocolo USB), el estándar de facto hoy en día de los periféricos en la Sección 2.3. En la Sección 2.4 discutiremos y acotaremos la definición de usabilidad, la cual será utilizada a lo largo de este documento. Para finalizar el capítulo, se describirá y analizará en detalle en la Sección 2.5 la tarea fundamental que se realiza en la interacción con el ordenador en las interfaces gráficas modernas.

\footnotetext{
${ }^{1}$ Existen un grupo especializado de la ACM que estudia esta disciplina: http://www.sigchi.org/
} 


\subsection{Elementos de la interacción hombre computador}

Cuando una persona y un computador entran en contacto existen una serie de factores que interactúan. La disciplina de Interacción hombre computador o "Human-Computer Interaction" 2 ofrece un modelo sobre los elementos de esta dinámica. Todos estos elementos están representados en la Figura 2.1 y serán detallados a continuación.

Por un lado, se encuentra la persona $(H)$, quien recibe información a través de los sentidos ( $\left.H_{4}\right)$ y manipula la computadora mediante gestos motores (H3). Por otro lado, se encuentra la computadora $(C)$, la cual emite estímulos, normalmente a través de una pantalla $(C 1)$ y recibe comandos a través de unas interfaces de acceso $(C 1)$, los cuales permiten cambiar el estado del sistema. Estos dos elementos están contextualizados dentro casos de uso concretos $(U)$.

El factor humano está compuesto por más elementos que los sentidos y los gestos de control. También incluye una capacidad cognitiva que le permita procesar los estímulos y generar gestos de control (H1 y H2). Además, existe un factor relacionado con la actitud o motivación de la persona $(H 6)$ y con el entrenamiento que ésta haya realizado (H5).

Por otro lado, el elemento ordenador también está compuesto por más elementos. Éste incluye técnicas de diálogo, como pueden ser el clic, arrastre, etc. (C2), géneros de diálogo, como por ejemplo iconos o listas desplegables (C3) y la interfaz gráfica que incluye definiciones de tamaño y colores de los objetos en pantalla $(C 4)$. Es importante destacar que el elemento que mide los gestos de la persona $(C 1)$ es el único elemento que incluye tanto software como hardware ${ }^{3}$, a diferencia del resto de los elementos que componen al ordenador, que son enteramente elementos software.

La interacción hombre computador además está condicionada por otro conjunto de elementos, relacionados con el contexto. El contexto lo forman diferentes elementos. El contexto del entorno es uno de ellos, que puede ser por ejemplo la casa (U1) y el contexto del usuario $\left(U_{4}\right)$, que tiene relación con elementos que condicionan al usuario, como por ejemplo si el usuario se encuentra en una silla de ruedas o acostado mientras se realiza la interacción. También tiene relación con la interacción la aplicación particular que se realiza (U2), por ejemplo, en la edición de textos o imágenes. Normalmente la forma de la interacción se encuentra documentada o detallada mediante guías de usuario u otros medios que ajustan el comportamiento de la persona al diseño (U3).

Resumiendo, los elementos presentados, vemos que la interacción está comprendida por 3 elementos: el hombre $(H)$, el ordenador $(C)$ y el contexto de uso $(U)$. Todos estos elementos y los factores de los cuales están constituidos entran en juego y generan una casuística amplia.

Esta interacción está siendo estudiada por grandes grupos de investigación alrededor del todo el mundo, pero centrándose en personas sin ningún tipo de discapacidad. Si nos apartamos de este patrón de diseño, centrándonos en usuarios con discapacidades motoras, muchas de las suposiciones sobre las capacidades de los usuarios dejan de cumplirse y se entiende que el problema se torne aún más complejo. Por ejemplo, en el caso de los usuarios con PC en los estadios más graves, los sentidos no son capaces de recibir correctamente la información ni tampoco de realizar gestos que permitan

\footnotetext{
${ }^{2}$ Existen un grupo especializado de la ACM que estudia esta disciplina: http://www.sigchi.org/

${ }^{3}$ Esto será discutido con más profundidad en las siguientes secciones
} 


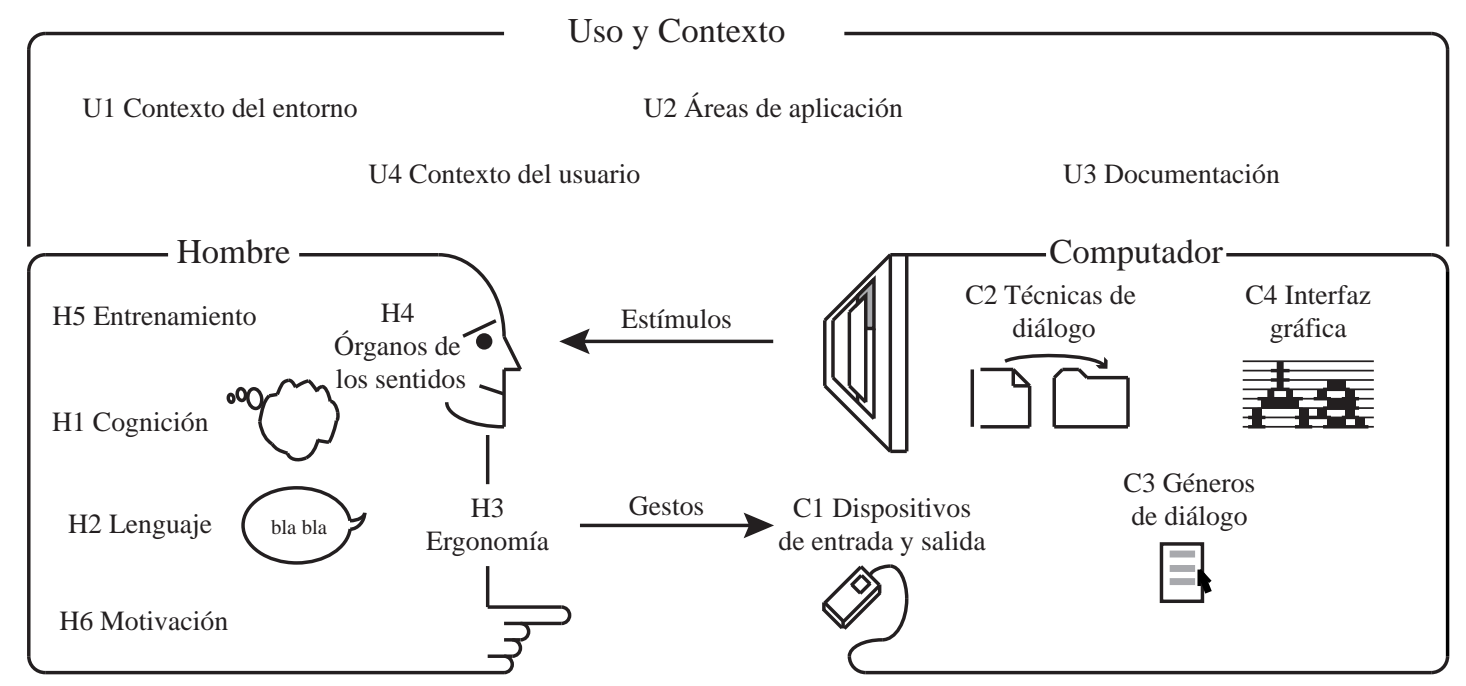

Figura 2.1: Esquema de los elementos que entran en juego durante la interacción hombre computador: Hombre $(\mathrm{H})$, Computador $(\mathrm{C})$ y Contexto y Uso (U). Este esquema está basado en uno de [1]

controlar un ratón o un teclado, interfaces comúnmente utilizados. En el mismo sentido, su sistema cognitivo puede estar afectado o no y pueden tener o no desarrollado el habla.

Las adaptaciones o nuevas técnicas se tienen que realizar en los elementos del ordenador $(C)$, no se puede manipular ni la persona $(H)$ ni el contexto $(U)$. En este sentido, los cambios se pueden realizar en los cuatro elementos identificados antes que componen el computador $(C)$ : en las interfaces de acceso, utilizando dispositivos capaces de recibir (hardware) e interpretar (software) información residual y no convencional del usuario $(C 1)$, en la forma de presentar la información al usuario (interfaz gráfica adaptada a sus necesidades de tamaño y color, C4), en la generación de técnicas especializadas de diálogo (clic por permanencia, C2) y en un lenguaje adecuado a sus capacidades (iconos mejor que listas, C3).

\subsection{Interfaz de acceso: del gesto al comando básico}

En general, podemos considerar a las interfaces como dispositivos identificadores de eventos. Estos eventos pueden estar caracterizados simplemente por su ocurrencia temporal (interruptor), o, como en otras interfaces como las pantallas táctiles, por su ocurrencia temporal y espacial.

Es conveniente, en el intento de generalizar y simplificar la descripción de una interfaz de acceso al ordenador en un sistema moderno basado en ventanas tipo Windows, describir las clases básicas de interfaces de acceso y sus acciones o comandos-eventos asociados. En este sentido existen: las clases reconocidas como teclados tradicionales (para escritura con caracteres alfanuméricos), clases del tipo puntero (ratón) y clases tipo interruptor (clic o switch). En general, las interfaces buscan asociar los gestos medidos (presión de un botón, movimiento de un elemento) a un evento, dentro del marco de una clase de interfaz. La estandarización de estas clases con sus respectivos eventos se encuentra recogida en la documentación relacionada con lo que se conoce comúnmente como $\mathrm{HID}^{4}$,

\footnotetext{
${ }^{4}$ www.usb.org/developers/hidpage/HID $1 \_11 . p d f$
} 
donde se especifican todos los atributos, características y protocolos para el uso estándar de los HID.

La información, desde que se genera hasta que se traduce en un comando básico HID pasa por una serie de pasos intermedios. Primero es necesario traducir el gesto físico en señales electrónicas, las cuales pueden ser interpretadas y procesadas por los sistemas digitales. Este proceso lo realiza un Hardware (HW) especializado. La señal digitalizada necesita ser procesada, para extraer posibles ruidos e identificar posibles eventos. De esto se encarga el Firmware (FW), que es un software con una tarea muy específica y fuertemente relacionado con un determinado Hardware. La transmisión de la información, según un protocolo estándar, con uno de los comandos básicos antes mencionados, es la última parte de este proceso, representado en la Figura como el bloque HID. El bloque FW además tiene definido la clase de dispositivo que es, de manera que se presentará al sistema operativo de esta manera. El computador, si conoce la clase de dispositivo que la interfaz dice ser, lo agregará como un dispositivo y ofrece sus eventos a las aplicaciones que lo necesiten.

Antes hemos llamado interfaz de acceso solo al dispositivo de entrada (C1), Como hemos visto, el periférico en realidad contiene más elementos, principalmente en su $\mathrm{FW}$, donde están las técnicas y géneros de dialogo que ofrecerá, etc. Como hemos visto, el computador debe tener un conocimiento previo de la clase y eventos-comandos de la interfaz de acceso. ¿Qué sucede cuando se desarrollan nuevas interfaces de acceso, especialmente diseñadas para personas con necesidades especiales? Esta cuestión será desarrollada en la siguiente sección.

\subsection{Las interfaces de acceso alternativas y el HID: una cuestión no resuelta}

Los elementos en juego en el desarrollo de una interfaz de acceso (IA) son: el protocolo de comunicación y de eventos y la aplicación que interpreta esta información, así como el sistema operativo (OS) que los orquesta. El mundo de las IAs, recorre un camino diferente al de las tradicionales en muchos sentidos. Se han identificado dos posibles escenarios en este contexto.

Escenario 1: Las aplicaciones de ordenador tradicionales y los OS están pensadas mayormente para IAs estándares HID. Es así, que se han desarrollado aplicaciones alternativas como: teclados virtuales, navegadores, aplicaciones de ofimática y sintetizadores de voz, casi todos ellos por barrido. Es decir, todas las opciones de la pantalla o correspondiente al estado de la aplicación se van recorriendo de forma automática, a la espera de que el usuario, mediante la selección a través de la IA adaptada, seleccione la opción resaltada en el momento oportuno. En este escenario, lo que se ha adaptado de la IA ha sido tanto el HW como el FW, no así el módulo HID, el cual sigue implementando los eventos de alguna de las clases predefinidas por el modelo HID. 
Escenario 2: Una IA para personas con discapacidad podría ser no funcional si no existe una aplicación adecuada para ser controlada por la misma y si el OS no lo reconoce. Es por esto que los fabricantes desarrollan las interfaces de acceso ligadas fuertemente a una aplicación y a un manejador que "presenta" a la IA al OS, definiendo sus clases y comando, que no son parte de la norma HID. Generalmente, como están muy asociadas a la aplicación y al manejador en sí, muchas de las IA vienen como parte de un paquete comercial que incluye las aplicaciones, los controladores y el hardware. Es así que se configura toda una solución $A d-H o c$ propietaria del fabricante. Esta aproximación va en detrimento de la estandarización, y por otra parte puede afectar a los esfuerzos de diseño de interfaces alternativas para aplicaciones tradicionales y la masificación que repercute en la bajada de los precios.

Los problemas de unificación y estandarización de las IAs se deben no solo a la aproximación comentada. También existe el problema de intentar responder a colectivos con una diversidad en las capacidades de manipulación muy diversas. Además, este colectivo es muchas veces postergado y resulta menos atractivo económicamente para la industria tecnológica. Así como aún no está resultado el enfoque de diseño y desarrollo de las IA, la orientación de la usabilidad tampoco está resulta. Sin embargo, la definiremos y delimitaremos a continuación.

\subsection{Usabilidad}

Hertzum et al. delinearon seis imágenes del término usabilidad, aclarando el aporte de cada una [35]. Aclararon que cuando se habla de usabilidad, la utilidad no se discute, sino principalmente la facilidad de utilización. Dos de las seis imágenes que mencionan son especialmente relevantes con esta tesis, las de usabilidad universal y la usabilidad situacional.

Según la imagen de "Usabilidad universal", la usabilidad implica aceptar el desafío de crear sistemas para que todos puedan utilizarlos. Sin embargo, sistemas usables universalmente implican sistemas tan variados como la humanidad misma, un requisito muy pretencioso, sino utópico. En este sentido, los desafíos para la usabilidad universal son: (1) la diversidad de los usuarios - edad, discapacidad, entusiasmo, nivel de entrenamiento, etc.- y, (2) la diversidad tecnológica - diferentes ordenadores, pantallas, procesadores, etc. -

De acuerdo con la imagen de "Usabilidad situacional", la usabilidad es equivalente a la calidad de uso de un sistema en una situación específica con sus usuarios, tareas y un contexto de uso. Los sistemas están co-constituidos por la situación en que se utilizan. Como consecuencia, la usabilidad debe ser entendida en relación con las personas específicas, las tareas concretas y otras condiciones contextuales que entran en situaciones de uso que constituyen. Dos de las características de la usabilidad situacional se derivan de esto. En primer lugar, la usabilidad es acerca de la situación de uso completo; no es un atributo del sistema tecnológico. Es decir, la usabilidad situacional implica un enfoque socio-técnico característico. En segundo lugar, los detalles de la situación de uso concreto son imperativos para saber si un sistema es usable. Esta situacionalidad es lo que más pesa entre los principios generales de usabilidad. La imagen situacional de la usabilidad puede considerarse pesimista en el sentido de que implica que no puede haber generalizaciones más allá de las situaciones de uso especificadas. Esto implica en gran medida que la usabilidad universal es un objetivo inalcanzable. Por el contrario, la 


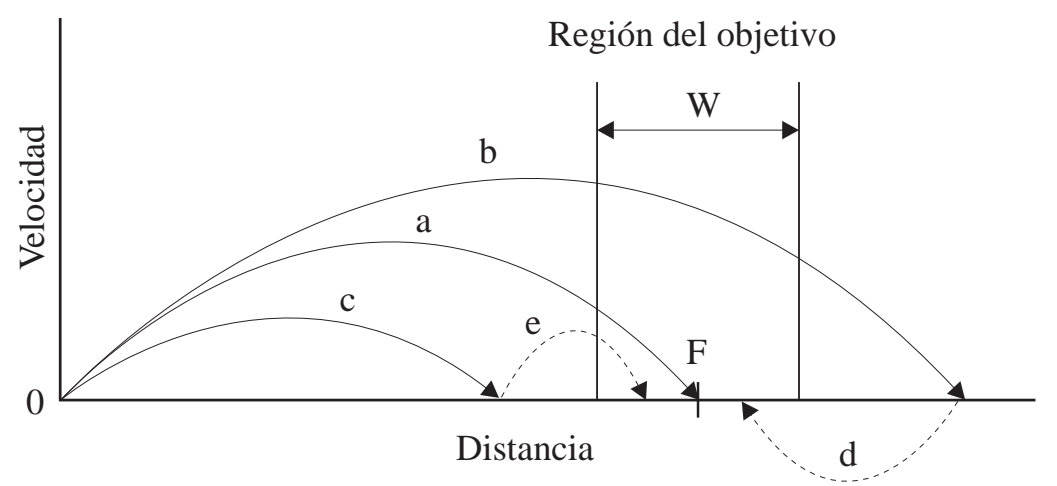

Figura 2.2: El modelo de Meyer [2] estable que el sistema motor inicia con un movimiento inicial rápido que cubre una distancia larga $(\mathrm{a}, \mathrm{b}, \mathrm{c})$ y uno o varios movimientos de corrección en la región cercana al objetivo (d, e). F es el centro del objetivo y $\mathrm{W}$ el ancho de este.

usabilidad situacional es consistente con los principios básicos de HCI tales como "conocer a tu usuario" y directamente aplicables al desarrollo de sistemas a medida, que son encargados por un cliente y personalizados a la situación concreta de este cliente.

El espíritu del enfoque de la "Usabilidad situacional" es el que más se acerca al ánimo de esta tesis. Según esta definición, la usabilidad es la calidad de la interacción. Será por tanto éste el enfoque y definición utilizado. Las técnicas para trabajar sistemáticamente con la usabilidad situacional incluyen, entre otras el análisis de tareas. La tarea de analizar será presentada en la sección siguiente.

\subsection{Tarea de apuntamiento: alcance y selección}

Un tipo especial de interfaz de acceso son los llamados dispositivos apuntadores. Un dispositivo apuntador es una interfaz de entrada al ordenador que permite a un usuario introducir datos al mismo mediante dos gestos físicos primitivos: apuntar, clic ${ }^{5}$. Esta información se refleja en la pantalla a través de los movimientos del puntero o cursor y otros cambios visuales.

A la combinación de los gestos primitivos de apuntar y hacer clic en las interfaces gráficas de usuario se conoce como tarea de apuntamiento (PT) y está compuesta por estas dos fases: la de alcance al objetivo y la fase de selección [36]. La PT puede ser caracterizada, según el modelo de Meyer [2], con un movimiento inicial rápido que cubre una distancia larga y uno o varios movimientos de corrección en la región cercana al objetivo, que son realizados con menor velocidad, Figura 2.2. Una PT es la unidad mínima de información que será analizada profundamente mediante métricas especiales, en un capítulo especialmente dedicado a este tema, el Capítulo 4.

Hoy en día, el dispositivo apuntador por excelencia es el ratón [37]. También existen otros dispositivos de control además del ratón: lápiz digital, trackballs, touchpad, touchscreen, etc. Todos estos periféricos permiten realizar esta misma tarea primitiva, [38]. Sin embargo, cuando el usuario presenta serios problemas de control motor, estos sistemas no pueden ser utilizado por estas personas. Una revisión de interfaces alternativas se presenta en el Apéndice A, especialmente desarrolladas para asistir en el apuntamiento en sus dos fases — Sección A.1-. En particular hemos revisado el estado de la cuestión

\footnotetext{
${ }^{5} \mathrm{El}$ arrastre es un tipo especial de gesto combinado de apuntar y hacer clic
} 
de los sistemas basados en visión, por su nula invasividad. Esta característica hace a este tipo de sistemas ideales para situaciones de bajo control motor, ya que así el usuario evita tener que portar algo. Entre estos dispositivos, los seguidores de la mirada se destacan por su mayor robustez ante las variaciones de iluminación y los movimientos de traslación de la cabeza del usuario, y por aprovechar el gesto residual de los ojos, presente en muchos casos de extrema limitación motora. Estos dispositivos junto a la dinámica ocular serán detallados en el siguiente capítulo.

\subsection{Conclusión}

En este capítulo se han visto los múltiples elementos y factores que están en juego cuando interactúan un hombre y un computador, mediante el modelo que ofrece la disciplina especializada en HCI. Todos estos elementos y sus respectivos factores constitutivos entran en juego y generan una casuística amplia, Hipótesis 8.

Si nos apartamos del patrón de diseño centrándonos en usuarios con discapacidades motoras, muchas de las suposiciones sobre las capacidades de los usuarios dejan de cumplirse y se entiende que el problema se torne aún más complejo, Hipótesis 9.

Hemos entrado en detalle respecto al elemento interfaz de acceso al ordenador, mostrando el recorrido que sigue la información desde que el usuario realiza el gesto de control hasta convertirse en un comando para el ordenador. Se comentó el protocolo HID, estándar que incluyen hoy día la mayoría de los periféricos de entrada tipo ratón o teclado y la relación de compromiso que implica este modelo respecto a las interfaces de acceso alternativas: normalmente tienden a caer en sistemas altamente personalizadas, en detrimento de la estandarización y la masificación, Hipótesis 10.

Dentro de la HCI, la usabilidad es un término ampliamente utilizado, que define, no la utilidad, sino más bien la facilidad de utilización o de uso de un dispositivo tecnológico. Hemos discutido las diferentes visiones de diferentes definiciones de usabilidad, indicando cual será utilizada a lo largo de esta tesis.

Para valorar la usabilidad de la interacción, se utiliza el análisis de la tarea con el ordenador. Hemos descrito la tarea de apuntamiento, con cada una de sus fases: el alcance y la selección, Hipótesis 11. Esta tarea primitiva será la única fuente de información para la evaluación y caracterización de la interacción. 


\section{Capítulo 3}

\section{Los sistemas de seguimiento de la mirada en la interacción hombre computador}

Este capítulo considera la aplicación de los movimientos oculares a interfaces de acceso al ordenador, como un medio de control en tiempo real, realizado a través de un dispositivo llamado seguidor de la mirada. Para usuarios afectados por serios problemas motores de control y coordinación, puede ser una de los únicos gestos de control residual. Para el uso en tiempo real, el problema es encontrar maneras apropiadas de responder correctamente a los movimientos oculares. Hay diferencias significativas entre una interfaz de acceso manual, como la posición del ratón, y una basada en los movimientos del ojo, que se deben considerar al estudiar este tipo especial de interacción. Por mencionar algunas podemos hablar por ejemplo de la velocidad del ojo - antes de operar cualquier dispositivo mecánico, nuestros ojos ya están puestos sobre el objetivo en cuestión-, la nula necesitad de entrenamiento de este órgano - para apuntar es necesario simplemente mirar, la relación de control entre el cursor y la pantalla se establece en el cerebro-, la relación directa entre la atención y la mirada - lo cual es tiene claras ventajas, no obstante, esto genera el efecto Midas, descrito más adelante-, etc. [39].

En este capítulo queremos dar protagonismo a los sistemas de seguimiento de la mirada, dentro del contexto de la interacción con el ordenador. Este uso de los seguidores de la mirada en HCI ha sido altamente prometedor durante muchos años, pero el progreso en el buen uso de los movimientos oculares en HCI ha sido lento hasta la fecha. Vemos que es una línea de trabajo de investigación prometedora, pero todavía no hemos visto un amplio y riguroso uso de estos sistemas en la práctica o en el mercado.

A continuación, presentaremos cuestiones relacionadas con la naturaleza del ojo humano, Sección 3.1. Después, introduciremos las principales técnicas para el seguimiento de la mirada, Sección 3.2, para luego entrar en detalles con los ETs basados en vídeo y remotos, Sección 3.2.1. Presentaremos un proceso crítico que debe realizarse con los ETs: la calibración, Sección 3.2.2. La Sección 3.3 dará a conocer el Efecto Midas que ocurre solamente cuando la interfaz de acceso es un ET. La Sección 3.3.1 relacionará unos conceptos presentados en el Capítulo anterior con unos nuevos, presentados en este capítulo. Este capítulo se complementa con los principales filtros y clasificadores presentados en el Apéndice B. Para finalizar este capítulo y la Parte II, queremos volver a retomar las principales cuestiones que hemos mencionado hasta aquí y las que mencionaremos en 


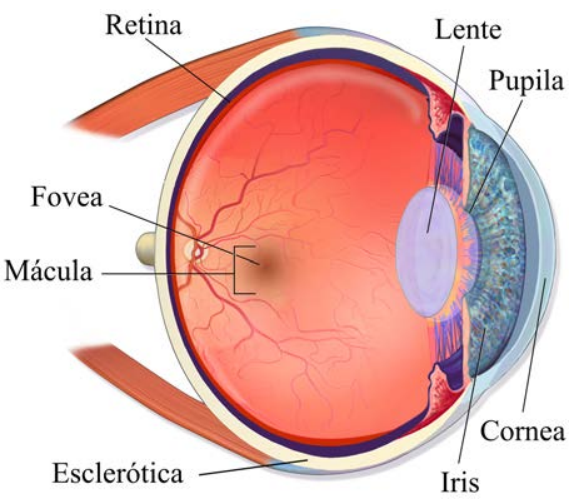

(a)

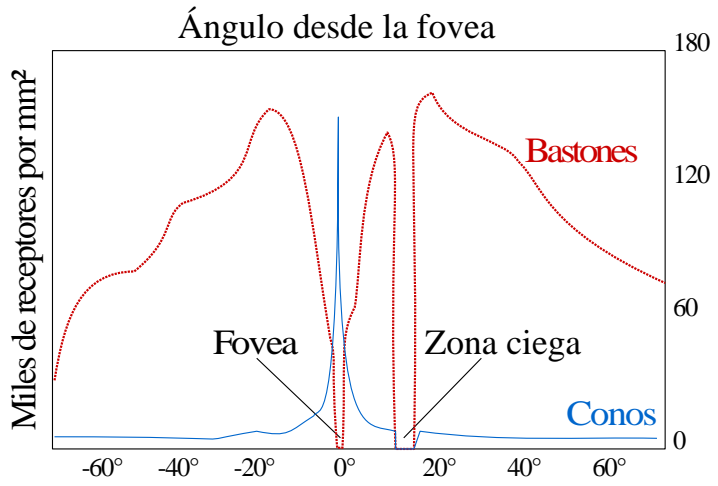

(b)

Figura 3.1: (a) Anatomía del ojo humano. Basado en [3]. (b) Distribución de los dos tipos de células nerviosas (conos y bastones) con respecto a la fóvea. La zona ciega no la percibimos naturalmente, aunque existen experimentos para verlo.

este capítulo en la Sección 3.4.

\subsection{El ojo humano y sus movimientos}

\subsubsection{Anatomía del ojo humano}

El ojo humano en un órgano que detecta, filtra y convierte un pequeño espectro de energía electromagnética en información significativa, que puede ser interpretada por el cerebro. Seis músculos, organizados en tres pares, dan al ojo tres grados de libertad. Los diferentes pares de músculos controlan los movimientos horizontales, verticales y de rotación alrededor de la dirección de la vista. Los músculos trabajan juntos, con el fin de compensar los movimientos de cabeza, guiados por el órgano de equilibrio en el oído interno.

Tres partes del ojo son visibles desde el exterior: la esclerótica (blanca y curvada), la pupila (negra), y el iris (de colores). La córnea cubre la pupila y el iris con una capa transparente, que refracta la luz antes de que entre en el ojo. La abertura en el centro del iris es la pupila, que regula la cantidad de luz que pasa a través ella. La lente es una parte transparente del ojo, detrás del iris, que ayuda a enfocar los rayos de luz en la retina, que es la capa de tejido sensible a la luz en la parte posterior en el ojo. La retina es un tejido sensible a la luz, donde se ubican los fotorreceptores. Una vista esquemática del ojo se muestra en la Figura 3.1a.

Las células fotorreceptoras convierten la luz en impulsos eléctricos que se transmiten al cerebro (corteza visual) a través del nervio óptico, que consta de más de un millón de fibras nerviosas. Los fotorreceptores consisten en dos grupos principales de células nerviosas: los conos y bastones.

Las células de tipo bastón proporcionan la visión monocromática. Responden a diferentes niveles de luminosidad en el ambiente. Los conos son menos sensibles al contraste y la luz tenue pero más sensible a los cambios de color y más rápidos. Los conos y bastones son responsables de la visión diurna. Los conos se colocan principalmente en la mácula, una superficie de unos $5^{\circ}$ que es responsable de la visión central. 
Dentro de la zona de la mácula se encuentra la fóvea, que es responsable de la visión más aguda y cubre un área circular de aproximadamente $1^{\circ}$. Alrededor de 150000 conos $/ \mathrm{mm}^{2}$, junto con un bajo número de bastones, se encuentra dentro de la fóvea, $\mathrm{y}$ en contraste, sólo $20000 \mathrm{conos} / \mathrm{mm}^{2}$ se encuentra fuera de la fóvea, Figura 3.1b. Esto significa que el campo visual no es igualmente sensible en diferentes zonas. Fuera de la fóvea la visión es de baja resolución, y sólo puede ayudar en la percepción del movimiento ambiente, aunque esta zona sea mucho más amplia que la fóvea, aproximadamente $220^{\circ}$. A esta zona se la conoce como zona periférica.

Esta distribución asimétrica hace del sistema visual un sistema más eficiente que si tuviéramos toda la zona visual cubierta de conos, lo que implicaría tanto un nervio óptico como una corteza visual mucho mayores. A cambio de esto, lo que hace nuestro cuerpo cuando quiere mirar algo es mover $\operatorname{los}_{\text {ojos }}{ }^{1}$ hacia la zona foveal, donde el cerebro puede captar mayor cantidad de información por la alta resolución de esta zona. Esta es la naturaleza de los movimientos y de la estabilización del ojo.

A los saltos bruscos del ojo se les llaman movimientos sacádicos. Después de estos saltos los ojos descansan por un período de tiempo corto, donde ocurre la proyección estable en la retina. A estos periodos de estabilidad se llaman fijaciones [6]. Estos movimientos serán detallados a continuación

\subsubsection{Los movimientos del ojo}

Los ojos se mueven en un número limitado de formas y esos son básicamente los mismos para la mayoría de las personas [40]. Las sacadas son los movimientos balísticos que no se pueden interrumpir ni cambiar. Cuando se produce una sacada ninguna información se recopila para el sistema visual. A este fenómeno se lo conoce como supresión sacádica. Durante una sacada el ojo gira a alta velocidad y para grandes amplitudes la velocidad pico es en determinadas circunstancias capaz de superar los $700^{\circ} / \mathrm{s}^{2}$, por lo que los movimientos sacádicos son los movimientos más rápidos producidos por el cuerpo humano [6]. Rommelse et al. [41] lista cuatro tipos diferentes de movimientos sacádicos:

- Movimientos sacádicos guiados visualmente, donde los ojos se mueven hacia un estímulo visual.

- Antisacadas, donde los ojos se mueven en una dirección opuesta a la dirección donde se presentó un estímulo.

- Movimientos sacádicos guiados por memoria, donde los ojos se mueven hacia un punto memorizado, sin ningún estímulo visual.

- Movimientos sacádicos predictivos, donde los ojos están realizando capturas hasta movimientos sacádicos mientras que después de un objeto en movimiento, también conocido como el seguimiento suave.

Además de los movimientos sacádicos, hay cuatro tipos adicionales de movimientos de los ojos: persecución o seguimiento suave, reflejo vestíbulo-ocular, de vergencia y nistagmo optocinético [42].

\footnotetext{
${ }^{1}$ Acompañado a veces de movimientos de la cabeza, lo que se conoce como reflejo vestíbulo-ocular

${ }^{2}$ Lo que equivale a $1466 \mathrm{~cm} / \mathrm{s}$ o $52 \mathrm{~km} / \mathrm{h}$ a una distancia de $60 \mathrm{~cm}$ de una pantalla
} 
- Los movimientos de seguimiento ocurren para corregir los errores posicionales entre el ojo y un objetivo en movimiento. Puede producirse previamente una sacada. Esto explica por qué los movimientos de seguimiento sólo pueden tener lugar cuando se da el seguimiento de un objeto visual y nunca bajo voluntad ${ }^{3}$.

- Como se ha mencionado anteriormente, el reflejo vestíbulo-ocular se produce cuando la cabeza está girando y los ojos giran en sentido contrario para mantener la imagen en la zona foveal, con la ayuda del oído interno.

- Vergencia se refiere a un movimiento simultáneo de ambos ojos, ya sea con una rotación convergente o divergente, para obtener o mantener la visión binocular. $\mathrm{Al}$ inspeccionar objetos cercanos a los ojos, éstos están girando uno hacia el otro. A esto se le conoce como convergencia, mientras que para los objetos más lejos, los ojos están girando lejos el uno del otro, y a esto se conoce como divergencia. La divergencia máxima es hasta que los ojos están paralelos, cuando miran al infinito. Los movimientos de vergencia son iniciados por un cambio de enfoque en los objetos.

- El nistagmo optocinético, que es una mezcla entre el perseguimiento suave y las sacadas. El movimiento se asemeja a un "diente de sierra" y se da por ejemplo al fijarse en diferentes objetos mientras se está sentado en un coche o en un tren.

\subsubsection{Las fijaciones}

Cuando se produce una fijación se recolecta información visual del entorno. La duración de una fijación normal ronda los 100 a 200 ms [39]. Una fijación no es un estado estable del ojo, ya que incluso cuando los ojos están fijos en un punto, se siguen moviendo. Estos movimientos durante las fijaciones visuales deberían ser visible, pero el cerebro filtra estos movimientos, haciendo que sean invisibles.

Si el ojo estuviera estable en una posición, la percepción visual se desvanecería completamente, como resultado de la adaptación neural. En otras palabras, esto significa que, si tuviésemos una fijación perfecta, los datos se desvanecerían de nuestra vista [43]. Aunque este efecto parece contradictorio a primera vista, es común en las demás modalidades sensoriales. Por ejemplo, durante el día, mientras usamos zapatos, necesitamos mover los dedos de los pies para notar aún tenemos los zapatos puestos. Esto es análogo con los ojos, por eso se evita la estabilización [44], Figura 3.2a.

Se ha sabido durante mucho tiempo que los ojos nunca están en reposo. Las primeras observaciones, tales como las de Jurin, en 1738, y Helmholtz, en 1860, indican que los investigadores habían notado estos micro movimientos durante la fijación [44]. En los tiempos modernos, los investigadores se han puesto de acuerdo en tres tipos de movimientos oculares durante las fijaciones: el micro temblor, las derivas y las micro sacadas. Martínez-Conde et al. [44] resume estos movimientos:

- Los micro sacádicos son pequeños y rápidos movimientos oculares que se producen durante la fijación, Figura 3.2b. Los movimientos son de aproximadamente 25 ms de duración y son capaces de moverse entre unas decenas a varios cientos de fotorreceptores. Una de las funciones de los movimientos micro sacádicos es

\footnotetext{
${ }^{3}$ Los movimientos de seguimiento suave son más lentos que los movimientos oculares sacádicos y tienen una latencia de aproximadamente $120 \mathrm{mseg}$.
} 


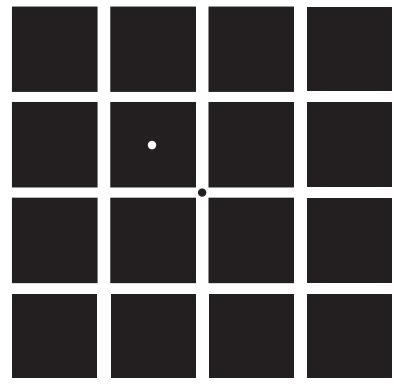

(a)

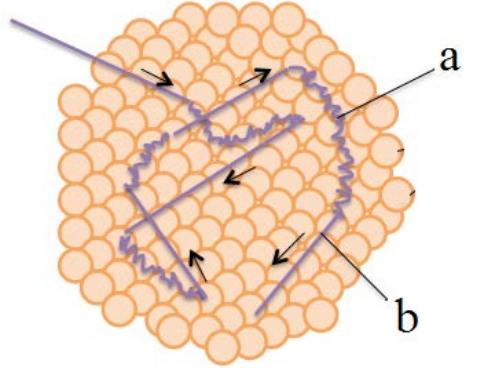

(b)

Figura 3.2: Izquierda: Patrón para demostrar los movimientos durante la fijación. Mantenga la mirada durante aproximadamente 1 minuto sobre el punto negro central. Después mire el punto blanco. Verá las líneas blancas (de la fijación anterior) en constante movimiento. Derecha: Dos de los movimientos que ocurren durante una fijación: a) las derivas y b) las micro sacadas. Los círculos representan a los fotorreceptores de la retina.

corregir los desplazamientos de la posición del ojo durante las derivas. Es decir, si las derivas llevan a la fijación lejos del objetivo de la fóvea, los movimientos micro sacádicos corregirán este error. Se ha sugerido que el mecanismo de generación de los grandes movimientos sacádicos y los movimientos micro sacádicos es el mismo, debido a una relación combinada entre la velocidad y la amplitud de los dos [45].

- Las derivas son un movimiento lento del ojo que se produce entre los micro sacádicos, Figura 3.2b. Durante una deriva, el objeto que se inspecciona puede moverse en torno a una docena de fotorreceptores. Las derivas parecen tener un papel compensatorio para mantener la visión precisa en ausencia de los micro sacádicos.

- El micro temblor es el más pequeño de todos los movimientos de los ojos, con la amplitud de aproximadamente el diámetro de un cono en la fóvea. El temblor se cree que opera de forma independiente en cada ojo, lo cual establece un límite inferior físico para el sistema visual durante la visión estereoscópica. Parece tener relación con el nivel de progresión de algunas enfermedades como el Parkinson [46] o la esclerosis múltiple [47].

\subsubsection{Las fijaciones y la atención visual}

Cada vez que miramos el mundo que nos rodea, consciente o inconscientemente nos centramos sólo en una fracción de la información total que potencialmente podríamos procesar, en otras palabras, realizamos un proceso de selección perceptual llamado atención [48].

Visualmente esto se hace más comúnmente moviendo nuestros ojos de un lugar del campo visual a otro. Este proceso se refiere a menudo como un cambio en la atención abierta - overt attention - , cuando nuestra mirada sigue nuestro cambio de la atención. Aunque preferimos mover nuestros ojos para cambiar nuestra atención, también somos capaces de mover la atención de nuestra mente a las áreas periféricas de nuestro campo visual, sin mover los ojos. Este mecanismo se llama atención encubierta — covert attention-.

Aunque podemos usar estos dos mecanismos por separado, ocurren con más frecuencia juntos. Un ejemplo es cuando estamos mirando un paisaje y primero usamos nuestra atención encubierta para detectar una forma o movimiento en nuestro campo visual 
que parece ser interesante y utilizamos nuestra visión periférica para identificar aproximadamente lo que es. Entonces dirigimos nuestra mirada a esa ubicación, permitiendo que nuestro cerebro tenga acceso a información más detallada. Por lo tanto, un cambio de nuestra atención es comúnmente iniciado por nuestra atención encubierta, seguida rápidamente por movimientos oculares y dar paso a nuestra atención abierta.

Nuestros ojos, revelando nuestra atención, revelan (en) que estamos pensando. Esta es la base de muchos estudios de neuromarketing, donde se analiza la atención a través de la mirada para análisis del diseño de imágenes publicitarias, distribución de elementos en una estantería de un supermercado, posicionamiento de la publicidad en una página web, etc. Y es de hecho, uno de los nichos de mercado de los ETs.

\subsection{Los eye-trackers}

En esta sección se presentan los métodos contemporáneos para conocer la dirección que sigue la mirada. Localizar la dirección de la mirada implica dos operaciones: seguir al ojo midiendo ciertas características y estimar la mirada en función de estas características medidas y una calibración previa.

Dependiendo de la técnica de estimación de la mirada empleada, la salida de los eyetrackers puede ser: el punto de la mirada (o point of regard, POR) en un plano de 2D (por ejemplo, en una pantalla del ordenador) o la línea de visión (o line of sight, LOS) en el espacio 3D. Las técnicas actuales de seguimiento de la mirada se dividen normalmente en tres categorías, según estén basadas en: electro-oculografía (EOG), lentes de contacto y vídeo-oculografía (VOG), Tabla 3.1. A continuación, se estudiarán y presentarán las técnicas basadas en VOG por su baja invasividad.

Los sistemas basados en VOG constan de una cámara y un sistema de procesamiento de imágenes que se encarga de estimar la posición de la mirada. Hansen [49] presenta una revisión reciente y detallada de los modelos de ojo y las técnicas para la detección y el seguimiento de los ojos. Pueden ser categorizados en dos clases: remotos o portátiles. En la configuración remota, los sistemas proporcionan datos siempre y cuando los ojos del usuario se mantengan dentro del campo de visión de la cámara. Para mejorar la calidad de las medidas, se suele emplear una mentonera para fijar la posición de la cabeza durante los experimentos. Los sistemas portátiles tienen las fuentes de luz y las cámaras integradas en un casco o un par de lentes, permitiendo así la interacción móvil, ya que el usuario no se limita a estar sentado, delante de una instalación fija. Dos ejemplos de la imagen que capturan cada uno de estos dos tipos de sistemas pueden verse en la Figura 3.3. Las características y las diferencias entre estas dos clases se resumen en la Tabla 3.2.

Es importante aclarar que existen proyectos de eye-tracking que no proporcionan datos de la mirada, sino solo del ojo, ofreciendo medidas de la posición del globo ocular según un sistema de coordenadas arbitrario. Estrictamente los sistemas remotos que proveen datos de la mirada deberían ser llamados gaze-trackers, sin embargo, esto no suele ser así, y los términos eye-tracker y gaze-tracker suelen utilizarse indistintamente generándose cierta ambigüedad. Los gaze-trackers normalmente ofrecen además de los datos de la mirada también los datos del ojo, por lo que incluso existe un tercer nombre para estos sistemas: eye-gaze-trackers. Por cuestiones de claridad, cuando no referimos a los eyetrackers nos referiremos a los sistemas que ofrecen datos de la mirada. 


\section{Taxonomía}

Tipos

Tipo de datos de la mirada

POR, Punto de la mirada

LOS, Línea de la mirada

Técnicas

EOG, Electro oculografía

Lentes de contacto

VOG, Vídeo oculografía

Tipos VOG

Portátiles

Remotos

Tipo de datos

De los ojos

De la mirada (normalmente también de los ojos)

Fuente de luz

IR, Infrarrojos

Luz visible

Efecto en la pupila

Pupila brillante

Pupila oscura

Tabla 3.1: Taxonomía de los eye-trackers, según distintas características.

\begin{tabular}{|c|c|c|}
\hline & Eye-trackers Remotos & Eye-trackers Portátiles \\
\hline \multirow[t]{3}{*}{ Configuración } & $\begin{array}{l}\text { Los componentes del sistema } \\
\text { (cámara y fuentes de luz in- } \\
\text { frarroja) se colocan lejos del } \\
\text { usuario. }\end{array}$ & $\begin{array}{l}\text { Suelen tener dos cámaras, } \\
\text { una para el ojo y otra con } \\
\text { vista delantera, ambas mon- } \\
\text { tadas en la cabeza. }\end{array}$ \\
\hline & $\begin{array}{l}\text { El sistema es capaz de traba- } \\
\text { jar de forma remota. Algunos } \\
\text { de estos sistemas tienen más } \\
\text { de una cámara para realizar } \\
\text { el seguimiento }\end{array}$ & $\begin{array}{l}\text { Algunos de estos sistemas no } \\
\text { tienen una cámara de vista } \\
\text { frontal y estiman la mirada } \\
\text { en el espacio 3D. }\end{array}$ \\
\hline & & $\begin{array}{l}\text { Los sistemas binoculares tie- } \\
\text { nen dos cámaras para cada } \\
\text { ojo. }\end{array}$ \\
\hline Rango de operación & $\begin{array}{l}\text { Estos sistemas generalmente } \\
\text { sólo permiten estimar el pun- } \\
\text { to de mirada en una super- } \\
\text { ficie plana fija, por ejemplo, } \\
\text { una pantalla de ordenador. }\end{array}$ & $\begin{array}{l}\text { Estos sistemas se utilizan co- } \\
\text { múnmente para la estima- } \\
\text { ción del punto de mirada del } \\
\text { usuario en su campo de vi- } \\
\text { sión. }\end{array}$ \\
\hline Ventajas & No invasivo & Movilidad \\
\hline Desventajas & Limitado rango de operación & Invasivo \\
\hline
\end{tabular}

Tabla 3.2: Los sistemas de eye-tracker basados en visión pueden ser categorizados en dos tipos: remotos o portátiles. 


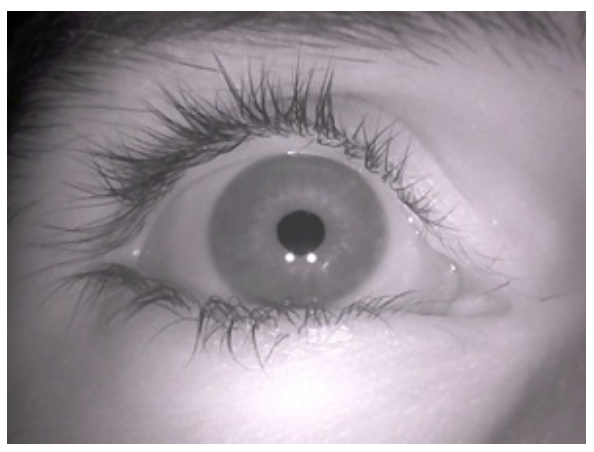

(a)

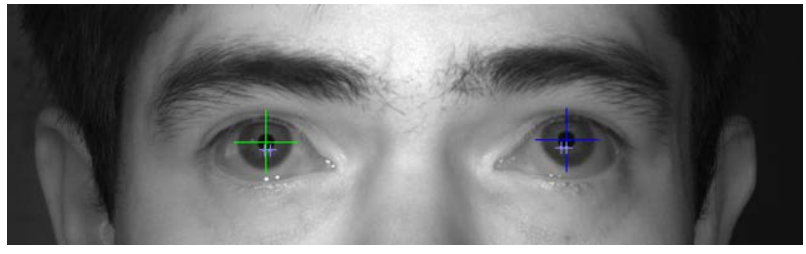

(b)

Figura 3.3: Ejemplo de la imagen que captura la cámara IR. En el caso a) el sistema es del tipo portátil, y en el caso b) del tipo remoto. En el caso a) las fuentes de luz se colocaron lejos del eje óptico de la cámara, por lo que se produce el efecto de pupila oscura (dark pupil). En esta subfigura se ve además los reflejos de las dos fuentes de luz infrarroja sobre el ojo, como dos puntos blancos bajo la pupila.

\subsubsection{Eye-trackers basados en vídeo-oculografía remotos}

Entre los eye-trackers remotos, existen dos clases de enfoques respecto a la fuente de luz: una solución amplia y efectiva se basa en iluminación infrarroja (IR); el segundo enfoque se basa en el análisis de grabaciones de vídeo bajo condiciones de luz natural.

El uso de luz IR es común en muchos sistemas de seguimiento ocular, para un mejor y más robusto seguimiento de las características de los ojos y la estimación de la mirada. Sin embargo, requieren el uso de una cámara especial capaz de capturar imágenes IR. La luz IR proporciona una iluminación estable. Además, se puede usar para generar reflexiones sobre la superficie de la córnea, que se conoce como las reflexiones de la córnea o reflejos corneales (glints), Figura 3.3a.

Dos técnicas se emplean típicamente cuando se utilizan fuentes de luz IR, dependiendo de la colocación de la luz en relación con el eje óptico de la cámara. La colocación de las fuentes de luz cerca del eje óptico de la cámara genera un efecto de pupila brillante (bright pupil), similar al efecto de ojos rojos que se produce en la fotografía estándar con un flash. Cuando las fuentes de luz se colocan lejos del eje óptico de la cámara se produce un efecto de pupila oscura (dark pupil) y la pupila aparece más oscura, como en la Figura 3.3a. El uso de las luces de IR en el seguimiento de los ojos no es perfecto, ya que tienen una baja tolerancia a la luz solar (ya que contiene IR) y esto restringe los sistemas para ser usados en interiores.

En el enfoque basado en la luz natural, las imágenes de los ojos se graban mediante los dispositivos tradicionales de adquisición de imágenes y luego se procesan para extraer información de la configuración del ojo. Generalmente no se necesita ningún hardware ad-hoc. Por otro lado, se requieren esfuerzos mayores en términos de procesamiento de imagen, en comparación con los sistemas basados IR, a fin de detectar las características de la cara y de los ojos. Los sistemas suelen tener menor precisión por el bajo contraste de la imagen. Una completa revisión de estos sistemas se presenta en [12] y en [50]. 


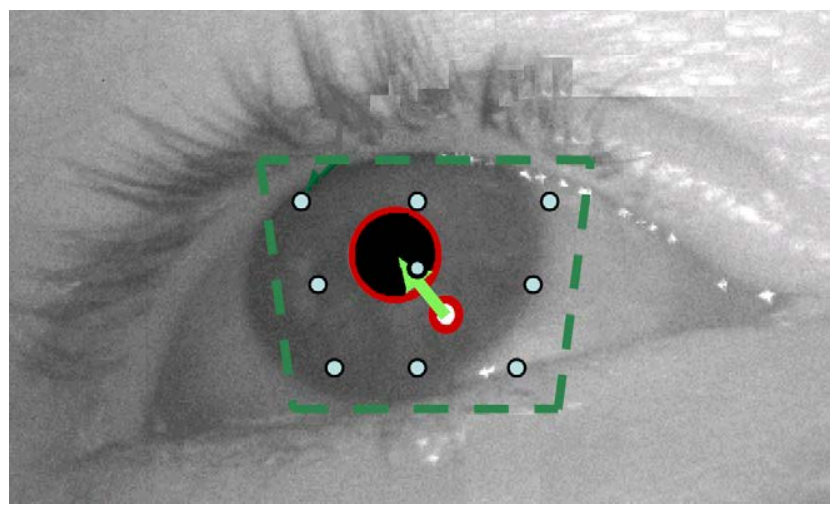

Figura 3.4: Esta imagen presenta un solo reflejo corneal. Para mejorar las prestaciones se puede usar dos puntos de reflejo corneal, como la Figura 3.3a. Basado en [4].

\subsubsection{Calibración}

Los ETs requieren una calibración para calcular la relación entre la dirección de la mirada de cada usuario y un plano de interés ${ }^{4}$. Este proceso es necesario por varios motivos: 1) el desplazamiento entre el eje visual y el óptico difiere de un sujeto a otro, 2) la calibración tiene relación con la posición de calibración, por lo que si una misma persona se mueve de esta posición será necesario realizar un nueva calibración y 3) la posición del ET respecto a plano de interés es desconocido y normalmente está fuera del rango de visión de la cámara.

El procedimiento normal consiste en mirar un punto que aparece en distintas posiciones conocidas de la pantalla, igualmente distribuidos (generalmente en 5, 9 o 16 posiciones) a una distancia de 50-70 cm entre el ojo y la pantalla. Las imágenes capturadas por la cámara del ET se asocian con las coordenadas de los puntos en pantalla correspondientes y se utilizan para generar una relación entre las imágenes y las coordenadas de los puntos en pantalla, Figura 3.4. En la figura se observan los puntos de calibración como círculos celestes y el borde de la pantalla como un recuadro verde, ambos mapeados sobre la imagen capturada por la cámara IR. Además, se ve la pupila en negro encerrada en un círculo rojo y el reflejo corneal como un círculo blanco encerrado en otro círculo rojo. Además, se ve el vector que une el punto del reflejo corneal y la pupila. Después de la calibración y con el modelo ajustado, se estiman las posiciones de la mirada de cada ojo a partir del vídeo que el ET captura mediante el vector pupila-reflejo corneal.

Este proceso se repite a menudo por varias razones y se considera como uno de los aspectos más tediosos y molestos de los sistemas de seguimiento ocular. Existe la posibilidad de almacenar en una base de datos las calibraciones de distintos usuarios, para resolver este problema. Aunque suele ser necesaria una re calibración debido a cambios en la configuración del entorno.

En la Sección 3.1.3 vimos que durante la fijación el ojo no se encuentra completamente estable y que tiene movimientos mínimos (micro sacadas, derivas y micro temblor). Además, la fóvea tiene un tamaño de aproximadamente $1^{\circ}$ de apertura, Sección 3.1.1. Todo esto implica que no existirá nunca una calibración con una precisión menor a $1^{\circ}$, o no ser que se realice con un ojo artificial ${ }^{5}$.

\footnotetext{
${ }^{4}$ Este plano de interés normalmente es la pantalla de un ordenador, aunque existen otras posibilidades: la imagen de un proyector, una imagen impresa en papel, etc.

${ }^{5}$ Medido con un ojo artificial, la precisión de los ET basados en vídeo se extiende desde alrededor de
} 


\subsection{Los eye-trackers como interfaz de acceso}

Existen dos áreas de acuerdo al uso de los ETs: diagnóstico e interacción. Las aplicaciones de diagnóstico capturan información del movimiento de los ojos, diseñadas para distintos campos de aplicación: psicología, salud, marketing y usabilidad. En general, para el diagnóstico importa la cognición y la atención del usuario mientras éste realiza una tarea específica, como leer, conducir, etc. En el diagnóstico el seguimiento de la mirada aporta información de dónde se realizan los movimientos oculares solamente. Por ejemplo, Kooiker et al. analizaron las fijaciones y las sacadas con el fin de identificar problemas en el sistema visual de los niños $[52,53]$. Kooiker evaluó el sistema visual del usuario cuando los participantes estaban en un modo pasivo, sin controlar el cursor, analizando las respuestas de los ojos a los estímulos visuales.

Sin embargo, en el modo interacción, el ET además de aportar información de donde está mirando el usuario, también controla el cursor. Unos trabajos interesantes en esta línea fueron presentados en $[54,55,56,57]$.

En la Figura 3.5 se esquematizan los elementos en juego en la interacción hombrecomputador en el caso especial donde la interfaz de acceso es un ET. Por un lado, el ser humano actúa mediante gestos y percibe la información mediante los sentidos. Por otro lado, el computador ofrece información mediante gráficos a través de la pantalla y recibe comandos mediante los controles, Sección 2.1. Un ejemplo concreto muy habitual para todos es el caso de la utilización del ratón. En este caso, se apunta mediante gestos manuales y se recibe la realimentación del ordenador mediante la visión, observando objetos en pantalla. En el caso del eye-tracker, sin embargo, la situación es diferente, ya que se "apunta" con el gesto que controla el cursor. Esto hace que una corrección por parte del usuario, cuando éste detecta un error en el apuntamiento, implique un gesto muy incómodo y complicado: mirar a dos puntos, donde se quiere apuntar y donde se está apuntando efectivamente ${ }^{6}$. En la Figura 3.5 podemos ver un esquema de lo que está sucediendo: el ojo, que es el que genera el gesto de control, es a la vez el sensor de sí mismo.

A esta situación se le suele llamar en la literatura como el "efecto de Midas", haciendo analogía a la situación del Rey Midas, de la antigua Frigia. Este Rey tenía una capacidad divina particular: todo lo que tocaba se convertía en oro. Este Rey disfrutó de este don celestial, hasta que un día accidentalmente, tocó a su hija, convirtiéndola en oro [43]. Ese día el pobre Rey cayó en la cuenta de que la misma mano que convertía las cosas en oro era la mano que le permitía coger las cosas. En el caso del control del ordenador, el ojo que es el órgano encargado de dar una realimentación visual de la posición del cursor (introducir información al usuario), es el mismo encargado de actuar sobre el cursor (emitir información del usuario), lo que genera una ambigüedad en el eye-tracker a la hora de decidir si los ojos están indicando una selección o simplemente están realizando una inspección [4]. Este no es un problema del ET, sino un problema en la naturaleza misma del control.

$0.001^{\circ}$ a $1.03^{\circ}$, donde los valores más bajos indican que las micro sacadas se detectan de forma fiable y el extremo superior de la escala dificulta la detección de las fijaciones [51].

${ }^{6}$ Esto lo podemos hacer gracias a la atención abierta y encubierta, Sección 3.1.4 


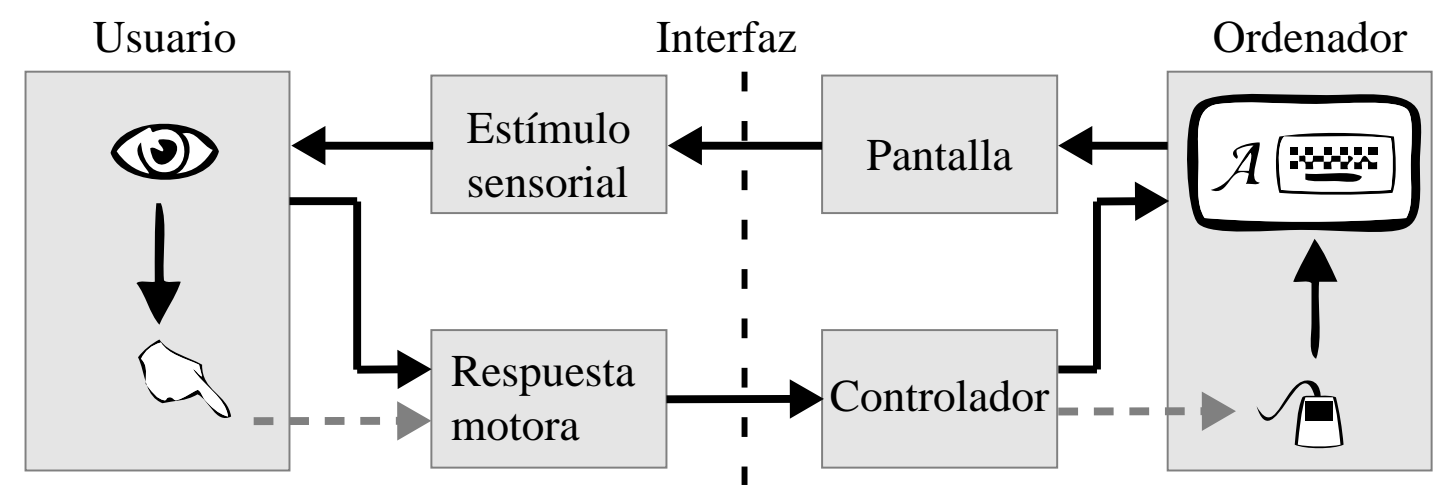

Figura 3.5: Efecto "toque de Midas": cuando el ojo es utilizado como gesto de control y como sentido para la percepción de lo que está ocurriendo se produce una ambigüedad en el lazo de control (lazo gris): ¿los ojos están apuntando o simplemente están realizando una inspección?.

\subsubsection{Relación entre el alcance \& selección y las sacadas \& fijaciones}

En esta sección relacionaremos los conceptos presentados en la Sección 2.5, donde presentamos el de alcance y selección, y las fijaciones y los movimientos sacádicos presentados en la Sección 3.1.

La fijación es el estado más estable de los ojos. Durante este estado los ojos recogen la información visual del ambiente. La fijación de la mirada se produce en elementos en la pantalla, por lo que, idealmente, cuando un usuario controla la computadora, el cursor también se espera que se encuentra en el objeto. Esta es la razón por la cual las fijaciones están asociadas con la fase de selección. Por otro lado, una sacada es un movimiento rápido y simultáneo de ambos ojos en la misma dirección. Durante una sacada, las imágenes de la retina no se procesan y el individuo se vuelve ciego. Las sacadas ocurren entre dos fijaciones y se asocian con la fase de alcance.

Los datos del eye-tracker se procesan para mejorar la experiencia de uso como interfaz de acceso al ordenador. El procesamiento suele incluir una serie de fases: un primer filtrado, una clasificación del estado del ojo - fijación o sacada - y finalmente una segunda etapa de filtrado. En el Apéndice B se detallan los algoritmos para la identificación de las fijaciones y para el filtrado de datos, en la Sección B.1 y en la Sección B.2 respectivamente.

\subsection{Interacción Hombre con PC Computador, mediante eye-tracking}

Existen muy pocos estudios de casos que examinen la validez objetiva de la interacción hombre computador con ETs [58]. La mejor evidencia disponible fue un estudio de 10 niños, de 1 a 15 años, nueve de los cuales tenían PC. Todos tenían discapacidad física grave y no podían hablar. Los niños tuvieron acceso a la tecnología de ET y, con sus familias y profesores, participaron en 14 días de intervención repartidos a lo largo de 9-10 meses. La intervención consistió en la instrucción individual y grupal de sus sistemas de control de la mirada, y el incentivo a los niños y sus encargados para utilizar el sistema en el hogar y la escuela. La comunicación en el hogar o la escuela ha mejorado en casi todos los casos. La mayoría de los niños aumentó el número de actividades que 
completaron o el tiempo que pasaron usando sus sistemas. Los padres reportaron una alta satisfacción con la tecnología. Este estudio está basado en encuestas, por lo que los resultados son subjetivos $[59,60]$.

Existen varias razones por las que se ha realizado tan poca investigación en torno a la evaluación de la tecnología de control con la mirada. La tecnología es relativamente nueva. Actualmente disponemos en el mercado de sistemas de ETs de un costo reducido en comparación con la década anterior, donde era impensable ver estos sistemas para un gran público. El problema implica un enfoque multidisciplinar, donde participen tanto médicos como ingenieros para proponer soluciones con un panorama global, lo que muchas veces suele ser complicado. Existen muchos factores involucrados en la personalización de cualquier sistema de interacción hombre-computador, en especial cuando el control es con ETs, por lo que es difícil definir una "intervención" única que evaluar. Cada usuario con PC es prácticamente único y tiene capacidades y necesidades singulares difícilmente comparables. El número de usuarios suele ser pequeño debido a que el coste de llevar a cabo una investigación con ETs suele ser alto e implica la necesidad de seguir a los usuarios durante un largo período de tiempo para evaluar si el control de la mirada es eficaz, lo que suele ser complicado. Todo esto dificulta la realización de esta línea de trabajo.

Sin embargo, el hecho de que se hayan realizado tan pocas investigaciones sobre sus efectos no debería disuadir a las personas con PC, sus familias, cuidadores y terapeutas especialistas de considerar un ensayo de la tecnología de control con los ojos. Esta tecnología de control de la mirada puede ser la única manera de que algunas personas con PC se comuniquen, usen computadoras y otras tecnologías y controlen e interactúen con su entorno. La tecnología de control de los ojos funcionará muy bien para algunas personas con parálisis cerebral, pero no será adecuada para todos. En este sentido, queremos conocer mejor cómo es la interacción y cómo evaluar mejor a este dispositivo cuando es utilizado como interfaz de acceso.

\subsection{Conclusión}

La naturaleza en su sabiduría ha creado al ojo, uno de los órganos más complejos, de una forma altamente eficiente en términos de cantidad de información que recoge para la corteza visual. Poseemos una ventana al mundo exterior con una capacidad de captura de información variable, alta en el centro - zona foveal - y menor en los costados. Este hecho es el origen de los movimientos oculares, los cuales permiten ubicar a la zona de "alta resolución" sobre el objeto que deseamos mirar. Además, esta asimetría estable una relación directa entre la dirección de la mirada y la atención a un objeto. Sobre estos hechos hemos sentado las bases para ubicar al cursor donde se localiza la mirada.

Hemos precisado que el ojo se encuentra cambiando entre dos estados cuando éste realiza tareas de alcance y selección durante la interacción hombre computador: sacadas y fijaciones, respectivamente. Las fijaciones son el estado estable de la mirada, y es cuando el cerebro procesa la información visual.

La tecnología que hace posible medir la mirada son los seguidores de la mirada o ETs, los cuales hoy día se basan en varias técnicas y tecnologías. El tipo más adecuado a las características de nuestra población objetivo son los ETs basados en video oculografía del tipo remoto, por su nula invasividad. Además, hemos señalado que los ETs basados en cámaras de luz visible tienen menos precisión y son menos robustos antes movimientos del 
usuario que los basados en luz infrarroja. Por estas razones, se han utilizado dispositivos con estas características en los ensayos que hemos desarrollado con personas.

Hemos señalado uno de los mayores problemas del acceso al ordenador y de la interacción a través de la mirada, el llamado efectos Midas. Esta cuestión surge por el hecho de que el ojo humano, como hemos dicho antes, mira donde presta atención. Esto en la práctica, mientras que el usuario controla el ordenador con los ojos, se traduce en una ambigüedad respecto a si el usuario está apuntando o simplemente están realizando una inspección.

Hemos realizado una revisión del estado de la cuestión que examinen la validez objetiva de la interacción hombre computador con ETs y nos hemos encontrado con muy pocos estudios al respecto. Si bien la tecnología es relativamente nueva, ya ha alcanzado al mercado y actualmente se disponen de sistemas con un costo accesible. No obstante, existe camino por recorrer.

Es en este contexto donde se sitúa este proyecto de tesis, que tiene no pocos ni pequeños desafíos. Sin embargo, el camino es prometedor y existe mucha población que podrá beneficiarse por los resultados de este y otros trabajos. 


\section{Capítulo 4}

\section{Valoración de la interacción hombre computador}

Apuntar con precisión a un objetivo en pantalla es un obstáculo para personas que experimentan impedimentos motores graves. Curiosamente, dos de las principales barreras para ayudar a los individuos con problemas de apuntamiento son la falta de: (1) métodos de evaluación de la capacidad para apuntar, que sean objetivos — basados en parámetros cuantitativos - y de bajo costo - no requieran nada aparte de realizar una serie de tareas de apuntamiento - y (2) de técnicas que permitan identificar y clasificar al usuario según su tipo de interacción. Esta tesis va en la dirección de crear una tecnología que evalúe automáticamente y de forma objetiva la calidad de apuntamiento durante el uso de un computador.

En este capítulo veremos cuestiones relativas al análisis de la interacción o medición de la usabilidad. Para ello, hemos recopilado y estudiado métricas o parámetros que cuantifiquen la calidad del apuntamiento. El problema radica en encontrar maneras apropiadas de medir los datos de la trayectoria del cursor. En primer lugar, se presentarán métricas que tienen relación con la fase de alcance, y a continuación con el clic ${ }^{1}$ y Sección 4.1 respectivamente. Algunas de las métricas tienen relación con el comportamiento dinámico y estático del ojo humano, Sección 3.1, reflejado en los movimientos del cursor.

Además, hemos revisado las técnicas utilizadas para analizar y procesar los datos, de manera a clasificar diferentes tipos de interacción de forma automática, según las métricas o parámetros que cualifiquen a la interacción. Se han incluido trabajos que se basan en técnicas de aprendizaje automático, Sección 4.2.

Este capítulo se basa parcialmente en el trabajo C.4 (Sección 8.1).

\subsection{Métricas de valoración de la interacción}

A continuación, se presentarán métricas que buscan obtener una descripción cuantitativa de la interacción hombre-computador mediante la información de la posición del cursor y del clic $[61,62]$. El objetivo de las métricas es tener medidas objetivas de las tareas de apuntamiento, tanto de personas con discapacidad como sin discapacidad. Además, las métricas permiten simplificar los datos que provienen de un eye-tracker, que contienen mucha información [63].

\footnotetext{
${ }^{1}$ El alcance y la selección eran las dos fases de una tarea de apuntamiento, Sección 2.5
} 
Las métricas que se presentarán estarán expresadas en el dominio espacial, temporal y funcional y tienen relación con diferentes aspectos de la tarea de apuntamiento, como su cinemática (distancia, velocidad, aceleración), o los movimientos oculares (duración de las fijaciones, distancias sacadas) entre otras medidas. Todas las métricas son para medir tareas con un solo objetivo en pantalla, para evitar tener que calcular el tiempo de decisión, establecido por la Ley de Hick-Hyman [64, 65]. Las mediciones espaciales (longitud, distancias) y las medidas derivadas (velocidades, aceleración) se basan en la posición del cursor 2D en pantalla. Además, existen métricas que valoran aspectos relacionados con la selección.

Las métricas han sido clasificadas según evalúan la fase de alcance o la del clic. Además, las que evalúan el alcance han sido clasificadas según necesiten o no de las características del objeto a alcanzar (posición y tamaño).

\subsubsection{Relativas al movimiento bidimensional del cursor, agnósticos del objetivo}

Las métricas presentadas a continuación son las que no necesitan de las características del objeto a alcanzar para ser calculadas.

\section{Distancia viajada normalizada - DTN}

La Distancia viajada normalizada (DTN) se definió de acuerdo a la Ecuación (4.1), donde $D V$ es la distancia recorrida por el cursor y $D I$ es la distancia entre el punto de inicio y el centro del objetivo en pantalla donde se debe hacer clic.

$$
D T N=\frac{|D V-D I|}{D I}
$$

\section{Relativas a la Velocidad y Aceleración - VEL ACC}

Se pueden calcular la velocidad (VEL), la aceleración (ACC) y la sobreaceleración (JER) ${ }^{2}$ instantánea del cursor a partir de una serie de diferenciaciones. Incluso se puede hacer un remuestreo de la señal, para mejorar la resolución y reducir el ruido (VES, ACS, JES).

A continuación, pueden calcularse la media, mediana, el valor máximo y mínimo de estos valores. Se espera que estas métricas representen la manera que una persona mueve el cursor en la pantalla.

En otros escenarios estas métricas se utilizan a menudo cuando se clasifican conductores a partir de sus patrones de cinemáticos [66]. La hipótesis es que puedan ser útiles también para valorar y caracterizar los patrones del cursor.

\section{Fijaciones y sacadas - NFIX, DFIX, LSAC}

El ojo humano está constantemente en dos estados: en movimiento (sacádicos), o estático (fijaciones), Sección 3.1.2. Una métrica interesante es el número de fijaciones (NFIX)

\footnotetext{
${ }^{2}$ La sobreaceleración es la derivada de la aceleración, también denominada jerk
} 
que se produce cuando se controla el cursor con la mirada y la duración de las mismas (DFIX), así como la Longitud de las sacadas (LSAC). Es importante aclarar que estas métricas sólo tienen sentido en las interfaces que son controladas con la mirada.

\section{Número de submovimientos y Fases de cero aceleración - NSUB y FCA}

El Número de submovimientos se determinó contando los cruces por cero de la función de velocidad, y el número de Fases de cero aceleración se determinó contando los cruces por cero en la función de aceleración. Ambas métricas miden la fluidez en el movimiento, indicando las veces que el cursor se ha detenido y ha vuelto a comenzar su viaje hasta el objetivo [67, 68, 69].

\section{Índices lineales, diagonales, horizontales y verticales - LI, DI, HI, VI}

Almanji et al. proponen una serie de métricas, relacionadas con la dirección del movimiento del cursor [22]. El Índice lineal (LI) es un recuento del número de diferencias angulares sucesivas que son iguales a cero [22]. Además, el Índice de diagonalidad, que es un recuento del número de veces que el cursor tuvo una dirección diagonal (lo que corresponde con una dirección con un ángulo de $45^{\circ}, 135^{\circ}, 225^{\circ}$ y $315^{\circ}$ ) y el Índice de horizontalidad y verticalidad, que es el recuento de direcciones del cursor igual a $0^{\circ} \mathrm{y}$ $180^{\circ}$ o 90 y $270^{\circ}$, respectivamente.

Todos estos índices están normalizados con el número total de puntos que incluye el movimiento, de manera que los índices pueden tener valores entre 0 (no incluye la dirección) y 1 (incluye totalmente la dirección en cuestión). Por ejemplo, un LI igual a 1 implicaría que el cursor ha seguido una línea recta.

\section{Índice lineal con $\mathbf{R}-\mathbf{L I W R} \star$}

Proponemos una definición alternativa al índice lineal LI (Sección 4.1.1). En nuestra propuesta, se incluye un rango $R$ de tolerancia, de manera que se cuenten las diferencias angulares entre puntos sucesivos que estén por debajo de $R$, a la cual llamaremos LIWR, Ecuación (4.2).

$$
\begin{aligned}
L I W R & =\frac{1}{N} \Sigma \mathrm{C} \begin{cases}C=1, & \text { if }\left(\theta_{i-1}-\theta_{i}\right) \leq R \\
C=0, & \text { de otra manera }\end{cases} \\
\theta_{i} & =\tan ^{-1} \frac{y_{i+1}-y_{i}}{x_{i+1}-x_{i}},
\end{aligned}
$$

\subsubsection{Relativas al movimiento bidimensional del cursor, con conoci- miento del objetivo}

\section{Cambios de dirección del movimiento y ortogonal - CPM, COM}

Los Cambios de dirección del movimiento (CPM) son los cambios de dirección del cursor que son paralelos al eje de la tarea y los Cambios de dirección ortogonales (COM) los producidos en una dirección perpendicular al eje [5], Figura 4.1 


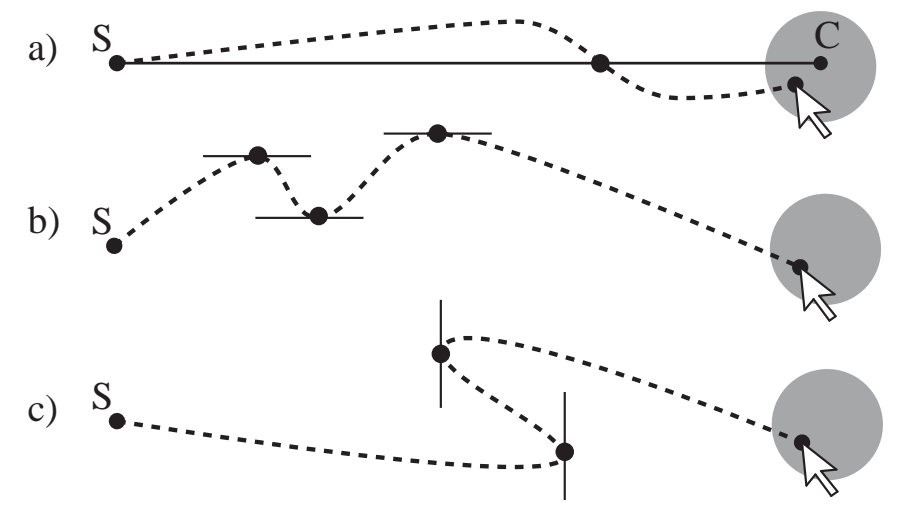

Figura 4.1: a) Número de cruces del eje de la tarea NAC igual a 1. b) Cambios de dirección de movimiento CPM igual a 3. c) Cambios de dirección ortogonal COM igual a 2. Basado en [5].

\section{Variabilidad, error y offset del movimiento - VMV, EMV, OMV}

Si asumimos que el eje de la tarea es $y=0, y_{i}$ es la distancia de cada punto al eje de la tarea, y que $\bar{y}$ es la distancia media de todos los puntos al eje de la tarea, Ecuación (4.3), la variabilidad del movimiento se computa como la desviación estándar de las distancias de las muestras al punto medio sobre el eje de la tarea, Ecuación (4.4), [5]. Una tarea perfecta tendría un $V M V=0$.

El error del movimiento (EMV) es la desviación promedio de todos los puntos al eje de la tarea. Si asumimos que el eje de la tarea es $y=0$, entonces Ecuación (4.5), [5]

El offset del movimiento (OMV) es la desviación media de todos los puntos al eje de la tarea. Si asumimos que el eje de la tarea es $y=0$, entonces Ecuación (4.6), [5].

$$
\begin{aligned}
\bar{y} & =\frac{\sum\left(y_{i}\right)}{n}, \\
V M V & =\sqrt{\frac{\sum\left(y_{i}-\bar{y}\right)^{2}}{n-1}}, \\
E M V & =\frac{\sum\left(\left|y_{i}\right|\right)}{n}, \\
O M V & =\bar{y}
\end{aligned}
$$

\section{Número de entradas al objetivo - CEO}

El Número de entradas al objetivo (CEO) se define como el número de veces que el cursor entra en el área que comprende el objetivo antes de realizar el clic [68]. A modo de ejemplo, en la Figura 4.2.a, la cantidad de entradas al objetivo es igual a 2. En esta Figura, las entradas son representadas mediante puntos verdes.

Esta métrica incorpora una medida que nos permite saber cuántas veces el participante ha tenido la posibilidad de conseguir el objetivo de la tarea (ya que si se encuentra dentro del área del objetivo y realiza un clic la tarea se ha cumplido) pero no lo ha conseguido, ya que ha vuelvo a salir del área del objetivo. Un alto valor de $C E O$ podría significar que el usuario se encuentra con problemas para mantener el cursor dentro del área del objetivo. 


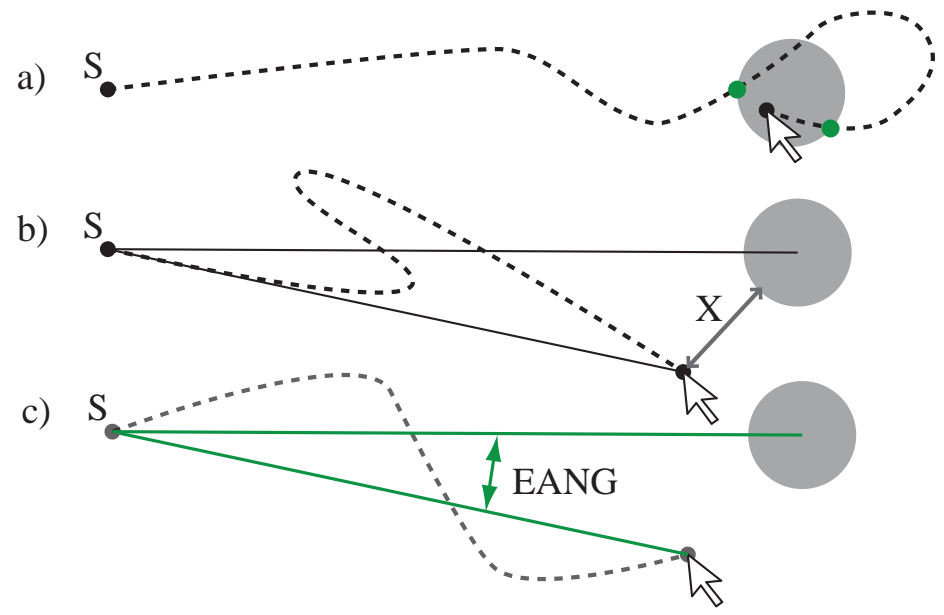

Figura 4.2: a) Número de entradas al objetivo CEO es igual a 2. b) Distancia del clic al objetivo DCO igual a la dimensión del vector X, sin normalizar con el radio del objetivo. c) Error de ángulo de movimiento EANG.

\section{Error de ángulo de movimiento - EANG}

Si el ángulo del eje de la tarea fuera $\alpha$ y el ángulo de movimiento global fuera $\beta$, entonces el error de ángulo de movimiento (EANG) queda definido por la diferencia entre estos dos ángulos, Ecuación (4.7), Figura 4.2.c, [68].

$$
E A N G=|\alpha-\beta|,
$$

\section{Cruces de eje de tarea - NAC}

El cruce de eje de la tarea (NAC) es el número de veces que el cursor cruza la línea que une el punto de inicio con el centro del objetivo, Figura 4.1, [5].

\section{Overshoots - OVER}

La métrica overshoots (OVER) no indica la cantidad de veces que el cursor se ha pasado más allá del borde extremo del objetivo, en relación con la posición del cursor, ya sea dentro o fuera del objetivo, [68].

\section{Throughput - TP (Ley de Fitts)}

El Throughput (TP), medida del estándar ISO 9241 parte $9^{3}$, permite la comparación de interfaces en cuanto a velocidad y precisión. Existe una escasez de medidas de valoración formales de interfaces alternativas. Una medida estándar es la propuesta por la ISO, que permite la comparación y caracterización tanto de interfaces como de usuarios, Tabla 4.1.

Este estándar, basado en la ley de Fitts [70], es una métrica completa, ya que modela el comportamiento psicomotor humano y está específicamente descrita para ejercicios

\footnotetext{
${ }^{3}$ www.iso.org/iso/catalogue_detail.htm? csnumber $=30030$
} 


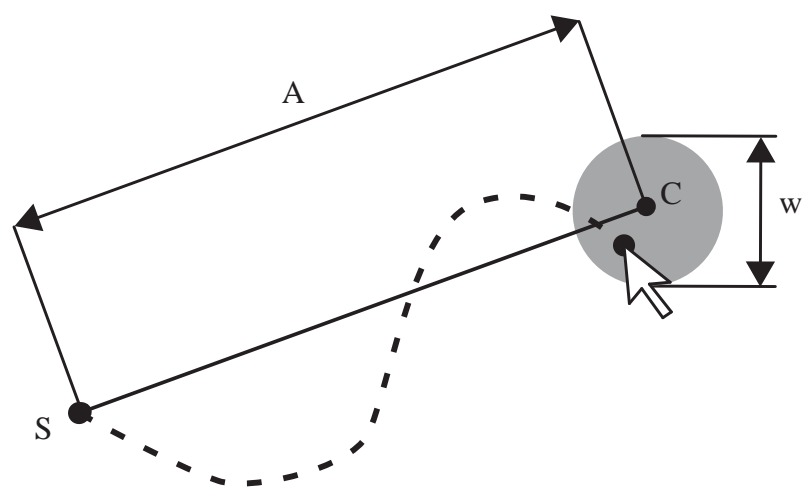

Figura 4.3: Representación gráfica de los parámetros amplitud de movimiento (A) y tamaño del objeto en pantalla $(\mathrm{W})$ de una tarea de alcance a un objetivo, los cuales definen el índice de dificultad según la Ley de Fitts. Además, se representa el eje de la tarea como la línea que une los puntos $\mathrm{S}$ y $\mathrm{C}$.

de alcance de objetivos y medida de la usabilidad de una interfaz persona-computador $[71,72]$. Fitts estable que existe una relación lineal entre la dificultad de una tarea de apuntamiento $(I D)$ y el tiempo que necesita el usuario para llevarla a cabo $(T M)$, Ecuación (4.8). El índice de dificultad $I D$ se define según la Ecuación (4.9), donde $A$ es la amplitud de movimiento necesaria para realizar la tarea y $W$ el ancho del objetivo [71], Figura 4.3.

Existen muchas definiciones para el $T P$ con distintas maneras de calcularse, Ecuaciones (4.10), (4.11) y (4.12). La definición $T P_{\text {task }}$ establece un valor preciso de $T P$ a cada tarea de apuntamiento, según la Ecuación (4.10). En esta ecuación, $T M$ es el tiempo de clic de una tarea e $I D$ la dificultad de esta tarea, medida a través de la Ecuación (4.9). Por otro lado, las definiciones $T P_{i n v}$ y $T P_{a v g}$ establecen un valor $T P$ a un grupo de tareas de apuntamiento, con sus respectivos $I D_{i}$ y $T M_{i}$. Así, para calcular el valor de $T P_{i n v}$, antes hay que realizar una regresión lineal entre distintos puntos $T M_{i}$ e $I D_{i}$. Posteriormente, se calcula $T P_{i n v}$ mediante la pendiente de la recta de la regresión, según la Ecuación (4.11). Y para calcular el valor $T P_{\text {avg }}$ hay que realizar la razón entre la media de los índices de dificultad $I D_{i}$ y sus respectivos tiempos de movimiento $T M_{i}$, según la Ecuación (4.12).

$$
\begin{aligned}
T M & =a+b * I D, \\
I D & =\log _{2}\left(\frac{A}{W}+1\right), \\
T P_{\text {task }} & =\frac{I D}{T M}, \\
T P_{\text {inv }} & =\frac{1}{b}, \\
T P_{\text {avg }} & =\frac{I D_{\text {avg }}}{T M_{\text {avg }}}=\frac{\sum\left(I D_{i}\right)}{\sum\left(T M_{i}\right)},
\end{aligned}
$$




\begin{tabular}{ll}
\hline Dispositivo & Throughput \\
\hline Ratón, [72] & $3,7-4,5$ \\
Joystick, [73] & 1,8 \\
Touchpad, [73] & $0,99-2,9$ \\
HeadJoystick (joystick basado en movimientos cervicales), [74] & $0.92-1.93$ \\
ViewPoint (eye-tracker utilizado con posa mentón), [75] & $2.3-3.7$ \\
RemotePoint (joystick isométrico, con palanca fija, velocidad del cursor & 1.4 \\
es proporcional a la fuerza aplicada), [76] & 2.8 \\
GyroPoint (dispositivo basado en giróscopo), [76] & \\
\hline
\end{tabular}

Tabla 4.1: Throughput de distintos dispositivos. Ninguno de estos dispositivos ha sido validado con personas con algún tipo de discapacidad

\subsubsection{Relativas al clic}

\section{Distancia del clic al objetivo - DCO (solo para pruebas fallidas) *}

Distancia del clic al objetivo (DCO) es una medida que utilizaremos para ponderar el error de las tareas donde los clics fueron realizados fuera del área del objetivo. Mediante este parámetro se busca medir cuánto de lejos se encuentra el clic del área del objetivo, cuando el clic se realiza fuera de dicha área. Se parte del hecho de que no es lo mismo hacer un clic lejos del área del objetivo que hacerlo muy próximo a éste. DCO es una medida válida solo para pruebas fallidas, es decir, para pruebas donde el clic se haya realizado fuera del objetivo, por lo que no se incluyen las tareas donde el clic se ha realizado dentro del objetivo en esta medida. Un valor bajo de DCO podría implicar que el usuario tiene muchas posibilidades de realizar correctamente la tarea, ya que suele implicar que el cursor se encuentra muy próximo al área del objetivo cuando se falla.

La Ecuación (4.13) define la distancia al objetivo, ERROR es la distancia euclídea entre la posición del clic y el centro del objetivo y $T_{R}$ es el radio objetivo. $D C O$ evalúa las tareas fallidas. Hacer clic lejos del objetivo es diferente de hacer clic cerca. Un valor bajo de $D C O$ indica que el error se puede disminuir mediante una mejor calibración del sistema o mejorando las capacidades del usuario.

$$
D C O=\frac{E R R O R-T_{R}}{T_{R}}
$$

En la Figura 4.2.b se puede ver una representación gráfica de la Distancia del clic al objetivo de una tarea, mediante el segmento $X$, sin normalizar por el radio del objetivo.

\section{Tiempo de reacción - $\mathrm{RT} \star$}

Asumimos que los participantes reaccionaron cuando el cursor empezó a moverse. Consideramos un movimiento iniciado cuando el cursor excede una velocidad umbral. El tiempo de reacción (RT) se definió como el tiempo que tarda el cursor en superar una velocidad umbral. 


\section{Tiempo de clic - CT}

El Tiempo de clic $(C T)$ se definió como el tiempo que los participantes tomaron para realizar un clic. Esta definición de $C T$ incluye el tiempo que el usuario debe reaccionar $(R T)$, para alcanzar el objetivo y realizar un clic.

\section{Tasa de error y Número de errores - TE y NE †}

Si solo se permite un clic por tarea, la Tasa de error (TE) se calcula como la relación entre el número de objetivos en los cuales se realizó el clic fuera del objetivo y la cantidad total de objetivos. La Ecuación (4.14) es la fórmula general que define la tasa de error. Esta métrica está acotada entre 0 y 1 (o entre 0 y 100 si se multiplica por 100 para expresarlo en porcentaje).

$$
T E=\frac{\text { clic fuera objetivo }}{\text { cantidad total objetivos }}
$$

Si se permite más de un clic por objetivo se puede calcular el Número de errores por tarea (NE). Esta métrica se calcula por cada objetivo, a diferencia de TE que se calcula por sesión. Esta métrica está acotada por abajo, ya que el número ideal es uno (un clic por objetivo). Sin embargo, no tiene cota por arriba.

TE y NE nos permiten conocer la eficiencia de las pruebas, ya que un alto valor implicará muchos clics fuera del objetivo.

\section{Fatiga - FA $\dagger$}

La Fatiga (FT) intenta medir la evolución temporal del Retardo. Se parte de la hipótesis de que el usuario se irá fatigando y esto se reflejará en una tendencia a aumentar el tiempo de clic (Métrica 4.1.3). La FT se define según la Ecuación (4.15). Este valor puede normalizarse respecto al $R E_{\text {inicial }}$.

$$
F T=R E_{\text {final }}-R E_{\text {inicial }}
$$

\section{Frecuencia Máxima - FM $\dagger, \star$}

La Frecuencia Máxima (FM) es el número de eventos por segundo capaz de recoger la interfaz cuando se produce un estímulo. Esta métrica intenta medir la velocidad máxima con la que la interfaz puede capturar eventos generados por el usuario. La FM está definida por la Ecuación (4.16)

$$
F M=\frac{\text { número de eventos }}{\text { tiempo transcurrido }}
$$

\section{Rebote - RE $\dagger, \star$}

El Rebote (RB) es un índice que indica la capacidad de la interfaz de mantenerse en un estado durante un periodo de tiempo preestablecido. Con esta métrica se quiere valorar una habilidad complementaria a lo que mide FM (Métrica 4.1.3). 

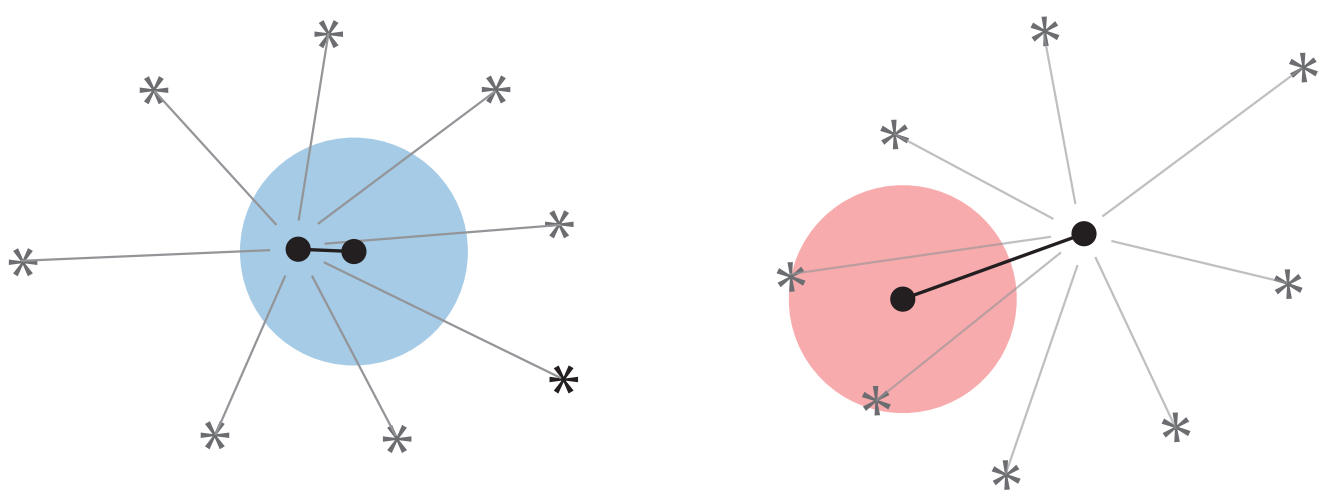

Figura 4.4: Valores que puede tomar DES. En el caso de la izquierda, el valor de DES normalizado será menor que 1 , en el caso de la derecha por el contrario será mayor a 1.

$$
R B=\text { Tiempo en un estado preestablecido }
$$

\section{Desviación media - DES †}

El objetivo de la Desviación media (DES) es verificar si en "promedio" el clic realizado por el usuario se encuentra sobre el objetivo. La definición matemática se puede ver en la Ecuación 4.18. Este valor puede ser normalizado con el radio del objetivo. Si el usuario, en promedio, realiza el clic sobre el objetivo, su DES normalizado será un valor menor que uno. Si, por el contrario, en promedio el usuario se encuentra alejado del objetivo, su DES será mayor a uno. En la Figura 4.4 puede verse un esquema de estos casos: en el caso de la izquierda el valor de DES normalizado será menor que 1, en el caso de la derecha por el contrario será mayor a 1.

$$
\text { DES = Distancia }(\text { posición media clic, centro objetivo })
$$

\section{Dispersión - DIS †}

La Dispersión (DIS) se calcula en relación a un grupo de clics e intenta cuantificar la separación de los mismos. La Dispersión se medirá en cada eje: horizontal y vertical, y serán etiquetados como $D I S_{x}$ y $D I S_{y}$ respectivamente. Este valor puede ser normalizado con el radio del objetivo.

$$
\begin{aligned}
& D I S_{x}=\text { Desviación estándar }\left(\text { clics }_{x}\right) \\
& D I S_{y}=\text { Desviación estándar }\left(\text { clics }_{y}\right)
\end{aligned}
$$

\subsubsection{Resumen global de las métricas}

En la Sección 2.5 hemos hablado de que las tareas de apuntamiento PT son la unidad mínima de información que se va a procesar para parametrizar la interacción con el ordenador. Los parámetros de las PTs son las métricas que hemos presentado y que miden distintas cuestiones relacionadas con la fase de alcance y con la fase de clic. 
Entre las medidas presentadas hay algunas que se calculan sobre cada tarea (tiempo de clic, número de fijaciones, etc.) y otras que se calculan sobre un grupo de tareas (tasa de error, etc.). Las métricas que se calculan con más de una tarea y no por tarea han sido identificadas con el símbolo $\langle\dagger\rangle$. Las métricas nuevas, propuestas en esta tesis están marcadas con el símbolo $\langle\star\rangle$. No hemos incluido métricas que son una distribución en vez de un valor: distribución angular [77], etc. Se puede ver en la Tabla 4.2 un resumen de todas las métricas presentadas.

\subsection{Clasificación de usuarios según la valoración de la in- teracción}

La utilización de métricas ofrece muchos beneficios [78]. Nuestro objetivo fue caracterizar la interacción de los usuarios. Por complejidad de procesamiento, para analizar las métricas se utilizan técnicas de aprendizaje automático.

Otros autores han trabajado también en esta dirección. Gajos presentó sus avances en torno a una hipótesis interesante: adaptar la interfaz gráfica (GUI) según las habilidades del usuario mejorará la interacción persona computador. En un primer trabajo presenta ARNAULD, el cual se basa en las preferencias del usuario para adaptar la GUI [79]. Las preferencias se recopilan explícitamente y luego se ajusta la GUI en función de las respuestas. En un trabajo posterior, la adaptación se realiza según las habilidades motoras del usuario $[54,55,56]$. Para ello solicita al usuario que realice unas tareas sencillas en el ordenador. Según los resultados de estas tareas, adapta posteriormente la GUI. Existe un interesante trabajo comparativo de ambas técnicas [80].

Todo el trabajo de Gajos se basa en la optimización de una función de coste según diferentes objetivos: en sus primeros trabajos los costes tenían relación con la preferencia del usuario y en su segunda aproximación, tenían relación con las habilidades motoras de unas pocas tareas.

Por otro lado, Hurst elaboró varias publicaciones en torno a la valoración del "rendimiento del apuntamiento" (pointing performance). En un primer trabajo clasifica a los usuarios mientras utilizan un software según dos clases: expertos o novatos [81]. En los siguientes trabajos realiza la clasificación de personas según tengan o no algún tipo de discapacidad. Para la clasificación han utilizado diferentes métricas, organizadas en cuatro categorías relativas a la tarea (veces que el cursor entra en el objetivo), el movimiento (distancia del movimiento), los clics (clics accidentales) y las pausas (número de pausas) [61, 62, 82]. Clasifican las tareas de apuntamiento a través de una técnica supervisada de aprendizaje automático, que requería datos etiquetados, con la clase de usuario establecida previamente. A diferencia de las técnicas de clasificación, las técnicas de agrupación no necesitan datos etiquetados, ya que su objetivo es descubrir grupos.

\subsection{Conclusión}

En este capítulo hemos presentado métricas o parámetros de la tarea de apuntamiento para la evaluación y caracterización de la interacción entre el ordenador y un usuario a partir de la información de la trayectoria del cursor. Las métricas se han clasificado de acuerdo a si valoran el movimiento bidimensional del cursor o del clic. Estas métricas se pueden utilizar para la valoración de cualquier interfaz de acceso, sea alternativa 


\begin{tabular}{|c|c|c|}
\hline $\begin{array}{l}\text { Tipo de } \\
\text { métrica }\end{array}$ & Sigla & Métrica \\
\hline \multirow{3}{*}{$\begin{array}{l}\text { Tiempo y } \\
\text { rendimiento }\end{array}$} & $\mathrm{CT}$ & Tiempo de clic \\
\hline & RT & Tiempo de reacción \\
\hline & $\mathrm{TP}$ & Throughput \\
\hline \multirow{14}{*}{$\begin{array}{l}\text { Movimiento } \\
\text { del } \\
\text { cursor }\end{array}$} & DTN & Distancia viajada normalizada \\
\hline & NSUB & Número de submovimientos \\
\hline & EANG & Error de ángulo de movimiento \\
\hline & LI & Índice lineal, \\
\hline & DI & Índice diagonal \\
\hline & HI & Índice horizontal \\
\hline & VI & Índice vertical \\
\hline & LIWR & Índice lineal con $\mathrm{R}$ \\
\hline & $\mathrm{CPM}$ & Cambios de dirección de movimiento \\
\hline & $\mathrm{COM}$ & Cambios de dirección ortogonal \\
\hline & VMV & Variabilidad del movimiento \\
\hline & EMV & Error del movimiento \\
\hline & OMV & Offset del movimiento \\
\hline & NAC & Cruce del eje de la tarea \\
\hline \multirow{3}{*}{$\begin{array}{l}\text { Movimiento } \\
\text { alrededor } \\
\text { del objetivo }\end{array}$} & OVER & Overshoots \\
\hline & CEO & Número de entradas al objetivo \\
\hline & DCO & Distancia al objetivo normalizada \\
\hline \multirow{6}{*}{$\begin{array}{l}\text { Velocidad } \\
\text { y } \\
\text { aceleración }\end{array}$} & VEL & Velocidad máxima, media y promedio \\
\hline & VES & Velocidad máxima (obtenida por sobremuestreo) \\
\hline & $\mathrm{ACC}$ & Aceleración máxima, mínima, media \\
\hline & ACS & Aceleración máxima (obtenida por sobremuestreo) \\
\hline & FCA & Fases de cero aceleración \\
\hline & JES & Jerk máxima (obtenida por sobremuestreo) \\
\hline \multirow{3}{*}{$\begin{array}{l}\text { Movimiento } \\
\text { del ojo }\end{array}$} & NFIX & Número de fijaciones \\
\hline & DFIX & Duración de las fijaciones (min., máx., media, promedio) \\
\hline & LSAC & Longitud de las sacadas (min., máx., media, promedio) \\
\hline
\end{tabular}

Tabla 4.2: Lista de métricas que se propone calcular para cada tarea de apuntamiento. 
o tradicional y no es necesario nada más que la información espacio-temporal de la trayectoria del cursor.

Además, hemos presentado técnicas para la caracterización y clasificación automática de la interacción de los usuarios mediante métricas. El gran número de características de la tarea de apuntamiento hace del análisis de los datos una tarea no trivial. Por ello se ha propuesto la utilización de técnicas de aprendizaje automático para el procesamiento de los datos.

El trabajo presentado responde a una necesidad creciente de metodologías y métricas estándares, teniendo en cuenta los esfuerzos científicos dispersos en desarrollo de interfaces alternativas, y el creciente uso de los ordenadores como herramienta de desarrollo e integración social. La valoración objetiva de las interfaces posibilitaría la comparación relativa de desempeños con cada usuario, así como la valoración del uso del ordenador en terapias de rehabilitación $[83,84]$. Por otro lado, la categorización persigue ayudar a identificar el tipo de interfaz más idónea para cada perfil de discapacidad. 


\section{Parte III}

\section{Aportaciones}





\section{Capítulo 5}

\section{Metodología de evaluación de la interacción}

Actualmente no existe una metodología normalizada, mundialmente aceptada, para medir la calidad de la interacción entre una persona y el ordenador, cuando el control se realiza a través de un eye-tracker y los usuarios son personas que sufren severos daños motores. Los fabricantes describen y evalúan sus sistemas de forma independiente, proporcionando valores descriptivos de la interacción, sin definirlos claramente. Las métricas que usualmente se utilizan para evaluar estos dispositivos son la precisión y veracidad, ambas expresadas en grados angulares. Estas medidas se llevan a cabo bajo condiciones controladas de luz y restringiendo los movimientos de la cabeza [85]. Además, las evaluaciones se suelen realizar con personas sin discapacidad. Sin embargo, las personas con trastornos motores graves suelen tener dificultades en el control cervical [86], por lo que es incorrecto extrapolar los resultados obtenidos con personas sin discapacidad a este grupo de usuarios, ya que no serán representativos. La proyección de estos resultados a los usuarios con PC puede llevar fácilmente a falsas expectativas. Los terapeutas, los familiares y los usuarios deben conocer las fortalezas y limitaciones de estas interfaces alternativas para poder determinar el uso o no de estos dispositivos [87]. Un procedimiento estandarizado y validado podrá responder efectivamente a esta cuestión.

En este capítulo queremos dar un paso adelante en el conocimiento formal de la interacción con el ordenador mediante ETs, cuando son utilizados con personas con PC, que sufren severos trastornos motores. Presentaremos cuatro estudios de evaluación exploratorios de la interacción mediante ETs. Además, presentamos la validación de las metodologías mediante ensayos con personas afectadas por la PC.

Los fabricantes suelen medir a sus dispositivos en condiciones especiales, restringiendo los movimientos de la cabeza, con el objetivo de demostrar la máxima capacidad posible de sus sistemas, Figura 5.1a. Sin embargo, con este procedimiento no sabemos dos cuestiones: (1) si los movimientos de cabeza afectan al ET y (2) en qué medida. Y es especialmente importante conocerlo ya que los usuarios con PC no tienen control motor cervical. Las medidas que utilizan son precisión y veracidad $(\mathrm{P} \& \mathrm{~V})$. En la Evaluación $I$, mediremos la $\mathrm{P} \& \mathrm{~V}$ de un eye-tracker, pero sin el uso de un posa mentón o posa barbilla, para verificar si las medidas que presentan los fabricantes son parecidas a las que se obtienen en la práctica, cuando no se restringe el movimiento de la cabeza. Los resultados indican que no es así, que la $\mathrm{P} \& \mathrm{~V}$ de nuestro ensayo son peores respecto a la hoja de datos técnica del dispositivo. Esto nos permitió concluir que estas dos métricas 
dependen del movimiento cervical. Esto es particularmente alarmante, ya que estas métricas generarán en el usuario con trastornos motores falsas expectativas respecto a la interacción. Además, estas métricas no son funcionales - uno de los requisitos del Objetivo 1-, ya que no están asociadas a la realización de la tarea de alcance y selección. Todas estas cuestiones nos indicaron que estas métricas no son adecuadas para valorar la interacción. Este trabajo se basa parcialmente en la aportación C.3 (Sección 8.1) y se describe a partir de la Sección 5.1.

A continuación, tras descartar la precisión y veracidad, evaluamos otro sistema ampliamente utilizado para la valoración de la interacción: la Ley de Fitts. Este modelo establece que existe una relación lineal entre el tiempo para realizar una tarea y la dificultad de la misma. Para valorar la linealidad se utiliza el cuadrado del coeficiente de Pearson $\left(R^{2}\right)$. En la Evaluación II valoramos la ley de Fitts, mientras personas con y sin trastornos motores controlan el ordenador con los ojos. Los resultados nos indicaron un valor de $R^{2}<0,01$, para ambos grupos de usuarios. Esto nos señaló que la relación entre ambas variables es baja. Este ensayo nos indicó que este modelo tampoco es adecuado para valorar la interacción. Este trabajo se basa parcialmente en el trabajo J.2 (Sección 8.1).

Por lo tanto, hemos descartado la precisión y veracidad y el modelo de Fitts. Buscamos valorar la interacción hombre computador, de manera funcional e integral. En la Evaluación III, presentamos una nueva metodología de evaluación de la interacción, basada en dos métricas: tasa de error y el tiempo de clic. Estas dos nuevas métricas describen la interacción en términos funcionales de forma integral. En concreto, utilizamos la metodología para evaluar dos técnicas de selección: clic por permanencia y por parpadeo. Esta metodología fue evaluada tanto con personas sin discapacidad como personas con PC. Mediante la metodología presentada, pudimos ver que, aunque ambos métodos de clic proporcionan tasas de error similares, el tiempo de clic es bastante menor con el clic por permanencia. Este trabajo se basa parcialmente en la aportación C.2 (Sección 8.1) y se describe a partir de la Sección 5.3.

Finalmente, en la Evaluación $I V$, además de utilizar la tasa de error y el tiempo de clic, investigamos la tasa de fallos en la calibración y lo incluimos en la metodología de evaluación. Esta metodología la utilizamos para valorar tres eye-trackers, con nueve usuarios con PC, mientras éstos realizaban clics con permanencia. Encontramos que la calibración es la primera gran barrera que deben sobrepasar estos usuarios debido a la alta tasa de fallo en la misma. Este trabajo se basa parcialmente en el trabajo en J.3 (Sección 8.1), presentado en la Sección 5.4.

Para los ensayos evaluamos ETs comerciales, de bajo costo, valorando la interacción de manera objetiva, mediante métricas cuantitativas.

\subsection{Evaluación I: Precisión y veracidad sin restricciones cervicales}

El IS0-5725 utiliza dos términos precisión y veracidad para describir la exactitud de un método de medición. Veracidad se refiere a la cercanía entre la media aritmética de un gran número de resultados de ensayos y el valor verdadero o de referencia aceptado. Precisión se refiere a la cercanía entre los resultados del ensayo [88]. Es importante que los estudios de usabilidad proporcionen la precisión y veracidad (P\&V) de los ETs en contextos de uso natural $[89,90]$. Los valores proporcionados por los fabricantes son 
representativos de la mejor capacidad posible del eye-tracker en condiciones controladas de luz, con restricciones en el movimiento de cabeza y realizando pruebas con participantes con buenas capacidades de seguimiento [91]. Sin embargo, no tenemos medidas de cómo se comportan estos dispositivos, por ejemplo, cuando no se restringe el movimiento de cabeza, lo cual es de suma importancia para entender lo que implica la interacción a través de ellos. Para responder a esta pregunta se realizó un experimento con el fin de identificar la $\mathrm{P} \& \mathrm{~V}$ de un ET, sin restringir los movimientos de la cabeza de los participantes de la prueba.

\subsubsection{Protocolo del test}

Antes de cada sesión, comprobamos la posición del eye-tracker con respecto a la pantalla. El dispositivo debía estar colocado en el centro de la pantalla, en la parte inferior. Si el eye-tracker no estuviese bien ajustado, se puede introducir un error en las medidas. También se verificó la posición de los participantes respecto al eye-tracker, de manera que éste se encuentre alineado con el dispositivo y que durante los ensayos se encuentre dentro del alcance del eye-tracker, de acuerdo con los datos técnicos provistos por el fabricante. Posteriormente se realizó una calibración del dispositivo con cada usuario. Se utilizaron cinco puntos para este proceso. A continuación, se realizaron las pruebas.

El estímulo visual que recibieron los participantes consistió en un objeto circular en pantalla, que mantenía su posición durante 5 segundos, para luego cambiar de posición automáticamente. Después de que el circulo pasara por 16 posiciones diferentes, la prueba terminaba. Se pidió a los participantes que miraran al centro de los objetos que aparecieron en la pantalla. Este ensayo se realizó dos veces con cada participante, con intervalos de descanso de 5 minutos. En total, cada participante mantuvo la mirada en 32 círculos (16 círculos por sesión x 2 sesiones).

El objeto circular consistió en dos círculos concéntricos, con un círculo negro interno de $1 \mathrm{~cm}$ de diámetro y un círculo rojo externo de $3,5 \mathrm{~cm}$ de diámetro. El objeto estímulo se posicionó sobre una de 4 columnas y 4 filas, Figura 5.1b. Cada ensayo duró en total 80 segundos (aproximadamente 1 minuto y medio): 5 segundos/objetivo x 16 objetivos $=80$ segundos. Entre cada uno de los dos ensayos realizados se pidió al usuario que descansara 2-5 minutos.

Las pruebas se realizaron en un ambiente con luz artificial y natural, sin ninguna fuente de luz que apuntara directamente a los ojos del participante ni al ET, para evitar medidas distorsionadas.

Bajo condiciones ideales, los participantes usarían un reposa mentón para evitar cualquier movimiento de la cabeza, con el objetivo de que las medidas no se vieran afectadas. El objetivo de este estudio fue describir el rendimiento del dispositivo en condiciones reales y cotidianas, donde la cabeza del usuario puede moverse libremente mientras usa un eye-tracker ${ }^{1}$.

\subsubsection{Equipos}

El eye-tracker utilizado para el experimento fue el Tobii X2-30 (Tobii, Suecia), que trabaja a una frecuencia de muestreo de $30 \mathrm{~Hz}$. Este dispositivo, basado en video oculografía, es del tipo remoto (el usuario no necesita portar nada), capaz de recoger datos de ambos

\footnotetext{
${ }^{1}$ Se muestra un vídeo del protocolo del test está disponible en: https://youtu.be/6C7el3UjXOg.
} 


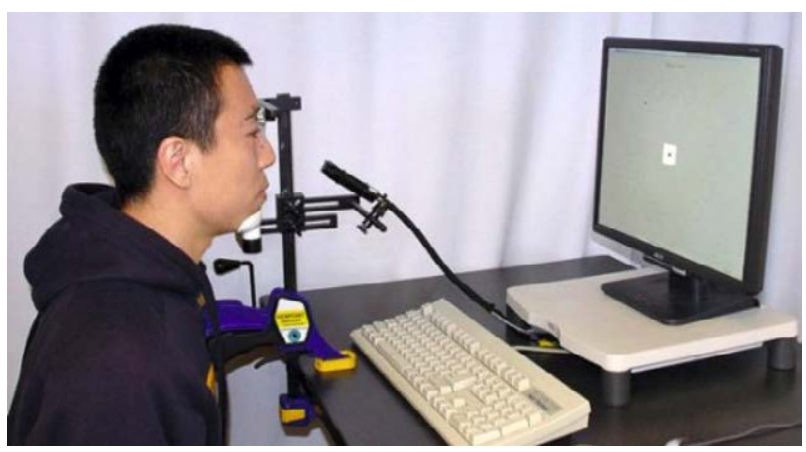

(a)

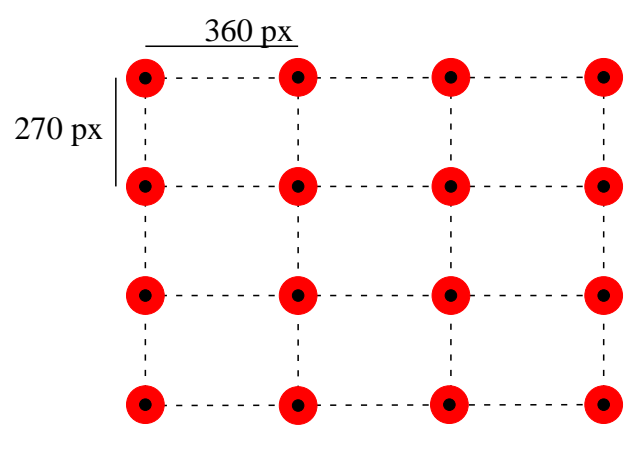

(b)

Figura 5.1: (a) Los fabricante miden a sus dispositivos en condiciones especiales, restringiendo los movimientos de la cabeza mediante un posa barbilla o posa mentón. Luego, los usuarios con trastornos motores graves no saben si el ET se ve afectado por los movimientos de la cabeza (b) El objeto estímulo consistió en dos círculos concéntricos, uno negro interno y otro rojo externo. El objeto estímulo apareció en una de 4 filas y 4 columnas. En la figura se muestran las 16 posiciones posibles del estímulo, sin embargo, solo se mostraba un objeto a la vez. El origen de coordenadas está en la parte superior izquierda.

ojos (binoculares). La $\mathrm{P} \& \mathrm{~V}$ en condiciones ideales es 0,4 y 0,26 grados, respectivamente. El eye-tracker es capaz de operar a una distancia de entre 40 a $90 \mathrm{~cm}$ del usuario y permite movimientos de la cabeza $($ a $70 \mathrm{~cm}$ ) de 50 y $36 \mathrm{~cm}$, en los ejes horizontal y vertical, respectivamente. Se ha tenido como criterio principal de selección la no invasividad de estos tipos de dispositivos y el bajo costo, como aspectos adicionales de usabilidad.

El software de grabación fue el Tobii Studio 3.2.1.190 Professional ${ }^{2}$. Este software permite diseñar el experimento (definir los estímulos visuales, orden de aparición, duración) y grabar los datos.

El equipo utilizado para la prueba fue un HP Compaq 8000 Elite CMT, con un procesador Intel Core 2 Quad Q9500 (velocidad de la CPU 2 x $2.83 \mathrm{Ghz}$ ), memoria RAM de 4 GB, sistema operativo Windows 7 Professional 32 bits y una tarjeta gráfica GeForce 8500 GT. En el momento de la prueba, sólo se estaba ejecutando el software Tobii Studio. La apariencia y el rendimiento de Windows se configuraron con el "mejor rendimiento" y las opciones de ahorro de energía fueron configuradas para "alto rendimiento".

La pantalla utilizada para la prueba fue una HP L1950g de 19 pulgadas $(48,25 \mathrm{~cm})$, con tecnología LCD, apertura de la pantalla de $37,8 \times 30,3 \mathrm{~cm}$, una relación de aspecto 5:4, una resolución de 1280x1024 y una frecuencia de $60 \mathrm{~Hz}$.

\subsubsection{Participantes}

En total, se reclutaron 10 participantes sin ningún tipo de discapacidad, cuyas características se muestran en la Tabla 5.1. El $40 \%$ de los participantes fueron mujeres. Todos los participantes son lectores regulares. 3 de los 10 participantes (U2, U7 y U10) han tenido contacto con un eye-tracker anteriormente. La mitad de los participantes normalmente usan gafas mientras trabajan con un ordenador y un usuario (U3) utiliza lentes de contacto. Estos usuarios realizaron las pruebas con sus correctores oculares. La edad media de los participantes fue de 29 años, \pm 5 años.

\footnotetext{
${ }^{2}$ http://www.tobiipro.com/product-listing/tobii-pro-studio/
} 


\begin{tabular}{llllll}
\hline Usuario & Edad & Sexo & Color ojos & Ojo dominante & Visión \\
\hline US01 & 40 & Mujer & Marrón & Derecho & - \\
US02* & 25 & Hombre & Marrón & Derecho & - \\
US03 & 26 & Hombre & Verde & Izquierdo & Lentillas \\
US04 & 27 & Hombre & Marrón & Derecho & Gafas \\
US05 & 24 & Mujer & Marrón & Derecho & Gafas \\
US06 & 25 & Mujer & Verde & Izquierdo & Gafas \\
US07* & 34 & Hombre & Marrón & Izquierdo & - \\
US08 & 28 & Hombre & Marrón & Derecho & Gafas \\
US09 & 30 & Mujer & Verde & Derecho & - \\
US10* & 31 & Hombre & Verde & Izquierdo & Gafas \\
\hline & $29( \pm 5)$ & Muj. 4 & Mar. 6 & Der. 6 & Gaf. 5 \\
& & Hom. 6 & Ver. 5 & Izq. 5 & Len. 1 \\
\hline
\end{tabular}

Tabla 5.1: Participantes con su edad, sexo, color de ojos, ojo dominante y corrector de vista. Los participantes $\mathrm{Ux}^{*}$ han tenido contacto con un ET anteriormente.

\subsubsection{Procesamiento de datos}

El procesamiento de los datos incluyó cuatro pasos: 1) simplificación de los datos, 2) cálculo del ángulo que se utilizó para calcular la $\mathrm{P} \& \mathrm{~V}, 3)$ descartar valores atípicos, y 4) cálculo de la $\mathrm{P} \& \mathrm{~V}$. A continuación, antes de describir estos pasos, ofreceremos más detalles acerca de los datos proveídos por el ET.

Los datos proporcionados por el ET fueron cuatro: dos puntos en la pantalla donde el ET estimó que miro cada ojo del participante — Gaze Left y Gaze Right-, y dos puntos que fueron la estimación de la posición de cada ojo - Eye Left y Eye Right-. También se almacenó la posición del círculo en la pantalla - Target - . Estos cinco puntos están representados en la Figura 5.2a. Estos datos están referidos a un sistema de coordenadas de 3 dimensiones, cuyo origen es la esquina superior izquierda de la pantalla. Según esta convención, los puntos Gaze Left, Gaze Right y Target tuvieron un valor de componente $z$ igual a cero, ya que estuvieron siempre sobre el plano $z=0$, durante todas las grabaciones. Por este motivo, en la Figura 5.2a y la Figura 5.2b, estos tres puntos no tienen esta componente.

Para cada muestra proporcionada por el eye-tracker se hicieron dos simplificaciones con los datos. Se calculó un punto de mirada medio - Gaze-, y la posición del ojo medio - Eye - , según la Ecuación (5.1) y Ecuación (5.2). Ambos puntos medios están representados en la Figura 5.2b.

Con estos tres puntos - Gaze, Target y Eye- se crearon tres vectores: $\vec{A}$, que unió los puntos Eye y Target, $\vec{B}$, que unió los puntos Eye y Gaze, y $\vec{C}$, que unió los puntos Eye con el punto medio de Gaze. El ángulo entre los vectores $\vec{A}$ y $\vec{B}$, denominado $\angle A B$, representa la diferencia entre el punto de la mirada estimado por el ET y el punto donde el usuario está mirando efectivamente, por cada dato que genera el ET. Idealmente el valor de $\angle A B$ debería ser cero, lo que implicaría que el ET estaría estimando el punto exacto de la mirada del usuario. Además, el ángulo $\angle A C$, formado entre los vectores $\vec{A}$ y $\vec{C}$, representa la diferencia entre el punto medio de la mirada estimado por el ET y el punto donde el usuario está mirada realmente. La representación de los vectores $\vec{A}$ y $\vec{B}$ y el ángulo $\angle A B$ se puede ver en la Figura 5.2b. 
El ángulo $\angle A B$ fue calculado con cada muestra del ET, a partir de los experimentos realizados. Antes de calcular los valores de $\mathrm{P} \& \mathrm{~V}$ se analizaron todos los valores $\angle A B$ y los que eran mayor a 3 veces la desviación estándar de todos los ángulos se consideraron valores atípicos y se descartaron del análisis. Finalmente, con los valores restantes, se calculó la precisión y veracidad, según las Ecuaciones 5.4. Según estas definiciones, la precisión tiene relación con la dispersión de las estimaciones del ET: un valor bajo implica que las medidas están agrupadas entre sí. Por otro lado, la veracidad tiene relación con la diferencia entre el objetivo real y la media aritmética de la estimación del ET.

Como mencionamos en la Sección 3.1.2 y la 3.1.3, los ojos están normalmente en dos estados: en movimiento o "fijos" en un punto. El movimiento del ojo se produce para que la fóvea tengo proyectada sobre sí la imagen que interesa mirar con mayor atención —en la Sección 3.1.4 se discute esta cuestión-. Según el paradigma de nuestro experimento, la imagen de interés es el círculo en la pantalla. Entonces, aunque cada círculo apareció durante 5 segundos, sólo se analizaron los últimos 4,25 segundos después de que el objetivo apareciera en la pantalla, para no incluir en la medida de la $\mathrm{P} \& \mathrm{~V}$ el movimiento del ojo hacia el objetivo. Es decir, los primeros 0,75 segundos no se usan para el análisis porque se considera el tiempo necesario para fijar la mirada. La Figura 5.3 representa los primeros 0,75 segundos como un área gris.

$$
\begin{aligned}
\operatorname{Gaze}(x) & =\text { Promedio(Gaze Left }(x), \text { Gaze Right }(x)) \\
\operatorname{Gaze}(y)= & \text { Promedio(Gaze Left }(y), \text { Gaze Right }(y) \\
\operatorname{Eye}(x)= & \text { Promedio(Eye Left }(x), \text { Eye Right }(x)) \\
\operatorname{Eye}(y)= & \text { Promedio(Eye Left }(y), \text { Eye Right }(y) \\
\operatorname{Eye}(z)= & \text { Promedio(Eye Left }(z), \text { Eye Right }(z) \\
\vec{A} & =\text { Eye }(x, y)-\operatorname{Target}(x, y) \\
\vec{B} & =\text { Eye }(x, y)-\operatorname{Gaze}(x, y) \\
\vec{C} & =\text { Eye }(x, y)-\operatorname{Media}(\operatorname{Gaze}(x, y)) \\
\angle A B= & \text { Ángulo }(\vec{A}, \vec{B}) \\
\angle A C= & \text { Ángulo }(\vec{A}, \vec{C}) \\
& \text { Precisión }=\operatorname{Std}(\angle A B) \\
& \text { Veracidad }=\angle A C
\end{aligned}
$$

\subsubsection{Resultados}

Se descartaron 534 medidas de un total de 44517, lo que representa una tasa de valores atípicos de 1,20\%. La precisión y la veracidad, sin valores atípicos, fueron igual a 1,91 y 2,46 grados respectivamente, Tabla 5.2. Por otro lado, la hoja de datos técnicos del dispositivo indica unos valores de $\mathrm{P} \& \mathrm{~V}$ de 0,26 y 0,40 grados respectivamente, Tabla 5.2. Es importante mencionar que, incluso sin el reposa mentón, la cabeza del usuario se mantuvo siempre dentro del rango del eye-tracker.

El histograma en 2D de los datos de la mirada (Gaze) se muestra en la Figura 5.4b como un mapa de calor sobre el círculo de estímulo, y el histograma de los ángulos $\angle A B$ en 


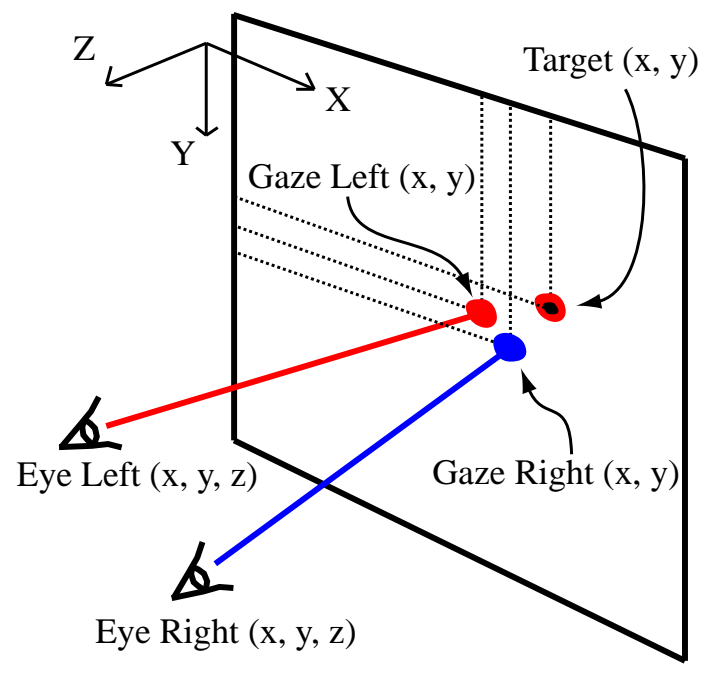

(a)

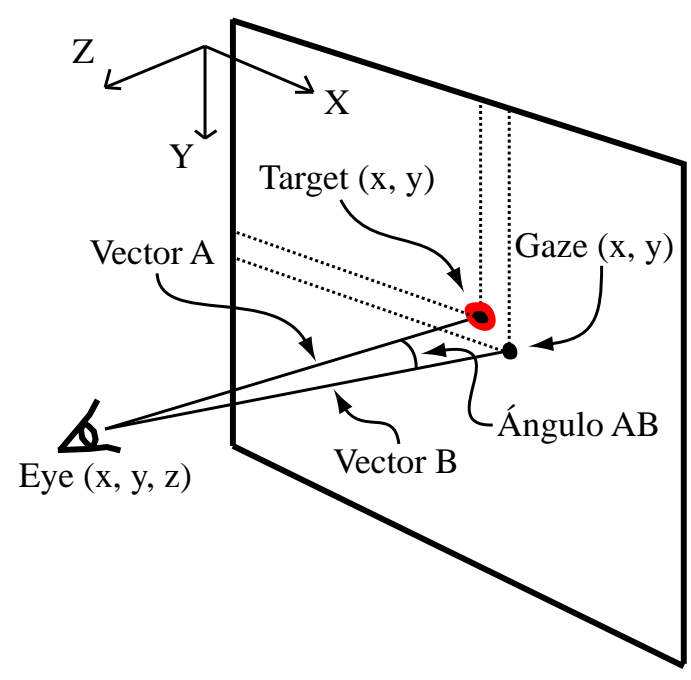

(b)

Figura 5.2: (a) Esta figura representa la mirada de cada ojo proyectada sobre la pantalla como una línea roja y azul. También se representan los puntos de intersección entre la mirada y la pantalla como los círculos rojo y azul. El origen de coordenadas 3D es la esquina superior izquierda de la pantalla. (b) Los datos posteriores a la simplificación son la posición del ojo medio (Eye), de la mirada media (Gaze) y del objeto estímulo (Target)

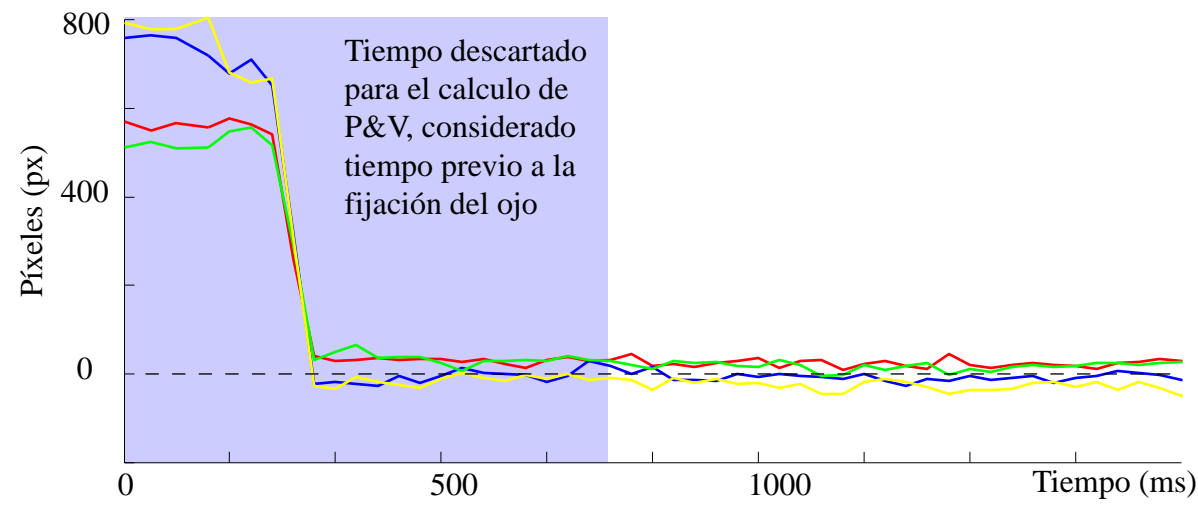

Figura 5.3: Distancia entre el centro del círculo estímulo (línea de puntos) y la mirada (líneas de colores), como función del tiempo. El rectángulo gris encierra los primeros 0,75 segundos no analizados en el procesamiento de datos, considerado el tiempo necesario para fijar el ojo en el círculo. Existen cuatro líneas de colores, porque la mirada de cada ojo tiene dos coordenadas, $\mathrm{x}$ e y. Entonces, las líneas rojas y la azul son la mirada x e y del ojo izquierdo, y las líneas verde y amarillo son la mirada $\mathrm{x}$ e y del ojo derecho.

\begin{tabular}{lll}
\hline Métrica & Medido $\left(^{\circ}\right)$ & Datos técnicos $\left(^{\mathbf{o}}\right)$ \\
\hline Precisión & 1,91 & 0,26 \\
Veracidad & 2,46 & 0,40 \\
\hline
\end{tabular}

Tabla 5.2: Precisión y veracidad de los datos proporcionados por la prueba y por la hoja de datos (Tobii X2-30 Eye Tracker Manual del usuario, Apéndice A: Especificaciones del Tobii X2-30 Eye Tracker, 2013), en grados. 
la Figura 5.4a. Ambos histogramas se realizaron sin los valores atípicos. La Figura 5.5 muestra la posición media de la mirada (Gaze) por cada uno de los 16 objetivos estímulo que se presentaron a los participantes por cada uno de los 10 participantes. Cada objetivo tiene asociados 20 puntos rojos, que representan cada una de las 2 pruebas que hicieron.

\subsubsection{Discusión}

Este ensayo planteó medir la $\mathrm{P} \& \mathrm{~V}$ en condiciones normales de uso - sin posa mentón-, para valorar cuanto se desvían estas medidas de las de fábrica. Nuestra hipótesis fue que las medidas serían peores a las que documentan los fabricantes, lo cual fue confirmado por nuestro estudio. Sin embargo, nuestras medidas reflejan con más realismo lo que un usuario va a percibir cuando interactúa con un ordenador mediante un ET.

Nuestros resultados indican valores de $\mathrm{P} \& \mathrm{~V}$ peores que los medidos por los fabricantes. Esto demuestra que el rendimiento de la interfaz se deteriora cuando los usuarios pueden mover la cabeza libremente. Todos los participantes en el estudio fueron sujetos sanos, con capacidad de control postural y motor. Sin embargo, los resultados nos dan una indicación de que las medidas $\mathrm{P} \& \mathrm{~V}$, en el contexto de un uso cotidiano sin posa mentón, son diferentes a las medidas por el fabricante. Es lógico esperar que las medidas con usuarios con PC, quienes tienen problemas serios para mantener la cabeza fija, sea incluso peor que las medidas con usuarios sin ningún tipo de patología.

Nuestro enfoque está orientado a valorar la interacción hombre-computador más que al dispositivo interfaz en sí. Para medir al dispositivo, los estudios reducen la influencia del elemento central en la interacción hombre-computador, el hombre, inmovilizando artificialmente la cabeza. La P\&V no describen cómo es la interacción, es decir, si el usuario podría realizar una tarea o no, sino más bien al dispositivo que sirve de interfaz de acceso. Son necesarias métricas funcionales que describan la capacidad de los usuarios de realizar las tareas. Este tema será abordado en la siguiente Sección, la Sección 5.3.

La precisión, que por definición tiene relación con la desviación estándar del error, se puede reducir mediante técnicas de filtrando de la señal. Sin embargo, la veracidad es más crítica que la precisión, ya que no se puede reducir con técnicas de filtrado. La veracidad tiene relación con la calibración, la cual calcula la relación entre la posición de la mirada y un objeto en pantalla con una posición conocida. Una mala calibración arrojará una mala veracidad. Este problema será profundizado en una sección posterior a la siguiente, donde estudiaremos la calibración con personas con PC, Sección 5.4.

\subsubsection{Conclusión de la Evaluación I}

Intentamos responder a la pregunta de si las medidas del fabricante de un eye-tracker son iguales a las medidas en la práctica, cuando no se restringe el movimiento de la cabeza. La metodología se valoró con diez personas, sin discapacidad. Para ello, diseñamos un método para la medición de la precisión y veracidad de un eye-tracker remoto sin la ayuda de un reposa mentón. Los resultados del ensayo arrojaron unos valores de precisión y veracidad peores a los descritos por la hoja técnica del dispositivo utilizado. La precisión y veracidad dependen del movimiento cervical. Con usuarios con trastornos motores esto sería aún peor. No podemos utilizar estas métricas para valorar la interacción de una persona con trastornos motores. Este estudio es importante porque permite descartar métricas que pueden causar falsas expectativas en los usuarios. 


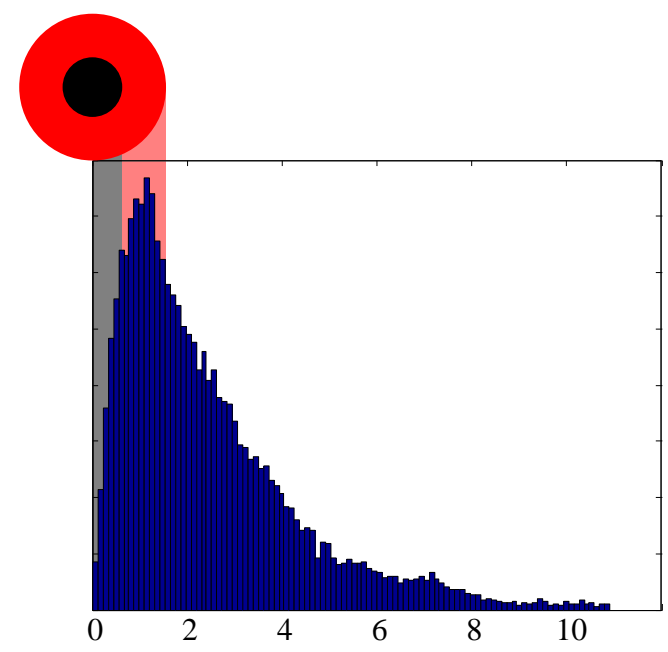

(a)

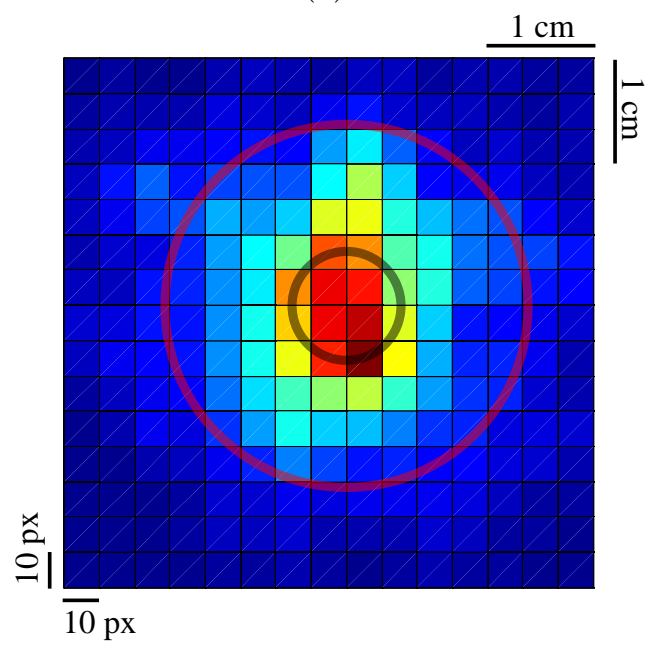

(b)

Figura 5.4: (a) Histograma de los ángulos $\angle A B$. El pico se produjo a los 1,15 grados. Se ha hecho una representación del estímulo visual, suponiendo que el usuario se encuentra a $60 \mathrm{~cm}$ de la pantalla. La función para calcular el ángulo de los círculos es $\alpha(x)=t g^{-1}(x / 60)$, donde $x$ son los radios 0,5 y 1,75 y $\alpha$ el ángulo resultante. Con esta suposición, el pico se encuentra en el área de círculo mayor, de color rojo. (b) Histograma en 2D de los datos de la mirada (Gaze), en píxeles 


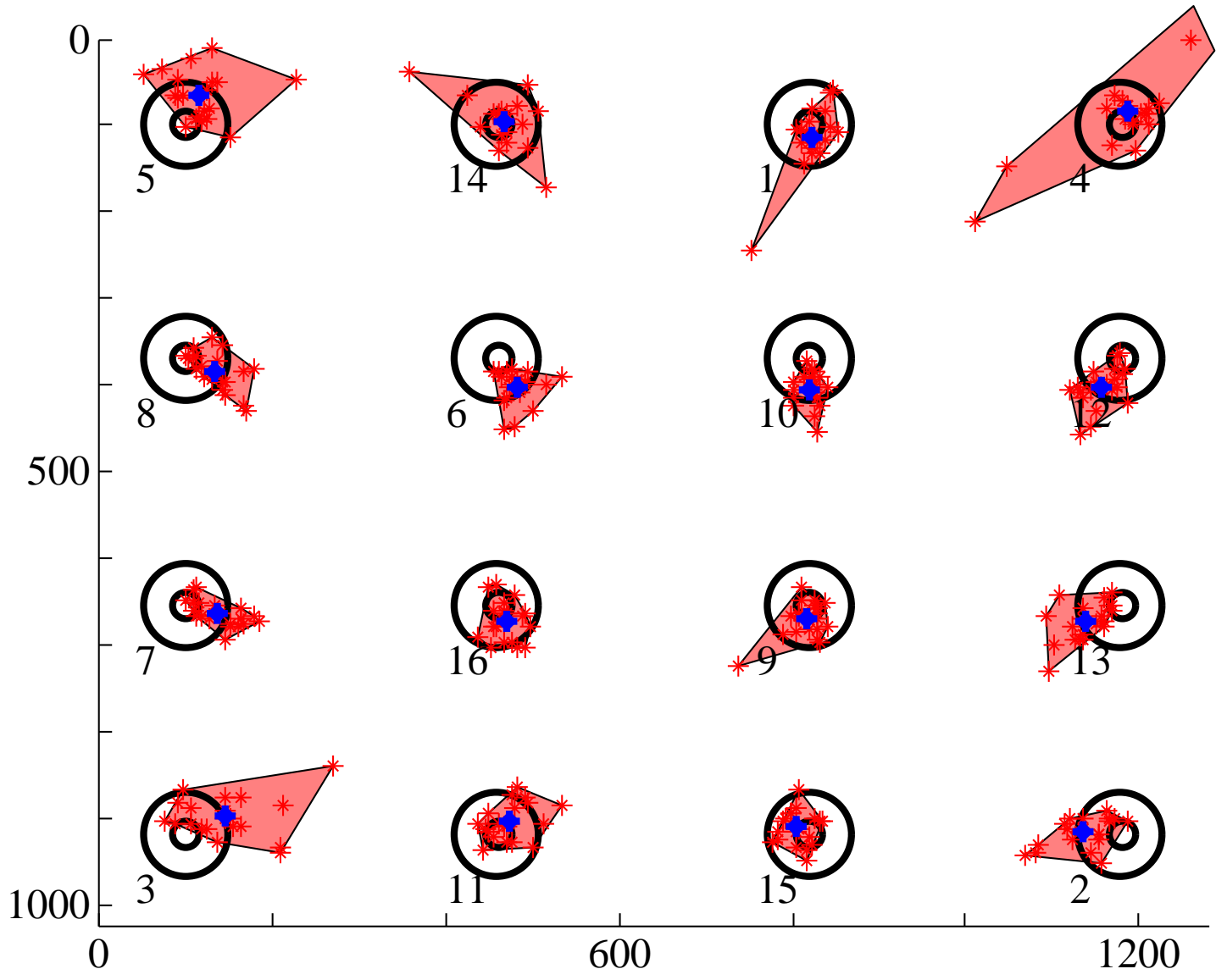

Figura 5.5: Cada cruz roja representa la posición media de la mirada (Gaze), por cada uno de los 16 círculos estímulo, por cada uno de los 10 participantes, por cada una de las 2 sesiones, en total 320 cruces. Además, la cruz azul representa la posición media por cada círculo. El eje está en píxeles 


\subsection{Evaluación II: Ley de Fitts}

La definición de la ley de Fitts es una de los más utilizadas para la evaluación de interfaces y tareas realizadas con una computadora. Como se ha visto en la Sección 4.1.2, la ley de Fitts establece una relación lineal entre la dificultad de una tarea $I D$ - definida por la amplitud del movimiento necesario para alcanzar el objeto y el tamaño del objeto, Ecuación (5.5) - y el tiempo necesario para alcanzar este objeto TM, Ecuación (5.6).

Existen estudios que demuestran que la relación lineal se cumple en dispositivos como el mouse [21] o el joystick [75]. Radwin et al. [92] propuso un método para evaluar la ley de Fitts para dispositivos controlados con movimientos de cabeza. Se estudiaron sujetos con y sin discapacidades. Desafortunadamente, no proporcionaron información sobre la correlación lineal entre tiempo y dificultad. Guness et al. [93, 94] evaluaron un head-tracker al igual que Raya et al. [95], pero tampoco estudiaron la relación lineal. Alonso et al. [96] evaluaron el desempeño de un eye-tracker como dispositivo de entrada para interfaces de control de tráfico aéreo. Encontraron que la relación entre el nivel de dificultad y el tiempo de selección objetivo no era lineal, lo que sugiere que el tiempo de selección no siguió la ley de Fitts. Surakka et al. [97] utilizaron un eye-tracker para controlar el cursor y la activación del músculo facial para hacer clic en los elementos. Con esta técnica, encontraron una relación lineal entre el tiempo de movimiento y el índice de dificultad con un valor de $R^{2}=0,988(p<0,001)$. Sin embargo, ninguno de estos experimentos reclutó personas con discapacidades motoras o cognitivas.

Debido a esta falta de claridad del tema en la bibliografía, hemos estudiado la ley de Fitts y en este capítulo presentaremos los resultados de esta evaluación, con interfaces basadas en movimientos oculares y el clic por permanencia, y en nuestro caso para personas con parálisis cerebral y con un grupo de control.

En la Sección 5.4.1 y la Sección 5.2.4 se presentará el método. En la Sección 5.2.5 los resultados. Este capítulo termina con la discusión sobre el método y los resultados junto con la conclusión en la Sección 5.2.6 y Sección 5.2.7 respectivamente.

$$
\begin{aligned}
I D & =\log _{2}\left(\frac{A}{W}+1\right), \\
T M & =a+b * I D,
\end{aligned}
$$

\subsubsection{Protocolo del test}

El protocolo se basa en el presentado en la Sección 5.3.1, con ligeras modificaciones. Los participantes controlaron el cursor con la mirada. Se les solicitó a los usuarios que apuntaran el cursor a la figura animada que aparecía en la pantalla en 10 posiciones y tamaños diferentes. La dificultad de las tareas ha sido establecida mediante la Ley de Fitts. Las amplitudes y tamaños de los objetivos en la pantalla fueron predefinidos para que las tareas tuvieran índices de dificultad establecidos entre 1 y 3,7 bits. El rango de la anchura del objeto $(W)$ se estableció entre 100 y 200 píxeles y la amplitud de movimiento $(A)$ entre 200 y 1200 píxeles. Aunque la amplitud $A$ entre objetos consecutivos se determinó de antemano, el ángulo en el que apareció la figura fue asignado al azar, lo que permitió que la posición del nuevo objeto fuera aleatorio.

Los clics se realizaron mediante la técnica de permanencia, descrita también en el protocolo presentado antes, en la Sección 5.3.1, por ser el tipo de clic que presentó mejores 
resultados, según la Evaluación II. Para este caso, el usuario tuvo solamente una oportunidad para realizar el clic por cada figura, cambiando de posición independientemente de si se hacía clic dentro o no. Tras la Evaluación II, donde se han registrado tasas de error promedio de casi $50 \%$, los terapeutas han recomendado que cuando los usuarios presentan problemas para realizar un clic en un objetivo, es mejor pasar al siguiente objetivo, para evitar desmotivación y frustración de los participantes.

Antes de cada sesión, se realizó un proceso de calibración con cada participante. La calibración se realizó pidiendo a los participantes que miraran nueve figuras animadas, cuyas posiciones eran conocidas (una parrilla de 3 por 3), pero cuyo orden de aparición fue aleatorio, con el objetivo de evitar el efecto del aprendizaje en los resultados. Un video del protocolo de calibración está disponible en ${ }^{3}$

Los participantes recibieron estímulos de realimentación sensorial durante las tareas. Por un lado, tuvieron una realimentación auditiva cuando se producían clics dentro y fuera del objetivo en pantalla. Para la realimentación visual, se mostró un cuadro verde alrededor de la figura objetivo, cuando el cursor ingresaba en el área de ésta. Durante la tarea el participante no tenía realimentación visual de la posición del cursor. La experiencia nos dijo que los participantes con PC considerados como principiantes tienden a distraerse con esta realimentación y los considerados expertos tratan de compensar la posición del cursor, ajustando su mirada según lo que ven en la pantalla.

Cada participante realizó la prueba en dos etapas: demostración y registro [98]. La etapa de demostración se utilizó para instruir y familiarizar al participante sobre cómo realizar la tarea sin recoger datos. En el modo de registro, el participante realizó una calibración y luego un grupo de tareas de apuntamiento y clic, y los datos fueron almacenados para su posterior análisis. Las sesiones duraron en total aproximadamente 40 minutos. Este tiempo incluyó el tiempo necesario para preparar adecuadamente al participante, para obtener una buena calibración y para descansar cuando el participante lo solicitaba. Se realizaron ocho sesiones en total, durante tres meses. Las dos primeras sesiones fueron dedicadas a la etapa de demostración, que se realizaron en un mes. En las siguientes seis sesiones se realizó la recopilación de datos, durante dos meses.

Un video del protocolo del test está disponible en ${ }^{4}$

\subsubsection{Equipos}

Tres ETs fueron seleccionados para este estudio: Tobii EyeX (Tobii, Suecia, etiquetado como ET01), Tobii X2-30 (ya descrito en la Sección 5.3.2, etiquetado como ET02) y TheEyeTribe (TheEyeTribe, Dinamarca, etiquetado como ET03). Todos basados en video oculografía, con fuentes de luz infrarroja, del tipo remoto. Los 3 ETs trabajan a una frecuencia de muestreo de $30 \mathrm{~Hz}$ y son capaces de obtener datos de ambos ojos de forma independiente (binoculares). Los ETs pueden operar a una distancia de entre 40 y 90 centímetros del participante, pero la distancia óptima es de $60 \mathrm{~cm}$ para todos los casos. También permiten que el participante mueva la cabeza hasta 50 y 35 centímetros horizontal y vertical respectivamente.

Utilizamos el mismo equipo de sobremesa y pantalla de la evaluación presentados en la Sección 5.3.2. El software desarrollado para la evaluación anterior fue modificado para que siga las directrices del nuevo protocolo.

\footnotetext{
${ }^{3}$ https://youtu.be/OXYB1cD3MFI

${ }^{4}$ https://youtu.be/KahOBmocsbY
} 


\begin{tabular}{lllllll}
\hline Grupo & Usuario & MACS & GMFCS & Sexo & Edad & Exp. ET \\
\hline Usuarios con CP & & & & & & \\
& US01 & 5 & 4 & M & 8 & Baja \\
& US02 & 3 & 5 & M & 15 & Baja \\
& US03 & 5 & 5 & F & 5 & Baja \\
& US04 & 5 & 5 & F & 11 & Baja \\
& US05 & 5 & 4 & F & 5 & Media \\
& US06 & 5 & 5 & M & 29 & Alta \\
& US07 & 5 & 5 & F & 31 & Alta \\
& US08 & 5 & 5 & M & 38 & Baja \\
& US12 & 4 & 4 & F & 8 & Baja \\
\hline Usuarios sin CP & & & & & & \\
& US20 & & & M & 30 & Alta \\
& US21 & & & M & 30 & Media \\
& US23 & & & M & 37 & Alta \\
& US24 & & & F & 23 & Media \\
& US25 & & & F & 26 & Media \\
& US26 & & & M & 26 & Media \\
US27 & & & M & 23 & Media \\
\hline
\end{tabular}

Tabla 5.3: Perfil de los nueve participantes con PC reclutados para las pruebas, con sus niveles MACS (M), GMFCS (G), sexo (S), edad (E) y experiencia en el uso de ETs y los siete participantes del grupo de control.

\subsubsection{Participantes}

Participaron 9 personas con PC, de dos centros especializados: ATENPACE y el Colegio de Educación Especial San Rafael, ambos de Madrid. El perfil de los participantes se puede ver en la Tabla 5.3, con las evaluaciones clínicas MACS [13, 99] y GMFCS [15]. Todos los participantes, a excepción de uno, tienen niveles MACS IV o V, que como hemos dicho antes, son los grados más severos de la escala, lo que justifica el uso de este tipo de interfaces. Los usuarios no son los mismos de la Evaluación anterior, sin embargo, comparten los mismos niveles de discapacidad: niveles IV y V según los sistemas MACS y GMFCS. La edad media de los participantes fue de 17 años ( \pm 13 años). Para la clasificación de la experiencia con los ETs hemos solicitado a los terapeutas que clasifiquen a los usuarios según la experiencia que los pacientes hayan tenido con éstos.

Además, 7 sujetos sin discapacidad participaron en los experimentos. El grupo sin PC estaba compuesto de 5 hombres y 2 mujeres, con edad media de 28 años ( \pm 5 años), Tabla 5.3. Ambos grupos llevaron a cabo las mismas tareas de alcance en el ordenador. Los datos de las personas sin PC se utilizaron como valores de referencia.

Los comités de ética de los dos centros aprobaron el estudio. Todos los pacientes fueron informados previamente y firmaron un consentimiento informado por escrito para participar de este experimento. 


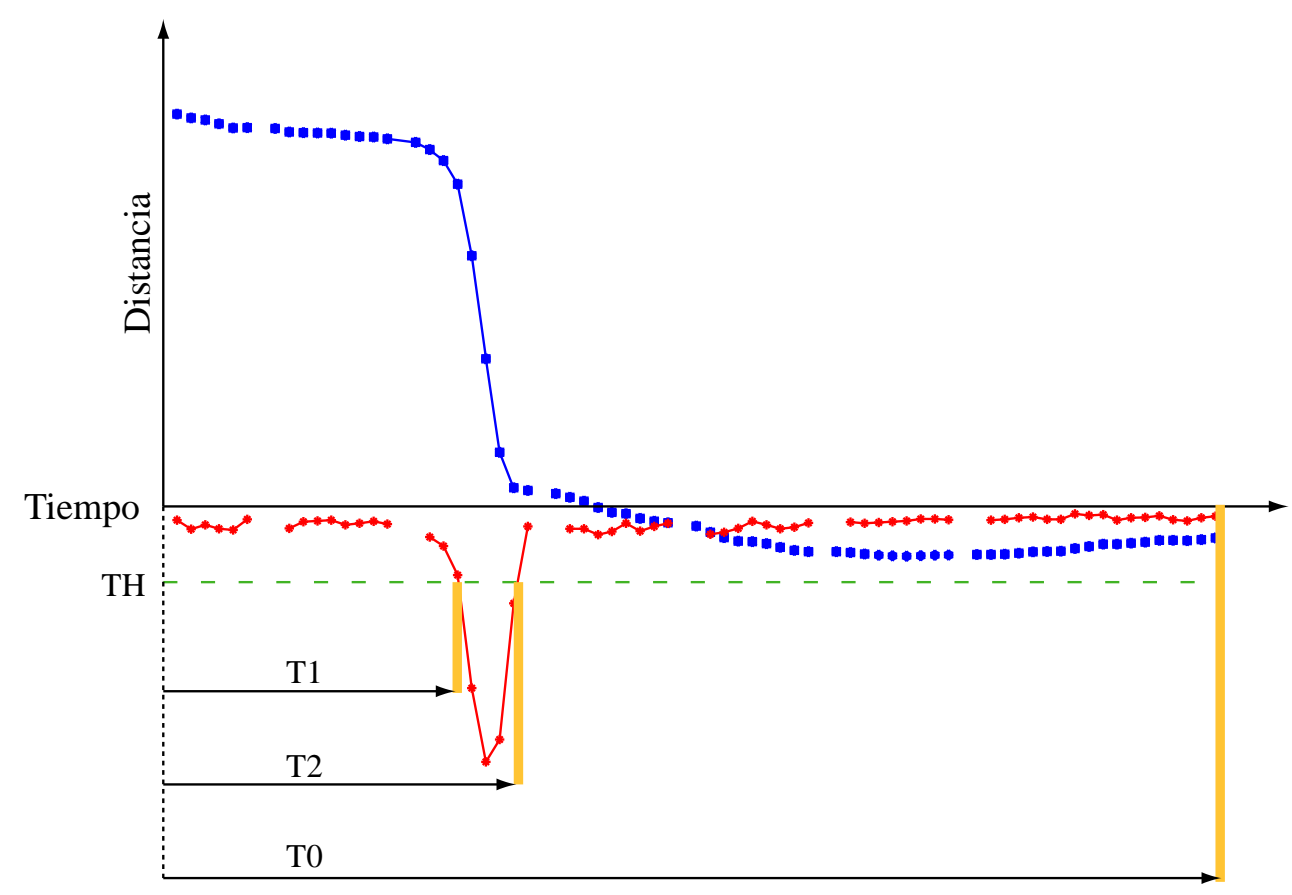

Figura 5.6: Representación de los tiempos T0, T1 y T2. En azul el valor Error, en rojo el valor DeltaError, en verde el valor de $T H$.

\subsubsection{Procesamiento de datos}

Hemos considerado un conjunto de medidas de tiempo en nuestro procesamiento. TM se considera generalmente como el tiempo que tardan los participantes en realizar un clic. Llamaremos a este tiempo T0. Además de esta medida, hemos considerado otros dos casos: el tiempo que tardan los ojos en iniciar y en terminar el movimiento una vez que se presenta el estímulo visual, denominados $T 1$ y $T 2$, respectivamente.

Para la obtención de $T 1$ y T2 hemos definido dos variables: Error y DeltaError. Error es la distancia euclídea entre el centro del objetivo en la pantalla y el cursor y DeltaError fue la diferencia entre las muestras consecutivas Error.

Las dos definiciones de tiempo alternativas T1 y T2 que proponemos se basan en estas dos variables. Definimos $T 1$ como el tiempo que tarda DeltaError en superar un determinado umbral TH y T2 como el tiempo que tarda DeltaError en volver por debajo de este umbral. Podemos ver en la Figura 5.6 un ejemplo gráfico de estas dos definiciones de TM. En la figura, los puntos azules representan el Error y los puntos rojos representan DeltaError. El umbral TH está representado por una línea verde discontinua.

En la Ecuación 5.7 se define el valor umbral TH, donde DeltaError ${ }_{H P}$ es el valor DeltaError de todas las pruebas realizadas con los participantes sin discapacidad, Pico es una función que calculó los valores máximos de DeltaError ${ }_{H P}$ - los valores picoy Promedio calculó el promedio de los valores máximos. Finalmente, 0,30 definió el $30 \%$ del valor promedio como el valor del umbral, con el que se obtiene un $T H$ igual a $30[100]$.

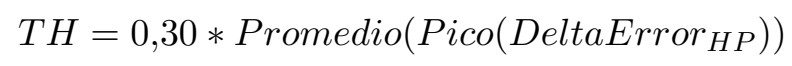




\begin{tabular}{lllll}
\hline TM & & Con PC & Sin PC & Total \\
\hline T0 & & & \\
& Clics exitosos (con outliers) & 172 & 363 & 535 \\
& Clics exitosos (sin outliers) & 137 & 290 & 427 \\
& Tasa de outliers & $20 \%$ & $20 \%$ & $20 \%$ \\
\hline T1 & & & \\
& Clics exitosos (con outliers) & 154 & 320 & 474 \\
& Clics exitosos (sin outliers) & 123 & 311 & 434 \\
& Tasa de outliers & $20 \%$ & $3 \%$ & $8 \%$ \\
\hline \multirow{2}{*}{ T2 } & & & \\
& & 153 & 318 & 471 \\
& Clics exitosos (con outliers) & 123 & 310 & 433 \\
& Clics exitosos (sin outliers) & $20 \%$ & $3 \%$ & $8 \%$ \\
& Tasa de outliers & & \\
\hline
\end{tabular}

Tabla 5.4: Información acerca del número y tasa de outliers identificados en cada tipo de TM y cada grupo de usuarios.

El procesamiento de datos incluyó los mismos pasos presentados en la Sección 5.4.2: (1) eliminación de sesiones con calibración baja, (2) eliminación de tareas con clics fallidos (fuera del objetivo), y (3) eliminación de tareas con tiempo de clics atípicos. Los valores atípicos de tiempo de clic $T M$ se calcularon con el método de Thompson Tau [101].

Después de este procedimiento, se calculó el coeficiente de correlación de Pearson $\rho$ y el coeficiente de determinación $R^{2}$ entre el índice de dificultad $I D$ — variable independientey los tres tiempos de movimiento $T M$ - variable dependiente-

\subsubsection{Resultados}

De un total de 662 tareas de alcance con buena calibración, descartamos 127 debido a que los clics fueron hechos fuera de la meta: 97 pertenecen al grupo de participantes con PC y 30 al grupo de control.

Con los clics realizados dentro del objetivo, calculamos los tres valores de TMs antes definidos: T0, T1 y T2. Los valores de $T M$ de algunas tareas no pudieron calcularse y fueron descartadas: 0 de To $-0 \%$ - 61 de $T 1-11 \%$ - y 64 de T2 - $12 \%$ -

Con los valores de $T M$ calculados, realizamos el análisis de valores atípicos. Descartamos $20 \%$ de las tareas exitosas de los participantes con PC de cada grupo de TMs: 35 de T0, 31 de $T 1$ y 30 de T2. En el caso de los participantes sin PC, descartamos 73 de T0-20\%-, 9 de T1-3\%- y 8 de T2 -3\%-. En total, después de todo el preprocesamiento de datos, se analizaron 427, 434 y 433 tareas, de T0, T1 y T2 respectivamente. En la Tabla 5.4 se muestran más detalles.

La prueba U de Mann-Whitney se utilizó para analizar los factores del experimento con sus diferentes niveles: los dos grupos de participantes y los tres tiempos de los movimientos. Se produjeron diferencias significativas entre los tres tiempos de movimientos, tanto para el grupo de control como para el grupo con PC $(p<0,05)$. Esto sugiere que los tres tiempos de movimiento son diferentes entre sí. Por último, se encontró una diferencia significativa entre los participantes con y sin PC, en el caso de $T M=T 0(p<0,05)$, 


\begin{tabular}{llllll}
\hline & Grupo & $\rho$ & Sig. & $R^{2}$ & N \\
\hline ID vs. T0 & & & & & \\
& Con PC & 0.08 & $\mathrm{p}=0.35$ & $<0.01$ & 137 \\
& Sin PC & 0.01 & $\mathrm{p}=0.82$ & $<0.01$ & 290 \\
\hline ID vs. T1 & & & & & \\
& Con PC & 0.10 & $\mathrm{p}=0.28$ & $<0.01$ & 123 \\
& Sin PC & 0.06 & $\mathrm{p}=0.25$ & $<0.01$ & 311 \\
\hline ID vs. T2 & & & & & \\
& Con PC & 0.14 & $\mathrm{p}=0.13$ & 0.02 & 123 \\
& Sin PC & 0.10 & $\mathrm{p}=0.07$ & 0.01 & 310 \\
\hline
\end{tabular}

Tabla 5.5: Correlación de Pearson ( $\rho$ ), significancia de los datos (Sig.), coeficiente de determinación $\left(R^{2}\right)$ y el número de muestras $(\mathrm{N})$ por cada grupo de usuarios y cada tiempo de movimiento.

\begin{tabular}{llllll}
\hline & Grupo & $\rho$ & Sig. & $R^{2}$ & $\mathrm{~N}$ \\
\hline T0 vs. A & & & & & \\
& Con PC & 0.02 & $\mathrm{p}=0.81$ & $<0.01$ & 137 \\
& Sin PC & 0.08 & $\mathrm{p}=0.18$ & $<0.01$ & 290 \\
\hline T0 vs. W & & & & & \\
& Con PC & -0.01 & $\mathrm{p}=0.87$ & $<0.01$ & 137 \\
& Sin PC & 0.07 & $\mathrm{p}=0.25$ & $<0.01$ & 290 \\
\hline
\end{tabular}

Tabla 5.6: Correlación de Pearson $(\rho)$, significancia de los datos (Sig.) y coeficiente de determinación $\left(R^{2}\right)$ por cada grupo de participantes y la amplitud de movimiento (A) y el tamaño del objeto $(\mathrm{W})$.

pero no para $T 1$ y $T 2$.

La Tabla 5.5 muestra los valores de la correlación de Pearson $(\rho)$, la significación de los datos (Sig.), los coeficientes de determinación $\left(R^{2}\right)$ y el número de muestras $(N)$ para cada uno de nuestros grupos de participantes y el tipo de tiempo de movimiento $T M$ correlacionado con $I D$.

Los resultados no proporcionan información suficiente para rechazar la hipótesis nula de independencia del tiempo de movimiento $T M$ y el índice de dificultad $I D$ para cualquiera de los grupos en el caso de $T M$ como T0, T1 y T2. Además, $R^{2}$ fue muy bajo con ambos grupos de participantes.

El índice de dificultad $I D$ frente al tiempo de movimiento de cada tarea para $T 0$ se representa en la Figura 5.7, para $T 1$ en la Figura 5.8 y para T2 en la Figura 5.9, para cada grupo de participantes. El eje horizontal representa el índice de dificultad $I D$, en bits, y el eje vertical el tiempo de movimiento $T M$, en segundos. Estas cifras muestran una pendiente casi horizontal que puede interpretarse como una baja dependencia del tiempo de movimiento $T M$ relacionado con el índice de dificultad $I D$.

Las ecuaciones de regresiones de $T M$ en función de $I D$, para ambos grupos de participantes, de todas las figuras mencionadas arriba, son las Ecuaciones 5.8 en el caso de T0, las Ecuaciones 5.9 en el caso de T1 y las Ecuaciones 5.10 en el caso de T2. 
Debido a la baja variabilidad de T0 (de 2,4 a 2,5s $<100 \mathrm{~ms}$ ), analizamos la correlación de este tiempo con la amplitud del movimiento $A$ y el tamaño del objeto en la pantalla $W$. La relación de Pearson de cada grupo de participantes se encuentra en la Tabla 5.6. No encontramos significación estadística, y nuevamente el valor $R^{2}$ fue bajo $(<0,01)$.

T0

$$
\begin{array}{ll}
T M_{\text {ConPC }}=0,00145 * I D+2,43 & \left(R^{2}<0,01\right) \\
T M_{\text {SinPC }}=0,00021 * I D+2,44 & \left(R^{2}<0,01\right)
\end{array}
$$

$T 1$

$$
\begin{array}{lll}
T M_{\text {ConPC }}=0,03 & * I D+0,47 & \left(R^{2}<0,01\right) \\
T M_{\text {SinPC }}=0,02 & * I D+0,50 & \left(R^{2}<0,01\right)
\end{array}
$$

$T 2$

$$
\begin{array}{lll}
T M_{\text {ConPC }}=0,047 & * I D+0,52 & \left(R^{2}=0,02\right) \\
T M_{\text {Sin } P C}=0,045 & * I D+0,56 & \left(R^{2}=0,01\right)
\end{array}
$$

\subsubsection{Discusión}

Este estudio se planteó evaluar la ley de Fitts en la tarea de controlar un ordenador por parte de personas con PC utilizando la mirada. En la sección 4.1.2 se mencionó que el Throughput es una medida estándar para valorar la velocidad y precisión de las tareas de alcance. Existe una discusión en la comunidad de HCI de si esta métrica puede o no utilizarse para el caso de tareas de alcance realizadas mediante los ojos a través de los eye-trackers. La discusión se debe principalmente a tres temas: 1) existen muchas definiciones del Throughput, 2) no está claramente definido el método para procesar los datos obtenidos y 3 ) no está claro cuál es el ancho del objeto para el ojo. A estas cuestiones se debe añadir la cuestión no trivial de las características especiales de los usuarios con discapacidad. Ya hemos visto múltiples definiciones para el Throughput en la sección 4.1.2, Ecuaciones (4.10)-(4.11)-(4.12). A continuación, discutiremos acerca del procesamiento de los datos y del tamaño del objeto para el ojo, junto con otros estudios donde se valora dicha cuestión.

\section{Método de procesamiento de datos}

Para valorar la ley de Fitts se suele calcular la correlación lineal $R^{2}$ entre el índice de dificultad ID (variable independiente) y el tiempo que una persona tarda en realizar el clic TM (variable dependiente). Sin embargo, el coeficiente de correlación depende del número de puntos utilizados para el análisis, en este caso, del número de IDs utilizados. En realidad, la correlación es sólo un indicador para la dependencia lineal. Se necesita un ensayo adicional (con hipótesis nula de que la correlación es cero, es decir, que las variables ID y TM son independientes) para averiguar la significancia de la correlación calculada.

Para ver la dependencia de la correlación con el número de puntos, vamos a ver un ejemplo. La Figura 5.10a representa una serie de tiempos de alcance TM en función del índice ID, simulados mediante ordenador. La Ecuación (5.11) representa la regresión 

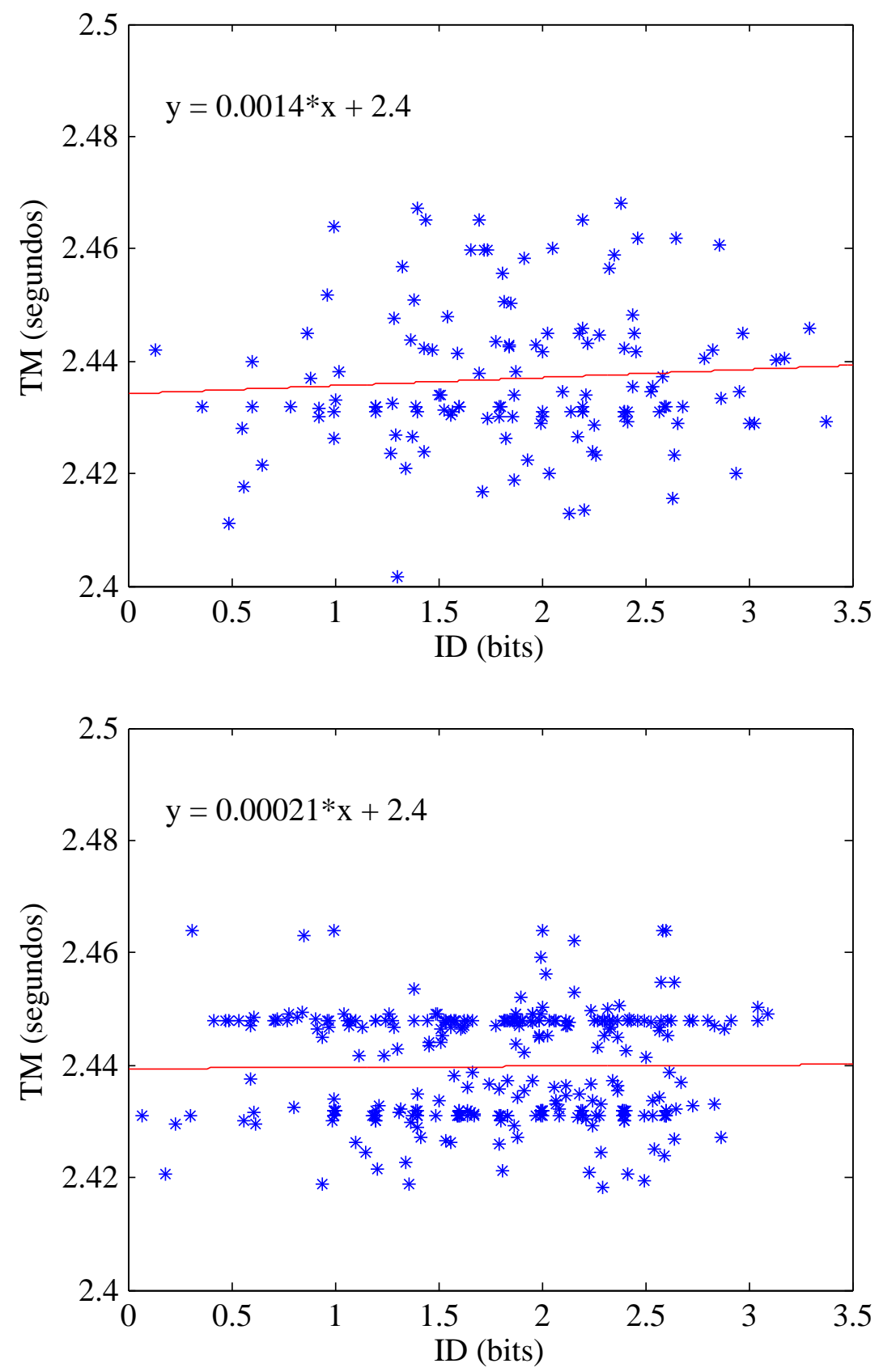

Figura 5.7: Índice de dificultad (ID, en bits) vs. T0 (en segundos), de los participantes con PC (arriba) y $\sin$ PC (abajo). 

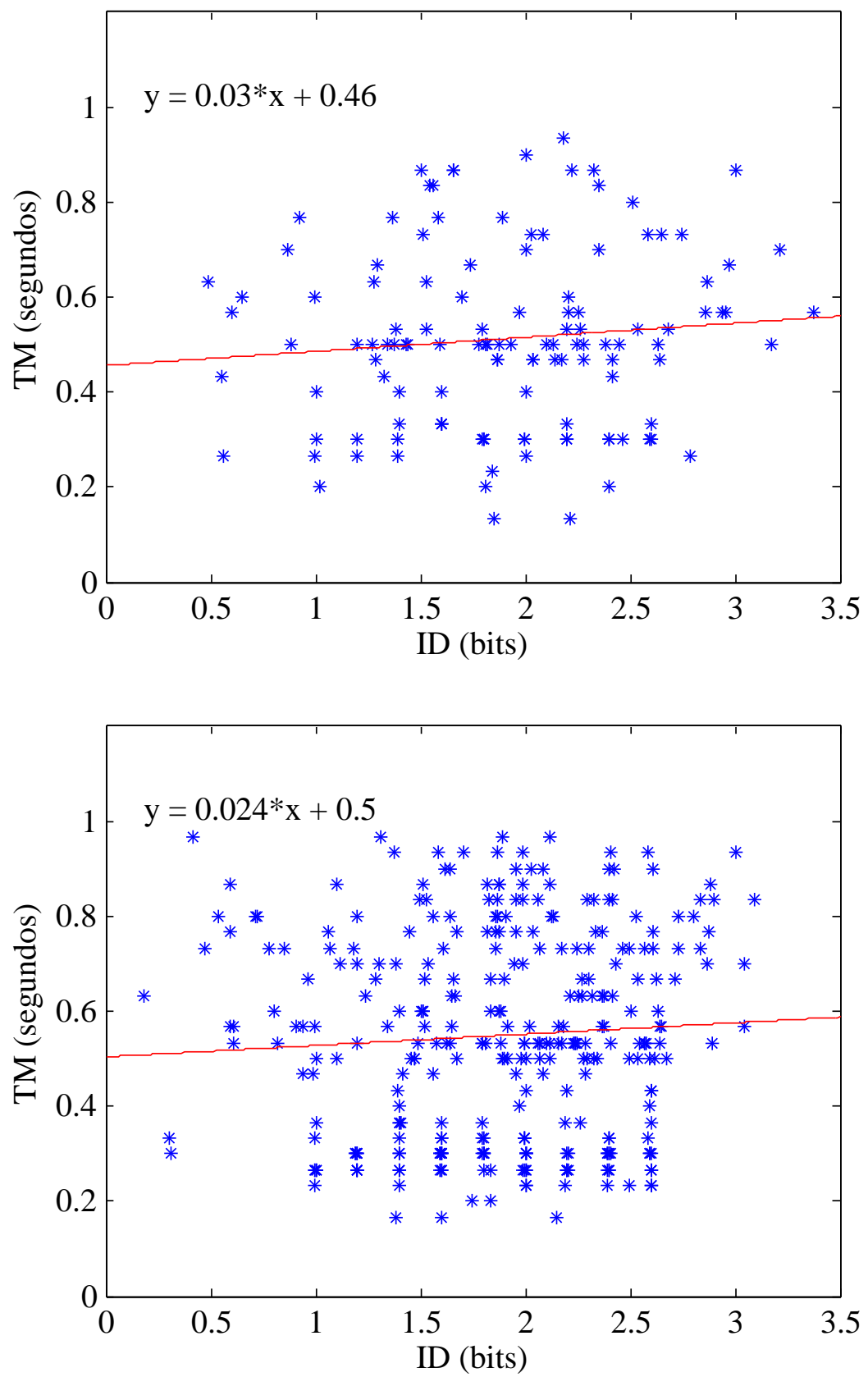

Figura 5.8: Índice de dificultad ( $I D$, en bits) vs. $T 1$ (en segundos), de los participantes con PC (arriba) y sin PC (abajo). 

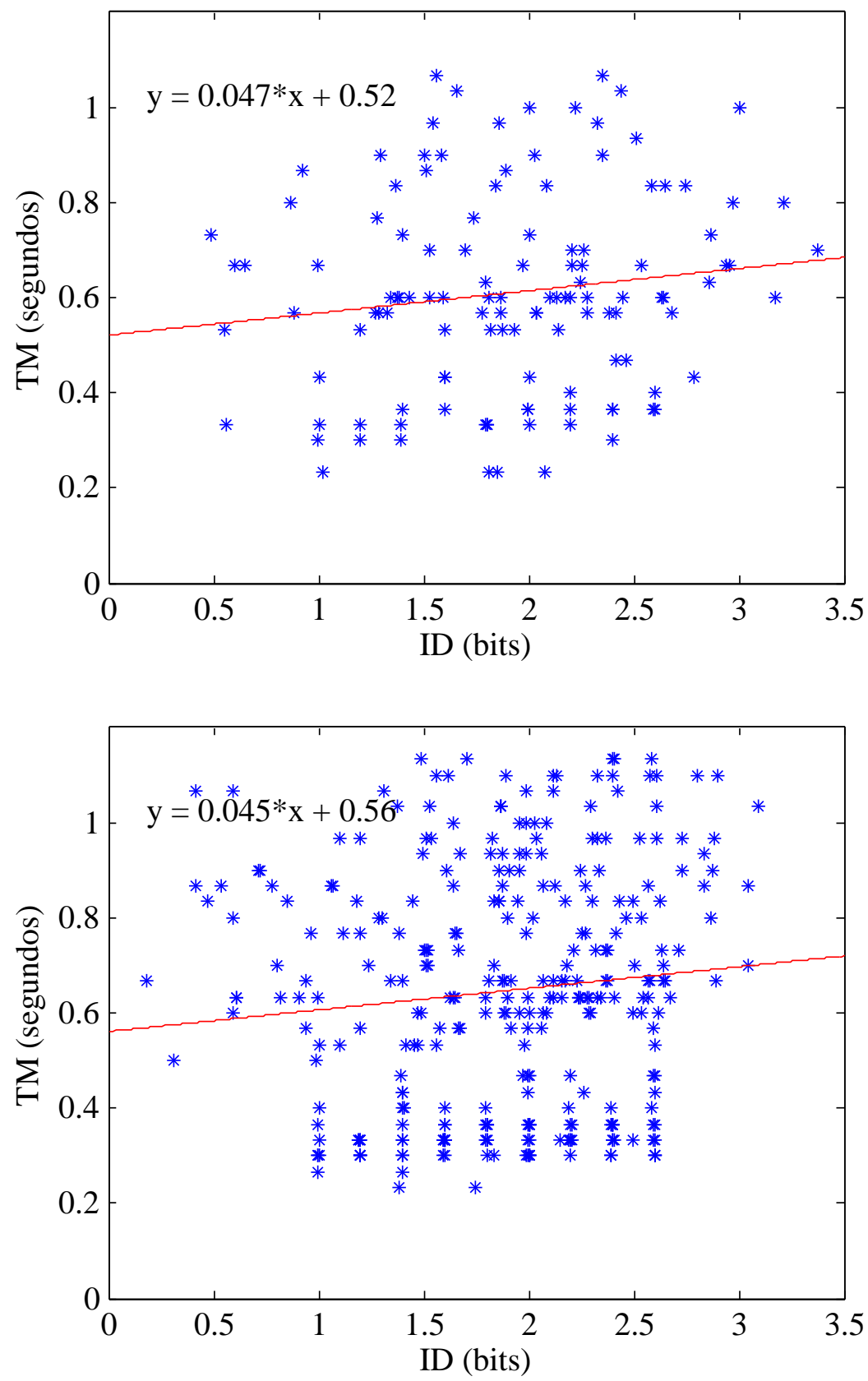

Figura 5.9: Índice de dificultad (ID, en bits) vs. T2 (en segundos), de los participantes con PC (arriba) y sin PC (abajo). 


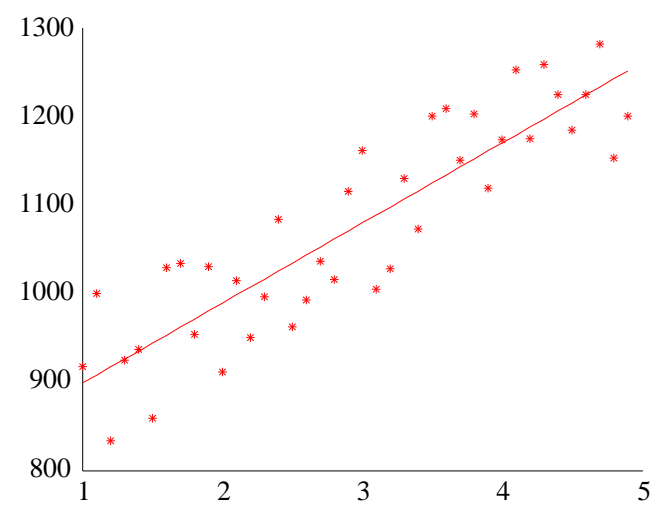

(a)

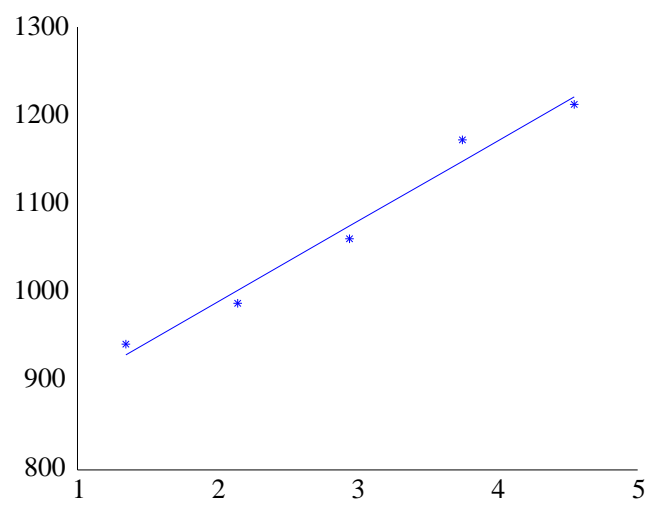

(b)

Figura 5.10: Gráfico típico de puntos TM en función de ID. (a) Representación de 40 puntos con su recta de regresión lineal en rojo. (b) Representación de 5 puntos con su recta de regresión lineal, en azul.

lineal de estos datos. Para este caso, el valor $R^{2}=0,65$, que se ha calculado a partir de 40 puntos $[T M, I D]$. Si reducimos el número de puntos $[T M, I D]$ a 5 valores, obtenemos la curva de la Figura 5.10b, cuya curva de regresión está dada por la Ecuación (5.12). Sin embargo, en este caso, $R^{2}=0,94$, mucho más alto que en el primer caso. La diferencia entre ambos casos es el número de puntos a partir del cual se calculó la regresión.

Con un número menor de puntos el valor $R^{2}$ es mucho mejor. Esto no es sorprendente, ya que con sólo dos puntos la recta de regresión encajaría perfectamente. Esto significa que la correlación por sí sola, sin indicar el número de datos a partir del cual se calcula, no refleja adecuadamente lo bien que los datos se ajustan a la ley de Fitts.

$$
\begin{gathered}
T M_{\text {continuo }}=82,71 * I D_{n=40}+716,63, R^{2}=0,65, n=40 \\
T M_{\text {discreto }}=73,86 * I D_{n=5}+846,38, R^{2}=0,94, n=5
\end{gathered}
$$

Fitts utiliza un conjunto discreto de valores como índice de dificultad [70]. La razón de esto radica en la configuración mecánica de los experimentos de Fitts, con rayas metálicas de tamaños discretos, como se ve en la Figura 5.11. Los experimentos con un ratón de ordenador o con un eye-tracker permiten valores arbitrarios para los tamaños de los objetos en pantalla y la amplitud del movimiento y se pueden proporcionar datos en una escala prácticamente continua.

Sin embargo, las publicaciones sobre la ley de Fitts con dispositivos señaladores o apuntadores presentan también conjuntos discretos para el $I D$, por lo general para cuatro tamaños de objeto en pantalla y cuatro amplitudes de movimiento resultantes en siete valores diferentes de $I D$, como en [38]. La razón parece estar en que los valores de correlación tienen mejor apariencia cuando primero se promedia el tiempo TM para ciertos rangos de $I D$ y luego se calcula la línea de regresión con los tiempos medios.

Esto sin embargo es peligroso. Existen muchos conjuntos de datos que pueden dar como resultado el conjunto de puntos de la Figura 5.10b. El cálculo con datos promediados pierde la información de la varianza. 


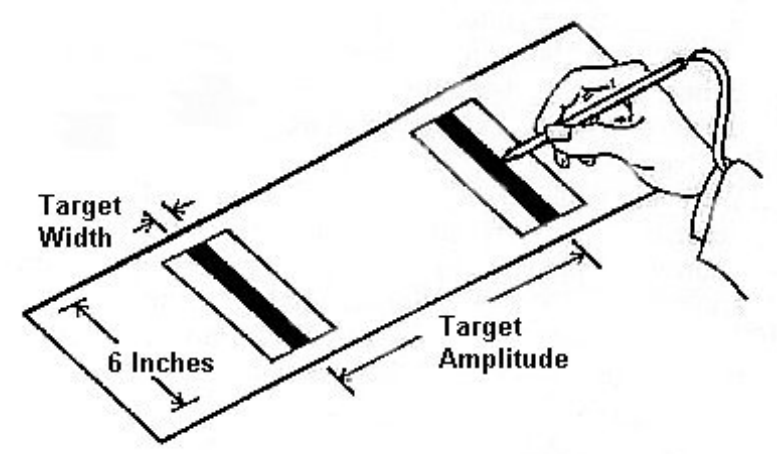

Figura 5.11: Configuración mecánica de los experimentos de Fitts, con rayas metálicas de tamaños discretos.

Por ambos motivos, en este estudio, los valores $T M$ no se han promediado ni tampoco se ha utilizado un rango discreto de valores $I D$. Es posible que este sea el motivo del bajo valor de $R^{2}$.

\section{Ancho del objeto para el ojo}

Otro tema que no ha sido rigurosamente discutido por la comunidad de HCI es cuál es el ancho del objeto en pantalla para el ojo. ¿El ojo se acerca más rápido a un objeto en pantalla más grande que a uno más pequeño? Si este fuera el caso, el ojo humano debería distinguir el tamaño del objeto antes de realizar el salto hacia éste. Sin embargo, sabemos que el ojo humano tiene una zona de alta resolución, la zona foveal, Sección 3.1. Cuando un objeto está fuera de esa zona el ojo se mueve para identificar el objeto, por lo que antes del salto no tiene información precisa de cómo es el objeto - como ya hemos señalado antes, este es de hecho el motivo por el cual se produce el movimiento sacádico- - Por lo tanto, el objeto no se conoce antes del salto sacádico. ¿Distingue el ojo humano el tamaño del objeto durante la sacada? Durante un movimiento sacádico no se procesan las imágenes del ojo (supresión sacádica [102]), luego no es durante la sacada donde se aclara el tamaño del objeto. ¿Sabemos el tamaño del objeto al terminar la sacada? Si esta fuera la respuesta, el tiempo de acercamiento a un objeto sería independiente de su tamaño.

Otra cuestión es si somos o no capaces de controlar los movimientos sacádicos, hacerlos más lentos o más rápidos. En la Figura 5.12 se puede ver la respuesta dinámica del ojo de dos de sus propiedades: la velocidad pico y la duración del movimiento [6]. En la Figura de la derecha se ve que, a partir de una cierta amplitud, existe una relación lineal entre la amplitud y el tiempo.

Todas estas preguntas están abiertas y afectan en gran medida a la aplicabilidad de la ley de Fitts a la interacción con el ordenador mediante movimientos oculares.

\section{Otros estudios}

Nos parece muy interesante el trabajo realizado por Vertegaal et al. [103], donde compararon un eye-tracker con otros canales de acceso manuales. Su estudio presenta un valor de $R^{2}=0,86$ entre el índice de dificultad y el tiempo de movimiento cuando el cursor lo controla el eye-tracker con clic por permanencia, igual que nuestro estudio. El artículo 

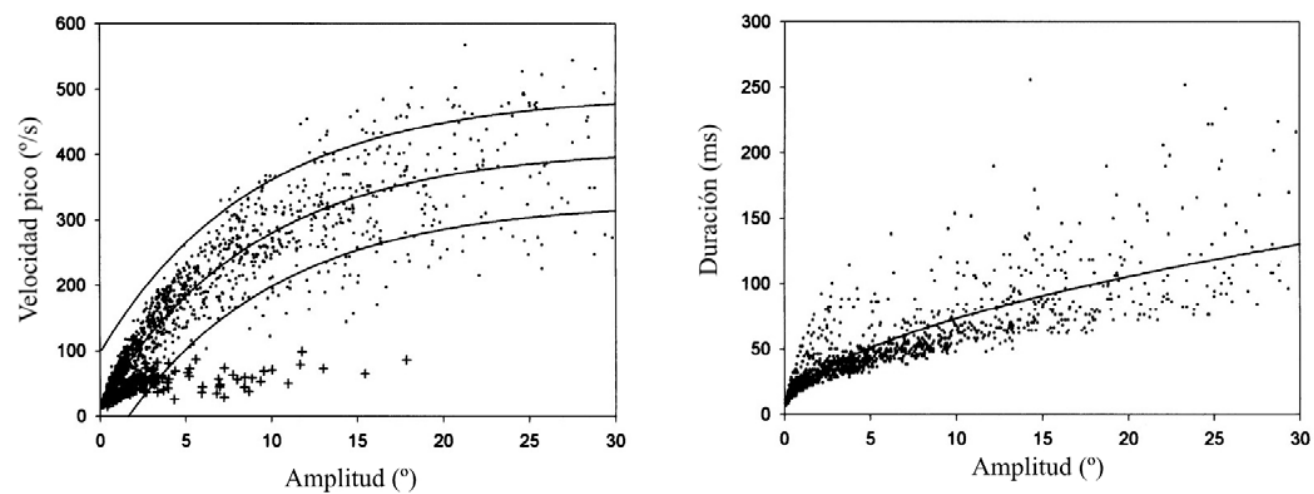

Figura 5.12: Propiedades dinámicas de un movimiento sacádico. Velocidad pico (izquierda) y duración (derecha) de movimientos sacádicos en función de la amplitud del movimiento, [6].

muestra una diferencia de aproximadamente 0,055 segundos/bits entre los índices de dificultad 1,3 y 3,7 bits, en contraste con nuestros resultados: 0, 0014 segundos/bits y 0,00021 segundos/bits para los participantes con y sin PC, respectivamente. En ninguno de los dos casos vemos este alto nivel de correlación. Vertegaal también mostró resultados positivos con un ratón y con un lápiz óptico. Consideraron 100ms como el tiempo necesario para realizar un clic. Este tiempo es demasiado bajo para usos prácticos e incluso es inferior a la duración de una fijación normal (típicamente 100-200 ms) [39]. Este tiempo suele estar en el orden de segundos ([104], [105], [106]).

Otro estudio interesante fue el presentado por Kim et al. [107], donde encontraron $R^{2}=$ $0,94(p<0,05)$. En este caso, el tiempo de permanencia se fijó en 1 segundo. El rango de TM medido fue entre 2,8 y 3,5 segundos aproximadamente, lo que es curioso porque es muy grande (de 1,8 a 2,5 segundos para alcanzar el objetivo y 1 segundo para hacer clic). Se incluyeron clics erróneos, que puede ser la razón de estos altos valores en $R^{2}$.

Tuisku et al. desarrollaron dos estudios para investigar la funcionalidad de un nuevo prototipo inalámbrico llamado Face Interface [108, 109], que combina el uso de la dirección de la mirada con las activaciones del músculo facial. Los cálculos de la ley de Fitts mostraron que las correlaciones para el modelo de ley de Fitts fueron $r=0,76$ $(p<0,05)$, en el caso del tiempo de permanencia establecido en $400 \mathrm{~ms}$, con una relación de 0,098 segundos/bits.

Una limitación de nuestro estudio fue el número reducido de participantes. Sin embargo, este número estuvo cerca de trabajos similares publicados en la literatura: un usuario en [110], siete usuarios en [111] y siete usuarios en [112]. La razón que nos impidió reclutar un número mayor de pacientes fueron nuestros criterios de inclusión, que fueron muy estrictos. Esto nos permitió extraer información más fiable en el estudio, evitando que problemas oculares o cognitivos interfirieran en los resultados, a expensas de reducir el número de sujetos que podrían participar en los experimentos.

El tiempo de movimiento TO incluye el tiempo de permanencia y el retardo de tiempo entre clics consecutivos. En principio, también se podría probar el análisis de T0 sin estos tiempos adicionales también podría ser probado. Sin embargo, esto no cambiaría los resultados, ya que ambos tiempos adicionales son un par de constantes. El restar a todos los tiempos registrados TO una constante no cambiaría la pendiente de la curva, que es la principal evidencia de una relación lineal. Por lo tanto, el resultado obtenido es igualmente válido. 


\subsubsection{Conclusión de la Evaluación II}

Estamos explorando activamente cómo evaluar mejor los eye-trackers cuando los participantes son personas con discapacidad. Tenemos la intención de proporcionar una metodología más estandarizada y métricas relevantes sobre el desempeño de los eyetrackers cuando se utiliza como un canal de acceso alternativo a la computadora por personas con parálisis cerebral.

Este capítulo proporciona un procedimiento consistente para evaluar la ley de Fitts con participantes de parálisis cerebral mientras utilizan eye-trackers. La validación se realizó con nueve personas con parálisis cerebral y siete personas sin discapacidad, tratando de responder la pregunta de si se cumple la ley de Fitts en el caso de las interfaces gráficas controladas mediante eye-trackers y clic por permanencia. Esta ley establece que existe una relación lineal entre el índice de dificultad $(I D)$ y el tiempo que se tarda en alcanzar un objeto en pantalla, llamado tiempo de movimientos $(T M)$. Se consideraron tres tipos de $T M$ : el tiempo para hacer clic en el objetivo $(T 0)$, el tiempo que tardan los ojos para iniciar el movimiento (T1) y el tiempo que tardan en detenerse T2).

De acuerdo a nuestros resultados, podemos ver que el análisis no proporciona suficiente información para rechazar la hipótesis nula de la independencia entre el tiempo de movimiento $T M$ y el índice de dificultad $I D$ en ninguno de los tres casos T0, T1, y T2. Además, el coeficiente de determinación fue bajo en todos los casos $\left(R^{2}<0,95\right)$. Esto indica que la ley de Fitts no parece cumplirse en este caso, con lo que sería necesario diseñar otras funciones de usabilidad, concebidas especialmente para eye-trackers y clic por permanencia, y que permitan evaluar la interacción de usuarios e interfaces.

\subsection{Evaluación III: Tasa de error y tiempo de clic con dos técnicas de clic}

En la Sección 5.1 anterior hemos evaluado dos métricas, la precisión y la veracidad, para personas sin discapacidad que miraban a círculos en la pantalla sin ningún tipo de restricción respecto a los movimientos de la cabeza. Esta evaluación estuvo centrada en el dispositivo que servía de interfaz, el ET. En esta sección evaluaremos otra metodología, orientada a medir la interacción de personas con PC. Para ello utilizaremos dos métricas, la tasa de error y el tiempo de clic, mientras realizan clic por parpadeos y por permanencia. Intentaremos además responder a la pregunta de cuál de estas dos técnicas es mejor para esta población.

\subsubsection{Protocolo del test}

Los usuarios controlaron el cursor del ordenador mediante la mirada. Se les pidió a todos que realizaran un clic sobre la figura que apareció en la pantalla, en 10 posiciones aleatorias. Cuando los participantes realizaban un clic, la figura de la pantalla cambiaba de posición. El primer objeto en pantalla aparecía siempre en alguna de las cuatro esquinas de la pantalla, a 100 píxeles del borde.

Las distintas posiciones y tamaños de las figuras en pantalla se eligieron de manera que se realizaran tareas con índices de dificultades $I D$ discretos (Ecuación 4.9 de la Sección 4.1.2), establecidos entre 1,00 y 2,60 bits, en pasos de 0,20 bits. Para ello, la amplitud entre las figuras consecutivas y sus respectivos tamaños fueron pre-establecidos de 


\begin{tabular}{llllll}
\hline Orden & ID (bits) & $\mathbf{A}(\mathbf{p i x})$ & $\mathbf{A}(\mathbf{c m})$ & $\mathbf{W}(\mathbf{p i x})$ & $\mathbf{W}(\mathbf{c m})$ \\
\hline $1^{\circ}$ & 1,4 & 327 & 9,6 & 200 & 5,9 \\
$2^{\circ}$ & 1,6 & 325 & 9,6 & 160 & 4,7 \\
$3^{\circ}$ & 2,6 & 505 & 14,9 & 100 & 2,9 \\
$4^{\circ}$ & 1,2 & 207 & 6,1 & 160 & 4,7 \\
$5^{\circ}$ & 2,2 & 575 & 16,9 & 160 & 4,7 \\
$6^{\circ}$ & 2,0 & 600 & 17,6 & 200 & 5,9 \\
$7^{\circ}$ & 2,4 & 427 & 12,6 & 100 & 2,9 \\
$8^{\circ}$ & 1,0 & 200 & 5,9 & 200 & 5,9 \\
$9^{\circ}$ & 1,8 & 248 & 7,3 & 100 & 2,9 \\
\hline Min & 1,0 & 200 & 5,9 & 100 & 2,9 \\
Max & 2,6 & 600 & 17,6 & 200 & 5,9 \\
\hline
\end{tabular}

Tabla 5.7: Secuencia de los índices de dificultad $I D$, distribuidos al azar, con las amplitudes de movimiento $A$ (en $\mathrm{cm}$ y píxeles) y tamaños de las figuras en pantalla $W$ (en $\mathrm{cm}$ y píxeles) necesarios para generar el $I D$ correspondiente.

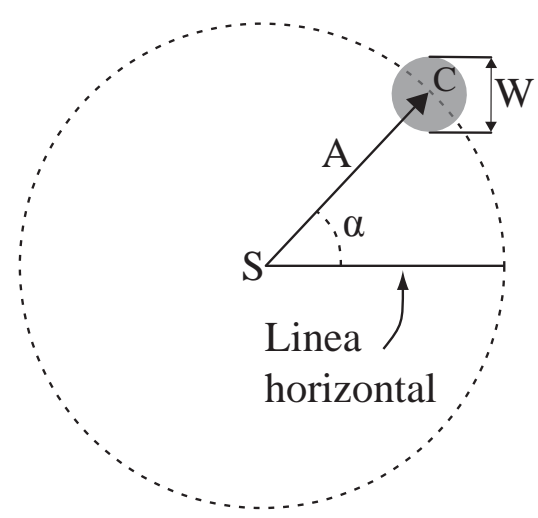

Figura 5.13: Representación gráfica de los parámetros amplitud de movimiento (A) y tamaño del objeto en pantalla (W) de una tarea de alcance a un objetivo, los cuales definen el índice de dificultad según la Ley de Fitts. Además, se representa el eje de la tarea como la línea que une los puntos $\mathrm{S}$ y $\mathrm{C}$, y el ángulo de aparición del objetivo con respecto a la horizontal $a$, establecido aleatoriamente en tiempo de ejecución.

antemano, con la intención de controlar la $A$ y la $W$ de la Ecuación 4.9. Los parámetros de las tareas pueden verse en la Tabla 5.7. Se ha decidido seguir este enfoque con el objetivo de simular tareas con dificultad similares a las que nos encontramos habitualmente. Aunque los tamaños y la separación de las figuras en pantalla fueron pre-establecidos, el ángulo de aparición $\alpha$ fue seleccionado aleatoriamente, en tiempo de ejecución (mientras se hacían los ensayos), lo que permitió garantizar la aleatoriedad de las posiciones entre figuras consecutivas, Figura 5.13.

El clic se realizó de dos maneras: mediante un parpadeo o mediante permanencia del cursor. Se consideraba que se había producido un clic por permanencia si se cumplía la siguiente relación: La dispersión de las posiciones del cursor sobre ambos ejes horizontal y vertical era menor a un umbral pre-establecido de $2 \mathrm{~cm}$, durante $1 \mathrm{~s}$ [113]. Ambos valores fueron sugerencia de los especialistas, sobre la base de sus experiencias. Para el caso del clic por parpadeo, se consideraba que se producía un clic cuando la duración del parpadeo era mayor a $250 \mathrm{~ms}$ y menor a $750 \mathrm{~ms}$. Una vez que se realizaba un clic, para 
volver a realizar otro clic debía pasar al menos $1 \mathrm{~s}$ (para evitar múltiples clics una vez se cumplía la condición de clic). Si el clic era realizado dentro del objeto (tarea correcta) se pasaba al siguiente objeto. Sin embargo, si el clic se realizaba fuera del objeto (tarea fallida) el usuario tenía otras dos oportunidades de realizar el clic en el mismo objetivo. $\mathrm{Al}$ tercer intento se pasaba al siguiente objetivo independientemente de si el clic se hacia dentro o fuera del objetivo en pantalla. Esto evita que los usuarios pierdan la motivación si no consiguen realizar clic dentro de un objetivo.

Los participantes recibieron estímulos de realimentación sensorial durante las tareas, según los consejos de Majaranta, [114]. Los clics dentro y fuera del objeto en pantalla fueron animados con dos tipos de sonidos diferentes, como realimentación para el usuario. Además, el usuario vio el cursor mientras lo controlaba.

Antes de realizar las pruebas se realizó la calibración del eye-tracker. La calibración consistió en mirar 5 figuras cuyo orden de aparición era aleatorio, pero cuyas posiciones fueron deterministas: en las 4 esquinas y en el centro de la pantalla.

Se puede observar un vídeo del protocolo del test en ${ }^{5}$.

\subsubsection{Equipos}

Para los ensayos se ha utilizado el mismo eye-tracker, equipo de sobremesa y pantalla de la evaluación presentada en la Sección 5.1. Para el control de los estímulos visuales, del cursor mediante el ET, del clic, y para la grabación de datos se desarrolló un software. El software ha sido desarrollado sobre la plataforma .NET. en el lenguaje C\# en el entorno de desarrollo Visual Studio.

El software desarrollado filtró los datos que provenían del ET y localizó el cursor en el punto donde el participante estaba mirando. El filtro utilizado para este experimento fue el filtro de medianas, aplicado a cada eje independientemente. Este filtro responde rápidamente a los movimientos del ojo, introduciendo poco retardo en el control del cursor.

\subsubsection{Participantes}

Hemos incluido en el estudio sólo a usuarios sin problemas de audición, con capacidad visual suficiente para identificar objetos en toda la pantalla del ordenador, con un tamaño mínimo de $1 \mathrm{~cm}$ a una distancia de $60 \mathrm{~cm}$ de la pantalla. La utilización de gafas o de lentes de contacto no ha sido un criterio de exclusión, ya que se no observó problema alguno en las pruebas realizadas por usuarios sin discapacidad. Por otro lado, se reclutaron solamente usuarios con una capacidad cognitiva suficiente para seguir las instrucciones del terapeuta y que permita mantener la atención en una tarea un mínimo de 15 minutos.

Con estos criterios, se reclutaron seis usuarios con PC, del centro de día ASPACE Cantabria, Tabla 5.8, con una edad media de 30 años $( \pm 5,7)$. Todos los participantes están clasificados con el nivel MACS [13, 99] o GMFCS [15] IV o V, que son los grados más severos de la escala. El nivel IV de la escala MACS implica que el usuario maneja un grupo limitado de objetos en situaciones y niveles adaptados y el nivel V que no maneja objetos y que tiene una habilidad muy limitada para realizar incluso acciones simples. Estos severos niveles de discapacidad son el principal motivo para la utilización de interfaces

\footnotetext{
${ }^{5}$ https://youtu.be/o_QtapwKhH4
} 


\begin{tabular}{llllll}
\hline Grupo & Usuario & MACS & GMFCS & Sexo & Edad \\
\hline Usuarios con PC & & & & & \\
& US01 & 4 & 5 & $\mathrm{M}$ & 33 \\
& $\mathrm{US02}$ & 5 & 4 & $\mathrm{M}$ & 39 \\
& $\mathrm{US03}$ & 5 & 4 & $\mathrm{M}$ & 24 \\
& $\mathrm{US04}$ & 4 & 5 & $\mathrm{~F}$ & 31 \\
& $\mathrm{US06}$ & 5 & 4 & $\mathrm{M}$ & 30 \\
& $\mathrm{US07}$ & 5 & 4 & $\mathrm{M}$ & 24 \\
\hline Usuarios sin PC & & & & & \\
& $\mathrm{US08}$ & & & $\mathrm{M}$ & 35 \\
& $\mathrm{US09}$ & & & $\mathrm{F}$ & 32 \\
& $\mathrm{US} 10$ & & $\mathrm{M}$ & 29 \\
& $\mathrm{US} 11$ & & $\mathrm{M}$ & 34 \\
\hline
\end{tabular}

Tabla 5.8: Perfil de los seis participantes con PC reclutados para las pruebas y los cuatro participantes del grupo de control.

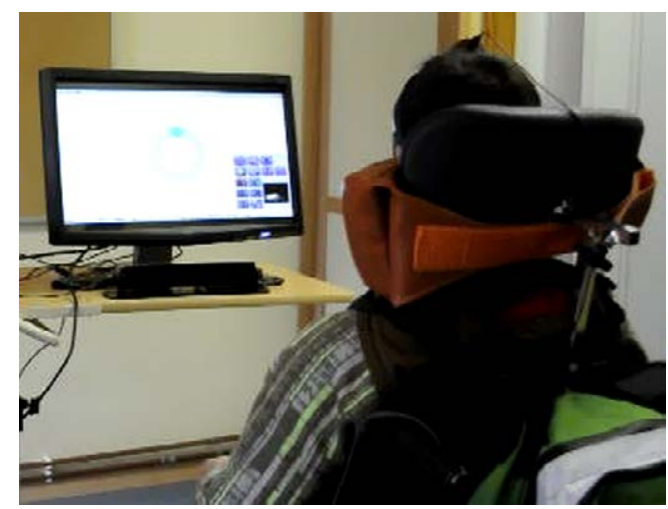

Figura 5.14: Captura de un momento de una sesión. El participante con PC está frente a la pantalla de la computadora y el ET (debajo de la pantalla).

del tipo seguidores de la mirada. Durante los ensayos personal de apoyo especializado han acompañado el experimento. Además, se han realizado ensayos con cuatro usuarios sin discapacidad, con una edad media de 32 años $( \pm 2,6)$. Ambos grupos han realizado las mismas tareas.

Los participantes con PC estuvieron acompañados por un terapeuta, de manera que éste se sintiese apoyado por alguien familiar durante los ensayos. Se ha tenido especial cuidado de que los usuarios estuvieran en el rango de visión del ET durante la prueba. Todos los participantes se localizaron a la distancia óptima del ET (aproximadamente $60 \mathrm{~cm}$ ), a la altura del centro de la pantalla, lo que garantiza las mejores medidas. La rutina de acomodación de los participantes incluía mover al participante, a la pantalla y al ET. La Figura 5.14 ilustra la disposición de un usuario durante la prueba.

\subsubsection{Procesamiento de datos}

Para la comparación de las estrategias de clic se utilizó la tasa de error y el tiempo de clic. La tasa de error es igual a la relación entre la cantidad de tareas falladas y la 


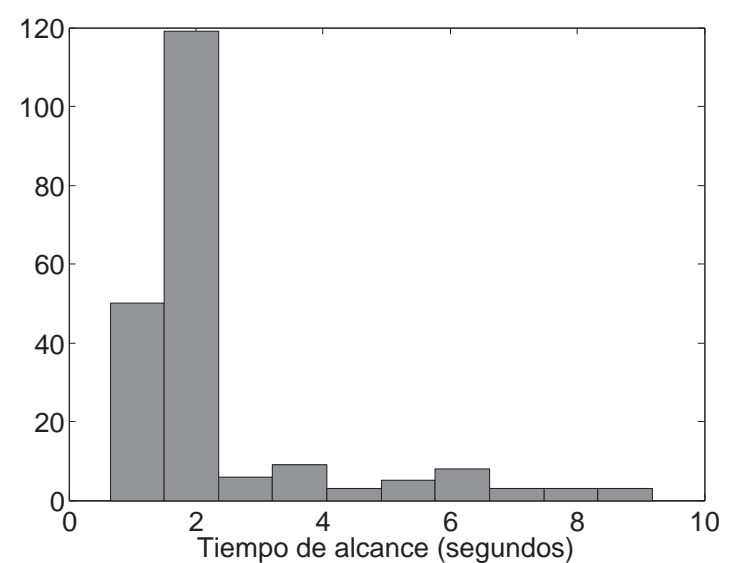

(a) Sin PC

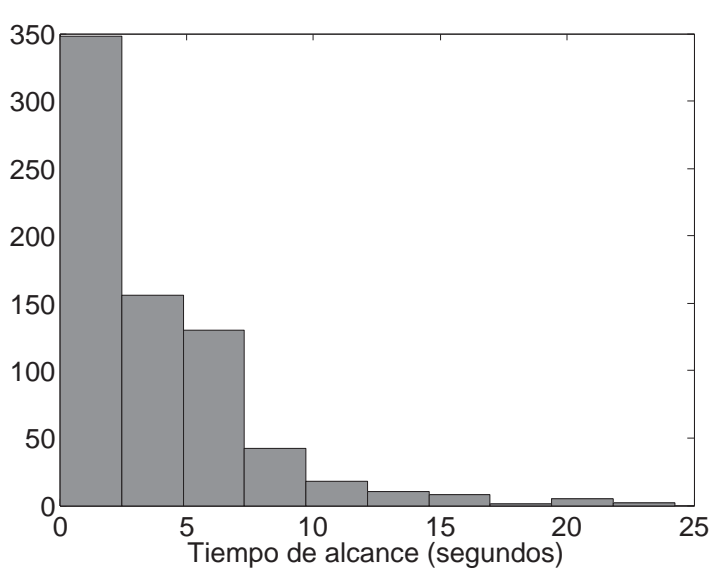

(b) Con PC

Figura 5.15: Histograma de los tiempos de clic de los usuarios sin PC (a) y con PC (b) luego de haber extraído los outliers.

cantidad de tareas en total. El tiempo de clic es el tiempo transcurrido entre el momento en el que aparece la figura en la pantalla y el momento en el que el usuario realiza un clic.

Para el procesamiento de datos se ha realizado el siguiente procedimiento: (1) extracción de outliers, (2) cálculo del tiempo de clic, (3) cálculo de la tasa de error. El primer clic no se incluye en el análisis ya que no se controló la posición inicial de la mirada.

Las tareas de alcance se consideraron outliers si el tiempo de clic fue mayor a un umbral. Este umbral se estableció analizando todos los tiempos de clic de cada grupo de usuarios. Se consideró outlier a una tarea de apuntamiento cuyo tiempo de clic fue mayor a 2 veces la desviación estándar de todos los tiempos de clic de todas las tareas, del grupo al que corresponde. Supusimos que en una tarea muy larga el usuario ha perdido la atención o se ha distraído. Además, supusimos que los umbrales para personas con PC no sería el mismo que para personas sin discapacidad.

\subsubsection{Resultados}

Se han descartado las tareas con un tiempo de clic mayor a $25,71 \mathrm{~s}( \pm 12,86 \mathrm{~s})$ en el caso de los usuarios con PC. Estas tareas representan el 2,06\% del total de tareas. Para el caso de los usuarios sin PC, el umbral ha sido igual a $9,96 \mathrm{~s}( \pm 4,98 \mathrm{~s})$, lo cual representa un 1,88\% del total de tareas. En la Figura 5.15a y en la Figura 5.15b se pueden observar los histogramas de los tiempos de clic una vez que fueron extraídos los outliers, para el caso de los usuarios sin y con PC respectivamente.

Después de la eliminación de los registros outliers, tenemos los siguientes datos. En promedio los usuarios sin PC han realizado 47 tareas de clic cada uno. Por otro lado, los usuarios con PC han realizado 111 tareas de alcance por usuario, más del doble. Más datos sobre el número de tareas de cada grupo de participantes se puede ver en la Tabla 5.9 .

En cuanto al tiempo de clic, véase la Tabla 5.10, los resultados nos indican que existe una ligera diferencia entre los tiempos de clic medio para las tareas realizadas por los participantes sin $\mathrm{PC}$, de alrededor de $0,2 \mathrm{~s}$, siendo el clic por parpadeo más rápido que 


\begin{tabular}{lllll}
\hline Grupo & Usuario & Parpadeo & Permanencia & Total \\
\hline Usuarios sin PC & & & & \\
& US08 & 19 & 50 & 69 \\
& US09 & 19 & 20 & 39 \\
& US10 & 19 & 20 & 39 \\
& US11 & 20 & 22 & 42 \\
& Total & 77 & 112 & 189 \\
& Media (Std) & $19( \pm 0,5)$ & $28( \pm 14)$ & $47( \pm 14)$ \\
\hline Usuarios con PC & & & & \\
& US07 & 29 & 107 & 136 \\
& US01 & 32 & 166 & 198 \\
& US03 & 17 & 9 & 26 \\
& US02 & 49 & 50 & 107 \\
& US06 & 57 & 50 & 100 \\
& US04 & 21 & 79 & 666 \\
& Total & 205 & 461 & $111( \pm 56)$ \\
\hline
\end{tabular}

Tabla 5.9: Número de tareas por cada usuario sin PC y con PC, según el tipo de clic.

el clic por permanencia, aunque la diferencia no es significativa. Por otro lado, para los usuarios con $\mathrm{PC}$ se observa que las tareas se realizan más rápido con el clic por permanencia (3,8 s contra $6,2 \mathrm{~s})$. Esta diferencia del $39 \%$ nos permite afirmar que el clic por permanencia es más veloz, al contrario de lo que sucede con las personas sin PC.

En cuanto a la tasa de error, no existe una diferencia significativa entre ambos tipos de clic ni para los usuarios sin PC (ambos tienen una tasa de error del $10 \%$ ) ni para el caso de los usuarios con PC (45\% y $47 \%$ para cada caso respectivamente), Tabla 5.11. En la Figura 5.16 se pueden ver las tasas de error para cada usuario. En particular se han agrupado a los usuarios con PC en función de si tienen menor tasa de error con el clic por parpadeo o por permanencia. Existe una ligera tendencia, la cual indica que los usuarios que tienen mayor tasa de error globalmente son mejores con el clic por parpadeo y que los usuarios con menor tasa de error global son mejores con el clic por permanencia.

\subsubsection{Discusión}

En esta sección presentamos una metodología de evaluación de la interacción de usuarios con PC mientras éstos utilizan un ET para controlar el ordenador. En particular, hemos evaluado dos técnicas de diálogo ${ }^{6}$ : clic por permanencia y por parpadeo.

Nuestros resultados indican que los usuarios sin PC no realizan el clic dentro del objetivo 1 de cada 10 veces y que los usuarios con PC no lo hacen 1 de cada 2 veces. Estos resultados son iguales para ambas técnicas de clic. Además, los usuarios realizan el clic un $40 \%$ más veloz con una técnica que con otra, la de permanencia sobre la de parpadeo. Estos datos aclaran más la calidad de la interacción con el ordenador que la precisión y veracidad utilizadas en la evaluación presentada en la sección anterior, la Sección 5.1.

\footnotetext{
${ }^{6}$ En la Sección 2.1 se mencionan las técnicas de diálogo dentro del contexto de la interacción hombrecomputador)
} 


\begin{tabular}{llll}
\hline Grupo & Usuario & Parpadeo (s) & Permanencia (s) \\
\hline Usuarios sin PC & & & \\
& US08 & $2,9( \pm 2,2)$ & $2,6( \pm 1,4)$ \\
& US09 & $3,5( \pm 2,1)$ & $2,5( \pm 1,2)$ \\
& US10 & $1,2( \pm 0,3)$ & $1,9( \pm 0,1)$ \\
& US11 & $1,6( \pm 1,7)$ & $2,9( \pm 2,3)$ \\
& Media (Std) & $2,3( \pm 1,1)$ & $2,5( \pm 0,4)$ \\
\hline Usuarios con PC & & & \\
& US07 & $8,6( \pm 6,3)$ & $4,3( \pm 3,2)$ \\
& US01 & $6,8( \pm 5,1)$ & $4,3( \pm 2,3)$ \\
& US03 & $5,8( \pm 3,9)$ & $7,2( \pm 4,8)$ \\
& US02 & $3,6( \pm 2,1)$ & $2,2( \pm 0,9)$ \\
& US06 & $3,3( \pm 2,7)$ & $1,6( \pm 0,6)$ \\
& US04 & $9,4( \pm 5,1)$ & $3,1( \pm 1,8)$ \\
& Media (Std) & $6,2( \pm 2,5)$ & $3,8( \pm 2,0)$ \\
\hline
\end{tabular}

Tabla 5.10: Tiempo de clic medio y desviación estándar por cada usuario sin PC y con PC, según el tipo de clic.

\begin{tabular}{llll}
\hline Grupo & Usuario & Parpadeo (\%) & Permanencia (\%) \\
\hline Usuarios sin PC & & & \\
& US08 & 21 & 20 \\
& US09 & 11 & 15 \\
& US10 & 0 & 0 \\
& US11 & 10 & 5 \\
& Media (Std) & $10( \pm 9)$ & $10( \pm 9)$ \\
\hline Usuarios con PC & & & \\
& US07 & 38 & 51 \\
& US01 & 38 & 77 \\
& US03 & 82 & 100 \\
& US02 & 20 & 10 \\
& US06 & 39 & 34 \\
& US04 & 52 & $47( \pm 36)$ \\
\hline
\end{tabular}

Tabla 5.11: Tasa de error de los usuarios sin PC y con PC, según el tipo de clic. 


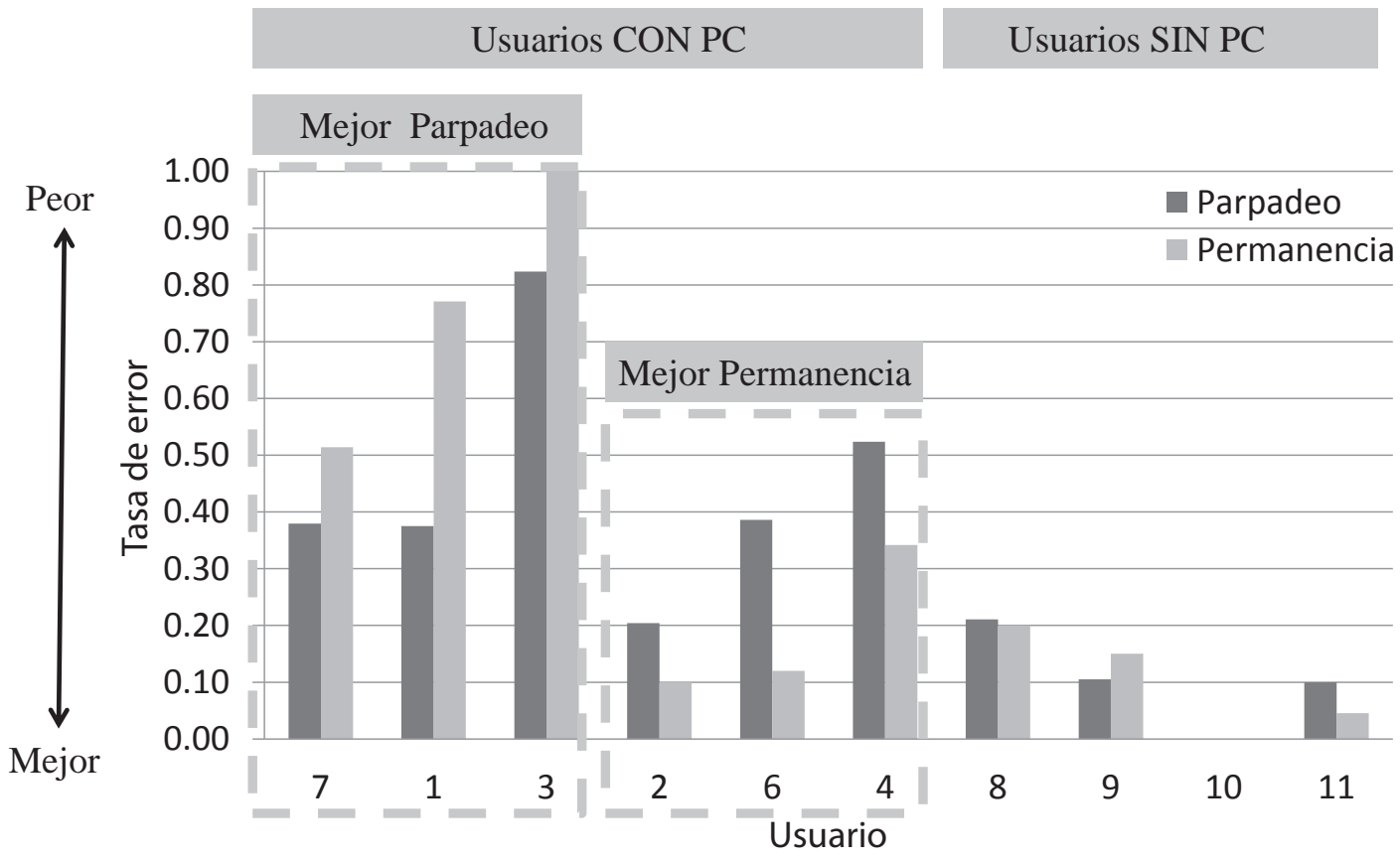

Figura 5.16: Tasas de error de los usuarios, con ambos tipos de clic. Los usuarios han sido agrupados según tengan mejor resultado con uno u otro tipo de clic.

Todos los usuarios con PC estaban familiarizados con la técnica de clic por permanencia en el momento del ensayo. Ya se habían realizado tareas (con otros instrumentos) con este tipo de clic. Por otro lado, el clic por parpadeo no era una técnica conocida por ningún usuario de ambos grupos. Es posible que con entrenamiento mejoren los resultados del clic por parpadeo. Sin embargo, se ha observado que el exigir a los usuarios con PC realizar tareas con un doble control (mirada para posición y parpadeo para clic) desencadena en muchos de ellos movimientos involuntarios no coordinados. Es posible que las exigencias de un control doble resulte ser una tarea muy compleja para este grupo.

\subsubsection{Conclusión de la Evaluación III}

Esta sección presentó una metodología para la valoración de la interacción entre usuarios con PC y sin PC y el ordenador, mediante un eye-tracker. Nuestro enfoque fue diferente al estudio presentado en la sección anterior, ya que nos centramos principalmente en medir, mediante la tasa de error y el tiempo de clic, como fue la calidad para realizar tareas básicas de apuntamiento a objetos en pantalla. En particular, analizamos dos estrategias de clic: por permanencia y por parpadeo. Nuestros resultados nos indican que: $10 \%$ de las tareas de apuntamiento de los usuarios sin PC se realizan fuera del objetivo, con ambas técnicas, y que la tasa de error de los usuarios con PC es cercana al $50 \%$, también con ambas técnicas. Aunque ambos métodos proporcionan tasas de error similares en promedio para cada grupo, se observó que el tiempo de clic es bastante menor con el clic por permanencia que con el clic por parpadeo. Todos estos datos no los podemos apreciar con las medidas que los fabricantes nos ofrecen de sus dispositivos, principalmente porque nos dan una medida de la calidad del dispositivo y no de la interacción. La evaluación presentada no redujo ni eliminó ninguno de los elementos del complejo sistema que se establece cuando se produce la interacción hombre-computador. 
Capítulo 5. Metodología de evaluación de la interacción

En este sentido, nuestras medidas son un reflejo más realista de lo que un usuario percibiría efectivamente si estuviese controlando un ordenador mediante los ojos.

\subsection{Evaluación IV: Fallos en la calibración de tres eye- trackers}

En la discusión de la primera Sección (página 64) comentamos que la veracidad no se puede reducir mediante técnicas de filtrado, debido a que tiene relación con la calibración, la cual calcula la relación entre la posición de la mirada y un objeto en pantalla con una posición conocida. Una mala calibración arrojará una mala veracidad de las estimaciones del ET. En la Sección anterior, donde estudiamos la interacción de usuarios con PC, nos encontramos con una alta tasa de fallos en el clic. Entonces nos quedó la pregunta de: ¿será una mala calibración la fuente de tan alta tasas de error en el clic?

En esta sección estudiamos la tasa de fallos en la calibración y la incluimos como métrica de evaluación. Nuestra hipótesis fue que esta medida dará información adicional de cómo es la interacción con el ordenador. Se utilizaron en total tres métricas de evaluación fueron utilizadas: las dos previamente utilizadas, tasa de error del clic y tiempo de clic, y una nueva, la tasa de fallos de calibración. Para calcular la tasa de error del clic esta vez solo utilizamos las tareas de apuntamiento con una buena calibración.

Validamos la metodología, comparando tres eye-trackers, con nueve participantes con PC con trastornos motores severos. Los resultados indican que la calibración es un proceso crítico en estos escenarios, como refleja la alta tasa medida de fallos de calibración. Los participantes con PC también tienen una alta tasa de error del clic, lo que indica que el uso de eye-trackers para alcanzar un objeto en pantalla es un proceso complejo para estos niveles de discapacidad motriz, confirmando los resultados previamente presentados, incluso con una buena calibración. Los tiempos de clics son similares entre todos los eye-trackers y participantes.

\subsubsection{Protocolo, equipos y participantes}

El protocolo, los equipos y los participantes reclutados son los mismos de la Sección 5.2 El procesamiento de datos cambia en ciertos aspectos, y se explica detalladamente a continuación.

\subsubsection{Procesamiento de datos}

Hemos definido tres métricas de comparación: tasa de fallos de calibración, tasa de error del clic y tiempo de clic. Estas dos últimas métricas ya fueron utilizadas en el protocolo anterior, Sección 5.3.1. La tasa de fallos de calibración es la relación entre el número de fallos de calibración debido a una calibración de baja calidad y el número total de calibraciones realizadas. La tasa de error del clic y el tiempo de clic se calcularon sólo con las sesiones que han tenido una calibración aceptable.

Después de la calibración, los ETs devuelven un número que tiene relación con la calidad de la calibración, o más precisamente, con el error del proceso de calibración. Cuanto más pequeño sea este valor devuelto mejor. Este valor se expresa en píxeles, para el caso de los ETs ET01 y ET02, y en grados, para el caso del ET ET03. 
El procesamiento de los datos capturados incluyó los siguientes pasos, Figura 5.17:

1. Calcular el error de calibración típico de los usuarios sin PC, a saber U0.

2. Establecer el umbral $U 1$, que define el error máximo de calibración de los usuarios con PC, como una función de U0, Ecuación 5.13.

3. Descartar tareas de personas con PC que estén por encima del umbral U1.

4. Calcular la tasa de error de calibración de los usuarios con PC.

5. Calcular el valor típico de tiempo de clic de cada grupo de usuarios.

6. Establecer el umbral U2, que define el valor máximo de tiempo de clic, para cada grupo de usuarios, Ecuación 5.14.

7. Descartar las tareas de cada grupo de usuarios cuyos tiempos de clic están por encima del umbral U2

8. Calcular la tasa de error en el clic de las tareas con buena calibración y que no se consideraron valores atípicos, para cada grupo de usuarios.

9. Descartar tareas cuyos clics fueron realizados fuera de la figura.

10. Analizar los tiempos de clic de las tareas, para cada grupo de usuarios. Llegados aquí, los tiempos analizados serán los que tengan asociados una buena calibración y un clic dentro del objetivo.

$$
\begin{aligned}
& U 1=4 * U 0, \\
& U 2=\text { Promedio(tiempo clic) }+2 * \text { Std(tiempo clic), }
\end{aligned}
$$

\subsubsection{Resultados}

Por razones de claridad, organizamos los resultados en secciones de acuerdo con las tres métricas antes definidas, junto con una descripción de las tareas atípicas. La descripción de los resultados será por grupo de usuarios (con PC y sin PC) y por ET (ET01, ET02, ET03).

\section{Tasa de error de calibración}

De media los usuarios sin discapacidad tuvieron un error en la calibración de 25 píxeles (ET01 y ET02) o 0,6 (ET03), Figura 5.18a. Como se explicó en la sección anterior, este valor se utilizó para establecer el umbral máximo de error de calibración de las personas con PC U1, para la clasificación de las calibraciones como aceptables o no. El valor umbral $U 1$ fue de 100 píxeles (ET01 y ET02) o 2,4º (ET03), Ecuación 5.13.

Se realizaron 81 calibraciones con los usuarios con PC. De estas, 57 presentaron baja calidad (error por encima del umbral establecido), lo que corresponde a una tasa de fallo de calibración global del $70 \%$. En la Figura 5.18b se ve un diagrama de cajas del error 


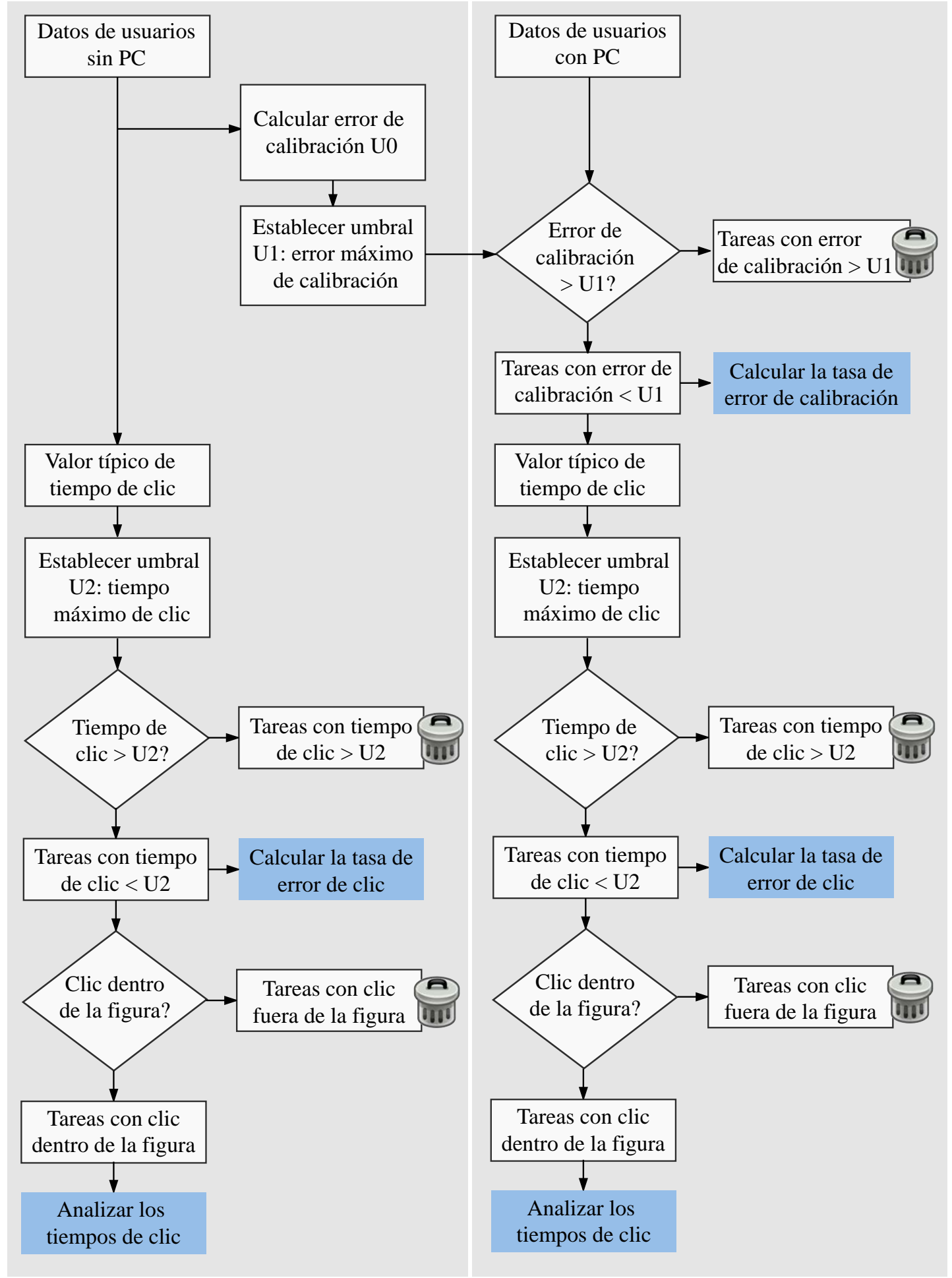

Figura 5.17: Flujo del procesamiento global de los datos. Las cajas en el recuadro gris de la izquierda señalan los cálculos con los datos de las personas sin PC y las que se encuentran en el recuadro de la derecha los cálculos con los datos de las personas con PC. Los cuadros con una papelera al lado implican tareas descartadas. Los cuadros celestes implican el cálculo de una métrica. 


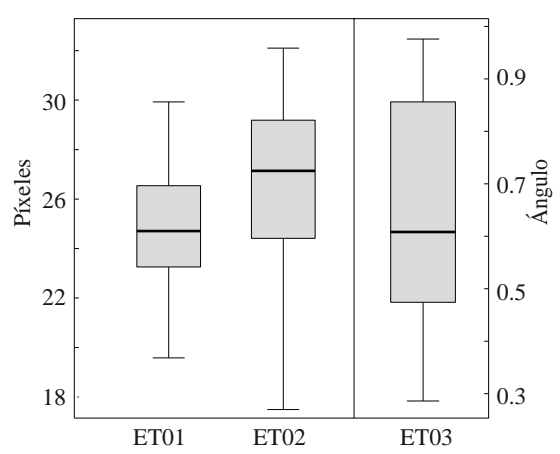

(a) Sin PC

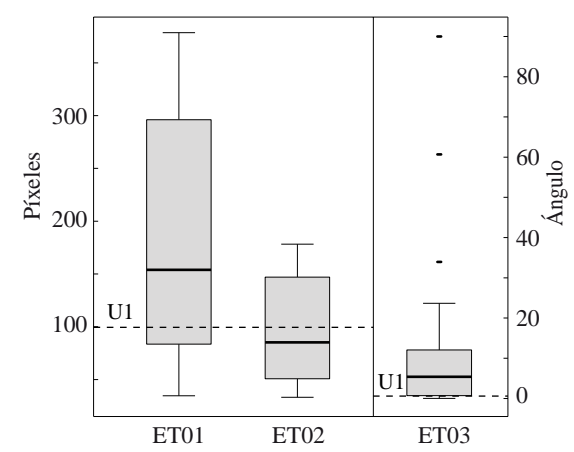

(b) Con PC

Figura 5.18: a) Gráfico de cajas del error de calibración de los participantes sin y b) con PC, por cada ET utilizado. En el gráfico de cajas de los participantes con PC (a) el umbral U1 se representa como una línea de trazos (100 píxeles y 2,4 grados)

de calibración de las personas con PC junto con el umbral $U 1$, como una línea de puntos horizontal.

En la Tabla 5.12 se muestran las tasas de fallos de calibración. Un análisis por ET nos muestra que el ET03 presentó la tasa de fallos de calibración media más alta, de más de $90 \%$. ET01 y ET02 tuvieron una calibración por debajo del umbral aproximadamente el $50 \%$ de los intentos. Los datos de los participantes con $\left(^{*}\right)$ en la Tabla no se utilizaron para el análisis posterior. Estos participantes decidieron abandonar las pruebas, posiblemente debido a su alta tasa de fallos de calibración.

El análisis por usuarios nos indica la dificultad de dos tercios de los usuarios -6 de 9- de tener una tasa de error de calibración por debajo del 50\%: solo US02, US06 y US07 han sido capaces de estar por debajo del $50 \%$. Esto pone en evidencia la alta heterogeneidad de los usuarios con PC en la interacción, así como la dificultad para realizar un buena calibración.

Considerando sólo las calibraciones correctas de los usuarios con PC se obtiene un error medio de $67( \pm 28)$ y $42( \pm 21)$ píxeles para el caso de ET01 y ET02 respectivamente y $0,8^{\circ}( \pm 0,4)$ para el caso de ET03.

\section{Tareas atípicas}

El valor medio del tiempo de clic de los usuarios con PC y sin PC fue de 3,0 s $( \pm 2,0 \mathrm{~s})$ y $2,5 \mathrm{~s}( \pm 0,16 \mathrm{~s})$ respectivamente. Con estos valores establecimos el umbral $U 2$, de tiempo máximo de clic según la Ecuación (5.14), como 7,0s y 2,8s, para los usuarios con PC y sin PC respectivamente, Ecuación 5.14. Con el umbral establecido, descartamos 3,35\% de las tareas de los usuarios con PC y 2,80\% de las tareas de los participantes sin discapacidad.

En total, después de descartar valores atípicos, se analizaron 616 tareas (393 de participantes del grupo sin PC y 223 de participantes con PC). En promedio, las personas sin discapacidad realizaron 56 tareas (18 con cada ET) y las personas con PC 44 tareas (15 con cada ET), Tabla 5.13. Todas estas tareas se han realizado con una calibración aceptable, según los términos definidos anteriormente. 


\begin{tabular}{lllll}
\hline Usuario & ET01 $(\mathbf{\%})$ & ET02 $(\mathbf{\%})$ & ET03 $(\mathbf{\%})$ & Media $(\%)$ \\
\hline US01* & 100 & 100 & 100 & 100 \\
US02* & 0 & - & 100 & 50 \\
US03* & 67 & 100 & 100 & 89 \\
US04 & 50 & 67 & 100 & 72 \\
US05 & 67 & 50 & 90 & 69 \\
US06 & 0 & 0 & - & 0 \\
US07 & 100 & 0 & 40 & 47 \\
US08* & - & 67 & 100 & 84 \\
US12 & 67 & 0 & 100 & 56 \\
Media (Std) & $56( \pm 36)^{\psi}$ & $48( \pm 43)^{\psi}$ & $91( \pm 21)^{\psi}$ & $65( \pm 39)^{\tau}$ \\
\hline
\end{tabular}

Tabla 5.12: Tasa de fallo de calibración por participante y por ET, para el grupo con PC. Las celdas con (-) indican que las calibraciones no se han realizado. Los datos de los participantes con $(*)$ no se utilizaron en el resto del análisis. Los valores $(\psi)$ se calcularon con las medidas de cada ET y los $(\tau)$ con todas las medidas.

\begin{tabular}{llllll}
\hline Grupo & Usuario & ET01 (n) & ET02 (n) & ET03 (n) & Total (n) \\
\hline Usuarios sin PC & & & & & \\
& US20 & 19 & 18 & 18 & 55 \\
& US21 & 18 & 19 & 19 & 56 \\
& US23 & 19 & 20 & 18 & 57 \\
& US24 & 20 & 19 & 18 & 57 \\
& US25 & 18 & 18 & 20 & 56 \\
& US26 & 18 & 19 & 18 & 55 \\
& US27 & 20 & 18 & 19 & 57 \\
& Total & 132 & 131 & 130 & 393 \\
& Media (Std) & $18( \pm 1)$ & $18( \pm 1)$ & $18( \pm 1)$ & $18( \pm 0)^{\psi}$ \\
& & & & & $56( \pm 1)^{\tau}$ \\
\hline Usuarios con PC & & & & \\
& US04 & 9 & 10 & $*$ & 19 \\
& US05 & 8 & 18 & 18 & 44 \\
& US06 & 18 & 19 & - & 37 \\
& US07 & $*$ & 39 & 43 & 82 \\
& US12 & 10 & 31 & $*$ & 41 \\
& Total & 45 & 117 & 61 & 223 \\
& Media (Std) & $9( \pm 5)$ & $23( \pm 12)$ & $12( \pm 18)$ & $15( \pm 7)^{\psi}$ \\
& & & & $44( \pm 23)^{\tau}$ \\
\hline
\end{tabular}

Tabla 5.13: Número de tareas de alcance por participante y por ET de ambos grupos de participantes. Las celdas con (-) corresponden con tareas no realizadas. Las celdas con * corresponden con tareas con una tasa de fallos en la calibración del $100 \%$, por lo que no se han analizado estos datos. Los valores $(\psi)$ se calcularon con las medidas de cada ET y los $(\tau)$ con las medidas de cada usuario. 


\begin{tabular}{llllll}
\hline Grupo & Usuario & ET01 (\%) & ET02 (\%) & ET03 (\%) & Media (\%) \\
\hline Usuarios sin PC & & & & & \\
& US20 & 0 & 0 & 0 & 0 \\
& US21 & 0 & 0 & 47 & 15 \\
& US23 & 0 & 0 & 0 & 0 \\
& US24 & 0 & 0 & 0 & 0 \\
& US25 & 0 & 0 & 50 & 16 \\
& US26 & 0 & 0 & 0 & 0 \\
& US27 & 0 & 0 & 0 & 0 \\
& Media (Std) & $0( \pm 0)^{\psi}$ & $0( \pm 0)^{\psi}$ & $14( \pm 24)^{\psi}$ & $5( \pm 15)^{\tau}$ \\
\hline Usuarios con PC & & & & & \\
& US04 & 0 & 100 & - & 50 \\
& US05 & 0 & 0 & 50 & 16 \\
& US06 & 50 & 52 & - & 51 \\
& US07 & - & 0 & 55 & 27 \\
& US12 & 100 & 100 & - & 100 \\
& Media (Std) & $38( \pm 48)^{\psi}$ & $50( \pm 50)^{\psi}$ & $52( \pm 4)^{\psi}$ & $46( \pm 42)^{\tau}$ \\
\hline
\end{tabular}

Tabla 5.14: Tasa de error del clic (\%) por participantes y por ET de ambos grupos de participantes. Las celdas con (-) corresponden a tareas no realizadas. Las celdas con * corresponden con tareas con una tasa de fallos en la calibración del $100 \%$, por lo que no se han analizado estos datos. Los valores $(\psi)$ fueron calculados con las medidas de cada ET y los $(\tau)$ con todas las medidas del grupo.

\section{Tasa de error del clic}

La tasa de error de clic de los participantes sin PC fue de $4 \%$ y la de los usuarios con PC de alrededor del $47 \%$. Estos valores son semejantes a los resultados de la Evaluación II: $10 \%$ y $47 \%$ respectivamente - Tabla 5.11, columna Permanencia-. El análisis por ETs nos indica que con ET01 y ET02 y ET03 la tasa de error fue de 38\%, $50 \%$ y $52 \%$, respectivamente. En el caso del grupo sin PC, la tasa de error fue de $0 \%$ con ET01 y T02 y del $14 \%$ con ET03.

Los participantes con PC US05, US06 y US12 tuvieron tasas de error similares con ambos ET01 y ET02. No sucedió lo mismo con el participante US04 (0\% con ET01 y $100 \%$ con ET02). Si consideramos el resultado de US04 un valor atípico, la tasa de error del clic de ambos ETs sería similar: $50 \%$ y $51 \%$ para ET01 y ET02 respectivamente. Los participantes con PC US05 y US07 tuvieron tasas de error diferentes con ET02 y ET03, en promedio $0 \%$ y $53 \%$ respectivamente. Los datos de todos los participantes están en la Tabla 5.14

\section{Tiempo de clic}

Los participantes sin PC han tardado 2,44s en realizar un clic, frente a los 2,67s que se han demorado los usuarios con PC. Los participantes con PC tomaron un promedio de 2,99s para realizar un clic con ET01 y 2,76s con ET02 (los participantes del grupo sin PC tomaron $2,45 \mathrm{~s}$ y $2,43 \mathrm{~s}$ respectivamente). Por otro lado, tomaron $2,55 \mathrm{~s}$ con ET02 y $2,98 \mathrm{~s}$ con ET03 (los participantes del grupo sin PC tomaron 2,43s y 2,44s respectivamente). 


\begin{tabular}{llllll}
\hline Grupo & Usuario & ET01 (s) & ET02 (s) & ET03 (s) & Media (s) \\
\hline Usuarios sin PC & & & & & \\
& US20 & 2,45 & 2,42 & 2,43 & 2,43 \\
& US21 & 2,45 & 2,43 & 2,43 & 2,44 \\
& US23 & 2,45 & 2,43 & 2,44 & 2,44 \\
& US24 & 2,45 & 2,43 & 2,44 & 2,44 \\
& US25 & 2,45 & 2,43 & 2,43 & 2,44 \\
& US26 & 2,45 & 2,43 & 2,42 & 2,43 \\
& US27 & 2,45 & 2,43 & 2,43 & 2,44 \\
& Media (Std) & $2,45( \pm 0,00)^{\psi}$ & $2,43( \pm 0,00)^{\psi}$ & $2,44( \pm 0,00)^{\psi}$ & $2,44( \pm 0,01)^{\tau}$ \\
\hline Usuarios con PC PC & & & & \\
& & & 2,75 & - & 2,98 \\
& US04 & 3,21 & 2,55 & 3,46 & 2,89 \\
& US05 & 2,65 & 2,81 & - & 2,77 \\
& US06 & 2,73 & 2,55 & 2,50 & 2,53 \\
& US07 & - & 2,95 & - & 3,17 \\
& US12 & 3,38 & $2,72( \pm 0,17)^{\psi}$ & $2,98( \pm 0,68)^{\psi}$ & $2,86( \pm 0,34)^{\tau}$ \\
\hline
\end{tabular}

Tabla 5.15: Tiempo de clic por participante por ET expresado en segundos. Este tiempo incluye el tiempo de permanencia y el margen entre clics consecutivos. Las celdas con (-) corresponden a tareas no realizadas. Las celdas con $*$ corresponden con tareas con una tasa de fallos en la calibración del $100 \%$, por lo que no se han analizado estos datos. Los valores $(\psi)$ se calcularon con las medidas de cada ET y los $(\tau)$ con todas las medidas del grupo.

Se pueden observar más detalles de estas medidas en la Tabla 5.15.

\subsubsection{Discusión}

La calibración es la puerta de acceso al control del ordenador mediante la mirada. Una calibración buena garantiza un control preciso del cursor. En esta sección nos hemos planteado investigar la tasa de error en la calibración de usuarios con PC. Para ello hemos planteado una metodología junto con la evaluación con personas con PC. A continuación, discutiremos temas relacionados con la tecnología y la metodología en función de los resultados obtenidos.

\section{Tasa de error de calibración}

Una buena calibración del ET es un requisito previo para ofrecer un control fiable a los usuarios y para extraer conclusiones bien fundadas sobre la interacción hombrecomputador. Hoy en día, la calidad de la calibración suele discutirse informalmente entre los investigadores, ya que no se mide, cuantifica ni informa de la capacidad de un ET de conseguir una calibración aceptable. Aquí hemos investigado sistemáticamente cómo es la calibración con un ET basado en video oculografía. Se cuantificó la tasa de fallo de la calibración y se encontró una alta tasa de error en la calibración, lo que sugiere que este proceso es complejo para los participantes con PC. Además, nuestros resultados proporcionan evidencia estadística y deja un precedente de cómo la PC influye en la calidad de la interacción. El método y los resultados proporcionan a los investigadores de 
la interacción - mediante movimientos oculares con usuarios con PC- una comprensión de lo que se puede esperar. Este tipo de evaluación nunca se había realizado y sin embargo es fundamental que los usuarios, fabricantes y operadores conozcan las posibilidades de estos sistemas de control ocular.

Existe un compromiso entre el número de puntos de calibración y la calidad de la misma $[115,116]$. De hecho, el ET03 — el ET que tiene mayor tasa de error en la calibraciónrequiere como mínimo 9 puntos de calibración. Es por esto que no es una opción viable utilizar menos puntos de calibración, incluso cuando de esta manera el proceso hubiese durado menos tiempo.

La precisión de los eye-trackers tiene dependencia con la posición de calibración del usuario [117]. Esto invalida reutilizar calibraciones buenas en diferentes sesiones, bajo la hipótesis de que de esta manera se podrían conseguir mejores resultados.

\section{Tasa de error del clic}

La alta tasa de error reveló que el uso de ETs en una tarea de alcance en una interfaz gráfica es un proceso complejo para estos niveles de discapacidad. Esto no es así para los usuarios sin ningún tipo de patología, los cuales pueden realizar tareas con tasas bajas de fallo. Existen trabajos que estudian la tasa de error, pero lo hacen con personas levemente afectadas por la PC, con niveles MACS o GMFCS I, II o II [118]. Nosotros hemos hecho pruebas con personas severamente afectadas, que se encuentran en los rangos más elevados como nivel IV o V, lo cual justifica el uso de interfaces alternativas como las basadas en la mirada. Un estudio de Man et al. revela los graves problemas de utilizar eye-trackers con personas con PC [87]. En su estudio los usuarios no han sido capaces de utilizar estos dispositivos, debido a que estos salían del rango de visión del eye-tracker. El tiempo de uso y la experiencia afectan a la tasa de error, [113], luego los resultados deben ser tomados con cautela.

Es importante mencionar que la tasa de error de este estudio es parecida a la del estudio anterior - Sección 5.3-, aunque en este estudio el procesamiento de datos descartó primero las tareas con mala calibración para luego calcular la tasa de error del clic. En este sentido, podemos descartar la hipótesis de que la alta tasa de error se debió al hecho de incluir datos con una mala calibración.

La tecnología parece ser suficientemente buena para personas sin discapacidad. Sin embargo, es necesario mejorar la técnica de estos dispositivos de bajo coste para poder ser utilizados por una población afectada gravemente por una lesión neuromotoras, como, por ejemplo, las personas con PC.

\section{Tiempo de clic}

Los tiempos de clics son similares entre todos los eye-trackers y participantes, alrededor 2,5 y 3 segundos. Este valor tiene sentido si tenemos en cuenta que los movimientos sacádicos son cortos —200ms [119]— y muy rápidos en relación con el tiempo total necesario para realizar un clic $-1 \mathrm{~s}-$.

En la Figura 5.19 se puede ver la distancia entre el centro de la figura en pantalla y el cursor (eje ordenadas) en función del tiempo (eje abscisa), de un usuario con PC para distintas tareas - cada tarea se representa mediante una línea azul-. Se puede ver que, al inicio, en el tiempo $t=0$, la distancia a la figura se encuentra estable (Tiempo de 


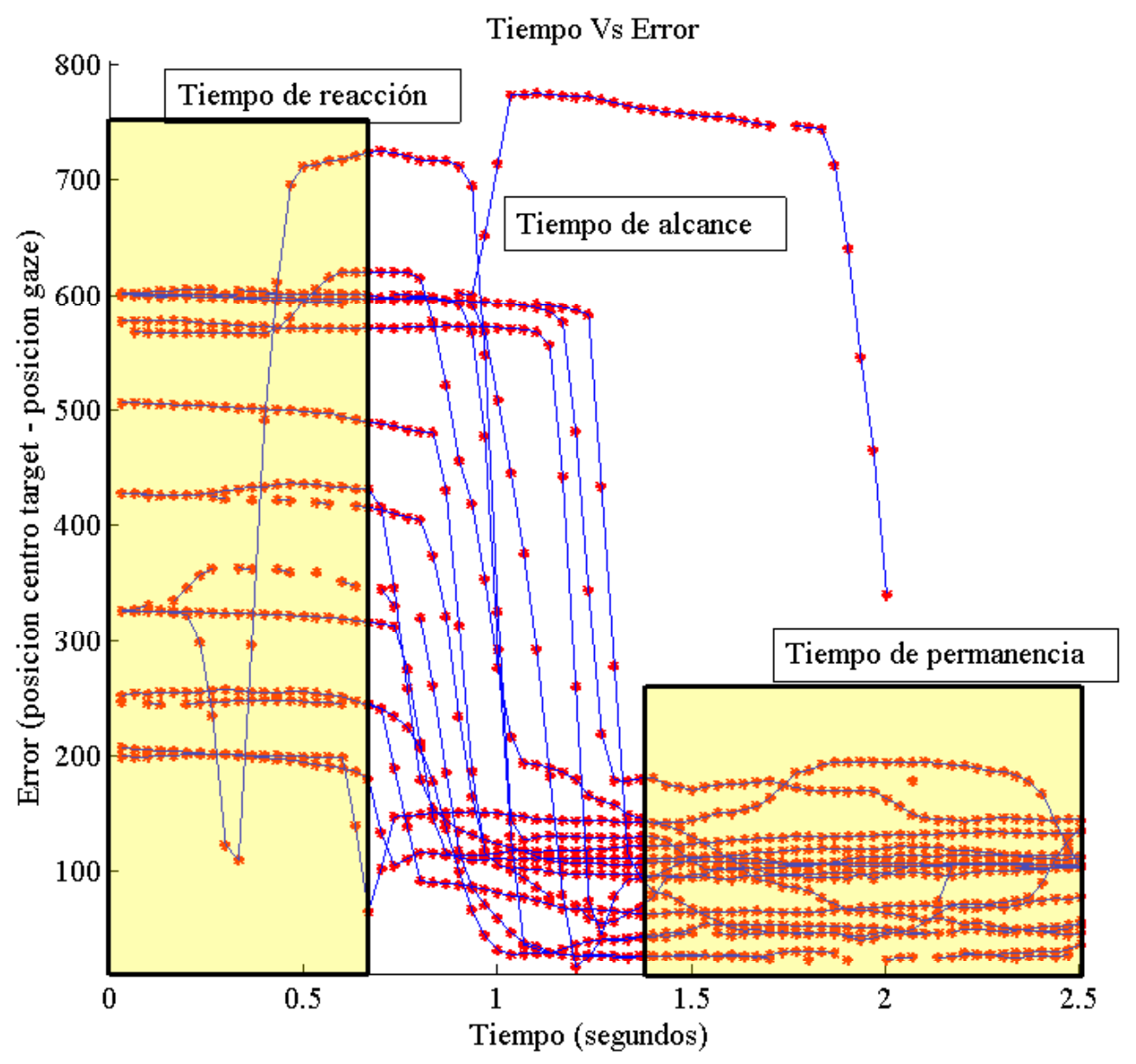

Figura 5.19: Distancia entre el cursor y el centro del objetivo en pantalla en función del tiempo, para distancias tareas realizadas por un mismo participante con PC.

reacción). Durante todo ese instante la figura ya se encuentra en una nueva posición en la pantalla, pero el usuario aún no ha reaccionado al estímulo. A continuación, la distancia disminuye rápidamente $(130 \mathrm{~ms})$ hasta que la mirada llega a la figura (Tiempo de alcance o acercamiento). Finalmente, la distancia vuelve a estabilizarse, mientras que el usuario espera que se realice el clic por permanencia (Tiempo de permanencia).

Es interesante la comparación de los tiempos de clic medio de este estudio con respecto al estudio de la Sección 5.3, en concreto con los datos de la Tabla 5.10. Según dicha tabla, el tiempo de clic medio de los usuarios con PC fue de $3,8( \pm 2,0)$, cuando para este estudio fue de 2,86 $( \pm 0,34)$. La diferencia entre ambos estudios es que con este último se ha establecido un umbral en el error de calibración. Con esta comparación queda claro que la interacción se vuelve más estable, en términos de tiempos de clic.

\section{Clic por permanencia}

El clic por permanencia fue implementado a través del análisis de la dispersión del cursor. Otro enfoque es considerar un clic cuando el cursor permanezca dentro de un área fija. Sin embargo, esta última estrategia es muy sensible a los movimientos involuntarios del 
participante, que es una condición común de las personas con PC. Nuestra estrategia no requiere que todos los puntos del cursor estén dentro de un área fija, sólo la mayoría de ellos. En este sentido, hemos favorecido la estrategia que permitía los mejores resultados.

Dependiendo de la tarea y de la experiencia del usuario, el tiempo óptimo para considerar un clic puede variar desde los pocos cientos de milisegundos a un segundo [120]. Se ha visto que el tiempo de permanencia tiene relación con la tasa de error [121]. Por este motivo, el tiempo de permanencia se ha ajustado con el objetivo de minimizar la tasa de error en el clic.

\subsubsection{Conclusión de la Evaluación IV}

En esta sección hemos presentado una metodología, basada en tres métricas, para valorar la interacción mediante ETs cuando se utiliza como un canal alternativo de acceso al ordenador por personas con PC. Además, presentamos la evaluación de la metodología mediante un ensayo con tres eye-trackers de bajo costo, con nueve usuarios con PC y un grupo de control de siete usuarios sin discapacidad. Encontramos que la calibración es la primera gran barrera que deben sobrepasar estos usuarios debido a la alta tasa de fallo en la calibración. Además, las altas tasas de error del clic revelaron que los eye-trackers como canal de acceso alternativo pueden no cumplir las expectativas de usabilidad de estos potenciales usuarios. Los tiempos de clics fueron similares entre todos los observadores y participantes. Notamos también una dependencia de la usabilidad con la tecnología, ya que los ETs utilizados no se comportan igual con los usuarios con PC. Este estudio no pretende desaconsejar la utilización de eye-trackers en la población con PC, sino establecer líneas metodológicas para la efectiva evaluación de estos dispositivos, que pueden llegar a ser una interesante alternativa de acceso al ordenador para esta población.

\subsection{Conclusión}

Los eye-tracker son hoy día una tecnología prometedora. La información de la mirada abre posibilidades nuevas a muchas áreas tecnológicas, por ejemplo, la realidad virtual [122]. Esta nueva tecnología puede incluso ser beneficiosa para personas con discapacidad, como es el caso de las personas con parálisis cerebral. Sin embargo, los beneficios aún no están claramente definidos y las metodologías de evaluación aún se encuentran en una fase muy temprana. En este capítulo hemos dado una serie de orientaciones para dar un paso adelante en cuanto a métodos y métricas.

En la Tabla 5.17 y en la Tabla 5.18 resumimos las evaluaciones realizadas, con las interrogantes de partida, las conclusiones y los aspectos claves del estudio. Las primeras dos evaluaciones - Sección 5.1 y Sección 5.2, resumidas en la Tabla 5.17- han intentado valorar dos métodos estándar, según el primer hito del Objetivo 1. A continuación, tras descartar ambos métodos, hemos propuesto una metodología, basada en la tasa de error en el clic, el tiempo de clic — propuesta en la Sección 5.3- y la tasa de fallos en la calibración - propuesta en la Sección 5.4-.

Este capítulo pretendió establecer líneas metodológicas para una evaluación efectiva de la interacción con el ordenador mediante los eye-trackes, que pueden llegar a ser una interesante alternativa de acceso al ordenador para personas severamente afectadas por discapacidades motoras. 


\begin{tabular}{lll}
\hline Métrica & Usuarios sin PC & Usuarios con PC \\
\hline Tiempo de clic (parpadeo), Sección 5.3 & $2,3 \mathrm{~s}( \pm 1,15 \mathrm{~s})$ & $6,2 \mathrm{~s}( \pm 2,55 \mathrm{~s})$ \\
Tiempo de clic (permanencia), Sección 5.3 & $2,5 \mathrm{~s}( \pm 0,45 \mathrm{~s})$ & $3,8 \mathrm{~s}( \pm 2,05 \mathrm{~s})$ \\
Tiempo de clic (permanencia), Sección 5.4 & $2,44 \mathrm{~s}( \pm 0,01 \mathrm{~s})$ & $2,86 \mathrm{~s}( \pm 0,34 \mathrm{~s})$ \\
Tasa de error del clic (parpadeo), Sección 5.3 & $10 \%( \pm 9 \%)$ & $45 \%( \pm 21 \%)$ \\
Tasa de error del clic (permanencia), Sección 5.3 & $10 \%( \pm 9 \%)$ & $47 \%( \pm 36 \%)$ \\
Tasa de error del clic (permanencia), Sección 5.4 & $5 \%( \pm 15 \%)$ & $46 \%( \pm 42 \%)$ \\
\hline
\end{tabular}

Tabla 5.16: Análisis comparativo entre usuarios sin y con PC de las medias y desviaciones estándar de las métricas presentadas en las dos últimas evaluaciones: Sección 5.3 y Sección 5.4.

\begin{tabular}{|c|c|c|}
\hline Contexto & Evaluación I & Evaluación II \\
\hline Cuestión & $\begin{array}{l}\text { ¿Son las medidas de fábrica de } \\
\mathrm{P} \& \mathrm{~V} \text { iguales en la práctica, sin } \\
\text { restringir el movimiento de la ca- } \\
\text { beza? }\end{array}$ & $\begin{array}{l}\text { ¿Es el modelo de Fitts adecuado } \\
\text { para valorar la interacción con el } \\
\text { ordenador de personas con tras- } \\
\text { tornos motores? }\end{array}$ \\
\hline Respuesta & $\begin{array}{l}\text { No, las medidas de nuestros en- } \\
\text { sayos son peores. Los movimien- } \\
\text { to de cabeza afectan a las medi- } \\
\text { das P\&V. Estas medidas generan } \\
\text { falsas espectativas en los usuarios } \\
\text { con trastornos motores. Además, } \\
\text { estas medidas no son funcionales. } \\
\text { La P\&V no son adecuadas para } \\
\text { valorar la interacción }\end{array}$ & $\begin{array}{l}\text { No, nuestros ensayos nos indica- } \\
\text { ron que el valor de } R^{2} \text { es }<0,01 \\
\text { para ambos grupos de usuario, lo } \\
\text { que nos señaló que la relación en- } \\
\text { tre el tiempo para realizar la ta- } \\
\text { rea y el índice de dificultad es muy } \\
\text { baja. Este modelo no es adecuado } \\
\text { para valorar la interacción }\end{array}$ \\
\hline Métricas & Precisión y Veracidad & $\begin{array}{l}\text { Cuadrado de coeficiente de Pear- } \\
\text { son } R^{2}\end{array}$ \\
\hline Orientación evaluación & Interfaz & Usuario \\
\hline Usuarios con PC & Usuarios sin patologías asociadas & $\begin{array}{l}\text { Grupo 2: Atenpace-Madrid, San } \\
\text { Rafael }\end{array}$ \\
\hline Software & Tobii Studio & Propio 2 \\
\hline Cursor visible & No & No \\
\hline Eye-tracker & Tobii X2-30 & $\begin{array}{l}\text { Tobii X2-30, Tobii EyeX, The } \\
\text { EyeTribe }\end{array}$ \\
\hline Puntos Calibración & Cinco & Nueve \\
\hline Ante clic erróneo & No se realizó clic & Siguiente figura \\
\hline Estímulo visual & Círculos & Figuras animadas \\
\hline
\end{tabular}

Tabla 5.17: Distintas evaluaciones presentadas, con las interrogantes de partida, las conclusiones y los aspectos claves del estudio. 


\begin{tabular}{|c|c|c|}
\hline Contexto & Evaluación III & Evaluación IV \\
\hline Cuestión & $\begin{array}{l}\text { ¿Es posible medir la interacción a } \\
\text { través de la tasa de error y tiem- } \\
\text { po de clic? ¿Es mejor parpadear o } \\
\text { permanecer para hacer un clic? }\end{array}$ & $\begin{array}{l}\text { ¿En qué medida la calibración de } \\
\text { los ETs es un proceso viable pa- } \\
\text { ra personas con PC? ¿Cuál es la } \\
\text { tasa de fallos en la calibración de } \\
3 \text { eye-tracker comerciales, de bajo } \\
\text { costo? }\end{array}$ \\
\hline Respuesta & $\begin{array}{l}\text { Una de cada dos personas con } \\
\text { PC no puede realizar un clic den- } \\
\text { tro de un objeto en pantalla, con } \\
\text { ambos métodos de clic. Aunque } \\
\text { las dos técnicas proporcionan ta- } \\
\text { sas de error similares, el tiem- } \\
\text { po de clic es menor con el clic } \\
\text { por permanencia. La metodología } \\
\text { propuesta nos permitió valorar la } \\
\text { interacción funcional e integral- } \\
\text { mente. }\end{array}$ & $\begin{array}{l}\text { La calibración es la primera gran } \\
\text { barrera que deben sobrepasar los } \\
\text { usuarios con PC: } 70 \% \text { de las ca- } \\
\text { libraciones han sido de baja cali- } \\
\text { dad, uno de los ETs evaluados tu- } \\
\text { vo una tasa }>90 \% \text {. Los ETs de } \\
\text { bajo costo pueden ser una opción } \\
\text { interesante para personas sin li- } \\
\text { mitaciones motoras. Sin embargo, } \\
\text { los malos resultados señalan que } \\
\text { para personas con trastornos mo- } \\
\text { tores aún tienen camino por re- } \\
\text { correr para ser una opción válida. } \\
\text { Es fundamental incluir en los es- } \\
\text { tudios de usabilidad la tasa de fa- } \\
\text { llos en la calibración. }\end{array}$ \\
\hline Métricas & $\begin{array}{l}\text { Tasas de error en el clic, tiempo } \\
\text { de clic }\end{array}$ & $\begin{array}{l}\text { Tasa de error en el clic, tiempo de } \\
\text { clic y tasa de error en la calibra- } \\
\text { ción }\end{array}$ \\
\hline Orientación evaluación & Interacción & Interacción \\
\hline Usuarios con PC & Grupo 1: Aspace-Cantabria & $\begin{array}{l}\text { Grupo 2: Atenpace-Madrid, San } \\
\text { Rafael }\end{array}$ \\
\hline Software & Propio 1 & Propio 2 \\
\hline Cursor visible & $\mathrm{Si}$ & No \\
\hline Eye-tracker & Tobii X2-30 & $\begin{array}{l}\text { Tobii X2-30, Tobii EyeX, The } \\
\text { EyeTribe }\end{array}$ \\
\hline Puntos Calibración & Cinco & Nueve \\
\hline Ante clic erróneo & Tres oportunidades & Siguiente figura \\
\hline Estímulo visual & Figuras animadas & Figuras animadas \\
\hline
\end{tabular}

Tabla 5.18: Distintas evaluaciones presentadas, con las interrogantes de partida, las conclusiones y los aspectos claves del estudio. 


\section{Capítulo 6}

\section{Metodología de caracterización de la interacción mediante técnicas de aprendizaje automático}

Las interfaces de acceso al ordenador están diseñadas en función de un conjunto de suposiciones en relación a las capacidades del usuario y la configuración del entorno [56]. Las personas con discapacidades motoras y su contexto no cumplen habitualmente estos supuestos y sufren problemas graves cuando entran en contacto con dispositivos electrónicos. Davies et al. encontraron que el $65 \%$ de los usuarios afectados gravemente por la parálisis cerebral no puede utilizar ni un ratón estándar ni el teclado [9]. Wobbrock et al. propusieron cambiar el paradigma de diseño y centrarse en la capacidad del usuario en lugar de en su discapacidad, con el objetivo de conocerlos mejor [123]. Sin embargo, existe una falta de procedimientos de evaluación de la interacción basados en las trayectorias del cursor [82]. En este capítulo intentaremos responder a la pregunta de cómo es la interacción de personas con PC con el ordenador, mientras lo controlan a través de la mirada.

Los experimentos del Capítulo 5 nos han confirmado la gran heterogeneidad de los usuarios con PC. Un análisis comparativo de las desviaciones estándar de las métricas de ambos grupos de usuarios confirma esta hipótesis, Capítulo 5 Tabla 5.16. Por lo tanto, tratar de analizar a los usuarios con PC como un grupo único no es una aproximación adecuada. Por otro lado, abordar a cada usuario por separado es un enfoque poco práctico y se corre el riesgo de diseñar soluciones ad hoc. Existe un punto intermedio: analizar grupos de usuarios con un comportamiento similar en la interacción. Es por esto que para conocer cómo se comportan los usuarios con PC en la interacción, primero los agruparemos según sus semejanzas en la interacción, obteniendo grupos de usuarios parecidos.

Tomamos una posición agnóstica con respecto al tipo de tarea que cada usuario puede realizar. Nuestra hipótesis es que los usuarios no tienen un comportamiento específico en función de su perfil patológico, es decir, que usuarios con perfiles patológicos diferentes pueden realizar un tipo de interacción muy similar [124]. En términos técnicos, quisimos encontrar una estructura en una colección de datos no etiquetados -además de complejos-, con el fin de encontrar usuarios similares, en términos de la interacción con el ordenador.

El área de aprendizaje automático — subcampo de las ciencias de la computación y una 
rama de la inteligencia artificial - nos ofrece dos tipos de técnicas para la agrupación o clustering de datos: aprendizaje supervisado y no supervisado ${ }^{1}$. La diferencia entre estas dos técnicas radica en la existencia o no de un "etiquetador", que proporciona una categoría, clase o etiqueta a los datos. En el caso de las técnicas no supervisadas este "etiquetador" no existe, por lo que los algoritmos buscan en los datos "grupos naturales" [125, pag. 16-17]. Como nuestra hipótesis fue que no nuestros datos no estaban etiquetados (dado que la única etiqueta es el identificador del usuario), el método de caracterización se basó en el tipo de aprendizaje no supervisado, que, como ahora veremos, nos permitió encontrar semejanzas entre usuarios de forma automática.

En la Sección 6.1 desarrollamos este método. Propusimos caracterizar la interacción de los usuarios en base a su tendencia de realizar trayectorias de un cierto tipo, dado un conjunto de tipos predefinido. Para la identificación de los tipos de trayectoria, procesamos una serie de métricas de las trayectorias con un algoritmo de agrupamiento. Este procedimiento nos permite asignar a cada usuario a un grupo. Para cada trayectoria se calcularon un conjunto de métricas o propiedades especialmente definidas a partir de varios aspectos del movimiento del cursor: cinemática, tiempo, espacio, etc.

Después de entender cómo son las características de cada uno de los grupos de usuarios de acuerdo a su interacción con el ordenador, realizamos dos aportaciones más en esta línea de caracterización: (1) con los usuarios ya etiquetados de acuerdo a su grupo de tipo de interacción valoramos la capacidad de distintos clasificadores - basados en técnicas de aprendizaje automático - de identificar la clase de una "nueva tarea de apuntamiento" y (2) evaluamos las métricas consideradas en función de su aportación a la clasificación para averiguar cuáles son las más relevantes. Estas dos aportaciones se desarrollan en la Sección 6.2.

Para este estudio se ha ampliado la muestra de la población y hemos incluido en el experimento a usuarios con características motoras similares a los usuarios con PC. Mediante esto hemos validado la Hipótesis 6: "No solo los usuarios con PC se podrán beneficiar con los resultados de este trabajo, sino también aquellos que padecen de trastornos similares o incluso menos afectados, como la esclerosis lateral amiotrófica o la lesión medular". Además, una muestra mayor ofrecerá resultados más significativos.

Este trabajo se basa parcialmente en las aportaciones C.1 y J.1 (Sección 8.1)

\subsection{Caracterización de usuarios según su interacción con el ordenador}

Nuestro objetivo fue identificar las habilidades de los usuarios y las posibles deficiencias cuando los usuarios controlaban la computadora a través de la mirada, de un modo activo, Sección 3.3. Para medir las habilidades del usuario, proponemos medir un conjunto de parámetros de las tareas de alcance y selección, Sección 4.1. Para la caracterización de las capacidades de los usuarios, se identificó la tendencia de cada participante a seguir cierto tipo de apuntamiento (PT). Para la definición de los tipos de PT, hemos separado los PT en grupos, a través de un método de aprendizaje automático no supervisado.

Para la evaluación del método, diseñamos un protocolo experimental en colaboración con tres centros especializados en trastornos motores: ASPACE Cantabria, Hospital Nacional

\footnotetext{
${ }^{1}$ Existe un tercer tipo de aprendizaje automático, llamado reforzado, aunque la literatura suele usar esta clasificación binaria en general
} 


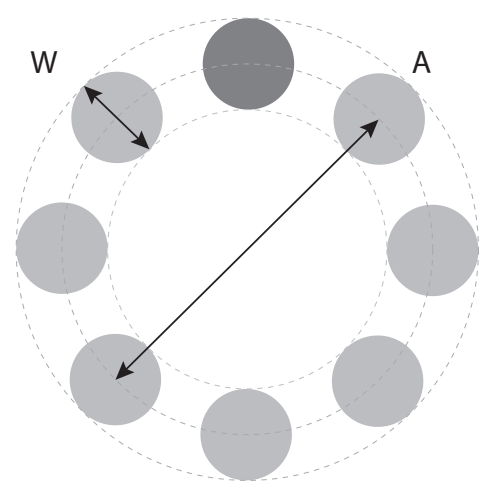

(a)

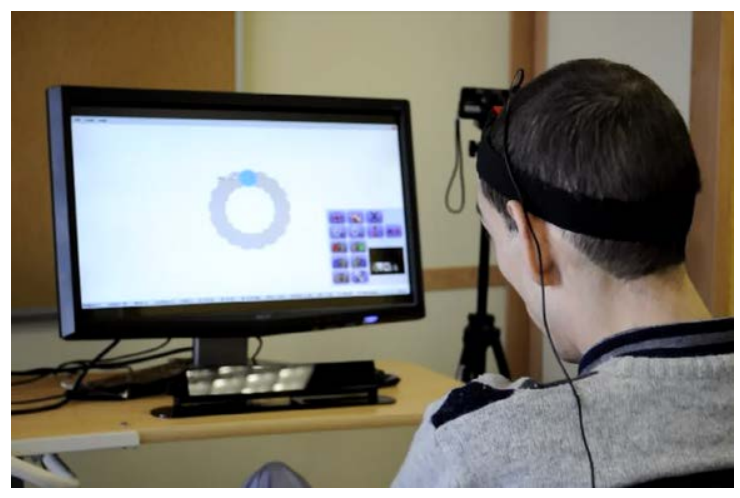

(b)

Figura 6.1: (a) Esquema de la tarea de apuntamiento (PT) y sus principales parámetros: amplitud de movimiento $(A)$ y diámetro del objetivo $(W)$. (b) Un momento de la prueba. Todos los participantes se localizaron en la distancia óptima al eye-tracker, a la altura del centro de la pantalla, lo que garantiza las mejores mediciones.

de Parapléjicos de Toledo (HNPT) y ADENGI. Se reclutaron trece participantes con trastornos motores severos y cuatro personas sin trastornos motores, que realizaron los mismos ensayos. Se registraron y analizaron las trayectorias del cursor y los objetivos en la pantalla de los participantes.

\subsubsection{Protocolo del test}

Establecimos la dificultad de las tareas por medio del índice de dificultad de la Ley de Fitts, Ecuación (4.9), Figura 6.1a. Hemos propuesto a los participantes del ensayo realizar las tareas de apuntamiento con cuatro diámetros de objetivo: 300, 200, 100 y 50 píxeles, $W$ en la Figura 6.1a. Los objetivos circulares estaban a una distancia de 500 píxeles unos de otros, $A$ en la Figura 6.1a. Estos valores definen IDs de 1,41, 1,80, 2,58 y 3,46 .

Cada tarea de apuntamiento finalizó cuando el usuario realizó un clic, manteniendo la mirada dentro de un área de 16 píxeles durante 1 segundo. Se pidió a los usuarios que hicieran la tarea de apuntar 10 veces por cada diámetro definido.

Al comienzo de cada sesión de trabajo, los participantes realizaron un proceso de calibración. Se estableció un umbral cuantitativo de 50 píxeles para comprobar la fiabilidad de la calibración antes de la ejecución de la tarea. Sólo los participantes que superaron este nivel continuaron con las pruebas.

Después de la calibración, cada participante practicó en una breve sesión de entrenamiento con el software "Look to Learn" para familiarizarse con la interfaz y el entorno de trabajo (rastreador de ojos, pantalla, etc.). No se recogieron datos durante esta fase.

Finalmente, se les pidió que completaran una serie de tareas de apuntar con el software FittsStudy. FittsStudy nos permitió controlar el tamaño de los objetivos, las distancias entre ellos y el orden de aparición, es decir, la dificultad de cada tarea de apuntamiento, de acuerdo a la Ley de Fitts [71]. Toda la información de las tareas de apuntamiento se registró para su posterior análisis.

En general, las sesiones de trabajo duraron aproximadamente 40 minutos. Este tiempo incluyó la preparación de los participantes, el proceso de calibración, las posibles 
repeticiones y algunas pausas entre ensayos para evitar la aparición de fatiga.

Los participantes con discapacidad fueron acompañados por un terapeuta, de manera que se sintieron acompañados por alguien familiar durante los ensayos. Tuvimos un cuidado especial en que los usuarios estuvieran en el rango de visión del eye-tracker durante la prueba. Todos los participantes se localizaron en la distancia óptima al eyetracker (aproximadamente $60 \mathrm{~cm}$ ), a la altura del centro de la pantalla, lo que garantiza las mejores mediciones. La rutina de acomodamiento de los participantes incluía mover al participante, la pantalla y el eye-tracker. La Figura 6.1b muestra un momento de la prueba.

Las pruebas se realizaron en un ambiente con luz artificial y natural, sin fuentes de luz que apuntaran directamente a los ojos del participante o al eye-tracker, para evitar medidas distorsionadas.

\subsubsection{Equipos}

Para este estudio se seleccionó un eye-tracker basado en video-oculografía con fuentes de luz infrarroja del tipo remoto. El criterio principal fue la no invasividad de este tipo de dispositivos. El dispositivo fue el PRIMMA ${ }^{2}$ (IRISBOND, España), que tradujo la posición de la mirada en la pantalla en coordenadas del cursor y también informaba de cuando se cumplía la condición del clic por permanencia.

El PRIMMA filtró los datos brutos on-line. El filtro que utiliza es el filtro [126], aplicado a cada eje independientemente. Este filtro responde rápidamente a los movimientos sacádicos, introduciendo un retardo reducido en el control del cursor.

Cada participante exploró y se familiarizó con la plataforma con el software "Look to Learn" (Sensory Software, Reino Unido) ${ }^{3}$. No se registró nada durante este proceso. Después de la fase de familiarización, se utilizó el software FittsStudy ${ }^{4}$ [68] para controlar el estímulo visual y se registró la trayectoria del cursor y la posición de destino.

El experimento se realizó en un Toshiba Satellite Pro R50B-15Z, con una pantalla de 15,6" con una resolución de 1366x768

\subsubsection{Participantes}

Sólo se incluyeron en el estudio a los usuarios sin problemas de visión o audición, con capacidad visual suficiente para identificar objetos en la pantalla del ordenador con un tamaño mínimo de $1 \mathrm{~cm}$. Por otro lado, se reclutaron sólo personas con capacidad cognitiva para seguir instrucciones y mantener la atención en una tarea durante al menos 15 minutos.

Con estos criterios, nuestros socios clínicos reclutaron un total de trece participantes: cinco con parálisis cerebral (PC) de ASPACE-Cantabria, cuatro con lesión medular (SCI) del Hospital Nacional de Parapléjicos de Toledo (HNPT), cuatro con trastornos neuromusculares (ND) de ADEMGI. Para este estudio se ha ampliado la muestra con una población con características motoras similares, para ofrecer resultados más significativos. El comité de ética local aprobó el estudio. Todos los participantes fueron

\footnotetext{
${ }^{2}$ http://www.irisbond.com/productos/irisbond-primma

${ }^{3}$ https://thinksmartbox.com/product/look-to-learn

${ }^{4}$ https://depts.washington.edu/aimgroup/proj/fittsstudy/
} 


\begin{tabular}{lllll}
\hline Grupo & Usuario & Sexo & Edad & Exp. ET \\
\hline Usuarios con lesión medular (SCI) & & & & \\
& US01 & M & 18 & Baja \\
& US02 & M & 36 & Baja \\
& US03 & F & 51 & Baja \\
& US04 & F & 5 & Alta \\
\hline Usuarios con PC & & & & \\
& US05 & F & 27 & Baja \\
& US06 & M & 34 & Media \\
& US07 & M & 40 & Media \\
& US08 & M & 41 & Media \\
& US10 & M & 31 & Alta \\
\hline Usuarios con trastornos neuromusculares (ND) & & & & \\
& US11 & M & 64 & Baja \\
& US12 & F & 48 & Baja \\
& US13 & F & 56 & Baja \\
& US14 & M & 47 & Baja \\
\hline Usuarios de control & & & & \\
& US94 & M & 30 & Alta \\
& US95 & M & 30 & Media \\
& US98 & M & 37 & Alta \\
& US99 & F & 23 & Media \\
\hline
\end{tabular}

Tabla 6.1: Participantes con su perfil clínico (P), sexo, edad y experiencia en el uso de eye-trackers (Exp. ET).

previamente informados y firmaron un consentimiento informado por escrito para participar.

El perfil clínico, el sexo, la edad y la experiencia de seguimiento de los ojos de los participantes con discapacidades se pueden ver en la Tabla 6.1. La edad promedio de los participantes es de 38 años ( \pm 16 años). Pedimos a los terapeutas que clasifiquen a los usuarios de acuerdo con la experiencia que tuvieron con los ET en tres categorías.

El grupo de personas sin trastorno motriz (HP) consistió en tres hombres y una mujer, con una edad media de 28 años ( \pm 5 años). Ambos grupos realizaron las mismas tareas en el ordenador. Los datos de los usuarios de sin discapacidad se utilizaron como valores de referencia.

\subsubsection{Procesamiento de datos}

Nuestra propuesta fue agrupar las trayectorias con la técnica no supervisada, con el fin de analizar cada grupo posteriormente. Una de las técnicas de agrupamiento de datos más populares en aplicaciones científicas e industriales es el algoritmo k-means, debido a su facilidad de implementación e interpretación de los resultados y velocidad de construcción del modelo [127]. Sus principales desventajas son la alta sensibilidad al punto de partida y la necesidad de conocer el número óptimo de grupos $k$ de antemano. Utilizamos 


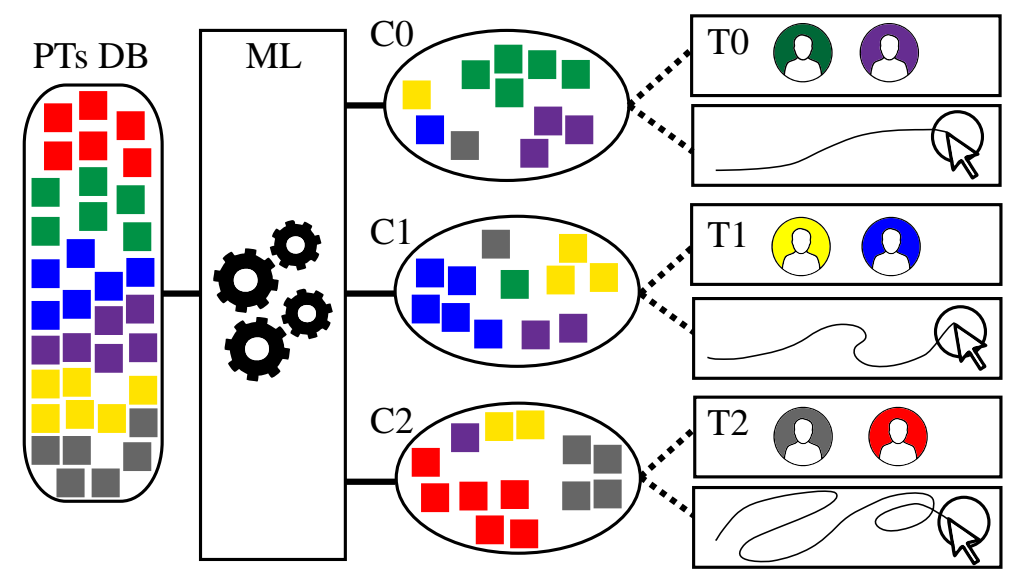

Figura 6.2: Esquema del método propuesto. Los cuadrados de colores representan instancias de PT y cada color representa un usuario diferente. El PTs-DB es la base de datos de PTs. ML es la técnica de agrupamiento que separó los PT en tres grupos $(\mathrm{C} 0, \mathrm{C} 1$ y $\mathrm{C} 2)$. T0, T1 y T2 representan la tendencia de cada usuario y las características de cada grupo.

la implementación de Arthur [128], del conjunto de herramientas de minería de datos de la aplicación Weka v3.7 ${ }^{5}$ [129]. La implementación de Arthur mejora la velocidad y la exactitud sobre el algoritmo original, mediante una técnica de selección del punto de partida, llamada $k$-means ++ . El número de grupos se determinó heurísticamente en tres, con el fin de caracterizar tres grupos de trayectorias.

El algoritmo k-means tiene dos fases: una inicialización y un bucle de aprendizaje. La inicialización selecciona $k$ instancias del espacio de instancias y asigna el centro de los clústeres a las posiciones de estas $k$ instancias. El bucle asigna todas las instancias restantes al clúster más cercano, calculando en cada iteración el centroide con el nuevo miembro del grupo [130].

Las métricas que describen a las PT son las presentadas en la Sección 4.1. Todos estos parámetros o métricas han sido normalizados antes del inicio de la agrupación de datos, que utilizó distancias euclídeas. Esto evita que algunas métricas dominen en la medida de distancia utilizada para la agrupación.

El análisis de componentes principales (PCA) es una técnica popular para la reducción de la dimensionalidad, que encuentra vectores ortogonales (componentes principales) linealmente no correlacionados, con el objetivo de reducir la complejidad de análisis [131]. Sin embargo, tiene el problema de no poder interpretar los datos a continuación y por esta razón no se implementó.

Los clústeres obtenidos se validaron a través de la SSE (suma del error cuadrático de todos los elementos a cada clúster correspondiente), la distancia entre clústeres, el radio máximo (mayor distancia de una instancia a su centroide), el radio mínimo (la distancia más corta de una instancia a su centroide) y el radio mediano (suma de las mayores distancias dividido por el número de clústeres). Después de esto, analizamos la tendencia de los participantes, los grupos y las métricas de cada clúster. Por último, analizamos estos clústeres visual y analíticamente con el fin de encontrar características y diferencias.

Como hemos mencionado antes, la principal desventaja del algoritmo $k$-means es que necesitamos conocer el número óptimo de grupos $k$ de antemano. Para la obtención del número de grupos hemos utilizado un algoritmo llamado en la plataforma Weka como

\footnotetext{
${ }^{5}$ http://www.cs.waikato.ac.nz/ ml/weka/index.html
} 


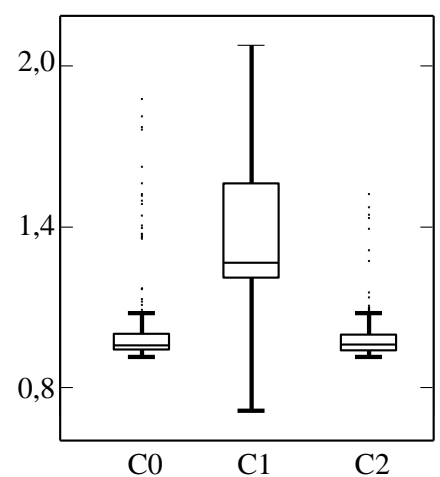

(a)

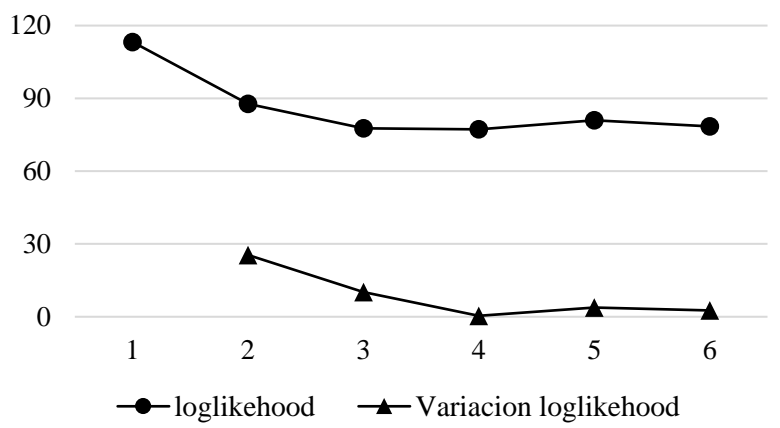

(b)

Figura 6.3: (a) K-means asigna a cada instancia una distancia al centroide del cluster correspondiente. En el diagrama de cajas vemos las distancias de cada instancia al centroide de su clúster correspondiente. (b) El algoritmo EM asigna a cada instancia una probabilidad de pertenecer a cada cluster, llamada loglikelihood. Además, este algoritmo puede decidir el número de clusters a generar por validación cruzada de forma recursiva. Para ello calcula la probabilidad loglikelihood promedio de todas las instancias con un número diferente de clusters, de forma incremental. Cuando el incremento es menor a un umbral, el algoritmo se detiene. En nuestro caso, el algoritmo se detuvo en 3 clusters. En la figura vemos el valor loglikelihood por cada número de clusters y la variación del valor loglikelihood.

Simple EM (EM de "expectation maximisation"), que calcula de forma automática este número. Para ello realiza un proceso iterativo, al igual que $k$-means, con validación cruzada. Este algoritmo asigna a cada instancia una probabilidad de pertenecer a cada cluster, llamada loglikelihood. En el proceso recursivo calcula la probabilidad loglikelihood promedio de todas las instancias con un número diferente de clusters, de forma incremental. Cuando el incremento es menor a un umbral, el algoritmo se detiene. Hemos configurado el algoritmo para que realice un máximo de 100 iteraciones, validación cruzada de 10 bloques, y un umbral nínimo de variación de $1 * 10^{-6}$.

En la Figura 6.2 se representa un esquema del método propuesto. Los cuadrados de colores representan instancias PT y cada color representa un usuario diferente. El PTsDB es la base de datos de PTs. Se propuso una técnica de agrupamiento con el fin de separar los PT (ML) en tres grupos (C0, C1 y C2). Luego se analizó la tendencia de cada usuario (T0, T1 y T2) y las características de cada grupo.

\subsubsection{Resultados}

Se registraron un total de 722 trayectorias durante los experimentos, de los 17 participantes: 180 de los participantes con SCI, 180 de los participantes con PC, 143 de los participantes con ND y 219 de los participantes sin discapacidad.

El algoritmo Simple EM se detuvo en 3 clusters. En la Figura $6.3 \mathrm{~b}$ vemos el valor loglikelihood por cada número de clusters y la variación del valor loglikelihood. A partir de esto, hemos configurado el algoritmo k-means con un número de grupos igual a tres.

\section{Características y validación de los clústeres}

El agrupamiento de datos procesó 40 parámetros de entrada y clasificó las 722 instancias de trayectoria de apuntamiento, independientemente del participante y la patología, en 
tres grupos como sigue:

- Clúster $C_{0}: 206$ instancias, $29 \%$ del total.

- Clúster $C_{1}$. 237 instancias, $33 \%$ del total.

- Clúster $C_{2} .279$ instancias, $39 \%$ del total.

Los valores de todos los parámetros correspondientes a los centroides de cada grupo se representan en la Tabla 6.2.

El valor SSE fue de 225.6. El radio máximo, mínimo y mediano de cada grupo se resumen en la Tabla 6.3, Figura 6.3a. Las distancias euclídeas entre los centroides muestran que uno de los clústeres $\left(C_{2}\right)$ está más separado de los otros. Se obtuvieron las distancias siguientes:

- Distancia entre $C_{0}$ y $C_{1}: 474$.

- Distancia entre $C_{0}$ y $C_{2}: 1579$.

- Distancia entre $C_{1}$ y $C_{2}: 1960$.

\section{Tendencia de los usuarios y de los grupos de cada clúster}

La Tabla 6.4 representa, para todos los participantes, qué porcentaje de sus trayectorias se clasificaron en cada uno de los grupos de trayectorias. Como se mencionó anteriormente, el análisis de las distancias entre los centroides de los clústeres muestra que $C_{0}$ y $C_{1}$ estás más cerca uno de otro respecto a $C_{2}$. Esto significa que las trayectorias descritas por ellos son más parecidas que las descritas por $C_{2}$.

Los usuarios con PC realizaron trayectorias clasificadas principalmente del tipo $C_{1}$ (4 de 5 participantes fueron clasificados como $C_{1}$ ). Además, hubo 2 de 4 participantes con NMD en este grupo. Sin embargo, este tipo de trayectorias no son realizadas por los individuos sin deterioro motor (HP) ni tampoco por aquellos con SCI.

Los participantes del grupo HP siguieron principalmente el tipo de trayectoria descrita por $C_{2}$ (3 de 4 participantes fueron clasificados como $C_{2}$ ) junto con 2 de 4 participantes con ND y 2 de 4 participantes con SCI.

Aquellos con SCI tendían a seguir trayectorias del tipo $C_{0}$ (3 de 4 usuarios), junto con 1 de 4 participantes de HP.

Los usuarios con ND presentan similitudes con los usuarios con PC y con el grupo HP, ya que produjeron trayectorias de los tipos $C_{1}$ y $C_{2}$, incluso cuando estos grupos son los menos similares. Esto sugiere que los usuarios de NMD tuvieron dos tipos de comportamiento antagónicos. Parece haber una tendencia en términos de patología agrupada por cada clúster:

- $C_{0}$ : dominada por usuarios con SCI, 3 de 4 están en este clúster

- $C_{1}$ : dominada por usuarios con PC, 4 de 5 están en este clúster, también 2 de 4 usuarios con ND

- $C_{2}$ : dominada por usuarios HP, 3 de 4 están en este clúster, también 2 de 4 usuarios con ND 


\begin{tabular}{|c|c|c|c|}
\hline Parámetro & $C_{0}$ & $C_{1}$ & $C_{2}$ \\
\hline Tiempo de clic (ms) & 4269 & 3865 & 2332 \\
\hline Distancia viajada $(\mathrm{N})$ & 2.154 & 1.245 & 0.125 \\
\hline Índice lineal & 0.248 & 0.203 & 0.198 \\
\hline Índice lineal con $\mathrm{R}$ & 0.322 & 0.298 & 0.281 \\
\hline Índice horizontal & 0.190 & 0.145 & 0.140 \\
\hline Índice vertical & 0.121 & 0.090 & 0.079 \\
\hline Índice diagonal & 0.080 & 0.076 & 0.061 \\
\hline Velocidad (Máx.) & 6.010 & 5.353 & 4.867 \\
\hline Velocidad (Prom.) & 0.461 & 0.371 & 0.353 \\
\hline Velocidad (Med.) & 0.117 & 0.077 & 0.053 \\
\hline Aceleración (Máx.) & 0.140 & 0.124 & 0.119 \\
\hline Aceleración (Mín.) & -0.076 & -0.086 & -0.101 \\
\hline Aceleración (Med.) & 0.001 & 0.000 & 0.000 \\
\hline Fases de cero aceleración & 26.602 & 21.253 & 15.305 \\
\hline Número de fijaciones & 3.814 & 3.408 & 2.043 \\
\hline Duración de fijaciones (Mín.) & 578 & 541 & 481 \\
\hline Duración de fijaciones (Máx.) & 2014 & 1842 & 1671 \\
\hline Duración de fijaciones (Prom.) & 1147 & 1105 & 1088 \\
\hline Duración de fijaciones (Med.) & 1102 & 1070 & 999 \\
\hline Longitud sacada (Mín.) & 80 & 70 & 63 \\
\hline Longitud sacada (Máx.) & 255 & 234 & 208 \\
\hline Longitud sacada (Prom.) & 156 & 140 & 122 \\
\hline Longitud sacada (Med.) & 154 & 123 & 108 \\
\hline Throughput (Ley de Fitts) & 1.017 & 0.855 & 0.635 \\
\hline Distancia al objetivo (N) & 3.229 & 3.229 & 3.229 \\
\hline Tiempo de reacción & 765 & 681 & 556 \\
\hline Error de ángulo de movimiento & 56.035 & 9.973 & 8.327 \\
\hline Número de entradas al objetivo & 1.481 & 1.422 & 1.014 \\
\hline Número de sub-movimientos & 20.561 & 10.893 & 5.351 \\
\hline Overshoots & 0.367 & 0.155 & 0.014 \\
\hline Velocidad (Max., S) & 5.951 & 5.280 & 4.867 \\
\hline Aceleración (Max., S) & 0.493 & 0.438 & 0.388 \\
\hline Jerk (Max., S) & 0.045 & 0.041 & 0.035 \\
\hline Cruces de eje de tarea & 1.903 & 1.747 & 1.258 \\
\hline Cambios de dir. de movimiento & 6.947 & 5.477 & 4.498 \\
\hline Cambios de dir. ortogonal & 4.505 & 4.283 & 1.932 \\
\hline Variabilidad del movimiento & 51.042 & 23.851 & 10.156 \\
\hline Error del movimiento & 66.655 & 27.156 & 14.100 \\
\hline Offset del movimiento & 3.564 & -0.331 & -1.320 \\
\hline
\end{tabular}

Tabla 6.2: Resultados del análisis cuantitativo de los centroides de cada clúster. $\mathrm{N}=$ normalizada, $\mathrm{S}=$ sobre muestreada. $C_{0}(\mathrm{n}=206), C_{1}(\mathrm{n}=237), C_{2}(\mathrm{n}=279)$ 


\begin{tabular}{llll}
\hline Clúster & Mínimo & Máximo & Mediano \\
\hline$C_{0}$ & 0.9155 & 2.574 & 0.9576 \\
$C_{1}$ & 0.7175 & 2.724 & 1.269 \\
$C_{2}$ & 0.9129 & 2.691 & 0.9603 \\
\hline
\end{tabular}

Tabla 6.3: El radio máximo, mínimo y mediano de cada clúster.

\begin{tabular}{llllll}
\hline Grupo & Usuario & $C_{0}$ & $C_{1}$ & $C_{2}$ & $\begin{array}{l}\text { Trayectoria } \\
\text { preferida }\end{array}$ \\
\hline Usuarios con SCI & & & & & \\
& US01 & $\mathbf{3 9}$ & 22 & $\mathbf{3 9}$ & $C_{0}, C_{2}$ \\
& US02 & 28 & 11 & $\mathbf{6 1}$ & $C_{2}$ \\
& US03 & $\mathbf{3 9}$ & 36 & 25 & $C_{0}$ \\
& US04 & $\mathbf{4 7}$ & 17 & 36 & $C_{0}$ \\
\hline Usuarios con PC & & & & & \\
& US05 & 0 & $\mathbf{1 0 0}$ & 0 & $C_{1}$ \\
& US06 & 22 & $\mathbf{7 8}$ & 0 & $C_{1}$ \\
& US07 & 31 & 11 & $\mathbf{5 8}$ & $C_{2}$ \\
& US08 & 11 & $\mathbf{8 3}$ & 6 & $C_{1}$ \\
& US10 & 33 & $\mathbf{3 9}$ & 28 & $C_{1}$ \\
\hline Usuarios con ND & & & & & \\
& US11 & 29 & $\mathbf{4 9}$ & 23 & $C_{1}$ \\
& US12 & 19 & 22 & $\mathbf{5 8}$ & $C_{2}$ \\
& US13 & 36 & $\mathbf{5 6}$ & 8 & $C_{1}$ \\
& US14 & 22 & 11 & $\mathbf{6 7}$ & $C_{2}$ \\
\hline Usuarios de control & & & & & \\
& US94 & $\mathbf{4 1}$ & 20 & 39 & $C_{0}$ \\
& US95 & 28 & 30 & $\mathbf{4 2}$ & $C_{2}$ \\
& US98 & 30 & 2 & $\mathbf{6 8}$ & $C_{2}$ \\
& US99 & 24 & 10 & $\mathbf{6 6}$ & $C_{2}$ \\
\hline
\end{tabular}

Tabla 6.4: Distribución (\%) de las trayectorias de los participantes entre los clústeres. La trayectoria preferida se define como el grupo con el número máximo de instancias. 
Es importante notar que los grupos o clúster no están separando por patología, ya que hay usuarios de control en $C_{0}$ (US94) y usuarios con PC en $C_{2}$ (US07). Esto es importante porque confirma nuestra hipótesis de que las estrategias de control de los participantes no están relacionadas exclusivamente con el perfil patológico - Hipótesis 23-.

\section{Tendencia de las métricas de cada clúster}

Identificamos cuál es el clúster asociado con el valor óptimo para cada parámetro, para identificar si existe una tendencia de las mejores métricas con respecto a un clúster. Para esto utilizamos el criterio de si un valor es mejor si es mayor o menor, Tabla 6.5.

Este análisis sugiere que el centroide del grupo $C_{2}$ logra en casi un $90 \%$ la mejor combinación de parámetros de los tres grupos. Ninguno de los parámetros en $C_{2}$ fue calificado como el peor. Las métricas más desfavorables están contenidas en $C_{0}$ y $C_{1}(42 \%$ y $55 \%$ respectivamente). Este resultado confirma la bondad del método, dado que en el clúster $C_{2}$ se encuentran la mayoría de los usuarios sin patologías. Se pueden observas más detalles en la Tabla 6.5.

\section{Interpretación visual y analítica de las trayectorias de cada clúster}

La Figura 6.4 muestra las trayectorias (en píxeles) asociadas a cada clúster, para cada tamaño objetivo. Para mejorar la claridad, se han girado las trayectorias para que estén en la misma dirección. En las figuras las líneas azules son las trayectorias, los puntos verdes son los puntos finales y los círculos rojos son el radio del objetivo.

Además, la Figura 6.5 muestra la velocidad del cursor (en píxeles/segundo) durante las tareas de apuntamiento, de nuevo, para cada clúster y para cada tamaño objetivo. En estas figuras, las líneas azules son la velocidad instantánea y las áreas naranjas son la velocidad media.

En las siguientes subsecciones analizaremos esas seis figuras para obtener una idea del tipo de trayectorias que contiene cada grupo.

\section{Usuarios de $C_{2}$. Rápidos y precisos}

Un análisis visual de la Figura 6.4 muestra que ninguna de las trayectorias en $C_{2}$ contiene overshoots. Las curvas de velocidad en la Figura 6.5 también sugieren que hay sólo unos pocos overshoots en $C_{2}$, ya que sólo hay un gran pico de velocidad (superior a 4 pix/s) que corresponde a una gran sacada, y velocidades bajas en las muestras que preceden al clic. Respecto a dónde se hizo el clic, las trayectorias en $C_{2}$ son las más exactas ya que casi todos los clics (representados como círculos verdes) están dentro del objetivo (círculo rojo).

De acuerdo con los parámetros del centroide, las trayectorias en $C_{2}$ realizaron el clic más rápido (tiempo de clic) y también reaccionan rápidamente (tiempo de reacción) y viajan menos distancia para realizar un clic (distancia recorrida normalizada).

\section{Usuarios de $C_{0}$. Precisos pero lentos}

A pesar de que la precisión del punto final de las trayectorias en $C_{0}$ es similar a la mostrada en $C_{2}$, éstas muestran más submovimientos y overshoots. Las trayectorias de este 


\begin{tabular}{|c|c|c|c|c|}
\hline Parámetro & Mejor si & Mejor & Medio & Peor \\
\hline Tiempo de clic & Bajo & $C_{2}$ & $C_{0}$ & $C_{1}$ \\
\hline Distancia viajada $(\mathrm{N})$ & Bajo & $C_{2}$ & $C_{0}$ & $C_{1}$ \\
\hline Índice lineal & Alto & $C_{2}$ & $C_{0}$ & $C_{1}$ \\
\hline Índice lineal con $\mathrm{R}$ & Alto & $C_{2}$ & $C_{1}$ & $C_{0}$ \\
\hline Índice horizontal & Alto & $C_{2}$ & $C_{1}$ & $C_{0}$ \\
\hline Índice vertical & Alto & $C_{2}$ & $C_{0}$ & $C_{1}$ \\
\hline Índice diagonal & Alto & $C_{0}$ & $C_{2}$ & $C_{1}$ \\
\hline Velocidad (Máx.) & Alto & $C_{2}$ & $C_{1}$ & $C_{0}$ \\
\hline Velocidad (Prom.) & Bajo & $C_{0}$ & $C_{2}$ & $C_{1}$ \\
\hline Velocidad (Med.) & Bajo & $C_{2}$ & $C_{0}$ & $C_{1}$ \\
\hline Aceleración (Máx.) & Alto & $C_{2}$ & $C_{1}$ & $C_{0}$ \\
\hline Aceleración (Mín.) & Bajo & $C_{2}$ & $C_{1}$ & $C_{0}$ \\
\hline Aceleración (Med.) & Bajo & $C_{2}$ & $C_{0}$ & $C_{1}$ \\
\hline Fases de cero aceleración & Bajo & $C_{2}$ & $C_{1}$ & $C_{0}$ \\
\hline Número de fijaciones & Bajo & $C_{2}$ & $C_{0}$ & $C_{1}$ \\
\hline Duración de fijaciones (Mín.) & Bajo & $C_{0}$ & $C_{2}$ & $C_{1}$ \\
\hline Duración de fijaciones (Máx.) & Bajo & $C_{2}$ & $C_{1}$ & $C_{0}$ \\
\hline Duración de fijaciones (Prom.) & Alto & $C_{0}$ & $C_{2}$ & $C_{1}$ \\
\hline Duración de fijaciones (Med.) & Alto & $C_{2}$ & $C_{0}$ & $C_{1}$ \\
\hline Longitud sacada (Mín.) & Alto & $C_{2}$ & $C_{1}$ & $C_{0}$ \\
\hline Longitud sacada (Máx.) & Bajo & $C_{0}$ & $C_{2}$ & $C_{1}$ \\
\hline Longitud sacada (Prom.) & Alto & $C_{2}$ & $C_{1}$ & $C_{0}$ \\
\hline Longitud sacada (Med.) & Alto & $C_{2}$ & $C_{1}$ & $C_{0}$ \\
\hline Throughput (Ley de Fitts) & Alto & $C_{2}$ & $C_{1}$ & $C_{0}$ \\
\hline Distancia al objetivo (N) & Bajo & - & - & - \\
\hline Tiempo de reacción & Bajo & $C_{2}$ & $C_{0}$ & $C_{1}$ \\
\hline Error de ángulo de movimiento & Bajo & $C_{2}$ & $C_{0}$ & $C_{1}$ \\
\hline Número de entradas al objetivo & \multicolumn{2}{|c|}{ Cercano a $1 C_{2}$} & $C_{0}$ & $C_{1}$ \\
\hline Número de sub-movimientos & Bajo & $C_{2}$ & $C_{0}$ & $C_{1}$ \\
\hline Overshoots & Bajo & $C_{2}$ & $C_{0}$ & $C_{1}$ \\
\hline Velocidad (Máx., S) & Alto & $C_{2}$ & $C_{1}$ & $C_{0}$ \\
\hline Aceleración (Máx., S) & Alto & $C_{2}$ & $C_{1}$ & $C_{0}$ \\
\hline Jerk (Máx., S) & Alto & $C_{2}$ & $C_{1}$ & $C_{0}$ \\
\hline Cruces de eje de tarea & Bajo & $C_{2}$ & $C_{1}$ & $C_{0}$ \\
\hline Cambios de dir. de movimiento & Bajo & $C_{2}$ & $C_{1}$ & $C_{0}$ \\
\hline Cambios de dir. ortogonal & Bajo & $C_{2}$ & $C_{1}$ & $C_{0}$ \\
\hline Variabilidad del movimiento & Bajo & $C_{2}$ & $C_{0}$ & $C_{1}$ \\
\hline Error del movimiento & Bajo & $C_{2}$ & $C_{0}$ & $C_{1}$ \\
\hline Offset del movimiento & Bajo & $C_{2}$ & $C_{0}$ & $C_{1}$ \\
\hline
\end{tabular}

Tabla 6.5: Resultados del análisis cualitativo de los centroides de los clústeres. $\mathrm{N}=$ normalizado, $\mathrm{S}=$ sobre muestreada 
clúster presentan un primer pico más pequeño (3-4 píxeles/s) en la curva de velocidad, correspondiente a la primera sacada, seguido por unos pocos picos más pequeños que corresponden a overshoots, lo cual es otro signo de menor exactitud. Además, las trayectorias en $C_{0}$ muestran un mayor porcentaje de clics fallidos (clics fuera del objetivo). Véanse las Figuras 6.4 y 6.5.

Como se indicó por las medidas de los centroides, las tareas de apuntamiento en $C_{0}$ fueron las más lentas realizando el clic (clickTime) y reaccionando (tiempo de reacción), las que viajaron más distancia para realizar un clic (distanceTraveledNormalized) y que menos viajaron en línea recta al objetivo (linearIndex y linearIndexWithR).

\section{Usuarios de $C_{1}$. Lentos y poco precisos}

Como se mencionó anteriormente, el grupo $C_{1}$ difiere de $C_{0}$ y $C_{2}$ más que $C_{0}$ y $C_{2}$ difieren entre sí. Este comportamiento también puede observarse en las trayectorias y las curvas de velocidad mostradas en las Figuras 6.4 y 6.5. Estas trayectorias tenían picos de velocidad que son ligeramente más pequeños que los de $C_{0} \mathrm{y}$ valores de velocidad más altos en las muestras antes de que se haga clic.

\subsubsection{Discusión}

En este estudio hemos presentado una metodología para caracterizar la interacción de usuarios con el ordenador mediante un eye-tracker. La caracterización se realizó detectando la tendencia de los usuarios de realizar cierto tipo de trayectorias en la pantalla. Este análisis nos permitió identificar los patrones de comportamiento de estos usuarios. A través de este análisis se encontró que los usuarios sin discapacidad y con trastornos neuromusculares eran rápidos y precisos, mientras que aquellos con problemas motores como la lesión medular eran lentos pero precisos y los usuarios con parálisis cerebral, severamente afectados por problemas motores, fueron lentos y poco precisos.

El eye-tracker utiliza un filtro on-line, con el fin de reducir los movimientos del cursor debido al ruido o grandes variaciones en la señal. Este filtro afectó a la interacción y al comportamiento dinámico del cursor en la pantalla. Sin embargo, los rastreadores de ojos no son viables sin un filtro. Además, todos los usuarios realizaron pruebas con el mismo filtro aplicado por lo que los resultados se vieron afectados por igual.

Un sistema de clasificación de la interacción con el ordenador nos permitiría evaluar nuestra caracterización, como lo han hecho Kooiker et al. con su estudio [53]. Sin embargo, hasta lo que conocemos, no existe un sistema de clasificación de la interacción con el ordenador. En este sentido, creemos que hemos dado un paso adelante con respecto a la valoración de la interacción con el ordenador mediante eye-trackers. Un sistema de clasificación bien establecido nos permitiría: realizar evaluaciones de usabilidad de diferentes dispositivos, identificar evoluciones, o realizar análisis comparativos de diferentes dispositivos o técnicas de asistencia.

Hemos analizado principalmente las fijaciones y las sacadas, aunque en la Sección 3.1.2 hemos dicho que existen tres tipos de movimientos de los ojos. El tercero, la persecución, es el movimiento de los ojos cuando la atención se fija en un objetivo de movimiento. Este tipo de movimiento ocular no se produjo en nuestro estudio, debido a la naturaleza estática de la tarea de apuntamiento propuesta, que no incluyen la fijación en el objeto en movimiento. 
$\mathrm{C} 2$
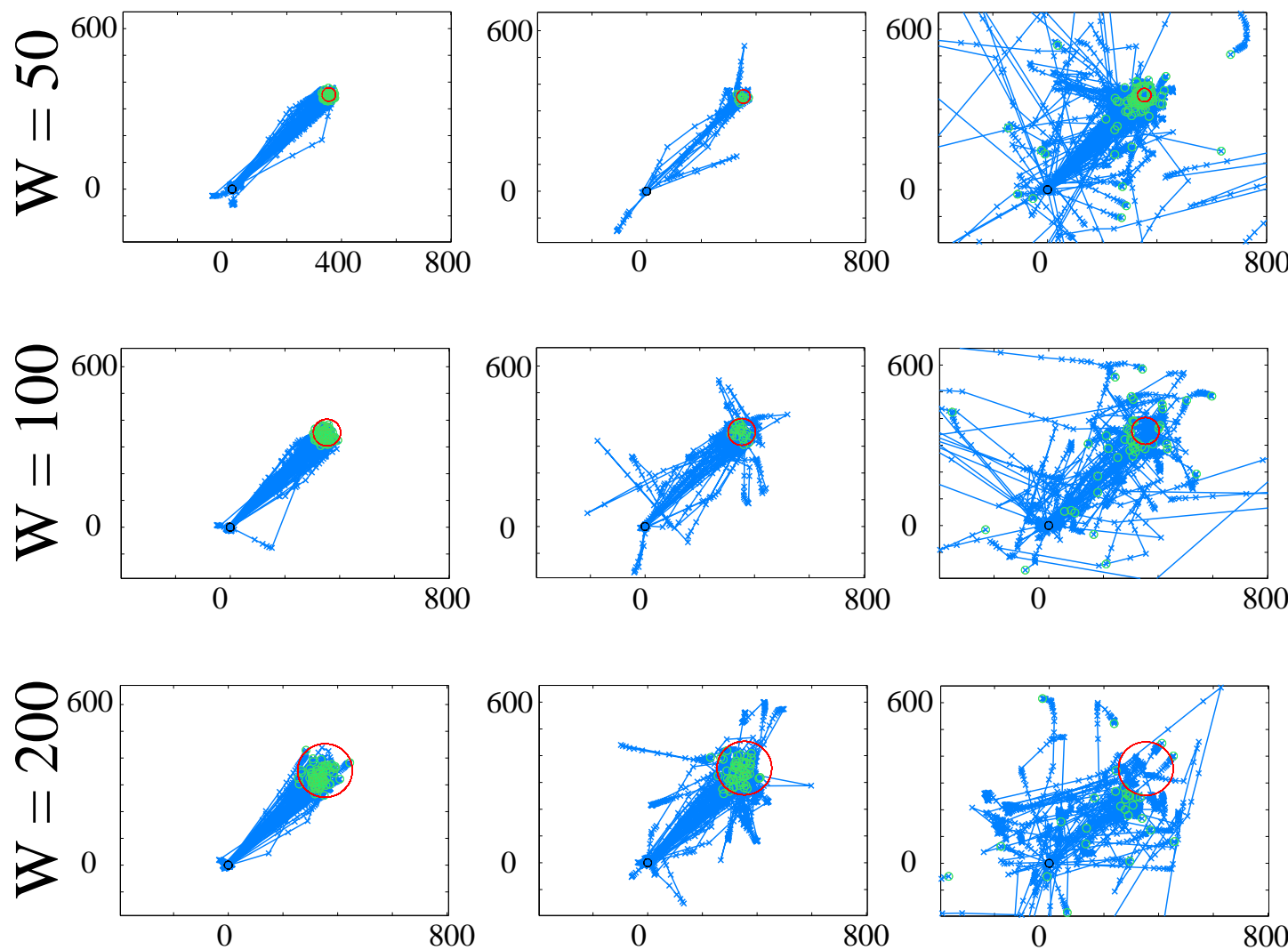

C1

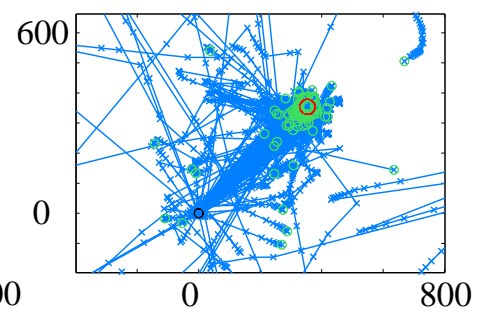

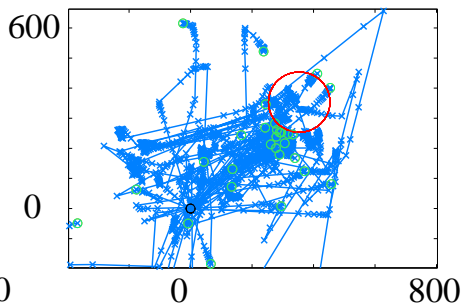
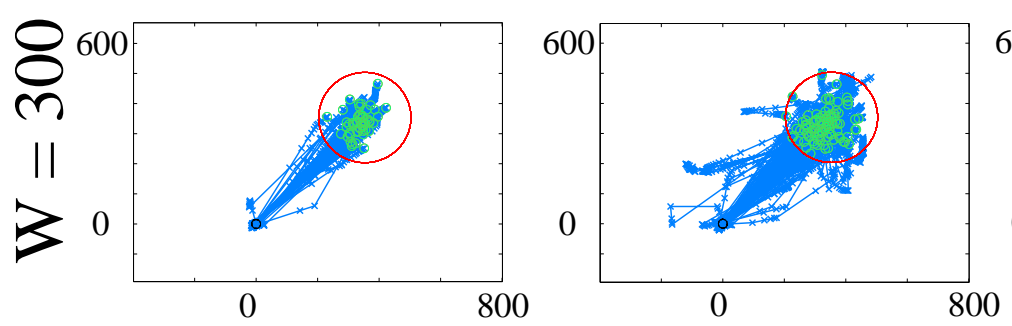

Figura 6.4: Trayectorias superpuestas y rotadas, asociadas a cada uno de los tres clústeres (la primera columna para $C_{2}$, la segunda para $C_{0}$, y la última para $C_{1}$ ), para cada uno de los cuatro tamaños de objetivo (la primera fila para un tamaño de objetivo 50, la siguiente 100, la tercera 200, y la última para 300). 
$\mathrm{C} 2$
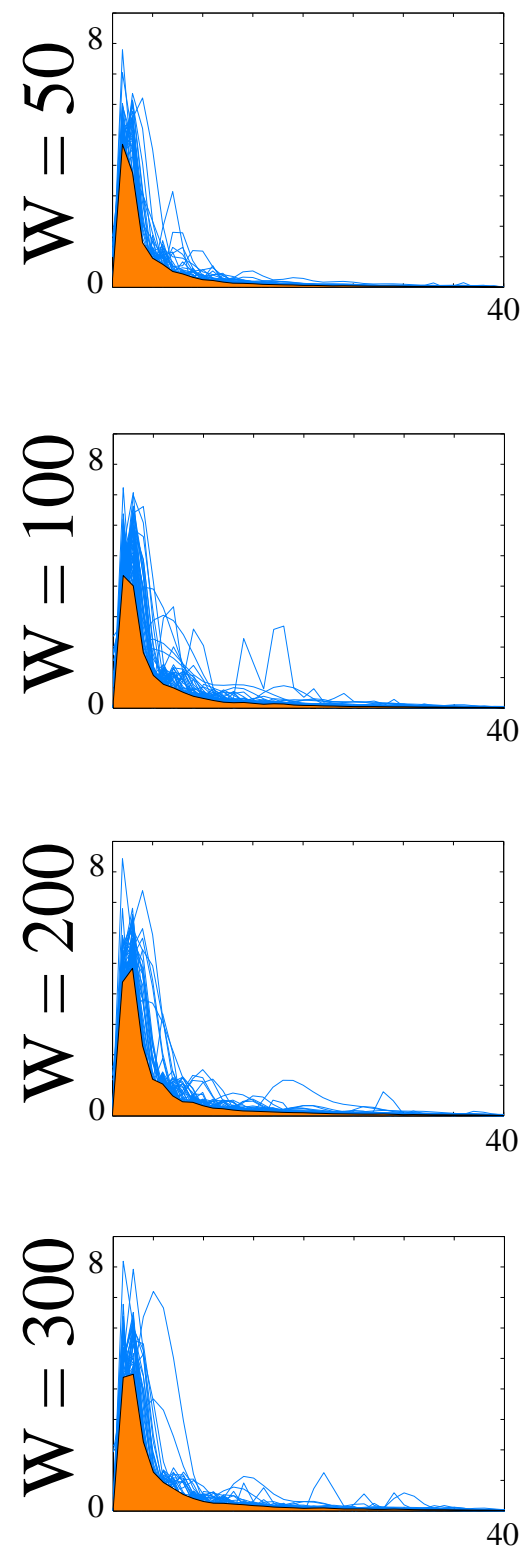

$\mathrm{C} 0$

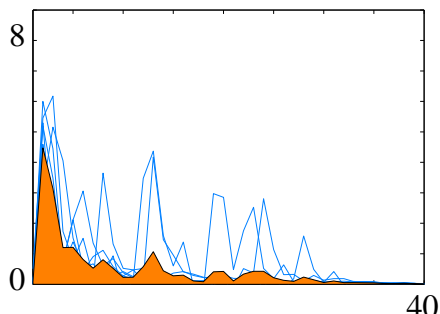

40
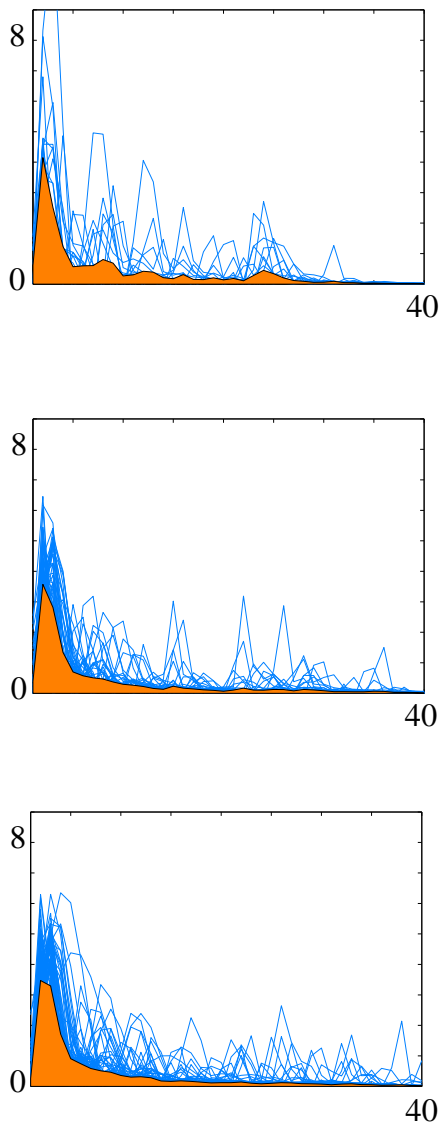
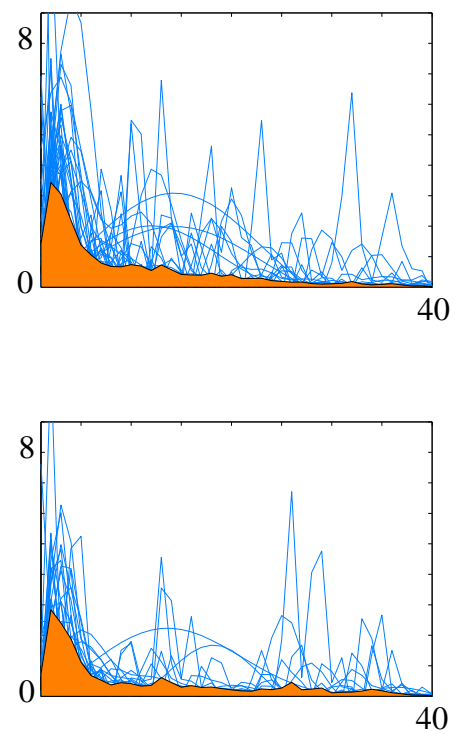

C1

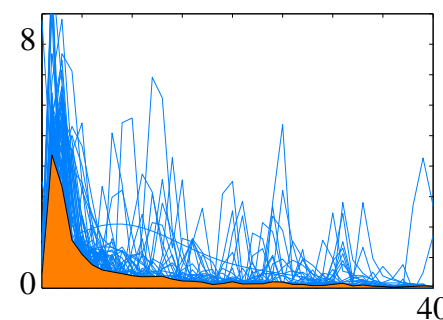

40

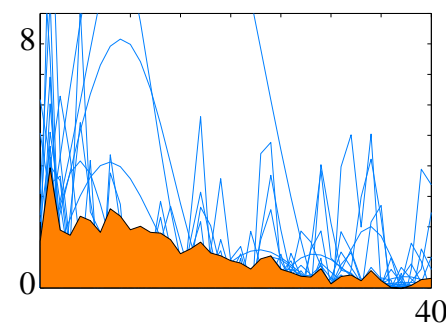

Figura 6.5: Velocidades superpuestas de las trayectorias asociadas a cada uno de los tres clústeres (columnas), para cada uno de los cuatro tamaños de objetivo (filas). 
El reducido número de participantes hace difícil sacar conclusiones sólidas sobre el tema. Sin embargo, la población es similar a trabajos similares publicados en la literatura: un participante en [110], siete participantes en [111], y siete participantes en [112]. La razón que nos impidió llegar a un mayor número de pacientes es que nuestros criterios de inclusión son muy estrictos. Esto, sin embargo, nos permitió extraer información más fiable sobre el estudio. Un grupo más amplio de participantes mejoraría y consolidaría claramente las conclusiones de este documento.

\subsubsection{Conclusión de la caracterización de la interacción}

Uno de los objetivos de esta tesis, Objetivo 2, fue el de explorar grupos o clústeres de usuarios relacionados por su semejanza en la interacción con el ordenador. Nuestra hipótesis fue que no todos los usuarios tienen la misma estrategia para controlar el equipo, por lo que cada grupo de usuarios se beneficiará de manera diferente de los nuevos desarrollos - Hipótesis 22-. Además, partimos también con la hipótesis de que el tipo de interacción con el ordenador no está estrictamente relacionado con el perfil patológico del usuario - Hipótesis 23-.

Mediante una técnica de aprendizaje automático no supervisada, llamada $k$-means, hemos agrupado a las tareas de alcance en tres grupos, según su semejanza en las características de las métricas de las tareas de alcance. A continuación, hemos explorado si existen diferencias entre estos grupos que validen la separación realizada por el algoritmo, mediante una serie de interpretaciones de los datos.

Hemos encontrado que los grupos tiene cierta relación con la patología, pero no de forma exclusiva: el grupo $C_{0}$ está dominado por tareas de alcance de usuarios con SCI -3 de los 4 usuarios están en este clúster-, el grupo $C_{1}$ contiene especialmente a las tareas de apuntamiento de usuarios con $\mathrm{PC}-4$ de 5 usuarios están en este clúster, también 2 de 4 usuarios con ND-, y el grupo $C_{2}$ agrupó mayormente a las tareas de usuarios HP -3 de 4 participantes están en este clúster, también 2 de 4 usuarios con ND-.

Además, hemos encontrado también que los valores de las métricas tienen una tendencia entre los clústeres, señalando que hay mejores clústeres que otros: $C_{2}$ logra en casi un $90 \%$ la mejor combinación de parámetros de los tres grupos y $C_{0}$ y $C_{1}$ contienen los parámetros más desfavorables (42\% y $55 \%$ respectivamente).

En la última interpretación, más llamativa por su naturaleza visual, vemos claras diferencias en las estrategias cinemáticas de los PTs de los diferentes grupos, lo cual consolida la agrupación de los datos.

Todas estas valoraciones nos permitieron clasificar a cada uno de los usuarios cualitativamente según al grupo al cual pertenecen como: los usuarios $C_{2}$ son rápidos y precisos, los usuarios $C_{0}$ también son precisos, pero más lentos, y finalmente los usuarios $C_{1}$ son usuarios lentos y poco precisos.

La metodología presentada permite establecer etiquetas de forma automática para clasificar a las tareas de alcance, con el fin de estimar de forma automática la clase de la tarea de apuntamiento, según los tres tipos de grupos de identificados y caracterizados. 


\begin{tabular}{llll}
\hline Clúster & Tipo de interacción & Clase & $\mathbf{N}^{\mathbf{o}}$ instancias \\
\hline$C_{0}$ & Precisos pero lentos & $C_{a}$ & 206 \\
$C_{1}$ & Lentos y poco precisos & $C_{b}$ & 237 \\
$C_{2}$ & Rápidos y precisos & $C_{c}$ & 279 \\
& & & 722 (Total) \\
\hline
\end{tabular}

Tabla 6.6: Las tareas de alcance han sido etiquetadas según a que clase pertenecen: $C_{a}, C_{b}, C_{c}$.

\subsection{Evaluación de la clasificación de tareas de alcance y de las métricas}

Después de identificar y caracterizar a grupos de usuarios según su tipo de interacción con el ordenador mediante una técnica de aprendizaje no supervisado, en esta sección vamos a valorar dos cuestiones: (1) la capacidad de diferentes clasificadores - basados en aprendizaje supervisado - para identificar la clase de tarea de apuntamiento a partir de las métricas y (2) el aporte de las distintas métricas en la clasificación de las tareas de apuntamiento - en términos de variación de la capacidad de clasificación-. Para valorar la capacidad de los clasificadores utilizamos la tasa de error.

Tener métricas, parámetros o atributos irrelevantes normalmente confunde a los sistemas de aprendizaje automático, [130, pag. 307]. Debido al efecto negativo de las métricas irrelevantes en la mayoría de los esquemas de aprendizaje automático, es común preceder al aprendizaje con una etapa de selección de atributos que intenta eliminar las menos relevantes, [130, pag. 308]. Tener un conjunto de métricas más compacto ayuda además a tener un sistema de atributos más fácilmente interpretable y centrado en los más importantes.

El protocolo del test, los aparatos y los participantes reclutados han sido los mismos que los de la Sección 6.1. El procesamiento de datos cambia y se describe a continuación.

\subsubsection{Procesamiento de datos}

Primero realizamos una clasificación de las tareas con todas las métricas con más de 10 clasificadores. A continuación, identificamos las métricas más relevantes y las menos importantes con 4 técnicas de selección de parámetros. Finalmente, volvimos a clasificar a las tareas de alcance con el clasificador con la menor tasa de error, pero sin las métricas menos influyentes identificadas por los diferentes selectores, para valorar el efecto sobre la clasificación.

Para la clasificación de las tareas de alcance necesitamos datos etiquetados. Para el etiquetado de los datos utilizamos los resultados del análisis anterior, donde identificamos la clase de cada tarea de alcance a uno de tres grupos, Tabla 6.6. Esto implica que un mismo usuario puede tener instancias que pertenecen a clases distintas, así como ha sucedido en la agrupación de los datos de la sección anterior.

Utilizamos más de 10 clasificadores para valorar tanto las técnicas de clasificación como el efecto de la selección de variables en la clasificación. Todos los clasificadores y los métodos de selección de atributos provienen de la plataforma Weka $3.7^{6}$ [129].

\footnotetext{
${ }^{6}$ http://www.cs.waikato.ac.nz/ ml/weka/index.html
} 
Para la valoración de la clasificación utilizamos la tasa de error del clasificador para identificar la clase de la tarea de alcance, que es la relación entre el número de fallos y el número total de tareas, expresada en porcentaje. Además, indicamos los intervalos de confianza o bandas de significancia de los resultados, con $95 \%$ de confianza $(\mathrm{z}=1,96)$, Ecuación (6.1). Los intervalos de confianza nos han permitido conocer la significancia de la diferencia de las tasas de error de los clasificadores. Para ello, verificamos que no exista solape entre las bandas de significancia.

$$
\text { Intervalo de confianza }=T \text {. acierto } \pm z \sqrt{\frac{\text { T. acierto } *(100-\text { T. acierto })}{\text { Número de instancias }}}
$$

A continuación, describiremos los clasificadores, con sus principales parámetros de configuración.

NaiveBayes. Utilizamos un clasificador bayesiano, el NaiveBayes, que utiliza la distribu-

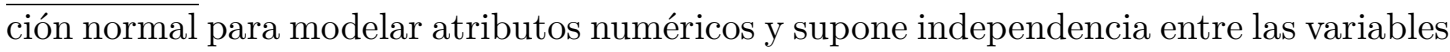
predictoras - asumiendo que la presencia o ausencia de una característica particular no está relacionada con la presencia o ausencia de cualquier otra característica-. Una ventaja del clasificador de Bayes ingenuo es que - como se asume que las variables son independientes-, solo es necesario determinar las varianzas de las variables y no toda la matriz de covarianza [130, pag. 451]. Este clasificador no tiene parámetros para configurar la clasificación.

J48, RandomTree, y RandomForest. Utilizamos también tres clasificadores basados en árboles de decisión: J48, RandomTree, y RandomForest. Estos clasificadores utilizan el enfoque "divide y vencerás". Los clasificadores basados en árboles construyen una serie de nodos de decisión jerárquicos, los cuales comparan un atributo particular con un valor constante [130, pag. 64]. El clasificador $J 48$ permite configurar el factor de confianza, que evita el sobre entrenamiento de nuestro modelo ofreciendo un resultado más genérico. Un valor más pequeño de este parámetro implica un modelo más general y viceversa. Los clasificadores RandomTree y RandomForest construyen el árbol de decisión a partir de $K$ atributos seleccionados aleatoriamente. Ambos clasificadores permiten establecer este número $K$ de atributos seleccionados aleatoriamente. RandomForest construye $I$ árboles con $K$ atributos seleccionados aleatoriamente.

Decision Table. Utilizamos un clasificador basado en reglas, DecisionTable. Este clasificador, dada una instancia nueva no etiquetada, busca una instancia que coincida con la tabla de instancias - puede haber muchas coincidencias en la tabla - Si no encuentra una instancia que coincida, se devuelve la clase mayoritaria de la tabla; de lo contrario, se devuelve la clase mayoritaria de todas las instancias coincidentes [132]. Este clasificador permite configurar la función para medir la coincidencia con las instancias.

Ibk. Utilizamos el método perezoso $I b k$ - conocido comúnmente como $k$ nearest neighbors, $k-n n-7$. Este clasificador, compara cada nueva instancia a clasificar con las existentes utilizando una métrica de distancia, y las $k$ instancias más cercanas se utiliza para asignar la clase a la nueva, asignando la clase mayoritaria de los $k$ vecinos más cercanos (o el promedio ponderado de distancia si la clase es numérica) [130, pag. 78]. Este clasificador permite configurar el número $k$ de instancias más cercanas.

MultilayerPerceptron. Utilizamos un clasificador de perceptrones multicapa MultilayerPerceptron, el cual es el tipo más destacado de red neuronal [130, pag. 241]. Los percep-

\footnotetext{
${ }^{7}$ Se le llama perezoso porque deja todo el trabajo de clasificación para el momento de clasificar una nueva instancia
} 
trones multicapa pertenecen a una clase de redes llamadas de realimentación positiva, porque las salidas de las neuronas van a las siguientes capas, pero no a las anteriores, de modo que no hay bucles de retroalimentación y la salida de la red depende solamente de la instancia de entrada actual. Este tipo de algoritmos son en términos computacionales muy costosos. Son una buena alternativa a problemas no linealmente separables. Es un método basado en regresión logística.

Logistic y SMO. Utilizamos un clasificador basado en regresión logística, el cual calcula la probabilidad de ocurrencia de cada clase mediante una función logística [130, pag. 126]. La regresión lineal no es una opción válida ya que nuestra clase es del tipo nominal y no numérica - a saber $C_{a} C_{b}$ y $C_{c}$ - . La mayor desventaja de este clasificador es que sólo puede representar límites entre clases lineales, lo que la hace demasiado simple para muchas aplicaciones prácticas. Las máquinas de soporte vectorial — support vector machines - utilizan modelos lineales para implementar límites de clase no lineales. Para ello, transforma la entrada utilizando un mapeo no lineal. En otras palabras, transforma el espacio de las instancias en un nuevo espacio. Con una asignación no lineal, una línea recta en el nuevo espacio no se ve directamente en el espacio de instancias original. Un modelo lineal construido en el nuevo espacio puede representar un límite de decisión no lineal en el espacio original [130, pag. 223]. Ambos clasificadores no clasifican como tal a una nueva instancia, sino que señalan una probabilidad de la clase. Al utilizarlo como clasificador, la clase reconocida es la que tiene más probabilidad. Utilizamos los clasificadores de regresión logística y de soporte vectorial que nos ofrece Weka v3.7, llamados Logistic y $S M O$ respectivamente. El algoritmo $S M O$ permite cambiar $C$, que es la ponderación a los errores durante el modelado. Para valores grandes de $C$, la optimización elegirá un hiperplano de margen más pequeño si ese hiperplano hace un mejor trabajo de conseguir que todos los puntos de entrenamiento estén clasificados correctamente. Por el contrario, un valor muy pequeño de $C$ hará que el optimizador busque un hiperplano de separación de mayor margen, incluso si ese hiperplano clasifica erróneamente más puntos.

AdaBoostM1 y el Vote. Además de todos estos clasificadores, existen técnicas de aprendizaje conjunto - ensemble learning - Este tipo de aprendizaje combina las predicciones de diferentes clasificadores. Su principal ventaja es que normalmente mejora los resultados. No obstante, son más difíciles de analizar. Entre los múltiples algoritmos basados en este paradigma se destacan dos aproximaciones: Boosting y Voting. Boosting entrena un mismo modelo con sub grupos distintos del conjunto total de datos y Voting entrena diferentes modelos con el mismo grupo de datos. Boosting construye modelos de forma iterativa, buscando modelos expertos en ejemplos mal clasificados por modelos anteriores. La idea detrás es generar modelos complementarios. Los algoritmos de votación o Voting utilizan estrategias simples, en las que se aglomeran los resultados de las decisiones de los clasificadores tomando, por ejemplo, la clase que aparece en la mayoría de los casos. Boosting también adopta este enfoque para el resultado final, pero deriva los modelos individuales de diferente manera. En Weka estos algoritmos están agrupados bajo el nombre de meta aprendices, ya que toman como argumento un algoritmo de aprendizaje o varios - llamados aprendices de base-, y crean un nuevo algoritmo. Los algoritmos específicos utilizados, basados en el paradigma de Boosting y Voting de la plataforma Weka, fueron el AdaBoostM1 y el Vote respectivamente. AdaBoostM1 permite modificar el número de iteraciones que tiene relación con el número de modelos a entrenar y Vote permite seleccionar distintas reglas de combinación — por ejemplo, la clase que aparezca más veces, la media de probabilidades de cada clasificador, etc.- . 
Para la evaluación de los clasificadores hemos utilizado validación cruzada de bloques. La validación cruzada divide el grupo de instancias en $n$ bloques de igual tamaño. Cada bloque es utilizado una vez para test y el resto para entrenamiento. Este proceso se repite de forma iterativa $n$ veces, de manera que al final del proceso cada instancia ha sido utilizada una vez para el test [130, pag. 153]. En nuestros ensayos $n=10$.

Para la selección de métricas a eliminar se han utilizado técnicas de valoración tanto de atributos individuales como de grupo de atributos.

Cfs-Subset y Wrapper-Subset. Las técnicas de selección de conjunto de atributos pueden utilizar distintos métodos de búsqueda de subconjuntos, así como incluir o no al clasificador final. Se utilizó el evaluador de grupo de atributos Cfs-Subset - el cual busca identificar un subconjunto de parámetros que esté muy correlacionado con la clase y que su intercorrelación sea baja- y el Wrapper-Subset - el cual utiliza una validación cruzada con el clasificador final con cada conjunto de atributos-. Ambos evaluadores se utilizaron junto con el método de búsqueda BestFirst, con las tres direcciones de búsqueda disponibles: hacia adelante, hacia atrás, y bidireccional.

Info-Gain y PCA. Para la evaluación de las métricas individualmente se utilizó InfoGain, el cual evalúa los atributos midiendo su ganancia de información con respecto a la clase. Este evaluador ha sido utilizado junto con método de ranking Ranker para ordenar a los atributos según su ganancia de información de mayor a menor. Además, se utilizó el análisis de componentes principales - Principal Components Analysis, PCA- para la reducción de dimensionalidad del problema, de manera a que el resultado explicara el $95 \%$ de la varianza.

\subsubsection{Resultados}

\section{Clasificación previa a la selección de métricas}

Con los datos etiquetados, clasificamos las 722 tareas de alcance con los 11 clasificadores seleccionados, mediante validación cruzada de 10 bloques, Tabla 6.7, Figura 6.6. Los parámetros de configuración de los clasificadores han sido seleccionados de manera que ofrezcan la menor tasa de error.

El clasificador NaiveBayes tuvo la peor tasa de error entre todos los clasificadores, $21,61 \%$. Este clasificador asume la independencia de los atributos. Es probable que la alta tasa de error de este clasificador se deba a que los atributos no son independientes entre sí. No hubo solape entre las bandas de significancia entre este clasificador y el siguiente $J 48$ - en orden decreciente de tasa de error-, por lo que se concluye que la diferencia es significativa. Esto ubica a este clasificador en el puesto seis en el ranking global.

El algoritmo $J 48$ presentó una tasa de error del 8,04\%, con un factor de confianza de 0,05 - se ha probado con valores de $0,05,0,10,0,25,0,40,0,50,0,70-$. Con este factor de confianza se creó un árbol de decisión con un tamaño de 27, con 14 hojas.

Con otro algoritmo basado en árboles de decisión, el Random Tree, obtuvimos una tasa de error del 7,90\%, con 15 atributos seleccionados aleatoriamente - hemos probado con $6,12,15$, y 18-, con un árbol de tamaño 87. El algoritmo RandomForest consiguió reducir la tasa de error casi a la mitad de lo conseguido por RandomTree, con una tasa de error de 4,44\%, mediante 150 árboles — hemos probado con valores de 100, 150, y 200 - con 15 atributos seleccionados — por ser el mejor valor para Random Tree-. 

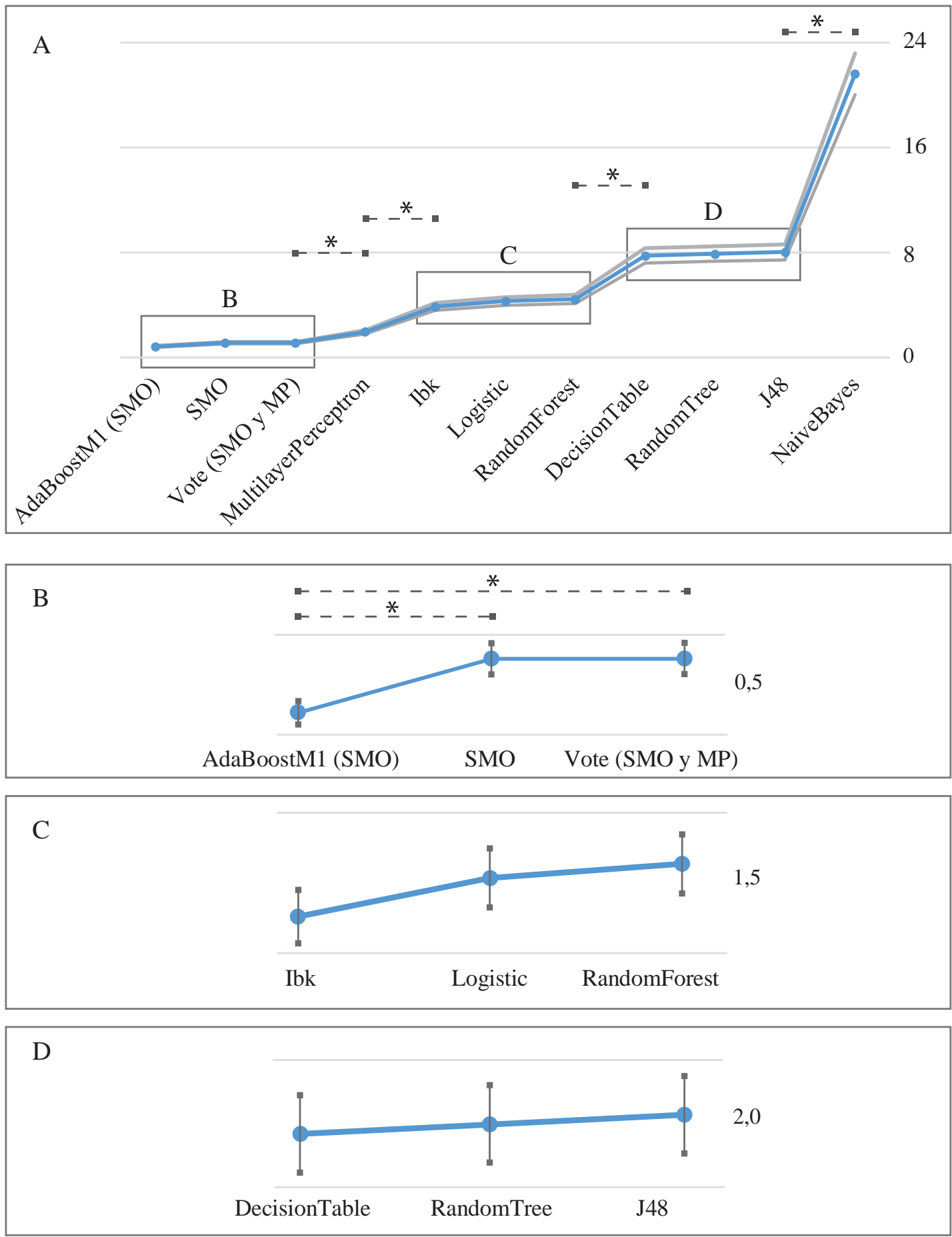

Figura 6.6: A: Tasa de error (\%) de todos los clasificadores seleccionados (línea azul) junto con sus bandas de significancia al $95 \%$ (línea gris), configurados con los mejores parámetros, previamente a la selección de atributos, Tabla 6.7. Además, los recuadros B, C, y D son detalles de la figura $\mathrm{A}$, donde se pueden apreciar los solapes de las bandas de significancia, excepto en B entre AdaBoostM1 y SMO. Los asteriscos (*) indican una diferencia significativa. 


\begin{tabular}{lllll}
\hline Clasificador & $\begin{array}{l}\text { Tasa } \\
\text { error } \\
(\mathbf{\%})\end{array}$ & $\begin{array}{l}\text { Bandas de } \\
\text { significancia }\end{array}$ & Pa \% & Puesto \\
\hline AdaBoostM1 (SMO) & 0,83 & {$[0,77-0,89]$} & 5 iteraciones & 1 \\
SMO & 1,11 & {$[1,03-1,19]$} & Ponderación errores: 5 & 2 \\
Vote (SMO y MP) & 1,11 & {$[1,03-1,19]$} & Reglas combi.: Majority vote & 2 \\
MultilayerPerceptron & 1,94 & {$[1,80-2,08]$} & 2 Capas de 6 neuronas c/u & 3 \\
Ibk & 3,88 & {$[3,60-4,16]$} & Knn: 10 & 4 \\
Logistic & 4,29 & {$[3,98-4,60]$} & - & 4 \\
RandomForest & 4,44 & {$[4,12-4,76]$} & Random trees: 150 & 4 \\
DecisionTable & 7,76 & {$[7,19-8,33]$} & Medida de evaluación: RMSE & 5 \\
RandomTree & 7,90 & {$[7,32-8,48]$} & Atributos seleccionados: 15 & 5 \\
J48 & 8,04 & {$[7,45-8,63]$} & Factor confianza: 0,05 & 5 \\
NaiveBayes & 21,61 & {$[20,03-23,19]$} & - & 6 \\
\hline
\end{tabular}

Tabla 6.7: Tasa de error de los distintos clasificadores, previamente a la selección de atributos, ordenados de manera ascendente, junto con sus bandas de significancia al $95 \%$ y los parámetros con los que se obtienen los mejores resultados.

El algoritmo basado en reglas Decision Table consiguió una tasa de error de 7,76\% con la medida de evaluación RMSE — hemos probado RMSE, AUC, ACC, MAE-, mediante la generación de 19 reglas para la decisión de la clase.

Los algoritmos $J 48$, RandomTree, y DecisionTable no son significativamente diferentes - existe solape entre sus intervalos de confianza-, por lo que los tres comparten el quinto puesto entre los clasificadores con la mayor tasa de error.

El clasificador Logistic obtuvo una tasa de error de 4,29\%, y el $S M O 1,11 \%$, con una ponderación a los errores durante el modelado de 5 - probamos valores $0,5,1,2$, y 5 Este último clasificador obtuvo la tasa de error más baja entre todos los clasificadores sin técnicas de aprendizaje conjunta. Por este motivo hemos utilizado este clasificador para los algoritmos con técnicas de aprendizaje conjunta Vote y AdaBoostM1.

El clasificador perezoso $I B k$, configurado para utilizar los 10 registros más cercanos, consiguió una tasa de error de $3,88 \%$ - hemos probado con 1, 5, 10, y 15 vecinos-.

Los algoritmos RandomForest, Logistic e IBk no son significativamente diferentes, por lo que los tres comparten el cuarto lugar entre los clasificadores con mayor tasa de error.

El clasificador basado en red neuronal MultilayerPerceptron consigue con 2 capas ocultas de 6 neuronas cada una tasa de error de 1,94\%. Hemos realizado pruebas con 1 y 2 capas ocultas con 6,13, y 45 neuronas cada una. Este es el segundo mejor algoritmo en términos de tasa de error, que no utiliza técnicas conjuntas. Debido a esto, MultilayerPerceptron fue utilizado, junto con el clasificador $S M O$, para el modelado conjunto Vote. Este clasificador es significativamente diferente de $I B k$, por lo se ubica en el tercer lugar entre los clasificadores con mayor tasa de error.

SMO y Vote - con SMO y MultilayerPerceptron - presentaron una tasa de error de $1,11 \%$. Vote fue configurado con la regla de combinación de Majority Voting — probamos además las técnicas de promedio de probabilidades, producto de probabilidades, mínima probabilidad, máxima probabilidad-. Vote no ha sido capaz de conseguir reducir la tasa de error de $S M O$ mediante la inclusión de la red neuronal. SMO y Vote son sig- 


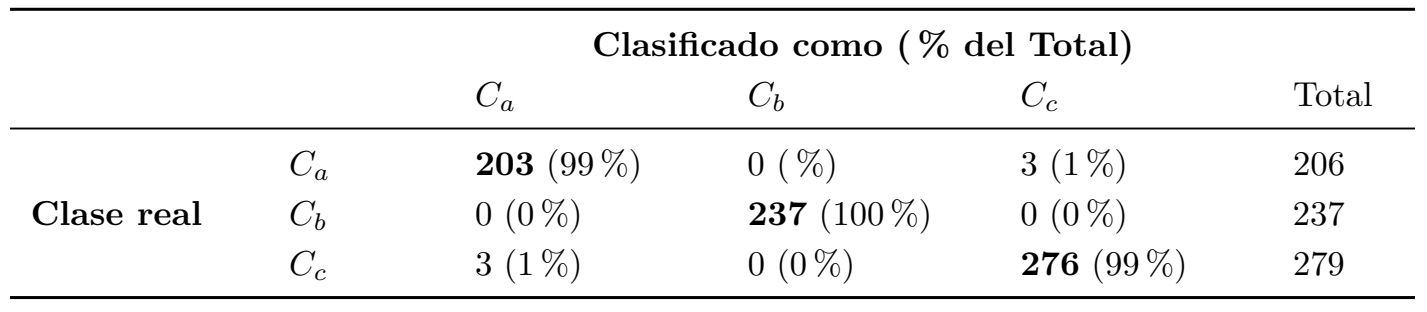

Tabla 6.8: Matriz de confusión del clasificador AdaBoostM1 junto con SMO, con todas las métricas.

nificativamente diferentes de MultilayerPerceptron. Por este motivo, ambos algoritmos comparten el segundo lugar entre los mejores clasificadores.

El clasificador AdaBoostM1 — con SMO - presentó la menor tasa de error, llegando hasta un $0,83 \%$, con 5 iteraciones — probamos además con 10 y con 15 iteraciones-. La diferencia con el siguiente clasificador $S M O$ y con el Vote es significativa, por lo que se puede concluir que este es el clasificador con la tasa de error más baja. La matriz de confusión de este clasificador indicó que la clase $C_{b}$ es mayoritariamente bien clasificada, mientras que las clases $C_{a}$ y $C_{c}$ tienden a confundirse ligeramente entre sí, aunque con una diferencia despreciable, Tabla 6.8.

\section{Selección de las métricas}

Tras evaluar la tasa de error de distintos clasificadores para la identificación de los tipos de tarea de alcance, en esta sección presentamos la valoración de las métricas con distintas técnicas de selección de atributos. Hemos evaluado a las métricas mediante técnicas de valoración de subgrupos de atributos — con Cfs-Subset y Wrapper-Subsety otras basadas en la valoración de forma individual — con Info-Gain y PCA-.

La evaluación con Wrapper-Subset junto con el método de búsqueda BestFirst y el clasificador AdaBoostM1 junto con $S M O$ - el cual obtuvo la menor tasa de error según la Tabla 6.7- da como resultado la selección de 15 métricas, con una figura de mérito de 0,99, Tabla 6.9. El mismo resultado se ha logrado con el método de búsqueda hacia adelante y bidireccional, tras evaluar 653 y 878 grupos de métricas. La búsqueda hacia atrás ha resuelto la selección de 34 métricas, con una figura de mérito de 0,99 , tras evaluar 536 grupos de métricas.

La evaluación por subgrupos de métricas con el evaluador $C f s$-Subset junto con el método de búsqueda BestFirst seleccionó 6 métricas, con una figura de mérito de 0,73, Tabla 6.9. Este resultado se ha alcanzado con las tres direcciones de búsqueda: hacia adelante, hacia atrás, y bidireccional, tras evaluar 231, 824, y 240 subgrupos respectivamente.

El análisis de los componentes principales - $P C A$ - transformó el espacio de métricas de 40 dimensiones a uno de 21 dimensiones para explicar el 95,42\% de la varianza total, Tabla 6.10.

La evaluación de métricas de forma individual con Info-Gain junto con Ranker dio como resultado la Tabla 6.11. Clic dentro del objetivo quedó primero en los 10 bloques de la validación cruzada, aunque otros parámetros tienen una figura de mérito promedio con un valor parecido.

Ya que Wrapper-Subset ha seleccionado 34 y 15 métricas, Cfs-Subset ha seleccionado 6, y $P C A$, para explicar el $95 \%$ de la varianza, ha seleccionado 21 combinaciones lineales de 


\begin{tabular}{lll}
\hline Cfs-Subset & Wrapper-Subset & Ranking \\
\hline Clic dentro & Clic dentro & 1 \\
Longitud sacada (Med.) & Longitud sacada (Med.) & 2 \\
& Longitud sacada (Prom.) & 3 \\
Distancia viajada (N) & Longitud sacada (Mín.) & 4 \\
& & 7 \\
& Velocidad (Máx.) & 8 \\
& Aceleración (Mín.) & 10 \\
& Error de ángulo de movimiento & 11 \\
Aceleración (Máx., S) & Aceleración (Máx.) & 13 \\
& Throughput (Ley de Fitts) & 16 \\
Índice horizontal & Aceleración (Máx., S) & 17 \\
Índice diagonal & Velocidad (Prom.) & 20 \\
& Fases de cero aceleración & 23 \\
& Índice horizontal & 29 \\
(Total atributos: 6) & & 32 \\
\hline
\end{tabular}

Tabla 6.9: Selección de métricas por subconjuntos. Atributos seleccionados por el evaluador de grupo de atributos Cfs-Subset y Wrapper-Subset. Los atributos repetidos con ambos evaluadores se encuentran en la misma fila. Además, se señala el Ranking de los atributos según la Tabla 6.11.

los atributos, utilizaremos estos números para seleccionar atributos del ranking generado por Info-Gain, para poder comparar las técnicas de selección de métricas: 34, 21, 15, y 6. Siguiendo esta misma idea, hemos reducido el porcentaje de la varianza explicada por $P C A$ hasta lograr combinaciones lineales de: 15 y 6 métricas $-88 \%$ y $67 \%$ de la varianza se explican con estos números de dimensiones-.

Resumiendo, tenemos los siguientes nuevos conjuntos de datos: con 34 atributos WrapperSubset (34 m.) e Info-Gain (34 m.), con 21 atributos PCA 95\% (21 m.) e Info-Gain (21 m.), con 15 atributos Wrapper-Subset (15 m.), Info-Gain (15 m.), y PCA 88\% (15 m.), y con 6 atributos $C f s$-Subset (6 m.), Info-Gain (6 m.), y PCA $67 \%$ (6 m.).

\begin{tabular}{lll}
\hline Eje & $\begin{array}{l}\text { Porcentaje de varianza total } \\
\text { explicada (\%) }\end{array}$ & $\begin{array}{l}\text { Porcentaje de varianza } \\
\text { total acumulada (\%) }\end{array}$ \\
\hline 6 & 4,64 & 67,20 \\
15 & 1,51 & 88,64 \\
21 & 0,87 & 95,42 \\
\hline
\end{tabular}

Tabla 6.10: Transformada de componentes principales (PCA) del conjunto de métricas: varianza de cada eje componente y varianza acumulada. 21 componentes explican más del $95 \%$ de la varianza total, 15 el $88 \%$ y 6 el $67 \%$. 


\begin{tabular}{|c|c|c|c|}
\hline Ranking & Mérito promedio & Ranking promedio & Métrica \\
\hline 1 & $0,91( \pm 0,00)$ & $1,00( \pm 0,00)$ & Clic dentro, $\dagger, \star$ \\
\hline 2 & $0,43( \pm 0,01)$ & $2,00( \pm 0,00)$ & Longitud sacada (Med.) $, \dagger, \star$ \\
\hline 3 & $0,39( \pm 0,02)$ & $3,00( \pm 0,00)$ & Longitud sacada (Prom.), ^ \\
\hline 4 & $0,34( \pm 0,01)$ & $4,00( \pm 0,00)$ & Longitud sacada (Mín.), ^ \\
\hline 5 & $0,31( \pm 0,01)$ & $5,20( \pm 0,40)$ & Longitud sacada (Máx.) \\
\hline 6 & $0,28( \pm 0,01)$ & $5,90( \pm 0,54)$ & Número de fijaciones \\
\hline 7 & $0,26( \pm 0,01)$ & $7,10( \pm 0,70)$ & Distancia viajada $(\mathrm{N}), \dagger$ \\
\hline 8 & $0,23( \pm 0,01)$ & $8,80( \pm 1,08)$ & Velocidad (Máx.), ^ \\
\hline 9 & $0,23( \pm 0,01)$ & $8,80( \pm 0,75)$ & Velocidad (Máx., S) \\
\hline 10 & $0,20( \pm 0,01)$ & $11,10( \pm 1,04)$ & Aceleración (Mín.), * \\
\hline 11 & $0,21( \pm 0,02)$ & $11,10( \pm 2,02)$ & Error de ángulo de movimiento, $\star$ \\
\hline 12 & $0,20( \pm 0,02)$ & $11,60( \pm 1,96)$ & Variabilidad del movimiento \\
\hline 13 & $0,19( \pm 0,02)$ & $12,90( \pm 1,81)$ & Aceleración (Máx.), ^ \\
\hline 14 & $0,19( \pm 0,01)$ & $12,90( \pm 0,94)$ & Error del movimiento \\
\hline 15 & $0,17( \pm 0,01)$ & $14,70( \pm 0,46)$ & Duración de fijaciones (Mín.) \\
\hline 16 & $0,15( \pm 0,01)$ & $16,90( \pm 1,04)$ & Throughput (Ley de Fitts), $\star$ \\
\hline 17 & $0,13( \pm 0,02)$ & $17,90( \pm 2,43)$ & Aceleración (Máx., S), †, ^ \\
\hline 18 & $0,14( \pm 0,01)$ & $17,90( \pm 1,04)$ & Tiempo de clic \\
\hline 19 & $0,13( \pm 0,01)$ & $18,20( \pm 0,98)$ & Offset del movimiento \\
\hline 20 & $0,11( \pm 0,01)$ & $21,30( \pm 1,90)$ & Velocidad (Med.) \\
\hline 21 & $0,11( \pm 0,02)$ & $21,70( \pm 2,15)$ & Número de sub-movimientos \\
\hline 22 & $0,11( \pm 0,01)$ & $22,00( \pm 1,26)$ & Duración de fijaciones (Med.) \\
\hline 23 & $0,10( \pm 0,01)$ & $22,30( \pm 1,90)$ & Fases de cero aceleración, $\star$ \\
\hline 24 & $0,10( \pm 0,02)$ & $23,90( \pm 3,24)$ & Jerk (Máx., S) \\
\hline 25 & $0,09( \pm 0,00)$ & $25,40( \pm 1,56)$ & Aceleración (Med.) \\
\hline 26 & $0,09( \pm 0,01)$ & $25,60( \pm 1,20)$ & Velocidad (Prom.),$\star$ \\
\hline 27 & $0,08( \pm 0,01)$ & $26,20( \pm 1,72)$ & Duración de fijaciones (Prom.) \\
\hline 28 & $0,07( \pm 0,01)$ & $28,20( \pm 1,60)$ & Tiempo de reacción \\
\hline 29 & $0,07( \pm 0,02)$ & $30,00( \pm 4,07)$ & Índice horizontal, $\dagger$ \\
\hline 30 & $0,06( \pm 0,00)$ & $30,40( \pm 1,43)$ & Overshoots \\
\hline 31 & $0,06( \pm 0,01)$ & $30,40( \pm 0,80)$ & Número de entradas al objetivo \\
\hline 32 & $0,06( \pm 0,01)$ & $31,70( \pm 1,10)$ & Índice diagonal, $\dagger, \star$ \\
\hline 33 & $0,05( \pm 0,01)$ & $33,40( \pm 2,11)$ & Cambios de dirección ortogonales \\
\hline 34 & $0,05( \pm 0,01)$ & $33,40( \pm 1,69)$ & Cambios de dirección de movimiento \\
\hline
\end{tabular}

Tabla 6.11: Evaluación de métricas individualmente. Ranking de métricas según su figura de mérito y ranking promedio. No se han incluido en la tabla todas las métricas que han quedado por encima del ranking 34. Las métricas señaladas con $(\dagger)$ han sido seleccionadas por el evaluador Cfs-Subset y las señaladas con (*) por Wrapper-Subset, Tabla 6.9. 


\begin{tabular}{llllll}
\hline & & \multicolumn{3}{c}{ Clasificado como (\% del Total) } & \\
& & $C_{a}$ & $C_{b}$ & $C_{c}$ & Total \\
\hline \multirow{3}{*}{ Clase real } & $C_{a}$ & $\mathbf{2 0 2}(98 \%)$ & $0(\%)$ & $4(2 \%)$ & 206 \\
& $C_{b}$ & $0(0 \%)$ & $\mathbf{2 3 7}(100 \%)$ & $0(0 \%)$ & 237 \\
& $C_{c}$ & $4(2 \%)$ & $0(0 \%)$ & $\mathbf{2 7 5}(98 \%)$ & 279 \\
\hline
\end{tabular}

Tabla 6.12: Matriz de confusión del clasificador AdaBoostM1 junto con SMO, con los 15 atributos seleccionados por Wrapper-Subset $(15 \mathrm{~m}$.).

\section{Clasificación posterior a la selección de las métricas}

En esta sección exploramos la influencia que tienen las métricas seleccionadas por las técnicas presentadas en la sección anterior en la clasificación de las tareas de alcance. Para ello, volvimos a clasificar las tareas de alcance, pero descartando las métricas menos relevantes según los resultados de cada una de las cuatro técnicas utilizadas. Para la evaluación utilizaremos el mejor clasificador identificado, a saber, el AdaBoostM1 junto con $S M O$.

La técnica de selección de atributos de subconjuntos Wrapper-Subset $(15 \mathrm{~m}$.) y el analizador de los componentes principales PCA $95 \%$ (21 m.) han conseguido las tasas de error más bajas, un 1,11\%, Tabla 6.13, Figura 6.7. Sin embargo, este valor es un 33,73\% mayor a lo que se consigue con todas las métricas. La matriz de confusión de la clasificación con las métricas indicadas por Wrapper-Subset $(15 \mathrm{~m}$.) nos permiten valorar la diferencia: la clase de tarea $C_{a}$ es confundida con la clase $C_{c}$, y viceversa, un punto más, Tabla 6.12.

Wrapper-Subset consigue mejores resultados con menos atributos: 1,11\% con 15 atributos contra $1,39 \%$ con 34 atributos. Sin embargo la diferencia no es significativa. Pasa lo contrario con Info-Gain, ya que con 34 atributos consigue mejores resultados que con 15: $3,33 \%$ y $6,79 \%$ respectivamente. Además, esta diferencia es significativa.

Un análisis comparativo entre las técnicas de selección de atributos con la misma cantidad de métrica se indica en la Tabla 6.14, Figura 6.8. En los grupos con el mismo número de métricas que incluyen un evaluador de subgrupos - 34, 15, y 6 - , ha sido este tipo de evaluador el que siempre ha obtenido mejores resultados con la clasificación. Entre los evaluadores de métricas individuales, $P C A$ ha permitido al clasificador obtener mejores resultados siempre, excepto con 6 métricas.

\subsubsection{Conclusión de la evaluación de clasificadores y de las métricas}

Hemos utilizado los grupos de tareas de alcance identificados en la Sección 6.1 para etiquetar a las mismas y valorar la capacidad de clasificación de más de 10 clasificadores basados en modelos lógicos — los de tipo árbol y regla —, probabilísticos — bayesianos-, geométricos — regresión logística—, y del tipo ensamblado o de aprendizaje conjunto Vote y Boosting - , con sus mejores parámetros de configuración, con validación cruzada de 10 bloques. Para la valoración utilizamos la tasa de error de clasificación, que se produce por una diferencia entre el etiquetado y la estimación de la clase.

La técnica de aprendizaje conjunto AdaBoostM1 (SMO) ha sido el clasificador que obtuvo la menor tasa de error - un $0,83 \%$, con una diferencia significativa con el siguiente en el ranking - AdaBoostM1 fue configurado con 5 iteraciones y $S M O$ con una ponderación 


\begin{tabular}{|c|c|c|c|}
\hline Evaluador ( $\mathrm{n}^{\circ}$ métricas) & $\begin{array}{l}\text { Tasa } \\
\text { error (\%) }\end{array}$ & $\begin{array}{l}\text { Bandas de signifi- } \\
\text { cancia al } 95 \%\end{array}$ & $\begin{array}{l}\text { Deterioro de la ta- } \\
\text { sa de error }(\%)\end{array}$ \\
\hline Todas las m. & 0,83 & {$[0,17-1,49]$} & - \\
\hline PCA $95 \%$ (21 m.) & 1,11 & {$[0,35-1,87]$} & 33 \\
\hline Wrapper-Subset (15 m.) & 1,11 & {$[0,35-1,87]$} & 33 \\
\hline Wrapper-Subset (34 m.) & 1,39 & {$[0,54-2,24]$} & 67 \\
\hline PCA $88 \%$ (15 m.) & 3,33 & {$[2,02-4,64]$} & 301 \\
\hline Info-Gain (34 m.) & 3,33 & {$[2,02-4,64]$} & 301 \\
\hline Info-Gain (21 m.) & 3,74 & {$[2,36-5,12]$} & 350 \\
\hline Info-Gain (15 m.) & 6,79 & {$[4,95-8,63]$} & 718 \\
\hline Cfs-Subset (6 m.) & 6,93 & {$[5,08-8,78]$} & 734 \\
\hline Info-Gain (6 m.) & 8,18 & {$[6,18-10,18]$} & 885 \\
\hline PCA $67 \%$ (6 m.) & 26,04 & {$[22,84-29,24]$} & 3037 \\
\hline
\end{tabular}

Tabla 6.13: Tasa de error del clasificador AdaBoostM1 con las distintas métricas seleccionadas por los evaluadores, ordenados de manera descendente con respecto a la tasa de error, donde $m$. indica métricas.

\begin{tabular}{|c|c|c|c|c|}
\hline $\begin{array}{l}N^{\circ} \text { métri- } \\
\text { cas }\end{array}$ & Evaluador & $\begin{array}{l}\text { Tasa } \\
\text { error } \\
(\%)\end{array}$ & $\begin{array}{l}\text { Bandas de signi- } \\
\text { ficancia al } 95 \%\end{array}$ & $\begin{array}{l}\text { Deterioro de la } \\
\text { tasa de error } \\
(\%)\end{array}$ \\
\hline Todas & - & 0,83 & {$[0,17-1,49]$} & \\
\hline \multicolumn{5}{|l|}{$34 \mathrm{~m}$} \\
\hline & Wrapper-Subset & 1,39 & {$[0,54-2,24]$} & 67 \\
\hline & Info-Gain & 3,33 & {$[2,02-4,64]$} & 301 \\
\hline \multicolumn{5}{|l|}{$21 \mathrm{~m}}$. \\
\hline & PCA $95 \%$ & 1,11 & {$[0,35-1,87]$} & 33 \\
\hline & Info-Gain & 3,74 & {$[2,36-5,12]$} & 350 \\
\hline \multicolumn{5}{|l|}{$15 \mathrm{~m}}$. \\
\hline & Wrapper-Subset & 1,11 & {$[0,35-1,87]$} & 33 \\
\hline & PCA $88 \%$ & 3,33 & {$[2,02-4,64]$} & 301 \\
\hline & Info-Gain & 6,79 & {$[4,95-8,63]$} & 718 \\
\hline \multicolumn{5}{|l|}{$6 \mathrm{~m}}$. \\
\hline & Cfs-Subset & 6,93 & {$[5,08-8,78]$} & 734 \\
\hline & Info-Gain & 8,18 & {$[6,18-10,18]$} & 885 \\
\hline & PCA $67 \%$ & 26,04 & {$[22,84-29,24]$} & 3037 \\
\hline
\end{tabular}

Tabla 6.14: Tasa de error del clasificador AdaBoostM1 con las distintas métricas seleccionadas por los evaluadores, ordenados de manera descendente con respecto al número de métricas, donde $m$. indica métricas. 

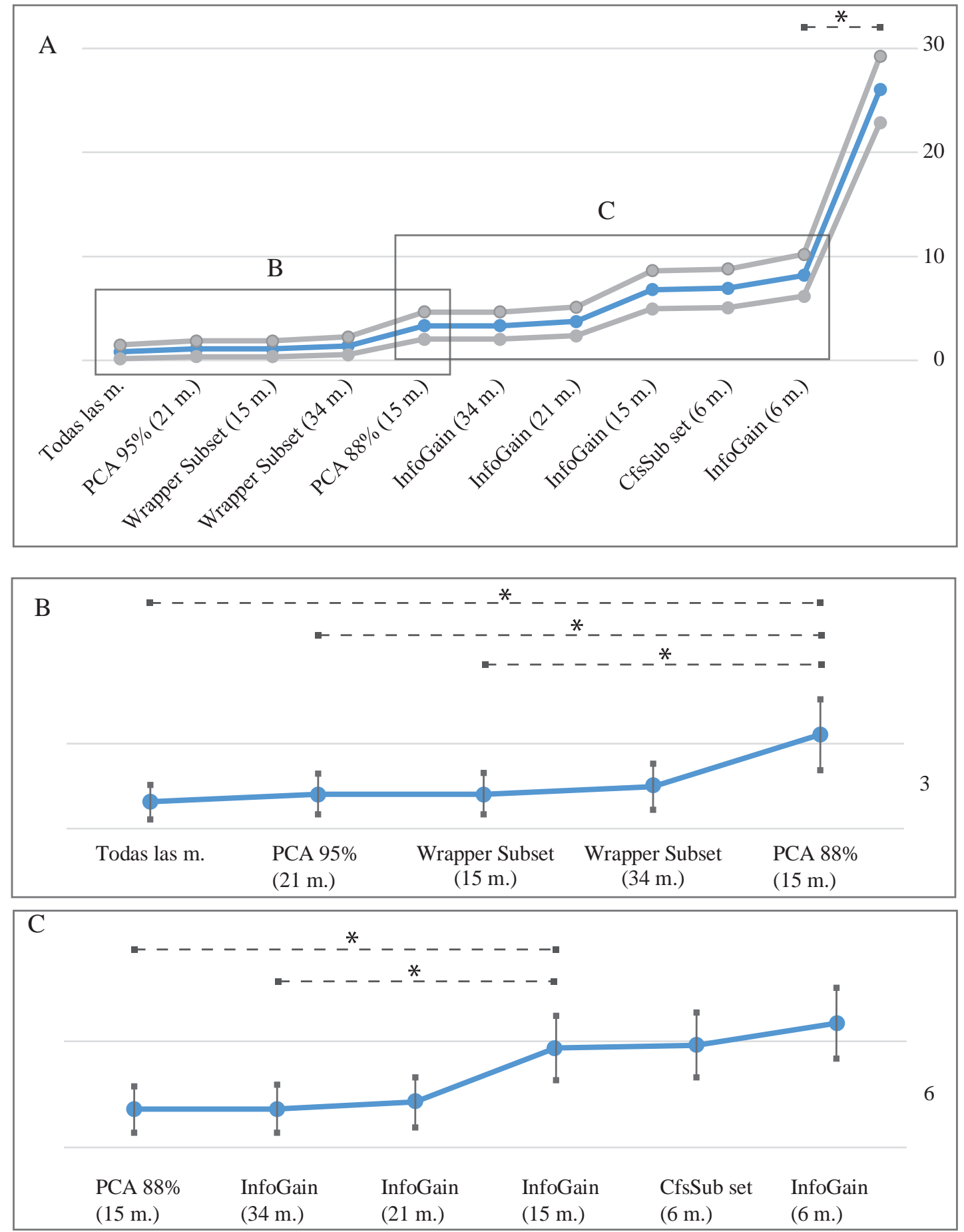

Figura 6.7: A: Tasa de error (\%) del clasificador AdaBoostM1 junto con SMO (línea azul) junto con sus bandas de significancia al $95 \%$ (línea gris), configurado con sus mejores parámetros, en función creciente de la tasa de error de los evaluadores, Tabla 6.13. Además, los recuadros B, y $\mathrm{C}$ son detalles de la figura $\mathrm{A}$, donde se pueden apreciar los solapes de las bandas de significancia. Los asteriscos $\left(^{*}\right)$ indican una diferencia significativa. 

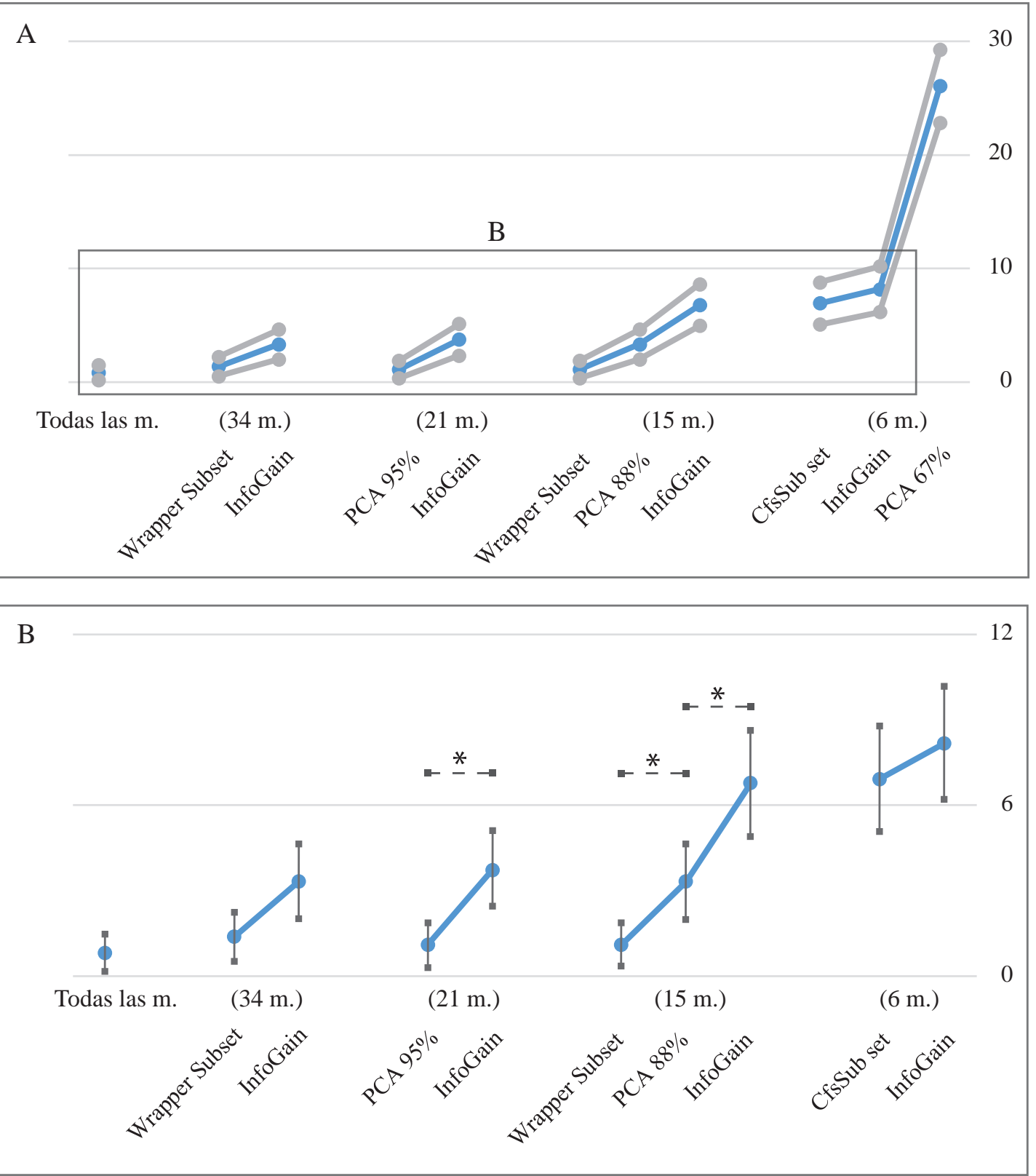

Figura 6.8: A: Tasa de error (\%) del clasificador AdaBoostM1 junto con SMO (línea azul) junto con sus bandas de significancia al $95 \%$ (línea gris), configurado con sus mejores parámetros, en función decreciente del número de métricas seleccionadas por los evaluadores, Tabla 6.14. Además, el recuadro B es un detalle de la figura A, donde se pueden apreciar los solapes de las bandas de significancia. Los asteriscos $(*)$ indican una diferencia significativa. 
de errores de 5. Este resultado se alcanzó clasificando a las tareas de alcance con todas las métricas. La matriz de confusión de este clasificador nos indicó que el error más común se da entre las clases $C_{a}$ y $C_{c}: 3 \%$ de tareas tipo $C_{a}$ son clasificadas según el tipo $C_{c}$ y $1 \%$ de tareas $C_{c}$ son clasificadas como $C_{a}$.

Posteriormente, hemos evaluado las métricas con cuatro técnicas de selección de atributos: dos de subconjuntos de métricas, Cfs-Subset y Wrapper-Subset, y dos de atributos individuales, Info-Gain y PCA. Es interesante notar que las métricas relacionadas con la fijación han sido descartadas - número de fijaciones, duración de las fijaciones-, con el tiempo - tiempo de clic y de reacción-. No obstante, prácticamente todas las métricas cinemáticas han sido seleccionadas — velocidad, aceleración, fases de cero aceleración-, y las relacionadas con la longitud de los movimientos sacádidos.

Finalmente, hemos vuelto a clasificar a las tareas de apuntamiento, pero con las métricas consideradas más importantes por las técnicas de selección de parámetros propuestas, junto con el clasificador que nos dio la menor tasa de error. Los resultados indicaron que las técnicas con las que se han conseguido las tasas de error más bajas - PCA 95\% (21 m.) y Wrapper-Subset $(15 \mathrm{~m}$.) - no consiguen reducir la tasa de error que se obtiene con todas las métricas. Sin embargo, un sistema de clasificación que en lugar de utilizar 40 métricas utiliza solo 15 - es decir, casi un $65 \%$ menos de atributos- para describir cada tarea de alcance es un sistema: más rápido de entrenar, más eficiente para estimar la clase de tareas de alcance más complejas, y más fácil de interpretar. Esta relación de compromiso entre la tasa de error y la rapidez, eficiencia y facilidad en la interpretación, que se expresa en términos del número de parámetros que utiliza el clasificador, no un problema trivial. Nuestro criterio para decidir por uno u otro enfoque ha sido utilizar el sistema más general, capaz de procesar datos nuevos — no utilizados para generar el modelo- y con mayor posibilidad de clasificar correctamente tareas más complejas, evitando utilizar un sistema sobre entrenado a los datos particulares recolectados. Según este criterio, creemos mejor alguno de los subconjuntos de elementos propuesto por alguno de los dos sistemas PCA o Wrapper-Subset $(15 \mathrm{~m}$.), en contraste con utilizar el conjunto total de atributos. $P C A$ convierte los atributos de partida en otros nuevos, que son combinaciones lineales de los primeros. Estos nuevos atributos resultan menos intuitivo a la hora de interpretar los datos. Por este motivo, hemos preferido optar por las métricas seleccionadas por la técnica Wrapper-Subset $(15 \mathrm{~m}$.), que nos permitirán analizar más fácilmente los resultados de la clasificación.

\subsection{Conclusión}

En la Sección 6.1, presentamos un método para explorar las habilidades y características de los usuarios con y sin discapacidad motora con cuarenta de las métricas detalladas en el Capítulo 4. Propusimos caracterizar a los usuarios en base a su tendencia de realizar trayectorias de cierto tipo. Para la identificación de los tipos de trayectoria, procesamos las métricas de las tareas de apuntamiento con un algoritmo de aprendizaje automático no supervisado con el objetivo de agrupar las trayectorias con parámetros de interacción similar. Este procedimiento nos permitió entender a cada usuario, de acuerdo a su pertenencia a cada grupo. Con este método aclaramos la pregunta de cómo se comportan los usuarios cuando interactúan con la computadora a través de un eye-tracker.

Posteriormente, en la Sección 6.2, evaluamos la capacidad de más de 10 clasificadores para identificar los tres tipos de interacción con el ordenador, reconocidos en la caracte- 
rización de la Sección 6.1, en base a la información de las métricas. Con esta clasificación hemos valorado la capacidad de las métricas de ser identificadoras predictoras del tipo de interacción con el ordenador. El mejor clasificador identificado ha sido el basado en aprendizaje conjunto AdaBoostM1 junto con el clasificador de soporte vectorial SMO, con una tasa de error de $0,83 \%$. Además, evaluamos las 40 métricas con cuatro técnicas de selección de atributos y volvimos a realizar la clasificación, pero con las métricas más relevantes identificadas por los evaluadores. El evaluador de análisis de componentes $P C A$ - que ha reducido la dimensión del vector de métricas a $21-\mathrm{y}$ la técnica de selección de métricas de conjunto Wrapper-Subset - que ha seleccionado 15 métricas - han logrado una tasa de error de $1,11 \%$. Aunque ninguna técnica de selección de atributos haya conseguido disminuir o igualar la tasa de error conseguida con todas las métricas, sí se ha reducido la dimesionalidad de vector de métricas un $37 \%$, lo que se traduce en un sistema más rápido y eficiente, en términos de entrenamiento del sistema y estimación de la clase de tarea de apuntamiento.

Con estos avances, en todos los casos mediante métricas basadas en la posición 2D del cursor controlado por usuarios mediante un eye-tracker, identificamos dos cosas: (1) distintos tipos de interacción con el ordenador mediante un algoritmo de aprendizaje no supervisado, (2) la capacidad de clasificación, de distintos algoritmos de aprendizaje supervisado, de los tipos de interacción identificados previamente con un grupo reducido de métricas. 


\section{Parte IV}

\section{Conclusiones y difusión de los resultados}





\section{Capítulo 7}

\section{Conclusiones}

Las aportaciones de la tesis se han concentrado en la Parte III. Sin embargo, en la Parte II también hemos realizado aportaciones interesantes al haber relacionado áreas de estudio que hasta ahora se estudiaban de forma aislada: la PC y los trastornos motores graves, la interacción hombre-computador, los sistemas de eye-tracking, y las metodologías y métricas de valoración de la interacción.

Entre las aportaciones teóricas interesantes de esta parte destacamos que - a pesar de que existen distintos sistemas de clasificación respecto a la capacidad de realizar alguna tarea funcional como por ejemplo caminar o coger cosas con la mano- aún no existe un sistema de clasificación o categorización del acceso al ordenador, a pesar de ser este dispositivo hoy día una herramienta para realizar amplias tareas, Capítulo 1.

En el siguiente capítulo se destacaron los elementos en juego en la interacción hombrecomputador, el problema concreto de las interfaces alternativas de acceso al ordenador de tender a ser sistemas ad-hoc y la estrategia de estudiar las tareas de apuntamiento para evaluar la interacción, ya que a través de ellas se puede controlar completamente el ordenador, Capítulo 2.

A continuación comentamos la naturaleza de los movimientos oculares, el fundamento para establecer el cursor donde se establece la mirada, los eye-trackers como interfaces de acceso al ordenador, entre los cuales destacamos los sistemas basados en infrarrojos, por su robustez y precisión, Capítulo 3.

Finalmente ofrecimos una compilación de métricas para la valoración de las tareas de apuntamiento y las técnicas de aprendizaje automático para la caracterización de la interacción de usuarios, Capítulo 4. Los objetivos de valoración y clasificación de la interacción con el ordenador han sido la guía para la recopilación de todas estas cuestiones.

En el Capítulo 5 hemos partido de la pregunta: ¿la precisión y veracidad de los eyetrackers dada por los fabricantes depende del movimiento cervical? Como era esperable, la respuesta ha sido clara: sí, estas medidas dependen de los movimientos de la cabeza ya que los resultados de nuestros ensayos son diferentes de los resultados del fabricante. El problema más grave de estas medidas es que da una falsa expectativa al usuario con graves trastornos motores graves. Además, estas medidas no son funcionales ya que no se asocian a la realización o no de la tarea de alcance y selección en pantalla. Creemos que las métricas precisión y veracidad están orientadas a medir la calidad de la interfaz y no la calidad de la interacción, donde entran en juego más elementos como por ejemplo el usuario junto con sus capacidades y limitaciones. Mediante este ensayo hemos visto que estas métricas no son adecuadas para valorar la interacción. 
A continuación, hemos valorado la Ley de Fitts, que establece una relación lineal entre la dificultad de una tarea de apuntamiento y el tiempo para realizar esta tarea. Hemos evaluado esta relación, para verificar si cuando el control del cursor se realiza a través de la mirada, también se aprecia la linealidad que se da con otros dispositivos, como por ejemplo el ratón, [74]. De acuerdo a nuestros resultados, no existe evidencia de una relación entre ambas variables. El tiempo de clic permanece prácticamente invariable en relación a la dificultad de la tarea. Propusimos otros dos tiempos para explorar otras opciones en búsqueda de la relación lineal: el tiempo en iniciar y finalizar el movimiento ocular. Tampoco encontramos la relación lineal. Nuestra hipótesis es que la naturaleza del ojo humano es la responsable de esta falta de linealidad. Además, existe un problema respecto al método de procesamiento de los datos, lo que hace difícil la comparación con otros estudios. Sin embargo, nuestros resultados son claros y parecen indicar que la Ley de Fitts no es adecuada para valorar la interacción con el ordenador cuando el control es realizado a través de un sistema de seguimiento de la mirada. Esta conclusión es igualmente válida para personas con y sin PC.

Tras descartar la precisión y veracidad así como el modelo de Fitts, hemos propuesto una metodología para valorar la interacción, basada en la tasa de error y el tiempo de clic. La metodología la valoramos en el contexto de una comparación de dos técnicas de clic: por parpadeo y por permanencia. Respecto a la valoración de las técnicas de clic hemos visto que la mitad de los clics de las personas con PC son clics que se realizan fuera del objeto en pantalla, con ambos métodos de clic. A pesar de que con las dos técnicas los usuarios obtienen la misma tasa de error, con el clic por permanencia necesitan menos tiempo para hacer una selección. Respecto a la metodología, vimos que la propuesta nos permitió valorar la interacción funcional e integralmente.

La alta tasa de fallo en el clic encontrada en el estudio previo y la relación directa entre la calibración de un ET con la calidad de sus medidas, nos ha hecho plantear el último asunto: ¿cuál es la tasa de fallos en la calibración de las personas con PC? Para responder a esta pregunta, hemos planteado una metodología para categorizar a las calibraciones como aceptables o no, según tengan un grado de calidad establecido. Para valorar la metodología, hemos realizado un estudio comparativo de tres ETs, modernos y comerciales. Los resultados arrojan que se produce una alta tasa de fallos al intentar calibrar los sistemas de eye-tracking, lo que indica que este proceso es la primera gran barrera que los usuarios deben sobrepasar, lo que justifica la alta tasa de fallo en realizar el clic dentro de un objeto en pantalla posteriormente.

Después de proponer distintos métodos de evaluación de la interacción, dejamos sentadas las bases para la categorización y clasificación de la interacción con el ordenador, en el Capítulo 6. Hemos analizado las características de grupos tareas de alcance y selección similares. La alta complejidad del procesamiento de datos nos hizo optar por las técnicas de minería de datos. En una primera instancia utilizamos algoritmos no supervisados para identificar la tendencia natural de los usuarios de seguir un cierto tipo de interacción. Los resultados fueron alentadores, ya que las tareas de apuntamiento fueron agrupadas según tres tipos de interacción — rápidos y precisos, precisos pero lentos, y lentos y poco precisos - simplemente a partir de las métricas del movimiento del cursor.

A continuación, con los grupos de usuarios definidos, utilizamos técnicas supervisadas para valorar la capacidad de más de 10 clasificadores de identificar el tipo de interacción con la única información de las características de la tarea de apuntamiento mediante las métricas. El mejor clasificador identificado fue el basado en aprendizaje conjunto del tipo Boosting AdaBoostM1, junto con el clasificador de soporte vectorial SMO, el 
cual logró identificar la clase de la tarea de interacción con una tasa de error de $0,83 \%$ $( \pm 0,66 \%)$. En esta misma línea, valoramos a las mejores métricas con 4 evaluadores, 2 del tipo conjunto y dos individuales, según su influencia en la clasificación de las PTs. Las métricas seleccionadas por los evaluadores de subconjuntos Wrapper-Subset y de análisis de componentes principales $P C A-15$ y 21 respectivamente - han permitido llegar hasta una tasa de error de $1,11 \%( \pm 0,76 \%)$, ninguna significativamente diferente de lo conseguido con AdaBoostM1. Tomamos como criterio de selección el hecho de que un sistema con menos métricas es un sistema: más rápido de entrenar, más generalista antes nuevos casos más complejos y más fácilmente interpretable. Con estos criterios, concluimos que utilizar las 15 métricas seleccionadas por Wrapper-Subset es mejor que utilizar todas las métricas.

\subsection{Principales aportaciones}

Las principales contribuciones de esta tesis doctoral han estado dirigidas al diseño de métodos de evaluación, categorización y clasificación de la interacción entre una persona con algún tipo de trastorno neuromotor severo y un ordenador, cuando el control del cursor se realiza a través de un sistema de seguimiento de la mirada. Todos los métodos cuantifican la interacción mediante métricas especiales que miden variables temporales, espaciales, cinemáticas, etc. Las aportaciones las agrupamos según tengan relación con la valoración o con la caracterización de la interacción.

\subsubsection{Respecto a la valoración de la interacción}

Respecto a la valoración de la interacción entre una persona con un trastorno motor como la parálisis cerebral y el ordenador, ofrecemos las siguientes contribuciones:

- No recomendamos las medidas de precisión y veracidad como métricas para valorar la interacción con el ordenador. Hemos visto que cuando no se restringe el movimiento de la cabeza de los usuarios sin trastornos motores, estas medidas son peores a las que miden los fabricantes $-1,91^{\circ}$ y $2,46^{\circ}$ respectivamente-, lo cual generará falsas expectativas en los usuarios con trastornos motores. Además, estas medidas no son funcionales ya que no miden la capacidad de realizar la tarea de alcance y selección con el cursor.

- Tampoco recomendamos la ley de Fitts para valorar a la interacción. Tras evaluar la ley de Fitts con participantes con parálisis cerebral mientras utilizan eyetrackers y clic por permanencia, considerando tres tipos de tiempo de movimiento - el tiempo para hacer clic en el objetivo, el tiempo que tardan los ojos para iniciar el movimiento, y el tiempo que tardan en detenerse - hemos visto que la dependencia entre el tiempo de movimiento y el índice de dificultad es del orden de $R^{2}<0,01$, una relación muy baja, con los tres tiempos propuestos. Esto resultados indican que la ley de Fitts no se cumple, por lo que descartamos este modelo para valorar la interacción.

- Proponer una metodología basada en la tasa de error y el tiempo de clic así como en la tasa de fallos en la calibración para valorar la interacción, representada esquemáticamente en la Figura 7.1. Esta metodología es funcional, ya que nos ofrece una medida de la realización de las tareas de alcance y selección 
con el ordenador, y es integral ya que está midiendo al resultado de la interacción y no solo al dispositivo que controla al cursor.

La valoración de la metodología nos ha permitido ofrecer las siguientes contribuciones:

- Cuantificar que una de cada dos personas con parálisis cerebral no puede realizar un clic dentro de un objeto en pantalla, tanto con clic por permanencia como por parpadeo.

- Mostrar que, aunque las dos técnicas de clic - parpadeo y permanencia-proporcionan tasas de error similares, el tiempo de clic es menor con el clic por permanencia. Luego, sugerimos a esta última técnica sobre la primera.

- Hemos visto que la mayor exigencia de control motor de la técnica de clic por parpadeo, que necesita de coordinación y sincronización de la mirada y los músculos faciales, termina desencadenando en usuarios con graves trastornos motores una serie de movimiento involuntarios asociados a la intención de realizar el parpadeo. Por tanto, sugerimos tener en cuenta este hecho para el desarrollo de nuevas técnicas de selección.

- Descubrir, mediante la alta tasa de fallo en la calibración — del orden del 70\%-, que la calibración de los sistemas de eye-tracking es la primera gran barrera que deben sobrepasar estos usuarios.

\subsubsection{Respecto a la categorización de la interacción}

Respecto a la categorización y clasificación de la interacción con el ordenador ofrecemos las siguientes contribuciones:

- Metodología y métricas para la agrupación de tareas de alcance y selección según su similitud, bajo la hipótesis de que la estrategia de control de los usuarios no estaba relacionada de forma exclusiva con su perfil patológico. La metodología está basada en la técnica de agrupamiento k-means y las métricas provienen de diferentes dominios: temporales, especiales, cinemáticos, etc.

Valoramos la metodología y las métricas mediante un ensayo con 13 personas con trastornos motores y vimos que:

- Los grupos formados tienen cierta relación con la patología, pero no de forma exclusiva: el grupo $C_{0}$ está dominado por tareas de alcance de usuarios con SCI - 3 de los 4 usuarios están en este clúster-, el grupo $C_{1}$ contiene especialmente a las tareas de apuntamiento de usuarios con PC -4 de 5 usuarios están en este grupo, también 2 de 4 usuarios con ND-, y el grupo $C_{2}$ agrupó mayormente a las tareas de usuarios HP -3 de 4 participantes están en este grupo, también 2 de 4 usuarios con ND-.

- Además, hemos encontrado también que los valores de las métricas tienen una tendencia entre los grupos, señalando que hay mejores grupos que otros: $C_{2}$ logra en casi un $90 \%$ la mejor combinación de parámetros de los tres grupos y $C_{0}$ y $C_{1}$ contienen los parámetros más desfavorables (42\% y $55 \%$ respectivamente). 


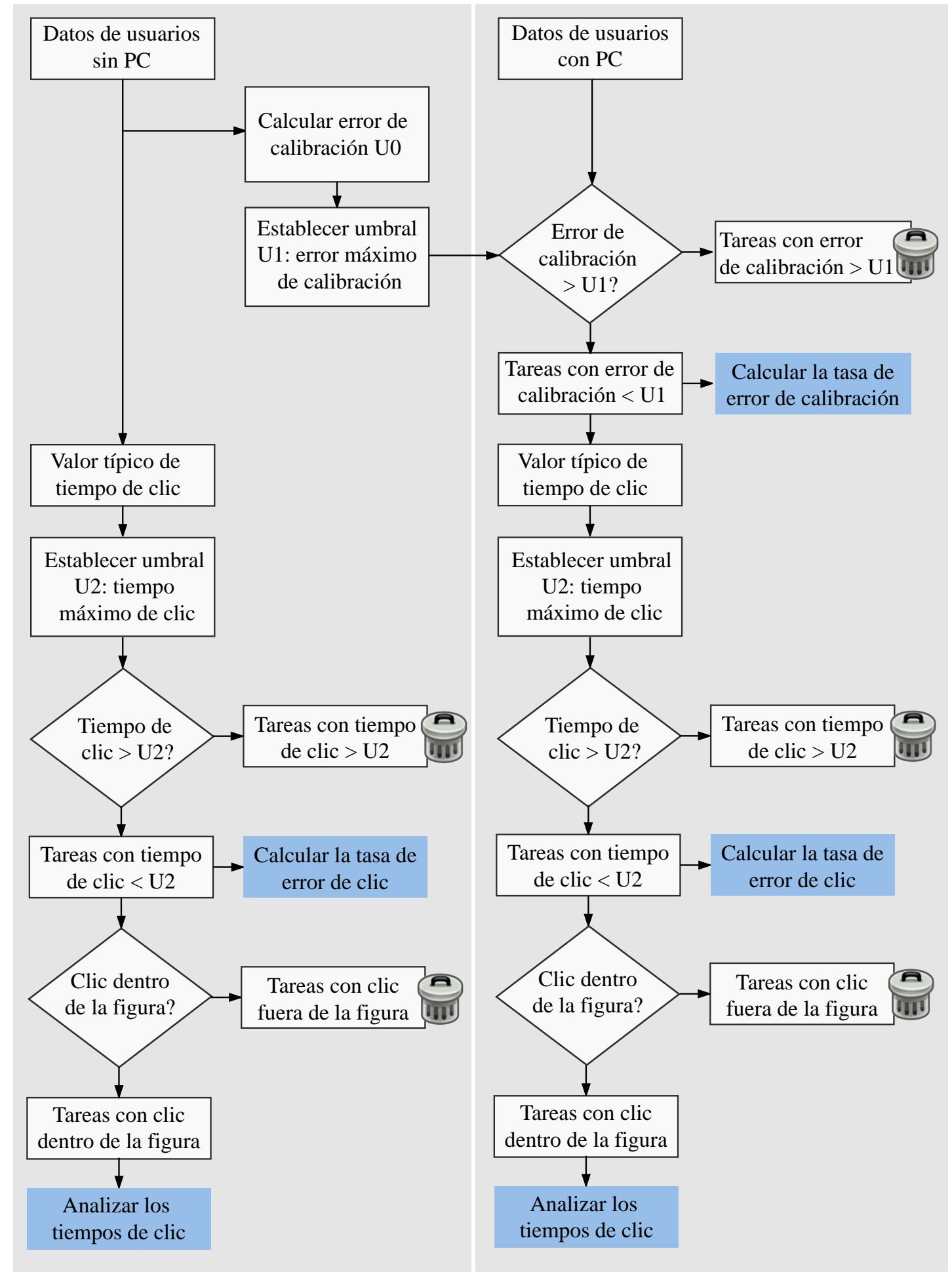

Figura 7.1: Flujo del procesamiento global de los datos. Las cajas agrupadas en el recuadro gris de la izquierda señalan los cálculos que se realizan con los datos de las personas sin $\mathrm{PC}$ y las que se encuentran en el recuadro de la derecha los cálculos con los datos de las personas con PC. Los cuadros con una papelera al lado implican datos descartadas. Los cuadros celestes implican el cálculo de una métrica. 

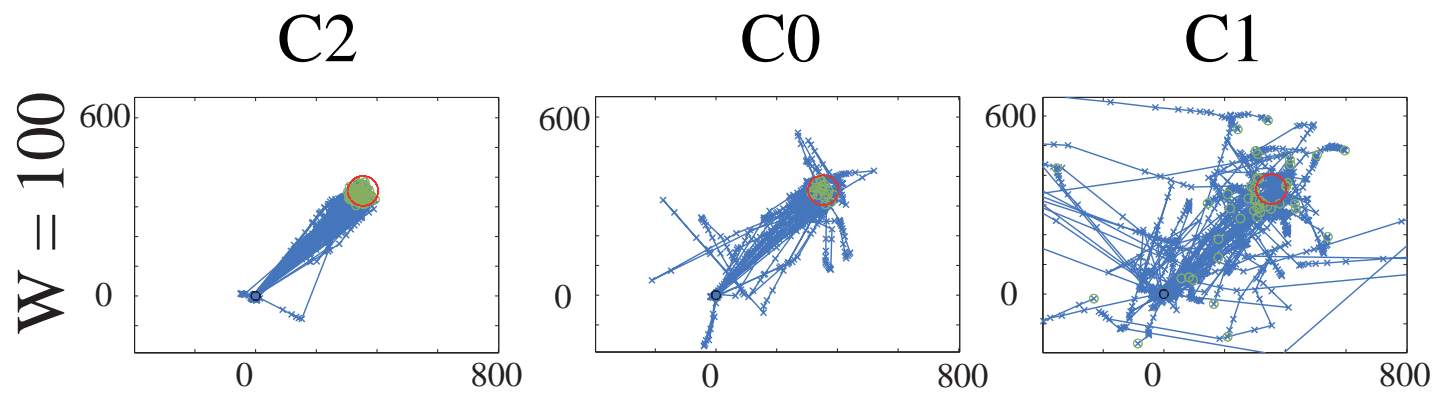

Figura 7.2: Valoración visual de las trayectorias del cursor de las tareas de alcance de cada uno de los tres grupos $C_{2}, C_{0}$, y $C_{1}$. La agrupación fue realizada a partir de las métricas, mediante la técnica de aprendizaje automático no supervisado $k$-means.

- En la última interpretación, más llamativa por su naturaleza visual, vemos claras diferencias en las estrategias cinemáticas de los PTs de los diferentes grupos, lo cual consolida la agrupación de los datos. Para comodidad del lector, se ha copiado una parte de la figura original a la que hacemos referencia en la Figura 7.2.

- Todas estas valoraciones nos permitieron clasificar a cada uno de los usuarios cualitativamente según al grupo al cual pertenecen como: los usuarios $C_{2}$ son rápidos y precisos, los usuarios $C_{0}$ también son precisos, pero más lentos, y finalmente los usuarios $C_{1}$ son usuarios lentos y poco precisos.

\subsubsection{Respecto a la clasificación de la interacción}

Tras identificar a los tipos de tareas de alcance, valoramos la capacidad de estimación de la clase de las tareas de apuntamiento de más de 10 clasificadores, basados en modelos lógicos — los de tipo árbol y regla - probabilísticos — bayesianos-, geométricos — regresión logística一, y del tipo ensamblado o de aprendizaje conjunto — Vote y Boosting-, con sus mejores parámetros de configuración, con validación cruzada de 10 bloques. Para la valoración utilizamos la tasa de error de clasificación, que se produce por una diferencia entre el etiquetado y la estimación de la clase. La conclusión sobre esta cuestión ha sido que:

- La técnica de aprendizaje conjunto AdaBoostM1 (SMO) ha sido el clasificador que obtuvo la menor tasa de error - un $0,83 \%$, con una diferencia significativa con el siguiente en el ranking-. AdaBoostM1 fue configurado con 5 iteraciones y $S M O$ con una ponderación de errores de 5. Este resultado se alcanzó clasificando a las tareas de alcance con todas las métricas. La matriz de confusión de este clasificador nos indicó que el error más común se da entre las clases $C_{a}$ y $C_{c}: 3 \%$ de tareas tipo $C_{a}$ son clasificadas según el tipo $C_{c}$ y $1 \%$ de tareas $C_{c}$ son clasificadas como $C_{a}$.

Posteriormente, hemos evaluado las métricas con cuatro técnicas de selección de atributos: dos de subconjuntos de métricas, Cfs-Subset y Wrapper-Subset, y dos de atributos individuales, Info-Gain y PCA. Tras clasificar a las tareas de apuntamiento con las métricas consideradas más importantes por las técnicas de selección de parámetros propuestas, junto con el clasificador que nos dio la menor tasa de error, y tomando como 
criterio el hecho de que un sistema con menos métricas es un sistema: más rápido de entrenar, más eficiente para estimar la clase de tareas de alcance más complejas, y más fácil de interpretar, hemos visto que:

- La técnica Wrapper-Subset ha seleccionado 15 de las 40 métricas, Tabla 6.9.

- Las métricas relacionadas con la fijación de la mirada han sido descartadas número de fijaciones, duración de las fijaciones-, con el tiempo - tiempo de clic y de reacción- por las técnicas de selección de atributos grupales.

- No obstante, prácticamente todas las métricas cinemáticas han sido seleccionadas - velocidad, aceleración, fases de cero aceleración-, y las relacionadas con la longitud de los movimientos sacádicos. Este dato es muy interesante, ya que vemos que la cinemática de la mirada y la distancia de los saltos entre fijaciones consecutivas son determinantes para distinguir y caracterizar el comportamiento de los distintos grupos de usuarios. Por este motivo tenemos bases para suponer que la mirada puede ser utilizada como un biomarcador de la interacción, ya que hemos visto que hemos podido caracterizar a la interacción a partir de estas métricas.

\subsection{Líneas futuras}

Los resultados obtenidos y la problemática a la que se ha enfrentado esta tesis doctoral sugieren un conjunto de trabajos que se deben abordar en el futuro.

Uno de los factores interesantes a considerar será analizar con precisión en qué grado influye el uso de los ETs en el control motor y cognitivo de los usuarios. Existen evidencias de que el uso de dispositivos alternativos basados en el movimiento de la cabeza mejora la postura de personas con PC [133]. Además, valorar si el uso de ETs mejora alguna de las diferentes dimensiones de la cognición - memoria, atención, lenguaje, memoria de trabajo, percepción- es obligatorio. Incluso, valorar la influencia en el contexto social, permitiendo a usuarios con trastornos motores que interactúen entre ellos lo que ha motivado el proyecto InteraPCión que será presentado más adelante, entre las distinciones, en D.1, el cual ha sido premiado por su carácter innovador y por su relevancia social-.

Además, será interesante valorar la interacción con el ordenador de usuarios con otras patologías, incluso sin trastornos motores, como, por ejemplo, usuarios con trastornos del neuro desarrollo, como el autismo [134], o con alteración del neuro desarrollo, como la dislexia [135]. La hipótesis de trabajo de que la mirada es un biomarcador de las personas promete una línea de trabajo muy interesante.

Será fundamental diseñar y valorar planes de entrenamiento en el uso del ordenador mediante eye-trackers, con objetivos cuantitativos, para dichas patologías [136]. Se puede pensar incluso en valorar la metodología propuesta, pero mientras el control se realiza con otro tipo de interfaces de acceso - en el Apéndice A se detallan un grupo de tecnologías alternativas - para identificar la idoneidad del método en otro contexto.

Otra cuestión interesante será explorar la relación que existen entre diferentes estrategias de ayuda que se pueden implementar con las distintas clases de interacción con el ordenador que se han obtenido de forma no supervisadas, mediante un estudio de las preferencias de los usuarios de cada clase (modelado de usuario). O incluso seguir el 
camino de Gajos de adaptación automática del tamaño y disposición de los elementos en pantalla según la capacidad de la interacción con el ordenador de los usuarios [56]. Así mismo, se pueden estudiar distinto número de clases y apoyarse en datos etiquetados manualmente para cada clase.

Nuestro trabajo utilizó para todos los estudios ETs basados en VOG infrarrojos, principalmente por ser sistemas más robustos y precisos respecto a los sistemas basados en luz natural. Sin embargo, una de las limitaciones de estos sistemas es que requiere de un hardware especial: una cámara de luz infrarroja y fuentes de luces infrarrojas. En el proyecto INTERAAC — uno de los proyectos marco de esta tesis, que será descrito con más detalles a continuación, en P.2 - se ha planteado desarrollar un sistema de ET basado en VOG y luz natural, especialmente diseñado para personas con trastornos motores graves. Para valorar los desarrollos se utilizará la metodología propuesta para comparar este nuevo sistema de ET con el sistema basado en infrarrojos.

\subsection{Limitaciones del estudio}

Una de las limitaciones de los estudios fue el reducido número de participantes con trastornos motores, lo que impide extraer conclusiones sólidas y estadísticamente significativas para la población con PC en su conjunto. Sin embargo, la población es similar a la de trabajos equivalentes publicados en la literatura: un participante en (Käthner, Kübler, and Halder 2015), siete participantes en [111], y siete participantes en [112]. Existe una gran dificultad para realizar sesiones regulares con este tipo de usuarios dadas su limitada disponibilidad. No obstante, se ha puesto especial énfasis en caracterizar con detalle el perfil de los usuarios, de modo que los resultados obtenidos en este trabajo puedan ser extrapolados a perfiles similares. En todo caso, un grupo más amplio de participantes mejoraría y consolidaría claramente las conclusiones de este documento. 


\section{Capítulo 8}

\section{Difusión científica de los resultados}

Los documentos realizados en el transcurso de estos años han sido recopilados y serán presentados a continuación, según distintas categorías. Serán presentados en cada categoría primero los más recientes ${ }^{1}$.

\subsection{Principales publicaciones científicas}

\subsubsection{En revistas}

J.1 A. Clemotte, M.A. Velasco, H. Arregui, L. Unzueta, E. Rocon, "Characterization of eye-gaze tracker users with motor disabilities from cursor trajectories", enviado a International Journal of Human-Computer Studies, 2017.

J.2 A. Clemotte, M.A. Velasco, R. Raya, R. de Córdoba, E. Rocon, "Assessment of Fitts' law with cerebral palsy users and eye-trackers", enviado a Universal Access in the Information Society, 2017.

J.3 A. Clemotte, M.A. Velasco, R. Raya, R. Ceres, R. de Córdoba, E. Rocon, "Metodología de evaluación de eye-trackers como dispositivos de acceso alternativo para personas con parálisis cerebral", aceptado con cambios menores por RIAI: Revista Iberoamericana de Automática e Informática industrial, 2017.

\subsubsection{En conferencias}

C.1 A. Clemotte, H. Arregui, M. A. Velasco, y L. Unzueta, "Trajectory clustering for the classification of eye-tracking users with motor disorders," en Libro de Actas de las Jornadas de Automática, Madrid, Spain, 2016, pp. 150-154. Mejor artículo presentado en el área de bio-ingeniería.

\footnotetext{
${ }^{1}$ Para una lista actualizada de la difusión científica diríjase al enlace https://scholar.google. es/citations?user=NTTGqrsAAAAJ o al enlace https://www.researchgate.net/profile/Alejandro_ Clemotte
} 
C.2 A. Clemotte, M. A. Velasco, R. Raya, R. Ceres, y R. de Córdoba, "Parálisis cerebral y sistemas de seguimiento de la mirada: ¿clic por parpadeo o permanencia?" en Actas de las XXXVI Jornadas de Automática, Bilbao, 2015, pp. 99-104.

C.3 A. Clemotte, M. A. Velasco, D. Torricelli, R. Raya, y R. Ceres, "Accuracy and Precision of the Tobii X2-30 Eye-tracking under Non Ideal Conditions," en International Congress on Neurotechnology, Electronics and Informatics Neurotechnix, Roma, 2014.

C.4 A. Clemotte, F. Brunetti, R. Raya, R. Ceres, y E. Rocon, "Interfaces alternativas de acceso al ordenador: principios comunes y propuesta de métricas de valoración," en VII Congreso Iberoamericano de Tecnologías de apoyo a la discapacidad, IBERDISCAP, Santo Domingo, 2013.

C.5 A. Clemotte, R. Raya, y R. Ceres, "Assessment of alternative human-computer interfaces with cerebral palsy users," en Summer School on Neurorehabilitation "Engineering for Clinical Practice", Elche, 2013.

C.6 A. Clemotte, R. Raya, R. Ceres, y E. Rocon, "Análisis experimental de interfaces para personas con discapacidades neuromotoras," en Seminario CYTED de la Red Temática IBERADA, V Jornadas AITADIS de Tecnologías de Apoyo a la Discapacidad, Experiencias y avances en tecnologías de accesibilidad para personas con discapacidad, Vitória-ES, Brasil, 2012, pp. 112-117.

\subsubsection{En capítulos de libro y Libros}

B.1 A. Clemotte, M. A. Velasco, R. Raya, y E. Rocon, "INTERPLAY - Advanced console for the playful rehabilitation of children with neuromotor disabilities," en Converging Clinical and Engineering Research on Neurorehabilitation II, J. Ibáñez, J., González-Vargas, J., Azorín, J.M., Akay, M., Pons, Ed. Segovia: Springer International Publishing, 2017, pp. 1067-1071.

B.2 A. Clemotte, R. Raya, y R. Ceres, Análisis de interfaces basadas en movimientos de iris y de cabeza para personas con parálisis cerebral. Editorial Académica Española, 2014. [Online]. Disponible: https://goo.gl/3GYVNO

B.3 A. Clemotte, R. Raya, R. Ceres, y E. Rocon, "Preliminary Result from a Multimodal Interface for Cerebral Palsy Users Based on Eye Tracking and Inertial Technology," en Converging Clinical and Engineering Research on Neurorehabilitation, J. L. Pons, D. Torricelli, y M. Pajaro, Eds. Springer Berlin Heidelberg, 2013, pp. 443-448. [Online]. Disponible: http://link.springer.com/ 10.1007/978-3-642-34546-3_72

\subsection{Otras publicaciones}

Durante la realización de esta tesis doctoral, he colaborado con investigadores y estudiantes de postgrado en actividades de investigación en áreas de rehabilitación, interacción persona-máquina y dispositivos de apoyo a la discapacidad. Esta colaboración ha dado lugar a las siguientes publicaciones: 


\subsubsection{En revistas}

J.4 M.A. Velasco, A. Clemotte, R. Raya, R. Ceres, E. Rocon, "A Novel Head Cursor Facilitation Technique for Cerebral Palsy. Functional and Clinical Implications", aceptado con cambios menores por Interacting with Computers, 2017.

J.5 M.A. Velasco, A. Clemotte, R. Raya, R. Céres, E. Rocon, "Head Orientation Based Human-Computer Interaction for Users with Cerebral Palsy. Can Cursor's Movement Be Modeled by Fitts' Law?", aceptado con cambios menores International journal of human computer studies, 2017.

J.6 M. A. Velasco, R. Raya, R. Ceres, A. Clemotte, A. Ruiz, y T. González, "Positive and Negative Signs of Head Motion en Cerebral Palsy: Assessment of Impairment and Task Performance." IEEE Systems Journal Manuscript, Vol. 8, 2014. [Online]. Available: https://doi.org/10.1109/JSYST .2014.2318075

\subsubsection{En conferencias}

C.7 M. A. Velasco, B. Valle, R. Raya, A. Clemotte, y E. Rocon, "BiMU - Inertial sensors and virtual reality games for the rehabilitation of the upper limb en cerebral palsy," en Converging Clinical and Engineering Research on Neurorehabilitation II, J. Ibáñez, J., González-Vargas, J., Azorín, J.M., Akay, M., Pons, Ed. Segovia: Springer International Publishing, 2017, pp. 401-406.

C.8 R. Ceres, E. Rocon, R. Raya, A. Clemotte, M. A. Velasco, N. Rando, J. Arambarri, C. Pérez de la Fuente, L. Zumárraga, I. Sanz, y P. Andradas, "Integrating Video Games and New Interactive Devices for Children Neuromotor Rehabilitation," en Neuroscience REDD Technologies Conference, Barcelona, Spain, 2015.

C.9 M. A. Velasco, A. Clemotte, R. Raya, E. Rocon, y R. Ceres, "MouseField. Técnica de ayuda al apuntamiento y selección en un interfaz persona-computador basado en el movimiento de cabeza para personas con parálisis cerebral," en Congreso conjunto de Tecnología y Turismo para todos, DRT4ALL, Madrid, Spain, 2015.

C.10 F. Martelli, R. Raya, M. Iosa, M. A. Velasco, A. Clemotte, L. Muzzioli, D. Morelli, D. Mattia, E. Rocon, y F. Cincotti, "Target estimation en pointing tasks. A new approach to improve the computer interaction for people with Cerebral Palsy," en Proceedings of Congresso del Gruppo Nazionale di Bioingegneria, Pavia, 2014.

C.11 M. A. Velasco, A. Clemotte, R. Raya, y R. Ceres, "Diseño e Implementación de un Sistema de Control de Entorno para Usuarios con Parálisis Cerebral," en Jornadas de Automática, 2014.

C.12 R. Raya, E. Rocon, A. Clemotte, y R. Ceres, "Caracterización de los patrones de movimiento y postura alterados de personas con parálisis cerebral discinética mediante una interfaz inercial persona-computador," en XXXIII Jornadas de Automática, JA, M. García y R. Sanz, Eds., Vigo, 2012, pp. 75-80. 


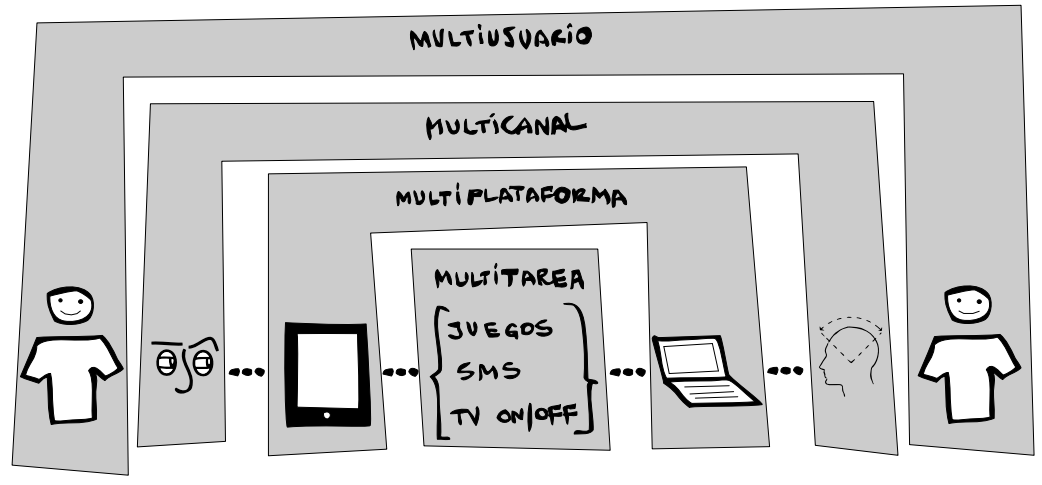

Figura 8.1: La propuesta de proyecto InteraPCion dio principal énfasis a la comunicación entre usuarios con PC (y no comunicación de usuarios con PC), de múltiples maneras con múltiples canales en múltiples contextos. En la figura se ve un esquema de la propuesta.

\subsubsection{En capítulos de libro y Libros}

B.4 R. Raya, E. Rocon, E. Urendes, M. A. Velasco, A. Clemotte, y R. Ceres, "Assistive Robots for Physical and Cognitive Rehabilitation en Cerebral Palsy," Intelligent Assistive Robots, pp. 133-156, 2015.

B.5 A. Frizera, R. Ceres, J. M. Azorín, C. A. Cifuentes, E. Rocon, A. Clemotte, y E. Iáñez, "Interfaces multimodales," en La Interacción de Personas con Discapacidad con el Computador: Experiencias y Posibilidades en Iberoamérica, T. F. José María Azorín, Ramón Ceres, Anselmo Frizera, Ed. Programa Iberoamericano de Ciencia y Tecnología para el Desarrollo (CYTED), 2013, ch. 7, pp. $147-168$.

\subsection{Distinciones}

D.1 Primer Puesto al proyecto InteraPCion, Premio INNOVACIENCIA: II Certamen de Ideas y Proyectos de Innovación para Jóvenes menores de 35 años, edición $2014^{2}$. El proyecto InteraPCion planteó ofrecer a las personas con parálisis cerebral la posibilidad de que interactúen entre ellas ${ }^{3}$, en el contexto de diferentes actividades (ocio, comunicación, control de entorno), mediante diferentes gestos alternativos (movimientos de cabeza, seguimiento de mirada, actividad muscular) a través de diferentes plataformas tecnológicas (tables, móviles, ordenadores), Figura 8.1.

D.2 Premio al "Mejor Trabajo en Bioingeniería", otorgado por el Comité Español de Automática (CEA), por el trabajo presentado en las Jornadas de automática en Madrid. En este artículo comentamos los primeros resultados de un sistema automático de clasificación de usuarios con desordenes motores, mediante técnicas de Aprendizaje Automático o Machine learning

\footnotetext{
${ }^{2}$ https://goo.gl/WkByqs

${ }^{3} \mathrm{El}$ nombre del proyecto hace un juego de palabras entre interacción y las siglas de la parálisis cerebral $\mathrm{PC}$
} 


\subsection{Proyectos de colaboración}

P.1 Proyecto INTERPLAY (2014-2016). Este proyecto está enfocado a niños con parálisis cerebral (PC) y síndromes afines. El objetivo de este proyecto es desarrollar un nuevo sistema de videoconsola que emplee canales alternativos de interacción, basados en movimiento del cuerpo, de la mirada y de los brazos principalmente. Se busca desarrollar nuevas actividades de atención temprana en niños con discapacidad neuromotora y desarrollar al máximo sus capacidades físicas y cognitivas. El sistema estará compuesto de interfaces personacomputador y videojuegos adaptables a la condición específica del usuario. Esta solución tecnológica ofrece al niño tareas lúdicas y funcionales estimulantes que constituyen en sí mismas ejercicios de rehabilitación y seguimiento, tratando de que se convierta en una herramienta de uso habitual.

P.2 Proyecto INTERAAC (2015-2018). Las personas con enfermedades neurodegenerativas, tetraplejia o parálisis cerebral generalmente no tienen control efectivo del movimiento de sus extremidades, cabeza y tronco necesarios para controlar periféricos convencionales de computador (ratón, teclado, joystick), y necesitan sistemas de comunicación alternativos para interactuar con el medio. Muchas veces sólo pueden mover de forma controlada los ojos, y por ello los sistemas de video-oculografía binocular (VOB), son una de las pocas vías de comunicación que tienen disponibles. Sin embargo, pese a su probada utilidad, estos sistemas altamente sofisticados tienen ciertos inconvenientes para el sector al que van dirigidos. El objetivo del proyecto es un nuevo sistema de VOB, el cual utilizará cámaras y lentes de menor coste, sin necesidad de utilizar luz infrarroja para localizar con gran precisión sus reflejos en los ojos y utilizar éstos para determinar el seguimiento de la mirada con precisión. De esta forma, si bien se reduce el coste del hardware, se incrementa en gran medida la dificultad de localizar los elementos necesarios para determinar la dirección de la mirada del usuario.

P.3 Proyecto Ivanpace. La finalidad de este programa fue la elaboración de nuevas técnicas y herramientas tecnológicas de rehabilitación y compensación funcional de personas con PC y síndromes afines a partir de una colaboración estable y multidisciplinar que favorezca un mejor conocimiento de las deficiencias neuromotoras y la puesta a punto de productos o servicios específicos de apoyo.

P.4 Proyecto ABC (2012-2014). ABC tuvo como objetivo aumentar las capacidades humanas mediante una interfaz al ordenador cerebral/neural (Brain/Neural Computer Interfaces, BNCI). El proyecto desarrolló aplicaciones dirigidas principalmente a personas con Parálisis Cerebral Discinética (Dyskinetic Cerebral Palsy, DCP). Debido a las condiciones particulares de la DCP, los sistemas basados en BNCI presentan un gran potencial para la mejora de la calidad de vida y la vida independiente de este grupo objetivo. En particular, los resultados del proyecto se centrarán específicamente en el aumento de las capacidades relacionadas con la comunicación, el aprendizaje, la participación social y el control de los dispositivos. El sistema ABC estará compuesto por cuatro módulos independientes basados en los últimos avances en el procesamiento de señales de la BNCI, Computación Afectiva, Comunicación Aumentada y Monitoreo de Bioseñal. 
Parte V

Apéndices 



\section{Apéndice A}

\section{Tecnologías de asistencia en la comunicación e interacción}

En este apéndice se presenta una extensa revisión de sistemas de asistencias en la comunicación e interacción.

Primero, en la Sección A.1 se expondrán una serie de ayudas tecnológicas para el apuntamiento, alternativas al ratón. Para la inclusión se han tenido como criterios: que el objetivo del trabajo haya sido el de permitir a las personas apuntar a un objeto en la pantalla y que tengan como tecnología base un sistema de visión. Este último criterio permitió identificar a los sistemas más cómodos para el usuario, ya que las tecnologías basadas en visión tienen nula invasividad. Las primeras tres tecnologías funcionan con hardware especialmente diseñado (Irisbond, Smart-Nav y los dispositivos de Tobii) y las cuatro últimas funcionan con una cámara web. En la Sección A.1.8, se presentarán las principales características identificadas.

Más adelante se mencionan ayudas que han sido desarrolladas especialmente para alguna de las dos fases de la tarea de apuntamiento: el alcance — Sección A.2- o la selección - Sección A.3-.

Por su interés también exponemos una serie de sistemas de estimulación visual y análisis del movimiento - Sección A.4- Para finalizar este apéndice presentamos otras tecnologías de asistencia, pero no basadas en visión — Sección A.5-.

\section{A.1 Tecnologías alternativas para el apuntamiento basadas en visión}

\section{A.1.1 Irisbond Primma}

Irisbond Primma ${ }^{1}$ es un sistema informático que permite el control del ordenador con el movimiento de los ojos. Es compatible con una gran variedad de programas y aplicaciones a modo de herramientas de Comunicación Aumentativa y Alternativa. Entre sus principales características se encuentran el ser de manejo sencillo e intuitivo, incluir programas de comunicación alternativa, interfaz configurable por el usuario y adaptable a diferentes posiciones del usuario. Para utilizarlo es necesario conectarlo al ordenador mediante una conexión USB e instalar un software propietario.

\footnotetext{
${ }^{1}$ http://www.irisbond.com/productos/irisbond-primma
} 

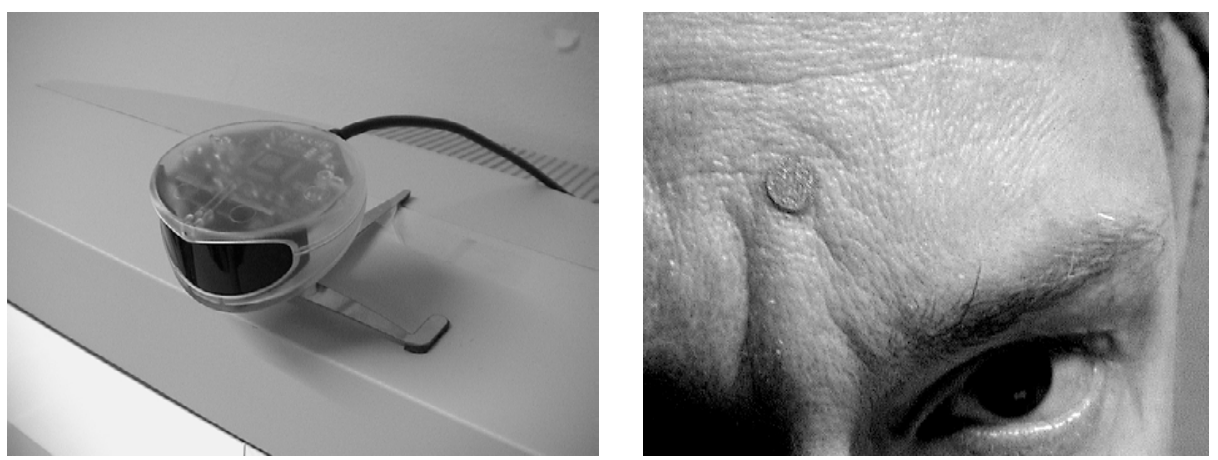

Figura A.1: El sistema seguidor de cabeza SmartNav (izquierda). La cámara sigue al punto reflectante de luz infrarroja puesto en la frente del usuario (derecha).

\section{A.1.2 Smart-Nav ${ }^{\mathrm{TM}}$}

Smart-Nav ${ }^{2}$ es un ratón capaz de utilizar la cabeza como control. Para estimar la posición de la cabeza, utiliza cuatro LEDs infrarrojos situados detrás de una lente frontal opaca para iluminar un material reflectante, tal como un punto adhesivo, situado en la frente del usuario. Una cámara recoge esta reflexión y transmite los datos de imagen a un sistema que procesa esta información y estima la orientación de la cabeza del usuario. Tanto los LEDs infrarrojos como la cámara y el sistema de procesamiento se encuentran integrados en una unidad. El punto reflectante puede ser colocado en cualquier punto que el usuario desee utilizar como control del cursor (manos, lentes). El sistema es utilizado por personas sin discapacidad y por personas con diversas limitaciones motoras. Hansen presenta un estudio comparativo de escritura con sistemas basados en seguimiento de iris y seguimiento de la cabeza (utilizando SmartNav) [137]. En la Figura A.1 podemos ver la cámara y el punto reflectante colocado en la frente de una usuario.

\section{A.1.3 Tobii EyeX y Tobii X2-30}

Tobii EyeX ${ }^{3}$ junto con el Tobii X2-30 ${ }^{4}, \mathrm{REX}^{5}$ o PCEye Go ${ }^{6}$ son las opciones más asequibles $(<1000$ EUR) de esta marca, especialmente el primer modelo. Trabajan a una velocidad de $30 \mathrm{~Hz}$ y son de tipo remoto (el participante no debe portar el dispositivo, a diferencia de los portables, tradicionalmente montados en la cabeza). Todos ellos son capaces de obtener datos de los dos ojos de forma independiente (binocular) y también son capaces de estimar la profundidad del usuario al dispositivo. Son capaces de operar a una distancia de entre 40 y 90 centímetros del participante, pero la distancia óptima es de $60 \mathrm{~cm}$ para todos los casos. También permiten que el participante mueva la cabeza $50 \mathrm{~cm}$ horizontalmente y $35 \mathrm{~cm}$ verticalmente. El primer modelo se conecta al ordenador mediante un USB 3.0 y los demás utilizan un USB 2.0. Estos dispositivos ofrecen una API para desarrollar software en diferentes plataformas: Unity, .NET $(\mathrm{C \#})$ y $\mathrm{C} / \mathrm{C}++$.

\footnotetext{
${ }^{2}$ http://www.naturalpoint.com/smartnav/

${ }^{3}$ http://www.tobii.com/xperience/products

${ }^{4}$ http://www.tobiipro.com/product-listing/tobii-pro-x2-30

${ }^{5}$ http://www.tobii.com/xperience/products/buy-rex/

${ }^{6}$ http://www.tobiidynavox.com/pceye-go/
} 


\section{A.1.4 Camera Mouse}

El Camera Mouse $^{7}$ [138] es un sistema que ha sido desarrollado para proporcionar acceso al computador a personas con discapacidades severas. El sistema rastrea los movimientos del usuario con una cámara de vídeo y los traduce en movimientos del puntero en la pantalla. Pueden ser rastreadas características del cuerpo, tales como la punta de la nariz del usuario o el dedo. Un grupo de 20 personas sin discapacidad han probado el sistema y rápidamente han aprendido a utilizarlo para deletrear mensajes o jugar videojuegos. Doce personas con parálisis cerebral severa o lesión traumática del cerebro han probado el sistema, nueve de los cuales han tenido éxito. Ellos interactuaron con su entorno, deletreando mensajes y navegando por Internet. El software puede ser descargado de Internet gratis desde la página web oficial ${ }^{8}$.

\section{A.1.5 Eviacam}

Enable Viacam ${ }^{9}$ (también conocido como eViacam) es un programa de ordenador que busca sustituir al ratón moviendo el puntero mediante los movimientos de la cabeza. Funciona en ordenadores comunes equipados con una cámara web. No es necesario hardware adicional. Es soportado tanto por las plataforma GNU/Linux como por Windows (2000, $\mathrm{XP}$, Vista, 7). eViacam, la aplicación y el código fuente, se proporciona bajo licencia GNU / GPL.

En [139] se presenta el proceso de una experiencia multidisciplinar de la aplicación de sistemas de interacción basados en Visión Artificial en usuarios afectados con PC. El estudio se ha llevado a cabo con los sistemas Eviacam y Webcolor en las instalaciones de la Asociación Provincial de Parálisis Cerebral en Tarragona. Los resultados obtenidos en general han sido positivos incluso superando, en determinadas ocasiones, las expectativas iniciales.

\section{A.1.6 SINA}

SINA se ha centrado en posibilitar el acceso al ordenador al colectivo de personas con una discapacidad motora grave y/o degenerativa (Parálisis Cerebral/Esclerosis Múltiple) y se basa en un diseño intuitivo que procura atender al máximo posible los criterios de normalización. La utilización es muy intuitiva y natural: se requiere sólo una cámara USB estándar y una aplicación multimodal que es capaz de detectar el movimiento de la cara de la persona e interpretar sus movimientos y que permite la utilización de la mayoría de aplicaciones instaladas en el ordenador [140]. El sistema SINA genera los movimientos del cursor en función de la posición de la cara y de la nariz. En la Figura A.2 se puede ver las fases del proceso de inicialización del sistema. Para la generación de eventos se dispone de una botonera gráfica que permite realizar acciones comunes del tipo: clic derecho, doble clic derecho, etc. A partir de la selección escogida en la botonera gráfica, se realizará este evento donde el usuario pose el cursor durante un tiempo determinado [141].

\footnotetext{
${ }^{7}$ http://www.cameramouse.org/

${ }^{8}$ http://www.cameramouse.org/index.html

${ }^{9} \mathrm{http}: / /$ eviacam.sourceforge.net/index_es.php
} 

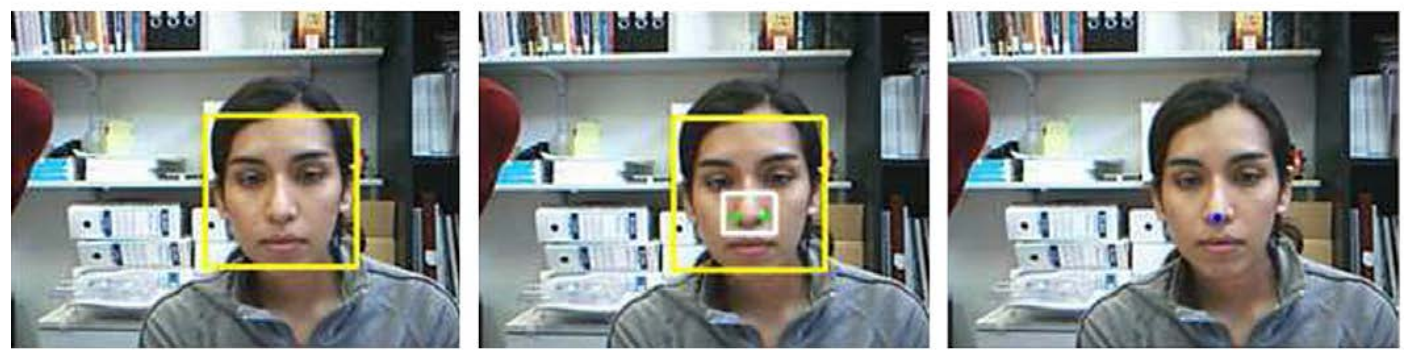

Figura A.2: Módulo de inicialización: a) detección automática de rostro. b) Selección de las mejores características usando restricciones de simetría. c) La media de todas las funciones: punta de la nariz.

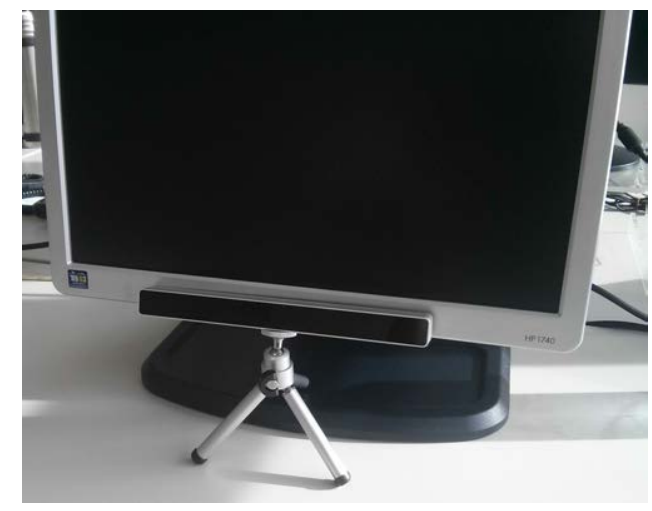

Figura A.3: The EyeTribe presume de ser el eye-tracker comercial más barato del mundo, con un coste de lanzamiento de $99 \$$ y una API en tres lenguajes para el desarrollo de aplicaciones.

\section{A.1.7 ITU Gaze Tracker - The EyeTribe}

ITU Gaze Tracker ${ }^{10}$ es un software de código abierto que puede ser utilizado con cámaras web. El software realiza un seguimiento de la pupila y una o dos reflexiones corneales producidas por fuentes de luz infrarroja. La primera versión del sistema fue introducida y evaluada por San Agustín y col. [142]. Los resultados obtenidos indicaron que un sistema de bajo costo construido con una cámara web podría tener el mismo rendimiento que sistemas comerciales más costosos. Sin embargo, el sistema requiere la colocación de la cámara web muy cerca de los ojos del usuario, lo que no es cómodo ni práctico ya que la cámara bloquea parte de la vista del usuario. Al ser un sistema montado en la cabeza, obliga al usuario a sentarse completamente quieto, ya que los movimientos de la cabeza afectan a la posición del cursor. La segunda versión del sistema [143] permite el seguimiento del ojo a distancia mediante el uso de una cámara con un campo de visión estrecho.

Posteriormente este software, junto a un hardware propio, ha sido transformado en un producto y ha sido lanzado a la venta con un coste único en el mercado. Este producto ha sido bautizado con el nombre The EyeTribe ${ }^{11}$, Figura A.3.

\footnotetext{
${ }^{10} \mathrm{http}: / /$ access.uoa.gr/ATHENA/eng/applications/view/643

${ }^{11}$ https://theeyetribe.com
} 


\begin{tabular}{llllllll}
\hline Tecnología & $\begin{array}{l}\text { Tipo } \\
\text { de } \\
\text { cámara }\end{array}$ & API & $\begin{array}{l}\text { Costo } \\
<\mathbf{1 0 0 0}\end{array}$ & Invasivos & $\begin{array}{l}\text { Orientado } \\
\text { a discapa- } \\
\text { cidad }\end{array}$ & $\begin{array}{l}\text { Seguidor } \\
\text { de } \\
\text { mirada }\end{array}$ & $\begin{array}{l}\text { Inmune } \\
\text { mov. } \\
\text { usuario }\end{array}$ \\
\hline I. Primma & IR & No & $\mathrm{No}$ & $\mathrm{No}$ & $\mathrm{Si}$ & $\mathrm{Si}$ & $\mathrm{Si}$ \\
Smart-Nav $^{*}$ & $\mathrm{IR}$ & $\mathrm{No}$ & $\mathrm{No}$ & $\mathrm{Si}$ & $\mathrm{Si}$ & $\mathrm{No}$ & $\mathrm{No}$ \\
Tobii & $\mathrm{IR}$ & $\mathrm{Si}$ & $\mathrm{Si}$ & $\mathrm{No}$ & $\mathrm{Si}$ & $\mathrm{Si}$ & $\mathrm{Si}$ \\
EyeTribe & $\mathrm{IR}$ & $\mathrm{Si}$ & $\mathrm{Si}$ & $\mathrm{No}$ & $\mathrm{No}$ & $\mathrm{Si}$ & $\mathrm{Si}$ \\
C. Mouse $^{*}$ & WebC & $\mathrm{No}$ & $\mathrm{Si}$ & $\mathrm{No}$ & $\mathrm{Si}$ & $\mathrm{No}$ & $\mathrm{No}$ \\
Eviacam $^{*}$ & $\mathrm{WebC}$ & $\mathrm{No}$ & $\mathrm{Si}$ & $\mathrm{No}$ & $\mathrm{Si}$ & $\mathrm{No}$ & $\mathrm{No}$ \\
SINA $^{*}$ & $\mathrm{WebC}$ & $\mathrm{No}$ & $\mathrm{Si}$ & $\mathrm{No}$ & $\mathrm{Si}$ & $\mathrm{No}$ & $\mathrm{No}$ \\
\hline
\end{tabular}

Tabla A.1: Distintas tecnologías revisadas con sus características respectivas según diferentes aspectos. WebC: Webcam

\section{A.1.8 Características de los trabajos revisados}

Hemos extraído características de las interfaces de acceso para el apuntamiento revisadas, según diferentes aspectos: tipo de cámara —infrarroja o web-, disponibilidad de interfaz de programación de la aplicación, costo reducido — menor a 1000 Eur —, si es invasivo en cualquier grado-, concebido para personas con discapacidad, seguidor de la mirada - si o no-, y inmunidad al movimiento de traslación del usuario, Tabla A.1. Todos los sistemas están basados en video, para evitar que el usuario tengo que portar algo durante la utilización del mismo.

Todas las tecnologías basadas en cámaras web no necesitan un hardware especial, salvo una cámara de luz visible tipo Webcam, la cual incluyen hoy día la mayoría de los ordenadores. Por otro lado, todos los seguidores de la mirada utilizan cámaras infrarrojas, para aumentar el contraste y reducir la dependencia con la iluminación natural, lo cual hace de estos sistemas más precisos y robustos [12].

Los sistemas de seguimiento de la mirada tienen menor dependencia a los movimientos de traslación de la cabeza del usuario, al contrario de los sistemas basados en cámaras web, debido a la naturaleza del tipo de control. Estos últimos identifican en la imagen de video una característica, por ejemplo la nariz del usuario en el caso de SINA o un punto reflectante en el caso del Smart-Nav. A continuación hacen el seguimiento de esta característica en el video. Esto presupone que los movimientos que se producen en la imagen de video son debido a la rotación de la cabeza del usuario. Sin embargo, los usuarios con trastornos motores y bajo control postural no suelen cumplir esta suposición, y se suelen desplazar de la posición inicial por movimientos de traslación y no de rotación, lo que produce finalmente un deterioro de la tarea de apuntamiento. Además, los seguidores de la mirada aprovechan el gesto residual de los ojos, presente en muchos casos de extrema limitación motora.

\section{A.2 Ayudas al alcance}

\section{A.2.1 Basado en el cambio de ganancia: Angle Mouse}

Las Ecuaciones A.1 describen lo que se conoce como la ganancia CD del ratón. Wobbrock presentó un nuevo método de adaptación dinámica de esta ganancia, que mejoró 
el alcance a objetos en pantalla de los usuarios con deficiencias motoras en un $10 \%$ comparado con la estrategia por defecto de Windows [144]. El método ajusta la ganancia del ratón basado en la desviación de los ángulos durante el movimiento. Cuando la desviación angular es baja, la ganancia se mantiene alta. Cuando la desviación angular es alta, la ganancia baja, haciendo al objetivo más grande en el espacio motor del usuario. Una característica clave del Angle Mouse es que, a diferencia de la mayoría de las técnicas de facilitación al apuntamiento, es independiente de la posición y las dimensiones del objetivo en pantalla, es decir, no requiere esta información del destino, se basa únicamente en el comportamiento del usuario.

$$
\begin{aligned}
& C D_{\text {gain }}=V_{\text {puntero }} / V_{\text {gesto }} \\
& V_{\text {puntero }}=\text { Velocidad del puntero } \\
& V_{\text {gesto }}=\text { Velocidad del gesto motriz }
\end{aligned}
$$

\section{A.2.2 Basados en el cambio de tamaño del cursor: Bubble Cursor y Bubble Lens}

Grossman presentó un trabajo basado en el cambio de tamaño del puntero llamado Bubble Cursor [145]. Esta técnica mejoró el apuntamiento cambiando dinámicamente el área de activación del puntero, dependiendo de la distancia a los objetos en los alrededores, de tal manera que sólo un objeto es seleccionable en cualquier momento. Sin embargo, cuando los objetos son pequeños y hay muchos en poco espacio, esta técnica degenera en un puntero convencional. Mott presentó una técnica llamada Bubble Lens, que intenta tomar las bondades de Bubble Cursor y mejorar las debilidades [146]. Para ello, cuando los objetivos son pequeños y existen muchos en poco espacio, la Bubble Lens aumenta automáticamente el tamaño de los objetivos cercanos, haciéndolas más grandes, tanto visual como en el espacio motriz. La ampliación se produce automáticamente mediante una técnica que examina continuamente la velocidad. Lamentablemente ninguno de los dos trabajos ha sido validado con usuarios con patologías motoras.

\section{A.2.3 Basados en la ampliación de un área (zoom)}

Findlater presentó un interesante trabajo sobre la técnica de ampliación de un área determinada (zoom) [147]. La técnica presentada exige para la selección de un objeto dos gestos: primero un clic que amplia el área cercana al clic y luego un cruce según los objetos que se encuentren en la zona del clic. La técnica ha sido validada con usuarios con diferentes patologías, donde los resultados indican una mejora en la tasa de error de alrededor de $82 \%$.

\section{A.3 Ayudas a la selección}

\section{A.3.1 Basados en activación muscular - EMG}

Dos trabajos interesantes que utilizan sistemas de seguimiento de la mirada con soporte de la actividad muscular superficial (EMG) son los trabajos de Chin [18] y Navallas [16]. Chin propone corregir la información absoluta de la posición de la mirada con la actividad muscular. Navallas por otro lado propone hacer el clic mediante activaciones 


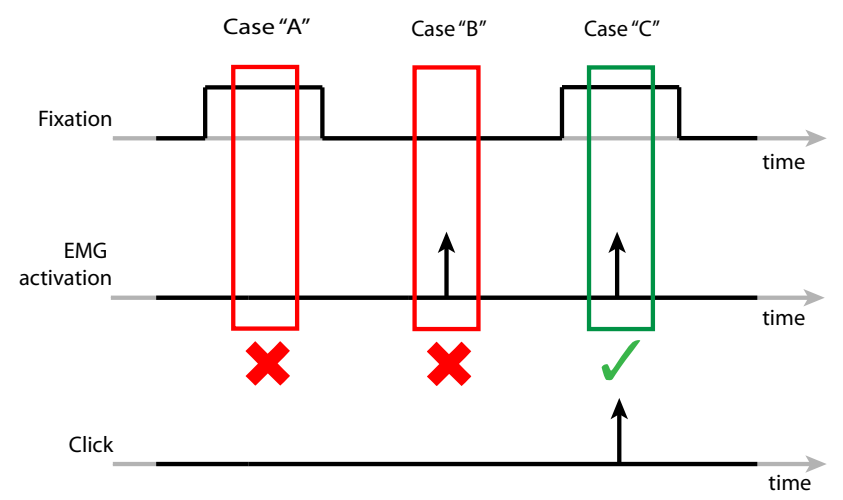

Figura A.4: Navallas propone realizar el clic mediante activaciones musculares solo cuando se produce una fijación de la mirada en un punto (Caso $\mathrm{C}$, en el recuadro verde).

musculares, habilitando el clic solo cuando se producen fijaciones de la mirada en un punto. La Figura A.4 detalla este esquema de habilitación de clic. Lamentablemente ninguno de ellos valida sus técnicas con personas con algún tipo de discapacidad.

\section{A.3.2 Basados en tiempo de permanencia - Dwell clicker}

Dwell clicker $2^{12}$ es una aplicación para Windows que permite utilizar un ratón u otro dispositivo apuntador/señalador sin hacer clic en los botones, ya que el clic lo genera la aplicación. Es ideal para las personas con limitaciones motoras y aquellas que usan dispositivos apuntadores alternativos tales como head-pointer o joystick.

\section{A.4 Sistemas de estimulación visual y evaluación del apun- tamiento}

\section{A.4.1 Look to learn}

Look to learn ${ }^{13}$ es una manera motivadora y divertida de empezar a trabajar con la tecnología de los eye-trackers. Incluye 40 actividades especialmente creadas para el proceso de aprendizaje inicial, divididas en cinco áreas clave: 1) sensorial, diseñada para enseñar causa y efecto; 2) exploratoria, anima al usuario a interactuar con la pantalla completa; 3) objetivo, ayuda a mejorar la exactitud de acceso a la mirada; 4) selección, desarrolla habilidades de selección; y 5) control, afina el acceso con la mirada. Cada actividad se ha desarrollado en consulta con los maestros y terapeutas para mejorar las habilidades de acceso y la toma de decisiones.

\section{A.4.2 FittsStudy}

FittsStudy ${ }^{14}$ es un software gratuito de código abierto, que permite la realización y el análisis de estudios de apuntamiento. Permite la manipulación de la amplitud de movimiento y el tamaño de los objetos en pantalla tanto en 1D como 2D. Otras características

\footnotetext{
${ }^{12}$ https://thinksmartbox.com/product/dwell-clicker/

${ }^{13}$ https://thinksmartbox.com/product/look-to-learn/

${ }^{14}$ https://depts.washington.edu/aimgroup/proj/fittsstudy/
} 


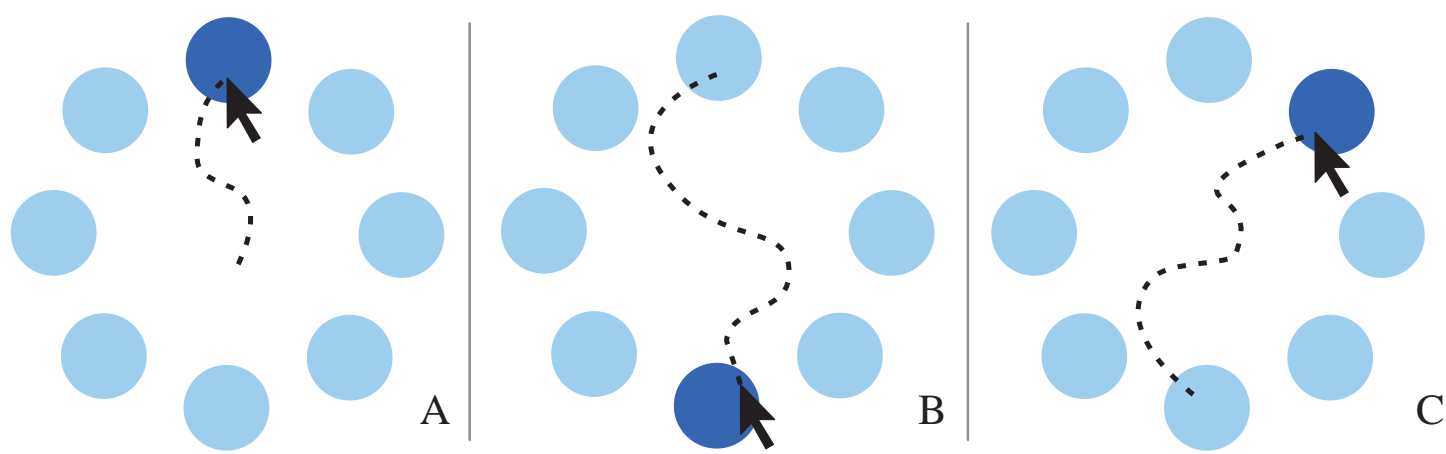

Figura A.5: Uno de los dos esquemas de estimulación visual que permite FittsStudy: círculos concéntricos. Se puede ajustar tanto la separación entre los círculos como el tamaño de los mismos.

incluyen: el cálculo automático de los modelos y métricas basadas en el ISO 9241-9, la posibilidad de exportar los resultados en hojas de cálculo y una herramienta para la exploración visual de los ensayos [68]. En la Figura A.5 puede observarse una de los ensayos que permite realizar este software.

\section{A.4.3 Cursor Trajectory Analyzer}

Cursor Trajectory Analyzer ${ }^{15}$ es un software de descarga gratuita, desarrollado por Amur Almanji. El software permite realizar experimentos y manipular la amplitud de movimiento, el ancho del objeto en pantalla y el ángulo en el que aparecerá el objeto respecto a un botón central. Además ofrece métricas y la posibilidad de analizar los experimentos visualmente. El software sin embargo no es completamente estable y tiene errores en la fase de análisis de los datos aunque ninguno es crítico para su utilización.

\section{A.4.4 Single switch performance test (SSPT)}

Single switch performance test ${ }^{16}$ es un software de descarga gratuita de código cerrado. Parte del hecho de que muchas personas con discapacidad utilizan interruptores individuales para controlar diversos elementos de tecnología de asistencia. El rendimiento global de un sistema de tecnología de asistencia está determinada por muchos factores, incluyendo el desempeño en la activación de un interruptor, según diferentes métricas, como pueden ser tiempo, capacidad de repetición, etc. La selección y la colocación de interruptores se lleva a cabo con mayor eficacia cuando se mide el rendimiento. SSPT es un software que facilita la medición de la capacidad de activar un solo interruptor. SSPT mide el tiempo medio necesario para activar o liberar el interruptor (siguiendo las indicaciones visuales y/o auditivas) y también se puede medir la velocidad de activaciones repetitivas $[148,149]$. En la web además ofrecen una lista de video-juegos de descarga gratuita gestionados por un solo interruptor ${ }^{17}$

\footnotetext{
${ }^{15} \mathrm{https}$ ://sites.google.com/site/amuralmanji/software

${ }^{16}$ https://aacinstitute.org/sspt/

${ }^{17}$ http://www.oneswitch.org.uk/2/switch-downloads.htm
} 


\section{A.4.5 Compass software}

Compass software ${ }^{18}$ permite medir las habilidades de los usuarios en diversos tipos de interacción con el ordenador. Está diseñado para ayudar a los profesionales de la tecnología de asistencia a realizar evaluaciones de acceso de equipos con sus clientes y estudiantes. Las competencias evaluadas incluyen el apuntamiento, la introducción de texto y el uso de interruptores midiendo la velocidad y la precisión de la tarea. El uso apropiado de este software permite: diagnosticar las dificultades con una interfaz existente; evaluar el rendimiento con diferentes sistemas de acceso; planificar las intervenciones de entrenamiento; realizar un seguimiento de los cambios en las capacidades de un usuario a través del tiempo; y medir la eficacia de una intervención [150].

\section{A.5 Tecnologías no basadas en visión}

\section{A.5.1 Interfaz basada en electro-oculografía (EOG)}

Úbeda describe una nueva interfaz portátil e inalámbrica basada en electro-oculografía (EOG), destinada a personas con trastornos motores graves [151]. Esta interfaz detecta el movimiento de los ojos midiendo el potencial entre la córnea y la retina. La interfaz utiliza cinco electrodos colocados alrededor de los ojos del usuario con el fin de registrar este potencial. La interfaz se ha utilizado para controlar un brazo robótico, para poner a prueba la electrónica de la interfaz. Se han medido la precisión y el tiempo, mostrando que el usuario es capaz de controlar el robot usando solamente sus ojos con resultados satisfactorios.

Himabundu propone la adquisición de señales bio-potenciales como la electro-miografía (EMG) y la electro-oculografía (EOG) del movimiento de los ojos y las contracciones musculares faciales [152]. El sistema de EOG de cuatro entradas, que registra los movimientos de los ojos, proporciona el movimiento del cursor en tiempo real y el sistema de EMG de dos entradas, que registra la presión de la mandíbula, realiza la acción de clic. Desafortunadamente, el sistema no ha sido validado.

\section{A.5.2 Interfaz basada en electro-encefalografía (EEG) o Interfaz cerebro- computador (BCI)}

Taherian describe cómo un individuo con parálisis cerebral espástica y tetrapléjico fue entrenado durante un período de cuatro semanas de usar una BCI comercial [153]. Después de varias sesiones el participante fue capaz de producir dos patrones de EEG distintos. Seis semanas después del entrenamiento aún podía controlar el BCI, utilizándolo para escribir una oración con un dispositivo de comunicación aumentativo alternativo. Los resultados de este estudio de caso ponen de relieve la importancia de crear un entrenamiento dinámico y atractivo para el BCI.

Kim describe una interfaz cerebro-computador, no invasiva de bajo costo, híbrida con un eye-tracker [107]. Para la evaluación utiliza la ley de Fitts. Parte de la hipótesis de que las dos interfaces pueden ser complementarias para alcanzar un mejor rendimiento. Los movimientos de los ojos se interpretan como el movimiento del cursor y la señal EEG selecciona un punto con un esquema de doble selección. La interfaz propuesta se

\footnotetext{
${ }^{18}$ http://www.kpronline.com/compass.php
} 


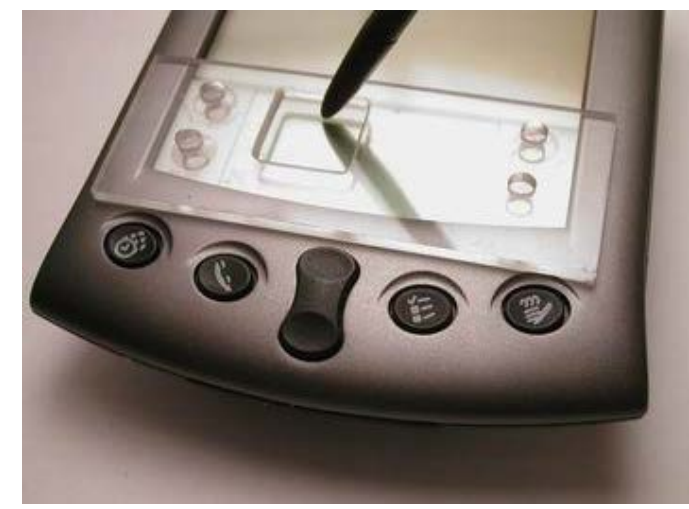

Figura A.6: Una PDA Palm con una plantilla de EdgeWrite sobre el área de entrada de texto.

compara mediante la ley de Fitts con otras interfaces tales como el ratón, eye-tracker con permanencia, y eye-tracker con teclado.

\section{A.5.3 Interfaz manual - EdgeWrite}

EdgeWrite es un nuevo método de entrada de texto Unistrokes (detalles Unistrokes [154]) para dispositivos de mano diseñado para proporcionar una alta precisión y estabilidad de movimiento para personas con deficiencias motoras. También es eficaz para las personas sin discapacidad. Un usuario introduce texto en EdgeWrite atravesando los bordes y las diagonales de un agujero cuadrado superpuesto sobre el área de entrada de texto normal.

Un estudio con cuatro personas con impedimentos motores (sujetos con enfermedad de Parkinson y temblor intenso, parálisis cerebral espástica, distrofia muscular y parálisis cerebral) reveló que algunos de ellos eran incapaces de introducir texto a través de Graffiti (software de reconocimiento de escritura manuscrita utilizado en el sistema operativo Palm OS para PDAs ${ }^{19}$ ) pero todos ellos podían introducir texto mediante EdgeWrite. Los que pudieron hacer los dos métodos tienen una precisión considerablemente mejor con EdgeWrite [155].

\section{A.5.4 Interfaz basada en comandos de voz}

La base del trabajo de Saz [156] es utilizar las emisiones de voz de un usuario severamente impedido para sustituir el ratón y a las pulsaciones de teclas. Las tecnologías del habla necesarias para realizar estas tareas se basan en la estimación robusta de energía y en el cálculo de los formantes para las personas con discapacidad.

\section{A.5.5 Interfaz basada en movimiento de la cabeza - ENLAZA}

Raya comenta que las personas con múltiples discapacidades físicas y cognitivas tienen dificultades para utilizar correctamente los dispositivos señaladores convencionales, lo que reduce sus posibilidades de comunicación y de mejorar sus habilidades físicas y cognitivas a través de computadoras [84]. En base a esto proponen un ratón controlado mediante la cabeza sobre la base de un sensor triaxial inercial centrado especialmente

\footnotetext{
${ }^{19} \mathrm{https}$ ://es.wikipedia.org/wiki/Graffiti_(Palm_OS)
} 

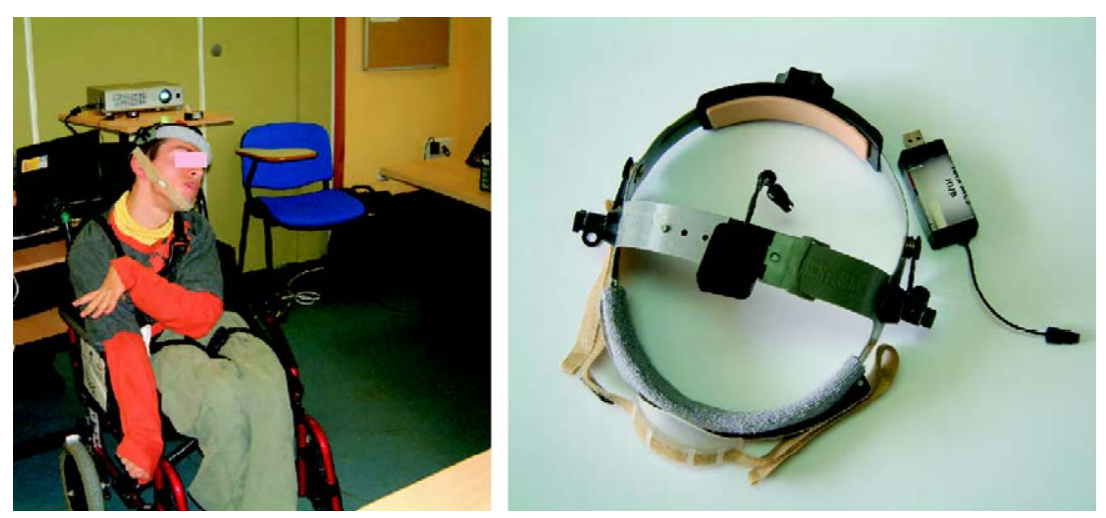

Figura A.7: Los ensayos con la interfaz inercial (izquierda). La interfaz inercial (derecha). La comunicación entre la interfaz y el ordenador puede ser USB o Bluetooth.

para niños con parálisis cerebral. Los resultados experimentales con dos niños con parálisis cerebral (casos de atetoide y distonías) demostraron que los sujetos son capaces de controlar el puntero con este dispositivo. A la izquierda de la Figura A.7 puede observarse a un usuario con el sistema ENLAZA durante una prueba, a la derecha el sistema ENLAZA con los sensores inerciales y el sistema de sujeción a la cabeza. 


\section{Apéndice B}

\section{Procesamiento de los datos del eyetracker}

Los datos del eye-tracker se procesan para mejorar la experiencia de uso como interfaz de acceso al ordenador. El procesamiento suele incluir una serie de fases: un primer filtrado, una clasificación del estado del ojo - fijación o sacada - y finalmente una segunda etapa de filtrado, como se muestra en la Figura B.1.

La primera etapa de filtrado es opcional y puede no existir. La etapa de clasificación debe ser capaz de identificar si el ojo está realizando una fijación o está realizando un movimiento sacádico. Como se mencionó anteriormente en la sección 3.1.3, cuando se produce una fijación es cuando se recolecta información visual, no así durante un movimiento sacádico. Es entonces durante una fijación donde interesa filtrar los datos del ET para que el usuario vea un cursor estable. A continuación se detallan los algoritmos para la identificación de las fijaciones y para el filtrado de datos, en la Sección B.1 y en la Sección B.2 respectivamente.

\section{B.1 Algoritmos para la identificación de fijaciones}

Durante las fijaciones el ojo no queda completamente estable, como se indicó en la sección 3.1.3. El movimiento continuo del ojo sumado a las limitaciones de precisión del eyetracker da como resultado una señal poco estable, lo que hace que identificar el estado del ojo no sea un problema trivial.

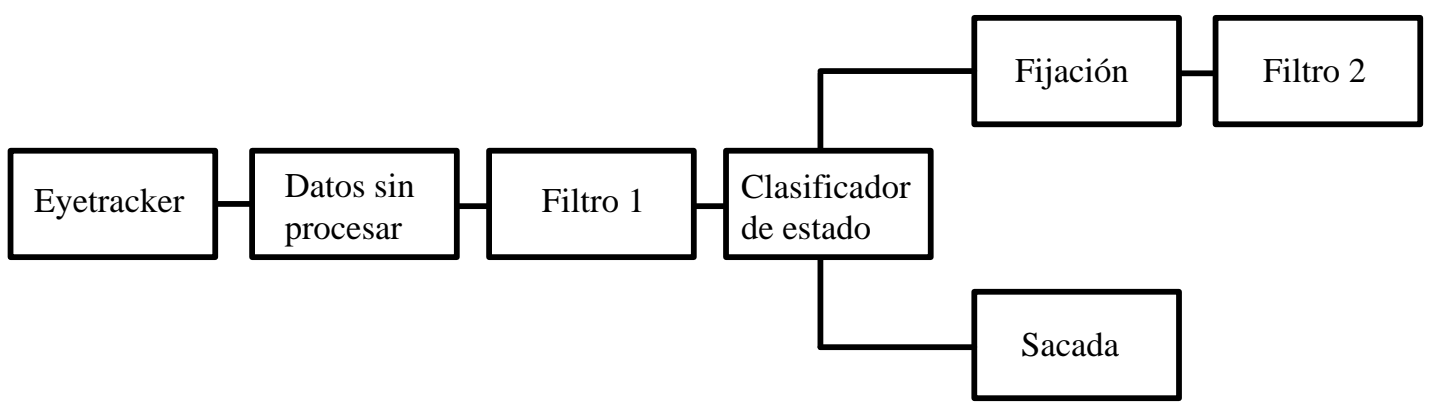

Figura B.1: Los datos que proveen los ETs, antes de utilizarlos, deben ser pre-procesados. Etapas de procesamiento de la información de los datos del eye-tracker. 
El objetivo de los algoritmos de identificación de fijaciones es determinar si el dato más reciente del eyetracker es el inicio de una sacada, la continuación de una fijación o un valor atípico.

Existen trabajos de identificación de fijaciones offline, como el de Salvucci [157]. Además existen trabajos que identifican las fijaciones online, como el de Kumar et al. [158] o el de Nystrom et al. [159]

\section{B.1.1 Basados en la velocidad (I-VT)}

Este algoritmo es el más simple de entender y aplicar de todos los métodos. I-VT es un método basado en la velocidad que discrimina entre fijación y sacadas en base a las velocidades de punto a punto. La velocidad de los movimientos oculares muestran esencialmente dos distribuciones: velocidades bajas para las fijaciones (es decir, <100 grados/seg), y las velocidades altas para movimientos sacádicos (es decir, >300 grados/seg). Este aspecto de los movimientos oculares hace que la discriminación basada en la velocidad sea bastante sencilla y robusta. Si bien es posible crear un algoritmo de identificación de fijaciones adaptado a nivel local, los perfiles de velocidad tienen fuertes fundamentos físicos y fisiológicos, y por lo tanto los criterios estáticos suelen ser suficientes [157].

I-VT calcula las velocidades entre muestra y muestra. Cada velocidad se calcula como la distancia entre el punto actual y el siguiente (o anterior) dividido por el tiempo transcurrido. I-VT entonces clasifica cada punto como una fijación o una sacada basado en un umbral de velocidad simple: si la velocidad del punto está por debajo del umbral, se convierte en un punto de fijación, de lo contrario se convierte en un punto sacada [160].

\section{B.1.2 Basados en la dispersión de los datos (I-DT)}

En contraste con la identificación basada en la velocidad I-VT, la identificación basada en la dispersión (I-DT) parte del hecho de que las fijaciones, debido a su baja velocidad, tienden a agruparse cercanamente. I-DT identifica las fijaciones como grupos de puntos consecutivos dentro de una dispersión particular, o con una separación máxima. Debido a que las fijaciones tienen una duración típica de al menos $100 \mathrm{mseg}$, las técnicas de identificación basada en la dispersión a menudo incorporan un umbral de duración mínima de 100-200 ms [161].

El algoritmo I-DT utiliza una ventana móvil con un número mínimo de puntos, determinado por la duración mínima de una fijación y la frecuencia de muestreo. I-DT comprueba la dispersión $D$ de los puntos en la ventana sumando las diferencias entre los puntos máximo y mínimos para cada eje $X$ e $Y$, según la Ecuación B.1.

$$
D=[\max (X)-\min (X)]+[\max (Y)-\min (Y)]
$$

Existen métricas de la dispersión $D$ alternativas basadas en la varianza o en el área. Si la dispersión es superior a un umbral, la ventana no representa una fijación, y se mueve un punto a la derecha. Si la dispersión es inferior al umbral de dispersión, la ventana representa una fijación. En este caso, la ventana se expande (hacia la derecha) hasta que la dispersión de la ventana está por encima de umbral. La ventana final estará 
catalogada como una fijación en el centroide de los puntos de la ventana, con el tiempo igual al tiempo de inicio y la duración dada por la ventana.

Podemos observar que esta caracterización de las fijaciones utiliza el centroide. Se suele suponer que la fijación tiene un área circular. La distancia media de cada muestra al centroide de fijación proporciona una estimación del radio de la fijación.

El algoritmo I-DT requiere dos parámetros, el umbral de dispersión $D$ y el umbral de duración mínima de una fijación y la función para definir la dispersión. El umbral de dispersión se puede configurar como mínimo $1^{\circ}$ de ángulo visual, si se conoce la distancia del ojo a la pantalla [162]. De lo contrario, el umbral de dispersión se puede estimar a partir de análisis exploratorio de los datos. El umbral de duración mínima de una fijación se establece normalmente a un valor entre 100 y $200 \mathrm{~ms}$ [161].

El algoritmo I-DT (aplicado off-line) es conceptualmente diferente de los métodos basados en algoritmos de agrupación o clustering, por ejemplo, el de k-medias. La mayoría de estos algoritmos requieren una estimación inicial del número de grupos o clusters, haciendo que sea menos útil para los datos de movimiento ocular, donde suele ser desconocido el número de fijaciones.

\section{B.1.3 Basados en el tamaño de las sacadas (I-ST)}

El algoritmo basado en el tamaño de las sacadas es un comparador sencillo de la distancia entre la ubicación del punto de la mirada actual y el último punto almacenado contra un umbral predefinido. Cuando se supera el umbral, se categoriza como una sacada [163]. En algunos estudios este detector fue mejorado mediante el calculo de un umbral dinámico, de acuerdo con la señal [164, 165].

\section{B.2 Algoritmos de filtrado}

\section{B.2.1 Filtros de promedio}

Este es posiblemente el filtro más sencillo de todos. Este filtro tiene como salida el promedio de las últimas $\mathrm{N}$ muestras digitales del eyetracker. La principal desventaja de este filtro es la velocidad de respuesta a las sacadas, cuando no se utiliza el Filtro 1 de la Figura B.1. Veneri et al. en su estudio utilizan este tipo de filtro [166].

\section{B.2.2 Filtros FIR}

Los filtros FIR tienen una ligera ventaja respecto a los filtros de promedio, ya que permiten ponderar los valores almacenados en la ventaja de filtrado según diferentes tipos de funciones y criterios. Existen diferentes tipos de funciones.

La triangular permite darle mayor peso a las muestras más recientes, permitiendo una respuesta más rápida a las sacadas. La Ecuación B.2 define una función de peso para cada una de las muestras que son almacenadas en la ventana de filtrado. En esta ecuación, $N$ es el número de muestras en la ventana de filtrado e $i$ el índice que identifica un valor en esta ventana, siendo $i=N$ la muestra menos reciente e $i=1$ la más reciente. Los pesos de las muestran están normalizas por $N$, de manera que la ponderación no afecte a la salida. 
Otra función es la Gaussiana [167], que determina los pesos según la Ecuación B.3. Cuando los pesos $W_{i}$ de la ecuación son menores a 0,05 son normalmente ignorados. Esto implica que en la ventana de filtrado solo hay muestras con un peso mayor o igual que 0,05 .

$$
\begin{aligned}
& W_{i}=\frac{N-i+1}{N} \\
& W_{i}=e^{-\frac{(i-1)^{2}}{2 \sigma^{2}}}
\end{aligned}
$$

\section{B.2.3 Filtros de Kalman}

Komogortsev y Khan [160] describen su aplicación exitosa del filtro de Kalman modificado, llamado "Attention Focus Kalman Filter" (AFKF), para suavizar los datos del eyetracker. El filtro estima la posición de la mirada y su velocidad.

\section{B.2.4 Tamaño dinámico de la ventana de filtrado}

Un método para manejar el tamaño de la ventana de filtrado es descrito en [166] y en [168]. Este método disminuye el tamaño de la ventana de filtrado a un mínimo (unos cuantos puntos) inmediatamente después de detectar una fijación y la incrementa gradualmente hasta un máximo, durante la fijación. Esto permite procesar los datos con los que efectivamente se cuenta durante una nueva fijación, afectando de diferentes maneras a los filtros antes mencionados. Un número de etapas dinámico permite tener una salida antes de llenar todas las etapas del filtro. 


\section{Bibliografía}

[1] Hewett, Baecker, Card, Carey, Gasen, Mantei, Perlman, Strong, and Verplank, "ACM SIGCHI Curricula for Human-Computer Interaction," 1996. [Online]. Available: http://old.sigchi.org/cdg/cdg2.html xv, 23

[2] D. E. Meyer, R. A. Abrams, S. Kornblum, C. E. Wright, and J. E. Smith, "Optimality in human motor performance: ideal control of rapid aimed movements," Psychological review, vol. 95, no. 3, pp. 340-70, jul 1988. [Online]. Available: http://www.ncbi.nlm.nih.gov/pubmed/3406245 Xv, 26

[3] "Medical gallery of Blausen Medical 2014," WikiJournal of Medicine, vol. 1, no. 2, 2014. [Online]. Available: https://en.wikiversity.org/wiki/WikiJournal_of Medicine/Medical_gallery_of_Blausen_Medical_2014 Xv, 30

[4] H. Drewes, "Eye Gaze Tracking for Human Computer Interaction," Ph.D. dissertation, Universidad de Múnich, 2010. [Online]. Available: http://nbn-resolving.de/urn:nbn:de:bvb:19-115914 xv, 3, 37, 38

[5] I. S. Mackenzie, T. Kauppinen, and M. Silfverberg, "Accuracy measures for evaluating computer pointing devices," in Proceedings of the SIGCHI conference on Human factors in computing systems. ACM, 2001, pp. 9-16. XVI, 45, 46, 47

[6] R. H. S. Carpenter, Movements of the Eyes, 2nd ed. London, UK: Pion, 1988. XVII, 31, 78, 79

[7] L. Pennington, D. Virella, T. Mjøen, M. da Graça Andrada, J. Murray, A. Colver, K. Himmelmann, G. Rackauskaite, A. Greitane, A. Prasauskiene, G. L. Andersen, and J. de la Cruz, "Development of The Viking Speech Scale to classify the speech of children with cerebral palsy," Research in Developmental Disabilities, vol. 34, no. 10, pp. 3202-3210, oct 2013. [Online]. Available: http://linkinghub.elsevier.com/retrieve/pii/S0891422213002849 xxI, 18, 19

[8] J. Rosado Ayala, "La competencia comunicativa en personas que presentan parálisis cerebral," ReiDoCrea, vol. 1, pp. 158-163, 2012. [Online]. Available: http://hdl.handle.net/10481/21996 3

[9] C. Davies, T. Chau, D. L. Fehlings, S. Ameratunga, and N. S. Stott, "Youth with cerebral palsy with differing upper limb abilities: how do they access computers?" Archives of physical medicine and rehabilitation, vol. 91, no. 12, pp. 1952-6, dec 2010. [Online]. Available: http://www.ncbi.nlm.nih.gov/pubmed/21112440 3, 15, 101

[10] M. Bax, M. Goldstein, P. Rosenbaum, A. Leviton, N. Paneth, B. Dan, B. Jacobsson, and D. Damiano, "Proposed definition and classification of cerebral palsy," 
Developmental medicine $\&$ child neurology, vol. 47, no. 8, pp. 571-576, jul 2005. 3,15

[11] A. Camacho and C. Pallas, "Parálisis cerebral: concepto y registros de base poblacional," Revista de Neurología, vol. 45, no. 8, pp. 503-508, 2007. [Online]. Available: http://www.neurologia.com/sec/resumen.php?id=2007309 3, 16

[12] C. H. Morimoto and M. R. Mimica, "Eye gaze tracking techniques for interactive applications," Computer vision and image understanding, vol. 98, no. 1, pp. 4-24, apr 2005. [Online]. Available: http://linkinghub.elsevier.com/retrieve/pii/ S1077314204001109 3, 36, 155

[13] A.-C. Eliasson, L. Krumlinde-Sundholm, B. Rösblad, E. Beckung, M. Arner, A.-M. Ohrvall, and P. Rosenbaum, "The Manual Ability Classification System (MACS) for children with cerebral palsy: scale development and evidence of validity and reliability." Developmental medicine $\& 3$ child neurology, vol. 48, no. 7, pp. 549-54, jul 2006. [Online]. Available: http://www.ncbi.nlm.nih.gov/pubmed/16780622 5, $18,69,82$

[14] R. Palisano, P. Rosenbaum, S. Walter, D. Russell, E. Wood, and B. Galuppi, "Development and reliability of a system to classify gross motor function in children with cerebral palsy." Developmental medicine 83 child neurology, vol. 39, no. 4, pp. 214-23, apr 1997. [Online]. Available: http://www.ncbi.nlm.nih.gov/ pubmed/9183258 5, 17

[15] R. J. Palisano, P. Rosenbaum, D. Bartlett, and M. H. Livingston, "Content validity of the expanded and revised Gross Motor Function Classification System," Developmental Medicine \& Child Neurology, vol. 50, no. 10, pp. 744-750, oct 2008. [Online]. Available: http://doi.wiley.com/10.1111/j.1469-8749.2008.03089.x $5,69,82$

[16] J. Navallas, M. Ariz, A. Villanueva, J. San Agustín, and R. Cabeza, "Optimizing interoperability between video-oculographic and electromyographic systems," Journal of Rehabilitation Research and Development, vol. 48, no. 3, p. 253, 2011. [Online]. Available: http://www.rehab.research.va.gov/jour/11/483/pdf/navallas. pdf 11, 156

[17] R. Bates and H. Istance, "Why are eye mice unpopular? A detailed comparison of head and eye controlled assistive technology pointing devices," Universal Access in the Information Society, vol. 2, no. 3, pp. 280-290, oct 2003. [Online]. Available: http://link.springer.com/10.1007/s10209-003-0053-y 11

[18] C. A. Chin, A. Barreto, J. G. Cremades, and M. Adjouadi, "Integrated electromyogram and eye-gaze tracking cursor control system for computer users with motor disabilities." Journal of rehabilitation research and development, vol. 45, pp. 161-174, 2008. [Online]. Available: http://www.rehab.research.va. gov/jour/08/45/1/Chin.html 11, 156

[19] "Encuesta de discapacidad, autonomía personal y situaciones de dependencia," Instituto Nacional de Estadística, Tech. Rep., 2008. 15

[20] D. Virella, L. Pennington, G. L. Andersen, M. d. G. Andrada, A. Greitane, K. Himmelmann, A. Prasauskiene, G. Rackauskaite, J. De La Cruz, and 
A. Colver, "Classification systems of communication for use in epidemiological surveillance of children with cerebral palsy," Developmental Medicine \& Child Neurology, vol. 58, no. 3, pp. 285-291, mar 2016. [Online]. Available: http://doi.wiley.com/10.1111/dmcn.12866 15, 18

[21] C. Davies, A. Almanji, and N. S. Stott, "A cross-sectional study examining computer task completion by adolescents with cerebral palsy across the Manual Ability Classification System levels," Developmental Medicine 83 Child Neurology, vol. 56, no. 12, pp. 1180-1186, dec 2014. [Online]. Available: http://doi.wiley.com/10.1111/dmcn.12521 15, 67

[22] A. Almanji, T. Claire Davies, and N. Susan Stott, "Using cursor measures to investigate the effects of impairment severity on cursor control for youths with cerebral palsy," International Journal of Human-Computer Studies, vol. 72, no. 3, pp. 349-357, mar 2014. [Online]. Available: http: //www.sciencedirect.com/science/article/pii/S1071581913001985 15, 45

[23] Surveillance of Cerebral Palsy in Europe, "Surveillance of cerebral palsy in Europe: a collaboration of cerebral palsy surveys and registers," Developmental medicine 8 child neurology, vol. 42, no. 12, pp. 816-24, dec 2000. [Online]. Available: http://www.ncbi.nlm.nih.gov/pubmed/11132255 15, 16

[24] P. Gómez, M. Martínez, M. Heras, and E. Moreno, Parálisis cerebral, D. Garrote Rojas and A. Palomares Ruiz, Eds. Universidad de Castilla-La Mancha, 2010. 15,16

[25] "Encuesta sobre discapacidades, deficiencias y estado de salud," INE-IMSERSOFundación ONCE, Madrid, Tech. Rep., 1999. 15

[26] S. McIntyre, C. Morgan, K. Walker, and I. Novak, "Cerebral Palsy-Don’t Delay," Developmental Disabilities Research Reviews, vol. 17, no. 2, pp. 114-129, nov 2011. [Online]. Available: http://doi.wiley.com/10.1002/ddrr.1106 16, 17

[27] I. Novak, M. Hines, S. Goldsmith, and R. Barclay, "Clinical Prognostic Messages From a Systematic Review on Cerebral Palsy," Pediatrics, vol. 130, no. 5, pp. e1285-e1312, nov 2012. [Online]. Available: http://pediatrics.aappublications.org/ cgi/doi/10.1542/peds.2012-0924 16

[28] I. Novak, "Evidence-Based Diagnosis, Health Care, and Rehabilitation for Children With Cerebral Palsy," Journal of Child Neurology, vol. 29, no. 8, pp. 1141-1156, aug 2014. [Online]. Available: http://jcn.sagepub.com/cgi/doi/10. $1177 / 088307381453550316$

[29] S. E. Jacobs, M. Berg, R. Hunt, W. O. Tarnow-Mordi, T. E. Inder, and P. G. Davis, "Cooling for newborns with hypoxic ischaemic encephalopathy," in Cochrane Database of Systematic Reviews, S. E. Jacobs, Ed. Chichester, UK: John Wiley \& Sons, Ltd, jan 2013. [Online]. Available: http://doi.wiley.com/10. 1002/14651858.CD003311.pub3 16

[30] A. Sotiriadis, A. Tsiami, S. Papatheodorou, A. A. Baschat, K. Sarafidis, and G. Makrydimas, "Neurodevelopmental Outcome After a Single Course of Antenatal Steroids in Children Born Preterm," Obstetrics $\&$ Gynecology, vol. 125, no. 6, pp. 1385-1396, jun 2015. [On- 
line]. Available: http://content.wkhealth.com/linkback/openurl?sid=WKPTLP: landingpage $\{\&\} a n=00006250-201506000-0001816$

[31] L. W. Doyle, C. A. Crowther, P. Middleton, S. Marret, and D. Rouse, "Magnesium sulphate for women at risk of preterm birth for neuroprotection of the fetus," in Cochrane Database of Systematic Reviews, L. W. Doyle, Ed. Chichester, UK: John Wiley \& Sons, Ltd, jan 2009. [Online]. Available: http://doi.wiley.com/10.1002/14651858.CD004661.pub3 16

[32] R. Raya, "Nuevas estrategias para la interacción y la movilidad de niños con parálisis cerebral según un modelo convergente," Ph.D. dissertation, Universidad de Alcalá, 2011. 16

[33] F. Alcantud and F. Soto, Tecnologías de ayuda en personas con trastornos de comunicación. Nau Llibres, 2003. 21

[34] L. Azevedo, H. Féria, M. Nunes da Ponte, E. Wann, and Z. Recellado, "HEART Report - Line E E3.2 European Curricula in Rehabilitation Technology Training. European comission DG DG XIII, Telematics Applications Programme, Disabled and Elderly Sector," The swedish handicap institute, Tech. Rep., 1994. 21

[35] M. Hertzum, "Images of Usability," International Journal of Human-Computer Interaction, vol. 26, no. 6, pp. 567-600, may 2010. [Online]. Available: http://www.tandfonline.com/doi/abs/10.1080/10447311003781300 21, 25

[36] R. Balakrishnan, "Beating" Fitts' law: virtual enhancements for pointing facilitation," International Journal of Human-Computer Studies, vol. 61, no. 6, pp. 857-874, dec 2004. [Online]. Available: http://linkinghub.elsevier.com/ retrieve/pii/S107158190400103X 26

[37] N. Milner, "A review of human performance and preferences with different input devices to computer systems," in Proceedings of the Fourth Conference of the British Computer Society on People and computers IV, 1988, pp. 341-362. [Online]. Available: http://dl.acm.org/citation.cfm?id=54675.54695 26

[38] I. S. MacKenzie, A. Sellen, and W. A. S. Buxton, "A comparison of input devices in element pointing and dragging tasks," in Proceedings of the SIGCHI conference on Human factors in computing systems Reaching through technology - CHI '91. New York, New York, USA: ACM Press, 1991, pp. 161-166. [Online]. Available: http://portal.acm.org/citation.cfm?doid=108844.108868 26, 77

[39] R. J. K. Jacob and K. S. Karn, "Eye Tracking in Human - Computer Interaction and Usability Research : Ready to Deliver the Promises," in The Mind's Eye: Cognitive and Applied Aspects of Eye Movement Research. Elsevier Science, 2003, pp. 573-605. 29, 32, 79

[40] M. Land and B. Tatler, Looking and Acting: Vision and eye movements in natural behaviour, 1st ed. Oxford University Press, 2009. 31

[41] N. N. Rommelse, S. Van der Stigchel, and J. A. Sergeant, "A review on eye movement studies in childhood and adolescent psychiatry," Brain and Cognition, vol. 68, no. 3, pp. 391-414, dec 2008. [Online]. Available: http://linkinghub.elsevier.com/retrieve/pii/S0278262608002704 31 
[42] Parves, Augustine, Fitzpatrick, Hall, Lamantia, McNamara, and Williams, Neuroscience, 3rd ed. Sinauer Associates, Inc., 2004. 31

[43] H. Skovsgaard, "Noise Challenges in Monomodal Gaze Interaction," Ph.D. dissertation, IT University of Copenhagen, 2011. 32, 38

[44] S. Martinez-Conde, S. L. Macknik, and D. H. Hubel, "The role of fixational eye movements in visual perception." Nature reviews. Neuroscience, vol. 5, no. 3, pp. 229-40, mar 2004. [Online]. Available: http://www.ncbi.nlm.nih.gov/pubmed/ 1497652232

[45] B. Zuber, L. Stark, and G. Cook, "Microsaccades and the velocity-amplitude relationship for saccadic eye movements," Science, pp. 1459-60, 1965. 33

[46] C. Bolger, S. Bojanic, N. F. Sheahan, D. Coakley, and J. F. Malone, "Ocular microtremor in patients with idiopathic Parkinson's disease," Journal of neurology, neurosurgery, and psychiatry, vol. 66, no. 4, pp. 528-31, apr 1999. [Online]. Available: http://www.ncbi.nlm.nih.gov/pubmed/10201430 33

[47] C. Bolger, S. Bojanic, N. Sheahan, J. Malone, M. Hutchinson, and D. Coakley, "Ocular microtremor (OMT): a new neurophysiological approach to multiple sclerosis." Journal of neurology, neurosurgery, and psychiatry, vol. 68, no. 5, pp. 639-42, may 2000. [Online]. Available: http://www.ncbi.nlm.nih.gov/pubmed/ 1076689733

[48] M. I. Posner, "Orienting of attention," Quarterly Journal of Experimental Psychology, vol. 32, no. 1, pp. 3-25, feb 1980. [Online]. Available: http: //www.tandfonline.com/doi/abs/10.1080/00335558008248231 33

[49] D. W. Hansen and Qiang Ji, "In the Eye of the Beholder: A Survey of Models for Eyes and Gaze," IEEE Transactions on Pattern Analysis and Machine Intelligence, vol. 32, no. 3, pp. 478-500, mar 2010. [Online]. Available: http://ieeexplore.ieee.org/lpdocs/epic03/wrapper.htm?arnumber $=477011034$

[50] G. Daunys, B. K. Ersbøll, M. Böhme, O. Stepankova, A. Villanueva, E. Barth, M. Vester-Christensen, T. Delbruck, D. Dervinis, D. Droege, J. Fejt, M. Fejtová, D. W. Hansen, L. K. Hansen, D. Leimberg, A. Meyer, T. Martinetz, N. Ramanauskas, and V. Vysniauskas, "D5.2 Report on new approaches to eye tracking," Communication by Gaze Interaction (COGAIN), Tech. Rep. IST-2003-511598: Deliverable 5.2, Tech. Rep., 2006. [Online]. Available: http://wiki.cogain.org/images/4/4f/COGAIN-D5.2.pdf 36

[51] K. Holmqvist, M. Nyström, R. Andersson, R. Dewhurst, and H. Jarodzka, Eye tracking: A comprehensive guide to methods and measures. Oxford University Press, 2011. 38

[52] M. J. Kooiker, J. J. Pel, S. P. van der Steen-Kant, and J. van der Steen, "A Method to Quantify Visual Information Processing in Children Using Eye Tracking," Journal of Visualized Experiments, no. 113, jul 2016. [Online]. Available: http://www.jove.com/video/54031/ a-method-to-quantify-visual-information-processing-children-using-eye 38

[53] M. J. G. Kooiker, J. J. M. Pel, H. J. M. Verbunt, G. C. de Wit, M. M. van Genderen, and J. van der Steen, "Quantification of visual function 
assessment using remote eye tracking in children: validity and applicability," Acta Ophthalmologica, vol. 94, no. 6, pp. 599-608, sep 2016. [Online]. Available: http://doi.wiley.com/10.1111/aos.13038 38, 113

[54] K. Gajos and D. S. Weld, "SUPPLE: automatically generating user interfaces," in Proceedings of the 9th international conference on Intelligent user interface - IUI '04. New York, New York, USA: ACM Press, 2004, p. 93. [Online]. Available: http://portal.acm.org/citation.cfm?doid=964442.964461 38, 52

[55] K. Z. Gajos, J. O. Wobbrock, and D. S. Weld, "Automatically generating user interfaces adapted to users' motor and vision capabilities," Proceedings of the 20th annual ACM symposium on User interface software and technology - UIST '07, p. 231, 2007. [Online]. Available: http://portal.acm.org/citation.cfm?doid= $1294211.129425338,52$

[56] K. Z. Gajos, D. S. Weld, and J. O. Wobbrock, "Automatically generating personalized user interfaces with Supple," Artificial Intelligence, vol. 174, no. 12-13, pp. 910-950, 2010. [Online]. Available: http://dx.doi.org/10.1016/j.artint. 2010.05.005 38, 52, 101, 142

[57] A. Almanji, C. Davies, and R. Amor, "Examining Dynamic Control-Display Gain Adjustments to Assist Mouse-Based Pointing for Youths with Cerebral Palsy," International Journal of Virtual Worlds and Human Computer Interaction, vol. 3, no. 1, 2015. [Online]. Available: http://vwhci.avestia.com/2015/001.html 38

[58] S. Federici, F. Corradi, F. Meloni, S. Borsci, M. Mele, S. De_Sylva, and M. Scherer, "Successful assistive technology service delivery outcomes from applying a person-centered systematic assessment process: A case study," Life Span and Disability, vol. 18, no. 1, pp. 41-74, 2015. [Online]. Available: http://www.lifespan.it/client/abstract/ENG290\{_\}2.Federici.pdf 39

[59] M. Borgestig, P. Rytterström, and H. Hemmingsson, "Gaze-based assistive technology used in daily life by children with severe physical impairments - parents' experiences," Developmental Neurorehabilitation, pp. 1-8, aug 2016. [Online]. Available: https://www.tandfonline.com/doi/full/10.1080/17518423.2016.1211769 40

[60] M. Borgestig, J. Sandqvist, G. Ahlsten, T. Falkmer, and H. Hemmingsson, "Gaze-based assistive technology in daily activities in children with severe physical impairments-An intervention study," Developmental Neurorehabilitation, vol. 20, no. 3, pp. 129-141, apr 2017. [Online]. Available: https://www.tandfonline.com/ doi/full/10.3109/17518423.2015.1132281 40

[61] A. Hurst, S. E. Hudson, J. Mankoff, and S. Trewin, "Automatically detecting pointing performance," in Proceedings of the 13th international conference on Intelligent user interfaces - IUI '08. New York, New York, USA: ACM Press, 2008, p. 11. [Online]. Available: http://portal.acm.org/citation.cfm?doid= $1378773.137877643,52$

[62] A. Hurst, "Automatic assessment and adaptation to real world pointing performance," in ACM SIGACCESS Accessibility and Computing, jan 2009, no. 93, pp. 4-10. [Online]. Available: http://portal.acm.org/citation.cfm?doid= $1531930.153193143,52$ 
[63] H. Jarodzka, K. Holmqvist, and M. Nyström, "A vector-based, multidimensional scanpath similarity measure," in Proceedings of the 2010 Symposium on Eye-Tracking Research 83 Applications - ETRA '10. New York, New York, USA: ACM Press, 2010, p. 211. [Online]. Available: http://portal.acm.org/citation.cfm? doid $=1743666.174371843$

[64] W. E. Hick, "On the rate of gain of information," Quarterly Journal of Experimental Psychology, vol. 4, no. 1, pp. 11-26, mar 1952. [Online]. Available: http://www.tandfonline.com/doi/abs/10.1080/17470215208416600 44

[65] R. Hyman, "Stimulus information as a determinant of reaction time." Journal of Experimental Psychology, vol. 45, no. 3, pp. 188-196, 1953. [Online]. Available: http://content.apa.org/journals/xge/45/3/188 44

[66] N. Lin, C. Zong, M. Tomizuka, P. Song, Z. Zhang, and G. Li, "An Overview on Study of Identification of Driver Behavior Characteristics for Automotive Control," Mathematical Problems in Engineering, vol. 2014, pp. 1-15, 2014. [Online]. Available: http://www.hindawi.com/journals/mpe/2014/569109/ 44

[67] S. Keates, F. Hwang, P. Langdon, P. J. Clarkson, and P. Robinson, "The use of cursor measures for motion-impaired computer users," Universal Access in the Information Society, vol. 2, no. 1, pp. 18-29, 2002. [Online]. Available: http://dx.doi.org/10.1007/s10209-002-0033-7 45

[68] J. O. Wobbrock, K. Shinohara, and A. Jansen, "The effects of task dimensionality, endpoint deviation, throughput calculation, and experiment design on pointing measures and models," in Proceedings of the 2011 annual conference on Human factors in computing systems - CHI '11, ACM. New York, New York, USA: ACM Press, 2011, p. 1639. [Online]. Available: http://dl.acm.org/citation.cfm?doid=1978942.1979181 45, 46, 47, 104, 158

[69] J. G. Phillips and T. J. Triggs, "Characteristics of cursor trajectories controlled by the computer mouse," Ergonomics, vol. 44, no. 5, pp. 527-536, apr 2001. [Online]. Available: http://www.tandfonline.com/doi/abs/10.1080/00140130121560 45

[70] P. M. Fitts, "The information capacity of the human motor system in controlling the amplitude of movement. 1954." Journal of experimental psychology. General, vol. 121, no. 3, pp. 262-269, sep 1992. [Online]. Available: http://www.ncbi.nlm.nih.gov/pubmed/1402698 47, 77

[71] I. S. Mackenzie, "Fitts' law as a research and design tool in human-computer interaction," Human-computer interaction, vol. 7, no. 1, pp. 91-139, 1992. 48, 103

[72] R. W. Soukoreff and I. S. Mackenzie, "Towards a standard for pointing device evaluation, perspectives on 27 years of Fitts law research in HCI," International Journal of Human-Computer Studies, vol. 61, no. 6, pp. 751789, dec 2004. [Online]. Available: http://linkinghub.elsevier.com/retrieve/pii/ S1071581904001016 48, 49

[73] S. A. Douglas, A. A. E. Kirkpatrick, and I. S. Mackenzie, "Testing pointing device performance and user assessment with the ISO 9241, Part 9," in Proceedings of the SIGCHI conference on Human factors in computing systems, no. May, ACM. New York, New York, USA: ACM Press, 1999, pp. 215-222. [Online]. Available: http://portal.acm.org/citation.cfm?doid=302979.303042 49 
[74] J. Music, M. Cecic, and M. Bonkovic, "Testing inertial sensor performance as hands-free human-computer interface," WSEAS Transactions on Computers, vol. 8, no. 4, pp. 715-724, 2009. 49, 136

[75] X. Zhang and I. S. Mackenzie, "Evaluating eye tracking with ISO 9241-part 9," in International conference on Human-computer interaction: intelligent multimodal interaction environments. Springer-Verlag, 2007, pp. 779-788. 49, 67

[76] I. S. MacKenzie and S. Jusoh, "An Evaluation of Two Input Devices for Remote Pointing," in Engineering for Human-Computer Interaction. Lecture Notes in Computer Science, M. Little and L. Nigay, Eds. Springer, Berlin, Heidelberg, 2001, pp. 235-250. [Online]. Available: http://link.springer.com/10. 1007/3-540-45348-2\{_\}21 49

[77] F. Hwang, S. Keates, P. Langdon, and P. J. Clarkson, "Multiple haptic targets for motion-impaired computer users," in Proceedings of the conference on Human factors in computing systems - CHI '03, ACM. New York, New York, USA: ACM Press, 2003, p. 41. [Online]. Available: http: //portal.acm.org/citation.cfm?doid $=642611.64262052$

[78] S. Pancani, W. Tindale, P. J. Shaw, C. J. McDermott, and C. Mazzà, "An Objective Functional Characterisation of Head Movement Impairment in Individuals with Neck Muscle Weakness Due to Amyotrophic Lateral Sclerosis," PloS One, vol. 12, no. 1, jan 2017. [Online]. Available: http: //dx.plos.org/10.1371/journal.pone.0169019 52

[79] K. Gajos and D. S. Weld, "Preference elicitation for interface optimization," in Proceedings of the 18th annual ACM symposium on User interface software and technology - UIST '05. New York, New York, USA: ACM Press, 2005, p. 173. [Online]. Available: http://portal.acm.org/citation.cfm?doid=1095034.1095063 52

[80] K. Gajos, J. O. Wobbrock, and D. D. S. Weld, "Improving the performance of motor-impaired users with automatically-generated, ability-based interfaces," in Proceeding of the 26th annual SIGCHI conference on Human factors in computing systems, ACM. New York, New York, USA: ACM Press, 2008, pp. 1257-1266. [Online]. Available: http://portal.acm.org/citation.cfm?doid=1357054.1357250 52

[81] A. Hurst, S. E. Hudson, and J. Mankoff, "Dynamic detection of novice vs. skilled use without a task model," in Proceedings of the SIGCHI Conference on Human Factors in Computing Systems. New York, New York, USA: ACM Press, 2007, pp. 271-280. [Online]. Available: http: //portal.acm.org/citation.cfm?doid=1240624.1240669 52

[82] A. Hurst, S. E. Hudson, J. Mankoff, and S. Trewin, "Distinguishing Users By Pointing Performance in Laboratory and Real-World Tasks," ACM Transactions on Accessible Computing (TACCESS), vol. 5, no. 2, pp. 1-27, oct 2013. [Online]. Available: http://dl.acm.org/citation.cfm?doid=2522990.2517039 52, 101

[83] A. P. H. Weightman, N. Preston, R. Holt, M. Allsop, M. Levesley, and B. Bhakta, "Engaging children in healthcare technology design: developing rehabilitation technology for children with cerebral palsy," Journal of Engineering Design, vol. 21, no. 5, pp. 579-600, oct 2010. [Online]. Available: http://www.tandfonline.com/doi/abs/10.1080/09544820802441092 54 
[84] R. Raya, J. O. J. Roa, E. Rocon, R. Ceres, and J. J. L. Pons, "Wearable inertial mouse for children with physical and cognitive impairments," Sensors and Actuators A: Physical, vol. 162, no. 2, pp. 248-259, aug 2010. [Online]. Available: http://linkinghub.elsevier.com/retrieve/pii/S0924424710001950 54, 160

[85] M. Nyström, R. Andersson, K. Holmqvist, and J. van de Weijer, "The influence of calibration method and eye physiology on eyetracking data quality." Behavior research methods, vol. 45, no. 1, pp. 272-88, mar 2013. [Online]. Available: http://www.ncbi.nlm.nih.gov/pubmed/22956394 57

[86] R. Raya, R. Ceres, J. O. Roa, and E. Rocon, "Assessment of the involuntary motion of children with motor impairments to improve the accessibility of an inertial interface," in Proceedings of the 9th International Conference on Interaction Design and Children. ACM, 2010, pp. 128-137. [Online]. Available: http://dl.acm.org/citation.cfm?id=1810558 57

[87] D. W. K. Man and M.-S. L. Wong, "Evaluation of computer-access solutions for students with quadriplegic athetoid cerebral palsy," The American journal of occupational therapy, vol. 61, no. 3, pp. 355-64, 2007. [Online]. Available: http://www.ncbi.nlm.nih.gov/pubmed/17569393 57, 95

[88] "Accuracy (trueness and precision) of measurement methods and results - Part 1: General principles and definitions," International Organization for Standardization, Standard, 1994. 58

[89] P. Blignaut and T. Beelders, "TrackStick: A Data Quality Measuring Tool for Tobii Eye Trackers," in Proceedings of the Symposium on Eye Tracking Research and Applications - ETRA '12. New York: ACM Press, 2012, p. 293. [Online]. Available: http://dl.acm.org/citation.cfm?doid=2168556.2168619 58

[90] D. Akkil, P. Isokoski, J. Kangas, J. Rantala, and R. Raisamo, "TraQuMe," in Proceedings of the Symposium on Eye Tracking Research and Applications ETRA '14. New York, New York, USA: ACM Press, 2014, pp. 327-330. [Online]. Available: http://dl.acm.org/citation.cfm?id=2578192 58

[91] Tobii, "Accuracy and precision Test report," Tech. Rep., 2013. 59

[92] R. G. Radwin, G. C. Vanderheiden, and M. L. Lin, "A method for evaluating head-controlled computer input devices using Fitts' law," Human factors, vol. 32, no. 4, pp. 423-438, aug 1990. [Online]. Available: http: //www.ncbi.nlm.nih.gov/pubmed/2150065 67

[93] S. P. Guness, F. Deravi, K. Sirlantzis, M. G. Pepper, and M. Sakel, "Evaluation of vision-based head-trackers for assistive devices." Annual International Conference of the IEEE Engineering in Medicine and Biology Society, vol. 2012, pp. 4804-7, jan 2012. [Online]. Available: http://www.ncbi.nlm.nih.gov/pubmed/2336700267

[94] _ _ "A novel depth-based head tracking and gesture recognition system," Assistive Technology: From Research to Practice, vol. 33, pp. 1021 - 1026, 2013. 67

[95] R. Raya, E. Rocon, and R. Ceres, "An inertial human-computer interface for cerebral palsy: The enlaza device," in Converging Clinical and Engineering Research on Neurorehabilitation, 1st ed., J. L. Pons, D. Torricelli, and M. Pajaro, Eds. Springer, 2013, pp. 1295-1300. 67 
[96] R. Alonso, M. Causse, F. Vachon, R. Parise, F. Dehais, and P. Terrier, "Evaluation of head-free eye tracking as an input device for air traffic control," Ergonomics, vol. 56, no. 2, pp. 246-255, feb 2013. [Online]. Available: http://www.tandfonline.com/doi/abs/10.1080/00140139.2012.74447367

[97] V. Surakka, M. Illi, and P. Isokoski, "Gazing and frowning as a new humancomputer interaction technique," ACM Transactions on Applied Perception, vol. 1, no. 1, pp. 40-56, jul 2004. [Online]. Available: http://portal.acm.org/ citation.cfm?doid $=1008722.100872667$

[98] C. Mauri, T. Granollers, A. Solanas, and E. Lleida Solano, "On the Assessment of the Interaction Quality of Users with Cerebral Palsy," in Second International Conference on Availability, Reliability and Security ARES. Vienna: IEEE, 2007, pp. $799-805.68$

[99] A.-M. Öhrvall, L. Krumlinde-Sundholm, and A.-C. Eliasson, "The stability of the Manual Ability Classification System over time," Developmental Medicine 86 Child Neurology, vol. 56, no. 2, pp. 185-189, feb 2014. [Online]. Available: http://doi.wiley.com/10.1111/dmcn.12348 69, 82

[100] H. Bekkering, J. J. Adam, H. Kingma, A. Huson, and H. T. Whiting, "Reaction time latencies of eye and hand movements in single- and dual-task conditions." Experimental brain research, vol. 97, no. 3, pp. 471-6, 1994. [Online]. Available: http://www.ncbi.nlm.nih.gov/pubmed/8187858 70

[101] W. Thompson, "On a criterion for the rejection of observations and the distribution of the ratio of deviation to sample standard deviation," The Annals of Mathematical Statistics, 1935. [Online]. Available: http: //www.jstor.org/stable/2957692 71

[102] E. Matin, "Saccadic suppression: A review and an analysis." Psychological Bulletin, vol. 81, pp. 899-917, 1974. [Online]. Available: http://psycnet.apa.org/ psycinfo/1975-06562-001 78

[103] R. Vertegaal, "A Fitts Law comparison of eye tracking and manual input in the selection of visual targets," in Proceedings of the 10th international conference on Multimodal interfaces ICMI. New York, New York, USA: ACM Press, 2008, pp. 241-248. [Online]. Available: http: //portal.acm.org/citation.cfm?doid=1452392.1452443 78

[104] M. R. Williams and R. F. Kirsch, "Evaluation of head orientation and neck muscle EMG signals as command inputs to a human-computer interface for individuals with high tetraplegia." IEEE Transactions on Neural Systems and Rehabilitation Engineering, vol. 16, no. 5, pp. 485-96, oct 2008. [Online]. Available: http://www.pubmedcentral.nih.gov/articlerender.fcgi?artid= $3638244\{\&\}$ tool $=$ pmcentrez $\{\&\}$ rendertype $=$ abstract 79

[105] A. Kurauchi and C. Morimoto, "HMAGIC : Head Movement And Gaze Input Cascaded Pointing Categories and Subject Descriptors," in 8th International Conference on Pervasive Technologies Related to Assistive Environments, (PETRA), 2015, p. 5.79 
[106] Y. S. Ryu, D. H. Koh, D. Ryu, and D. Um, "Usability Evaluation of Touchless Mouse Based on Infrared Proximity Sensing," Journal of usability studies, vol. 7 , no. 1, pp. 31-39, 2011. [Online]. Available: http://citeseerx.ist.psu.edu/viewdoc/summary?doi=10.1.1.365.1936 79

[107] M. Kim, B. H. Kim, and S. Jo, "Quantitative evaluation of a low-cost noninvasive hybrid interface based on EEG and eye movement." IEEE Transactions on Neural Systems and Rehabilitation Engineering, vol. 23, no. 2, pp. 159-68, 2015. [Online]. Available: http://www.ncbi.nlm.nih.gov/pubmed/25376041 79, 159

[108] O. Tuisku, V. Surakka, T. Vanhala, V. Rantanen, and J. Lekkala, "Wireless Face Interface: Using voluntary gaze direction and facial muscle activations for human-computer interaction," Interacting with Computers, vol. 24, no. 1, pp. 1-9, 2012. [Online]. Available: http://iwc.oxfordjournals.org/cgi/doi/10.1016/j.intcom. 2011.10.002 79

[109] O. Tuisku, V. Rantanen, O. Spakov, V. Surakka, J. Lekkala, O. Pakov, V. Surakka, and J. Lekkala, "Pointing and Selecting with Facial Activity," Interacting with Computers, vol. 28, no. 1, pp. 1-12, jan 2016. [Online]. Available: http://iwc.oxfordjournals.org/lookup/doi/10.1093/iwc/iwu026 79

[110] I. Käthner, A. Kübler, and S. Halder, "Comparison of eye tracking, electrooculography and an auditory brain-computer interface for binary communication: a case study with a participant in the locked-in state," Journal of NeuroEngineering and Rehabilitation, vol. 12, no. 1, p. 76, dec 2015. [Online]. Available: http://www.jneuroengrehab.com/content/12/1/76 79, 116

[111] D. Ding, S. P. Rodriguez, R. a. Cooper, and C. N. Riviere, "Improving Target Acquisition for Computer Users With Athetosis," Assistive Technology, vol. 27, no. 1, pp. 52-58, 2015. [Online]. Available: http://www.tandfonline.com/doi/abs/ 10.1080/10400435.2014.984260 79, 116, 142

[112] M. A. Velasco, R. Raya, R. Ceres, A. Clemotte, A. Ruiz, and T. González, "Positive and Negative Signs of Head Motion in Cerebral Palsy: Assessment of Impairment and Task Performance." IEEE Systems Journal Manuscript, vol. 8, no. 0, 2014. $79,116,142$

[113] M. Borgestig, J. Sandqvist, R. Parsons, T. Falkmer, and H. Hemmingsson, "Eye gaze performance for children with severe physical impairments using gaze-based assistive technology - A longitudinal study," Assistive Technology, vol. 28, no. 2, pp. 93-102, apr 2016. [Online]. Available: http://www.tandfonline.com/doi/full/ 10.1080/10400435.2015.1092182 81, 95

[114] P. Majaranta, I. S. MacKenzie, A. Aula, and K.-J. Räihä, "Effects of feedback and dwell time on eye typing speed and accuracy," Universal Access in the Information Society, vol. 5, no. 2, pp. 199-208, aug 2006. [Online]. Available: http://link.springer.com/10.1007/s10209-006-0034-z 82

[115] K. M. Wilkinson and T. Mitchell, "Eye Tracking Research to Answer Questions about Augmentative and Alternative Communication Assessment and Intervention," Augmentative and Alternative Communication, vol. 30, no. 2, pp. 106-119, jun 2014. [Online]. Available: http://www.tandfonline.com/doi/full/10. 3109/07434618.2014.90443595 
[116] E. D. Guestrin, "Remote, Non-Contact Gaze Estimation with Minimal Subject Cooperation," Ph.D. dissertation, University of Toronto, 2010. 95

[117] J. J. Cerrolaza, A. Villanueva, M. Villanueva, and R. Cabeza, "Error characterization and compensation in eye tracking systems," in Proceedings of the Symposium on Eye Tracking Research and Applications - ETRA '12. New York, New York, USA: ACM Press, 2012, p. 205. [Online]. Available: http://dl.acm.org/citation.cfm?doid=2168556.2168595 95

[118] S. Saavedra, M. Woollacott, and P. Van Donkelaar, "Head stability during quiet sitting in children with cerebral palsy: Effect of vision and trunk support," Experimental Brain Research, vol. 201, pp. 13-23, 2010. 95

[119] H. Drewes, "Eye Gaze Tracking," in Interactive Displays. Chichester, UK: John Wiley \& Sons, Ltd, jul 2014, pp. 251-283. [Online]. Available: http://doi.wiley.com/10.1002/9781118706237.ch8 95

[120] P. Majaranta and K.-J. Räihä, "Twenty years of eye typing," in Proceedings of the symposium on Eye tracking research 83 applications - ETRA '02. New York, New York, USA: ACM Press, 2002, p. 15. [Online]. Available: http://portal.acm.org/citation.cfm?doid $=507072.50707697$

[121] G. Tien and M. S. Atkins, "Improving hands-free menu selection using eyegaze glances and fixations," in Proceedings of the 2008 symposium on Eye tracking research \& applications - ETRA '08. New York, New York, USA: ACM Press, 2008, p. 47. [Online]. Available: http://portal.acm.org/citation.cfm?doid= 1344471.134448297

[122] J. Constine, "Oculus acquires eye-tracking startup The Eye Tribe," Techcrunch.com, 2016. [Online]. Available: https://techcrunch.com/2016/12/28/ the-eye-tribe-oculus/ 97

[123] J. O. Wobbrock, S. K. Kane, K. Z. Gajos, S. Harada, and J. Froehlich, "Ability-Based Design: Concept, Principles and Examples," ACM Transactions on Accessible Computing (TACCESS), vol. 3, no. 3, pp. 1-27, apr 2011. [Online]. Available: http://portal.acm.org/citation.cfm?doid=1952383.1952384 101

[124] M. Velázquez-Mariño, M. Atencia, R. García-Bermúdez, D. Pupo-Ricardo, R. Becerra-García, L. V. Pérez, and F. Sandoval, "Cluster Analysis of Finger-to-nose Test for Spinocerebellar Ataxia Assessment," in 13th International Work-Conference on Artificial Neural Networks, IWANN 2015, Palma de Mallorca, Spain, June 10-12, 2015. Proceedings, Part II, 2015, pp. 524-535. [Online]. Available: http://link.springer.com/10.1007/978-3-319-19222-2\{_\}44 101

[125] R. O. Duda, P. E. Hart, and D. G. Stock, Pattern Classification, 2nd ed. Wiley, 2000. [Online]. Available: http://eu.wiley.com/WileyCDA/WileyTitle/ productCd-0471056693.html 102

[126] D. M. Stampe, "Heuristic filtering and reliable calibration methods for video-based pupil-tracking systems," Behavior Research Methods, Instruments, 8 Computers, vol. 25, no. 2, pp. 137-142, jun 1993. [Online]. Available: http://www.springerlink.com/index/10.3758/BF03204486 104 
[127] P. Berkhin, "A Survey of Clustering Data Mining Techniques," in Grouping Multidimensional Data. Berlin/Heidelberg: Springer-Verlag, 2006, pp. 25-71. [Online]. Available: http://link.springer.com/10.1007/3-540-28349-8\{_\}2 105

[128] D. Arthur and S. Vassilvitskii, "k-means++: the advantages of careful seeding," in SODA '07 Proceedings of the eighteenth annual ACM-SIAM symposium on Discrete algorithms, 2007, pp. 1027-1035. [Online]. Available: http://dl.acm.org/citation.cfm?id=1283494 106

[129] I. H. Witten, E. Frank, and M. A. Hall, "The Weka Data Mining Workbench," in Data Mining: Practical Machine Learning Tools and Techniques, third edit ed. Elsevier, 2011, pp. 401-584. 106, 117

[130] I. H. Witten, F. Eibe, and M. A. Hall, Data mining: practical machine learning tools and techniques, 3rd ed. Morgan Kaufmann Publishers Inc., 2011. 106, 117, 118, 119, 120

[131] A. Sears and J. A. Jacko, The Human-Computer Interaction Handbook. Fundamentals, evolving technologies and emerging applications. Lawrence Erlbaum Associates, 2008, vol. 29, no. 2. 106

[132] R. Kohavi, "The power of decision tables," in Machine Learning: ECML-95. ECML 1995. Lecture Notes in Computer Science (Lecture Notes in Artificial Intelligence), N. Lavrac and S. Wrobel, Eds. Springer, Berlin, Heidelberg, 1995, pp. 174-189. [Online]. Available: http://link.springer.com/10.1007/3-540-59286-5\{_\}57 118

[133] M. A. Velasco, R. Raya, L. Muzzioli, D. Morelli, M. Iosa, F. Cincotti, and E. Rocon, "Evaluation of Cervical Posture Improvement of Children with Cerebral Palsy After Physical Therapy with a HCI Based on Head Movements and Serious Videogames," in Bioinformatics and Biomedical Engineering, 2016, pp. 495-504. [Online]. Available: http://link.springer.com/10.1007/978-3-319-31744-1\{_\}44 141

[134] K. Pierce, S. Marinero, R. Hazin, B. McKenna, C. C. Barnes, and A. Malige, "Eye Tracking Reveals Abnormal Visual Preference for Geometric Images as an Early Biomarker of an Autism Spectrum Disorder Subtype Associated With Increased Symptom Severity," Biological Psychiatry, vol. 79, no. 8, pp. 657-666, apr 2016. [Online]. Available: http://linkinghub.elsevier.com/retrieve/ pii/S0006322315003108 141

[135] C. Silva, E. Ramos, I. Meister, M. Navarro, and F. Mancini, "Eye Tracking and Artificial Neural Networks Application to Detection of Visual Patterns of Reading Performance in Dyslexic Persons," in Brazilian Symposium on Human Factors in Computing Systems, São Paulo, 2016. 141

[136] T. M. Pessoa, D. S. Coutinho, V. M. Pereira, N. P. d. O. Ribeiro, A. E. Nardi, and A. C. d. O. e. Silva, "The Nintendo Wii as a tool for neurocognitive rehabilitation, training and health promotion," Computers in Human Behavior, vol. 31, pp. 384-392, feb 2014. [Online]. Available: http://www.sciencedirect.com/science/article/pii/S0747563213003750 141

[137] J. P. Hansen, K. Tørning, A. S. Johansen, K. Itoh, and H. Aoki, "Gaze typing compared with input by head and hand," in Proceedings of the Eye tracking 
research $\&$ applications symposium on Eye tracking research 83 applications ETRA'2004. New York, New York, USA: ACM Press, 2004, pp. 131-138. [Online]. Available: http://portal.acm.org/citation.cfm?doid=968363.968389 152

[138] M. Betke, J. Gips, and P. Fleming, "The camera mouse: visual tracking of body features to provide computer access for people with severe disabilities," IEEE Transactions on Neural Systems and Rehabilitation Engineering, vol. 10, no. 1, pp. 1-10, mar 2002. [Online]. Available: http://www.ncbi.nlm.nih.gov/pubmed/ 12173734153

[139] N. Buira Clua, M. García González-sama, C. Mauri Loba, N. Buira, M. García, and C. Mauri, "Parálisis Cerebral y Nuevas Tecnologías : Ayudas Técnicas basadas en visión artificial," in IV Jornadas Onubenses Sobre Parálisis Cerebral, Huelva, 2005, pp. 1-9. 153

[140] J. J. Muntaner Guasp, F. J. Perales López, F. Negre Bennasar, J. Varona, J. J. Muntaner, F. J. Perales, F. Negre, and C. Manresa-yee, "Sistema de Interacción Natural Avanzado ( SINA ): Proceso de mejora y ajuste para usuarios con parálisis cerebral y esclerosis múltiple," in La igualdad de oportunidades en el mundo digital, M. D. Hurtado Montesinos and F. J. Soto Pérez, Eds. Universidad Politécnica de Cartagena, 2008, pp. 139-151. 153

[141] J. J. Muntaner, F. F. Negre, F. J. Perales, J. Varona, and C. Manresa-yee, "SINA : acceso natural al ordenador para personas con PCI," in IV Jornadas Iberoamericanas de Tecnologías de Apoyo a la Discapacidad. Las tecnologías de apoyo en Parálisis cerebral, 2009, pp. 26-27. 153

[142] J. San Agustín, H. Skovsgaard, J. P. Hansen, and D. W. Hansen, "Low-cost gaze interaction: Ready to Deliver the Promises," in Proceedings of the 27th international conference extended abstracts on Human factors in computing systems - CHI EA. New York, New York, USA: ACM Press, 2009, p. 4453. [Online]. Available: http://portal.acm.org/citation.cfm?doid=1520340.1520682 154

[143] H. Skovsgaard, J. San Agustín, S. A. Johansen, J. P. Hansen, and M. Tall, "Evaluation of a remote webcam-based eye tracker," in Proceedings of the 1st Conference on Novel Gaze-Controlled Applications - NGCA. New York, New York, USA: ACM Press, 2011, pp. 1-4. [Online]. Available: http://portal.acm.org/citation.cfm?doid=1983302.1983309 154

[144] J. O. Wobbrock, J. Fogarty, S. Liu, S. Kimuro, and S. Harada, "The angle mouse: target-agnostic dynamic gain adjustment based on angular deviation," in SIGCHI Conference on Human Factors in Computing Systems, ACM. Boston, Massachusetts, USA: ACM, 2009, pp. 1401-1410. [Online]. Available: http://dl.acm.org/citation.cfm?id=1518912 156

[145] T. Grossman and R. Balakrishnan, "The bubble cursor: enhancing target acquisition by dynamic resizing of the cursor's activation area," in Proceedings of the SIGCHI conference on Human factors in computing systems - CHI '05, no. c, ACM. New York, New York, USA: ACM Press, 2005, p. 281. [Online]. Available: http://portal.acm.org/citation.cfm?doid=1054972.1055012 156

[146] M. E. Mott and J. O. Wobbrock, "Beating the bubble: Using Kinematic Triggering in the Bubble Lens for Acquiring Small, Dense Targets," in Proceedings 
of the 32nd annual ACM conference on Human factors in computing systems CHI '14. New York, New York, USA: ACM Press, 2014, pp. 733-742. [Online]. Available: http://dl.acm.org/citation.cfm?id=2557410 156

[147] L. Findlater, A. Jansen, K. Shinohara, M. Dixon, P. Kamb, J. Rakita, and J. O. Wobbrock, "Enhanced area cursors: reducing fine pointing demands for people with motor impairments," in Proceedings of the 23nd annual ACM symposium on User interface software and technology. ACM, 2010, pp. 153-162. 156

[148] B. Romich, K. Hill, and B. Liffick, "Single Switch Performance Software," in RESNA Conference, Atlanta, GA, 2005. 158

[149] — - "Free Software for Measuring Single Switch Use Performance," in ATIA Conference and Vendor Fair, Orlando, FL, 2006. 158

[150] H. H. Koester, R. C. Simpson, D. Spaeth, and E. LoPresti, "Reliability and Validity of Compass Software for Access Assessment," in Proceedings of RESNA 2007 Annual Conference, Phoenix, AZ, 2007. 159

[151] A. Úbeda, E. Iáñez, and J. M. Azorín, "Wireless and Portable EOG-Based Interface," IEEE/ASME Transactions on mechatronics, vol. 16, no. 5, pp. 870-873, 2011. 159

[152] J. Himabundu, S. Vivekanandan, K. Sourabh, and D. Emmanuel, "Cursor Control Using Bio-potential Signals for People with Motor Disabilities," International Journal of Bioinformatics and Soft Computing, vol. 1, no. 1, pp. 9-21, 2011. 159

[153] S. Taherian, D. Selitskiy, J. Pau, C. Davies, and R. G. Owens, "Training to use a commercial brain-computer interface as access technology: a case study." Disability and Rehabilitation: Assistive Technology, vol. 00, no. 00, pp. 1-6, oct 2014. [Online]. Available: http://www.ncbi.nlm.nih.gov/pubmed/25270615 159

[154] S. Castellucci and I. S. Mackenzie, "Graffiti vs. unistrokes: an empirical comparison," in 26th annual SIGCHI conference on Human factors in computing systems. ACM, 2008, pp. 305-308. 160

[155] J. O. Wobbrock, B. A. Myers, and J. A. Kembel, "EdgeWrite : A Stylus-Based Text Entry Method Designed for High Accuracy and Stability of Motion," in ACM Symposium on User interface software and technology, UIST. ACM, 2003, pp. 61-70. 160

[156] O. Saz Torralba, W. Ricardo, R. Dueñas, and E. L. Solano, "Development of VoiceBased Tools for Accessibility to Computer Services," Computación y Sistemas, vol. 15 , no. 1 , pp. $7-15,2011.160$

[157] D. D. Salvucci and J. H. Goldberg, "Identifying fixations and saccades in eyetracking protocols," in Proceedings of the symposium on Eye tracking research 8 applications - ETRA '00. New York, New York, USA: ACM Press, 2000, pp. 7178. [Online]. Available: http://portal.acm.org/citation.cfm?doid $=355017.355028$ 164

[158] A. Kumar and S. K. Agarwal, "Spoken web: using voice as an accessibility tool for disadvantaged people in developing regions," ACM Transactions on Accessible Computing (TACCESS), no. 104, pp. 3-11, sep 2012. [Online]. Available: http://dl.acm.org/citation.cfm?id=2388818.2388819 164 
[159] M. Nyström and K. Holmqvist, "An adaptive algorithm for fixation, saccade, and glissade detection in eyetracking data," Behavior Research Methods, vol. 42, no. 1, pp. 188-204, feb 2010. [Online]. Available: http: //www.springerlink.com/index/10.3758/BRM.42.1.188 164

[160] O. V. Komogortsev and J. I. Khan, "Kalman Filtering in the Design of Eye-Gaze-Guided Computer Interfaces," in Human-Computer Interaction. HCI Intelligent Multimodal Interaction Environments. Berlin, Heidelberg: Springer Berlin Heidelberg, 2007, pp. 679-689. [Online]. Available: http: //link.springer.com/10.1007/978-3-540-73110-8\{_\}74 164, 166

[161] H. Widdel, "Operational Problems in Analysing Eye Movements," in Advances in Psychology, 1984, pp. 21-29. [Online]. Available: http://linkinghub.elsevier.com/ retrieve/pii/S0166411508618142 164, 165

[162] P. Blignaut, "Fixation identification: The optimum threshold for a dispersion algorithm," Attention, Perception, \&5 Psychophysics, vol. 71, no. 4, pp. 881-895, may 2009. [Online]. Available: http://www.springerlink.com/index/10.3758/APP. 71.4 .881165

[163] O. Spakov, "Comparison of eye movement filters used in HCI," Proceedings of the Symposium on Eye Tracking Research and Applications - ETRA '12, p. 281, 2012. [Online]. Available: http://dl.acm.org/citation.cfm?doid=2168556.2168616 165

[164] J. R. Tole and L. R. Young, "Digital Filters for Saccade and Fixation Detection," in Eye Movements: Cognition and Visual Perception, Fisher, Monty, and Senders, Eds. Lawrence Erlbaum Associates, 1981, pp. 7-17. 165

[165] A. Duchowski, Eye tracking methodology: Theory and practice. Springer-Verlag New York Inc, 2007. 165

[166] G. Veneri, P. Federighi, F. Rosini, A. Federico, and A. Rufa, "Influences of data filtering on human-computer interaction by gaze-contingent display and eye-tracking applications," Computers in Human Behavior, vol. 26, no. 6, pp. 1555-1563, nov 2010. [Online]. Available: http://linkinghub.elsevier.com/retrieve/ pii/S0747563210001706 165, 166

[167] J. Jimenez, D. Gutierrez, and P. Latorre, "Gazebased Interaction for Virtual Environments," Journal of Universal Computer Science, vol. 14, no. 19, pp. 3085-3098, 2008. 166

[168] J. van der Kamp and V. Sundstedt, "Gaze and voice controlled drawing," in Proceedings of the 1st Conference on Novel Gaze-Controlled Applications - NGCA '11. New York, New York, USA: ACM Press, 2011, pp. 1-8. [Online]. Available: http://portal.acm.org/citation.cfm?doid=1983302.1983311 166 